AUTOCONSCIENCIA, ALTERIDAD Y ESTADO EN LAS TEORÍAS DE HERMANN COHEN Y JOHANN G. FICHTE 


\section{AUTOCONSCIENCIA, ALTERIDAD Y ESTADO EN LAS TEORÍAS DE HERMANN COHEN Y JOHANN G. FICHTE}

TESIS DOCTORAL

LIC. HECTOR ARRESE IGOR

DIRECTORA: PROF. DRA. MARÍA JULIA BERTOMEU

CODIRECTOR: PROF. DR. EDGARDO CASTRO

PRESENTADA ANTE EL DEPARTAMENTO DE FILOSOFÍA (FACULTAD DE HUMANIDADES Y CIENCIAS DE LA EDUCACIÓN, UNIVERSIDAD NACIONAL DE LA PLATA) 
AGRADECIMIENTOS 


\section{AGRADECIMIENTOS}

Quisiera agradecer especialmente a los Profs. Dres. María Julia Bertomeu y Edgardo Castro por su dedicación y acompañamiento en la difícil tarea de la composición y redacción de este trabajo. También al Prof. Jürgen Stolzenberg (Universidad de Halle-Wittenberg, República Federal de Alemania), con quien he podido discutir gran parte de los textos que fueron surgiendo en el proceso de investigación que culminó con esta tesis. Ha sido de fundamental importancia la ayuda financiera y el marco institucional del DAAD (Deutscher Akademischer Austauschdienst), sin cuyo apoyo hubiera sido imposible que la tarea llegara a feliz término.

Considero que algunos colegas, con quienes trabajé en el Seminario "Teorías de la Subjetividad" (Instituto de Filosofía de la Universidad de Halle-Wittenberg) también son artífices de esta investigación, porque el intercambio fecundo que tuvo lugar a lo largo de mi estadía de investigación en esta universidad me permitió reformular algunas hipótesis iniciales y sobre todo releer los textos de Cohen y Fichte desde otra perspectiva. En particular, quisiera mencionar el aporte del PD Dr. Robert Schnepf, el MA Gunnar Schumann (ambos de la Universidad de Halle-Wittenberg), el MA Oliver von Rudolph (Universidad de Göttingen), el Dr. Liu Zhé (Universidad de Pekín), el MA Ken Wakahata (Universidad de Osaka), la Dra. Karin Hartebecke (Universidad de Münster), el Dr. Stephan Lang (Universidad de Viena), el PD Dr. Jindrich Karasek (Universidad de Praga), el PD Dr. Peter Grove (Universidad de Copenhagen), y la MA Anne Polock (Universidad de Marburg).

La colaboración de la PD Dr. Ursula Renz y el Prof. Em. Dr. Helmut Holzhey (Cohen Archiv, Universidad de Zürich) ha sido muy importante para acceder a parte de la bibliografía primaria y secundaria.

Asimismo, quisiera agradecer a la Universidad Nacional de La Plata por haberme brindado el marco institucional indispensable para recorrer todas las etapas de mi trayecto formativo. En este sentido, ha sido fundamental el aporte de innumerables profesores y compañeros, que aportaron mucho a mi desarrollo académico, desde las materias y seminarios que he cursado en esta Universidad a lo largo de mi carrera de grado y de posgrado.

Finalmente, no quisiera terminar esta sección sin agradecer la ayuda inestimable de mis padres y mi familia en todo mi camino formativo, tanto académico como humano. 
INDICE 


\section{INDICE}

Introducción. ..p. 9

Capitulo 1: El rol de la intersubjetividad en la constitución de la autoconsciencia. p. 15

El problema de la autoconsciencia en Cohen y Fichte. p. 16

I. El carácter dialógico de la autoconsciencia en la ErW.... p. 18

I. 1. La vuelta a Kant. p. 18

I. 2. La crítica de Cohen al psicologismo. .p. 26

I. 3. A la búsqueda de un punto de partida para la ética. p. 27

I. 4. La ética y la psicología p. 30

I. 5. La alteridad y la autoconsciencia. p. 31

I. 6. Autoconsciencia, alteridad y religión. El amor y la alteridad en la tradición judía profética. p. 34

I. 7. Autonconsciencia, relación legal y contrato................................p. 37

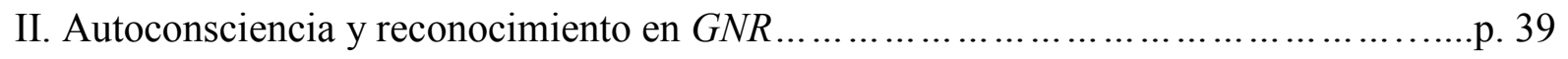

II. 1. El concepto de autoconsciencia................................................. 39

II. 2. La crítica del entendimiento humano común.................................... 41

II. 3. La explicación de la autoconsciencia......................................... 43

II. 4. La deducción de la existencia del otro...................................... 47

II. 5. Conclusiones de la deducción de la autoconsciencia................................p. 49

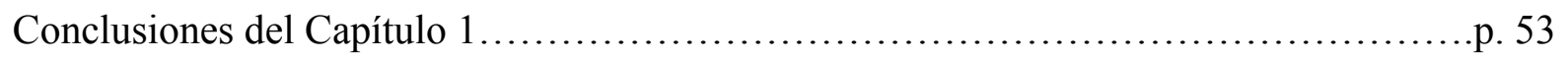

\section{Capítulo 2: La estructura de la relación legal}

I. La relación legal como una persona jurídica....................................p. 55

I. 1. Deducción de la autoconsciencia a partir del concepto de persona jurídica..............p. 56

I. 2. Persona jurídica y cooperativa: la voluntad común de los cooperantes.................... 58

I. 2. 1. La persona jurídica de la cooperativa................................... 58

I. 2. 2. La disputa del antisemitismo............................................p. 64

I. 2. 3. La crítica del concepto de comunidad........................................ 69

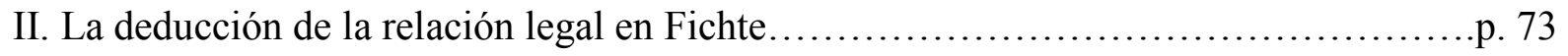

II. 1. El mutuo condicionamiento y determinación de los sujetos involucrados en la situación de exhortación.................................................................... 74

II. 2. Demostración del principio del derecho (Rechtsatz)........................... 77 


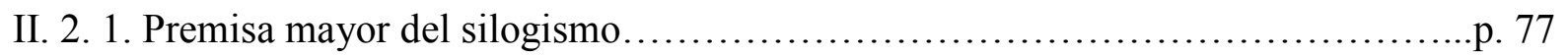

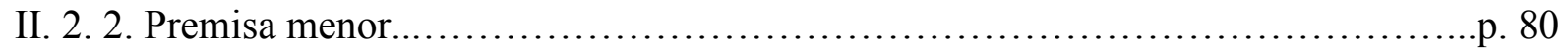

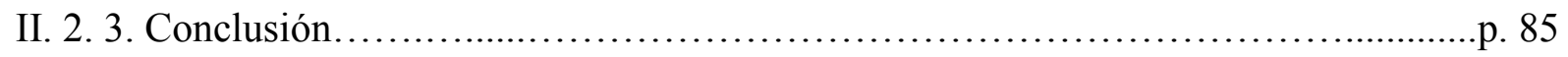

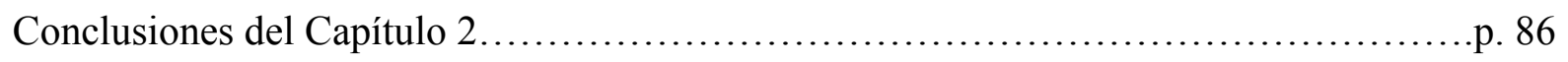

\section{Capítulo 3: La teoría del Estado}

I . La deducción de la autoconsciencia a partir de la persona jurídica del Estado............p. 88

I . 1. El socialismo kantiano.......................................................... 89

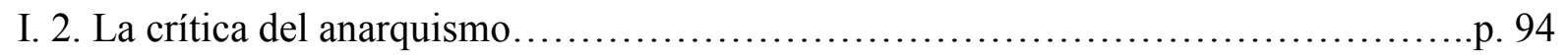

I. 3. La realización de la autoconsciencia en el Estado....................................p. 98

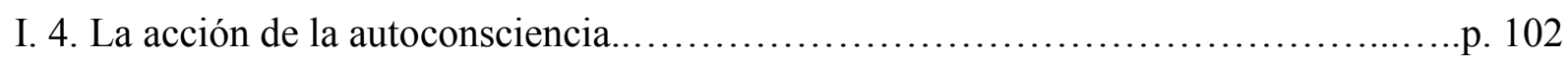

II. El Estado como garante de la libertad y la propiedad del individuo........................ 110

II. 1. Los escritos de Fichte sobre la revolución francesa..................................p. 110

II. 2. La necesidad del Estado en la teoría del GNR .........................................p. 113

II. 3. La autoconservación de la voluntad común......................................... 115

II. 4. La forma de gobierno más justa................................................... 117

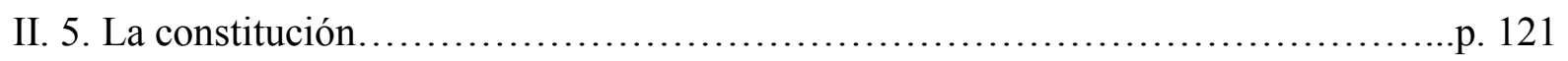

II. 6. El contrato de transferencia (Übertragunscontract)................................... 122

II. 7. El eforato como poder negativo................................................ 125

II. 8. El ejercicio de la soberanía popular........................................... 128

II. 9. Balance de la teoría fichteana de la soberanía popular..............................p. 134

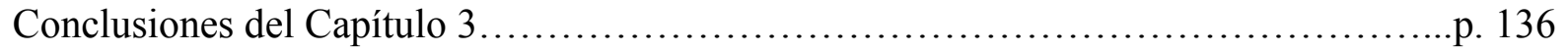

Capitulo 4: El rol de la corporalidad del individuo en la fundamentación del sistema

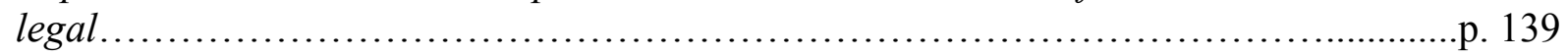

I. La autoconservación como condición del derecho..................................... 140

I. 1. La libertad como autonomía................................................... 140

I. 2. La autonomía como autolegislación (Selbstgesetzgebung)............................ 143

I. 3. La autonomía como autodeterminación (Selbstbestimmung).......................... 148

I. 4. La autonomía como autorresponsabilidad (Selbstverantwortung)...................... 152

I. 5. La crítica de Winter a la teoría de la autonomía moral de la ErW ....................p. 158

I. 6. La autonomía como autoconservación (Selbsterhaltung)............................p. 160

II. La deducción del cuerpo a partir del principio del derecho.............................. 165

II. 1. La atribución a sí mismo del propio cuerpo........................................ 166 
II. 2. La influencia de la otra persona como condición de la atribución del propio cuerpo p. 170

II. 3. Los órganos superior e inferior y las materias dura y sutil......................p. 172

II. 4. La deducción de la "figura" humana en cuerpo de la otra persona..................p. 178

II. 5. El cuerpo como condición de la aplicación del derecho..............................p. 184

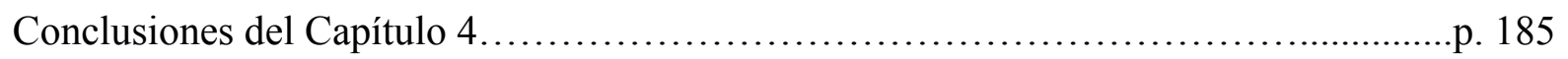

Capítulo 5: El derecho a la existencia .................................................. 187

1. El derecho a la existencia................................................ 190

1. 1. La deducción del derecho de propiedad a partir del concepto de autoconsciencia.

1. 2. El contrato de propiedad.....................................................p. 191

1. 3. La deducción del derecho a la existencia a partir del concepto del cuerpo humano como un producto natural organizado............................................... 193

1. 4. El derecho a la existencia y la obligación de trabajar.............................p. 195

2. La propiedad de los productores (die Producenten)................................. 200

2.1. La agricultura....................................................... 200

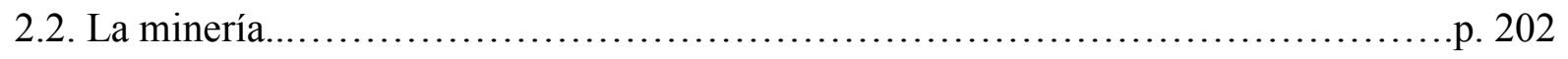

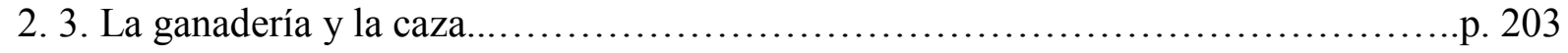

3. La propiedad de los artesanos (Künstler) .................................... 206

4. La propiedad de los comerciantes (Kaufmannsstand) .................................. 207

4.1. La necesidad de la clase de los comerciantes para el funcionamiento del Estado. .p. 207

4. 2. Teoría del dinero..................................................... 208

5. El derecho a la propiedad privada (absolutes Eigenthum).......................... 211

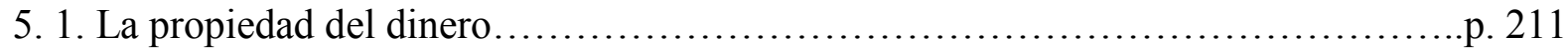

5. 2. El problema del manejo privado del dinero...................................p. 213

5. 3. La protección de la seguridad y la inviolabilidad personales en el derecho

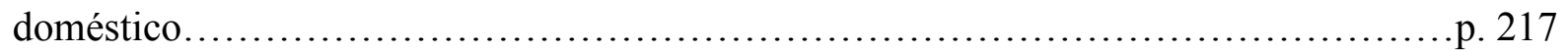

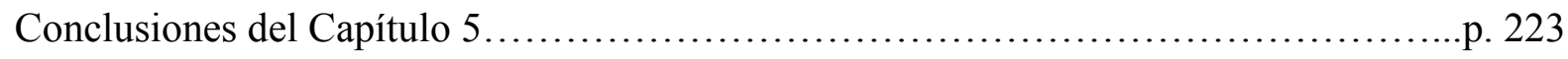

Conclusiones finales...................................................... 228

Bibliografia Consultada..................................................... 231 
Introducción 


\section{Introducción}

La obra y la memoria de Hermann Cohen y Johann G. Fichte han quedado marcadas a fuego de modo indeleble por el mismo hecho histórico: la instauración del régimen nacionalsocialista en la Alemania de 1933. Es sabido que Adolf Hitler mandó quemar en público las obras de los pensadores judíos más renombrados, entre ellos Cohen, creyendo que de este modo podría sepultar en el olvido para siempre a esta gran tradición filosófica que tanto ha dado a la cultura alemana. Pero el nazismo no sólo quiso eliminar la obra de Cohen, sino que también asesinó a su esposa y estrecha colaboradora, Martha Cohen, en el campo de exterminio de Theresienstadt.

La filosofía y la figura de Fichte tuvieron un destino muy diferente al de Cohen. Gracias al esfuerzo propagandístico de Heinrich Rickert, Fichte se convirtió en un filósofo nacional. El régimen nazi encontró, sobre todo en sus Discursos a la nación alemana, la quintaesencia de la germanidad.

Pero el destino dispar que sufrieron Cohen y Fichte no significa necesariamente que sus teorías sean tan diferentes como se creyó durante el nazismo. Ante todo, tienen un punto en común, porque se fundan en la idea kantiana de que la libertad es un fin en sí mismo. ${ }^{1}$ En la Ethik des reinen Willens, la autonomía de los ciudadanos como co-legisladores en el Estado es una condición fundamental para la realización histórica de la autoconsciencia.

El Grundlage des Naturrechts también basa la relación de reconocimiento recíproco, que el derecho debe garantizar, en la exigencia de que cada sujeto promueva la libertad del otro por sí misma. Este es el objetivo de la relación de exhortación, donde se busca despertar al otro a la autoconsciencia y la racionalidad.

Pero la tesis de la presencia de elementos fichteanos en el neokantismo no es nueva, dado que ya ha sido sostenida por intérpretes reconocidos. Es el caso de Hans-Georg Gadamer, quien ha afirmado que "El neokantismo había sido más bien un retorno a Fichte“. 2 . En este sentido, también ha dicho que:

\footnotetext{
${ }^{1}$ Acerca del poder explicativo de la formulación del imperativo categórico de la humanidad como fin en sí mismo, Cfr. Rawls, (1980).

2 "Der Neukantianismus war viel eher eine Rückwendung zu Fichte gewesen." (Gadamer, 1975, b, 88). Antes de Gadamer, Heidegger ya había afirmado que el neokantismo es más bien un neo-fichteísmo (Heidegger, 1919, 142 ss.).
} 
Ya en una primera fase del redescubrimiento coheniano del pensamiento fundante de la 'Crítica' se esconde un hegelianismo inconfesado, pero el logro de Natorp es haber retomado el impulso sistemático de Fichte y Hegel en el pensamiento coherente de las consecuencias de este neokantismo. ${ }^{3}$

Asimismo, en otra de sus obras puede leerse:

Pero es un hecho probado, que el slogan de la vuelta a Kant, que fue arrojado hacia 1860 contra el predominio académico del hegelianismo del idealismo especulativo, pero también contra el materialismo victorioso, el naturalismo, el psicologismo que habian surgido en su contra, e introdujo el asi llamado neokantismo, que era el sucesor de Fichte y Hegel, mucho más de lo que eran conscientes quienes siguieron este lema. ${ }^{4}$

Gadamer sostiene también que Natorp retomó la idea fichteana de la determinación del objeto de conocimiento como una tarea infinita (eine unendliche Aufgabe). ${ }^{5}$ Otra afirmación concluyente de Gadamer es:

Entonces esta [la pretensión del neokantismo] ha sido también la pretensión de Hegel: que él habría desarrollado la filosofía trascendental en su máxima extensión, autonomía y universalidad, luego del primer acontecimiento de Fichte, sin ser del todo consciente de su comienzo no kantiano. ${ }^{6}$

Como apunta Köhnke, ya en los primeros tiempos del neokantismo, la filosofía de Kant fue interpretada a través de Fichte, por ejemplo en la obra de Kuno Fischer. ${ }^{7}$ El idealismo fichteano impulsó la recepción de Kant en la Alemania de la segunda mitad del siglo XIX, dominada por el materialismo, el psicologismo y el cientificismo matemáticonatural, luego de la pérdida de vigencia de la dialéctica hegeliana. La razón de la seducción que ejerció Fichte fue su defensa de la libertad absoluta del yo frente al determinismo de la causalidad mecánica natural.

A partir de Fichte, se intentó fundamentar la autonomía moral del yo, entendido como una razón volente. Los festejos en su honor del 19 de mayo de 1868, atestiguan el entusiasmo

\footnotetext{
3 'Schon im Ansatz der Cohenschen Wiederentdeckung des Grundgedankens der 'Kritik' steckt ein uneingestandener Hegelianismus, und es ist Natorps Verdienst, im konsequenten Weiterdenken dieses Neukantianismus die systematischen Antriebe Fichtes und Hegels bewusst aufgegriffen zu haben" (Gadamer, 1995, 380).

4 "Es bleibt aber die Tatsache bestehen, dass die Parole des Zurück zu Kant, die um 1860 gegen die Hegelsche Schulherrschaft des spekulativen Idealismus, aber auch gegen den dagegen aufgetretenen siegreichen Materialismus, Naturalismus, Psychologismus geschleudert wurde und den sogenannten Neukantianismus einleitete, weit mehr in der Nachfolge Fichtes und Hegels stand, als denen bewusst war, die dieser Parole folgten." (Gadamer, 1975, 213).

${ }^{5}$ Gadamer, (1975), 215.

6 "Denn das war ja auch noch der Anspruch Hegels gewesen, dass er nach dem ersten Vorgange Fichtes die Transzendentalphilosophie in ihrer vollen Weite, Autonomie und Universalität zur Entfaltung gebracht habe, ohne sich seines unkantischen Beginnens je ganz bewusst zu werden" (Gadamer, 1981, 304).

${ }^{7}$ Köhnke, (1986), 186 ss.
} 
general que provocó el llamado del retorno a Fichte en unión con Kant. ${ }^{8}$ De allí que en aquellos tiempos se denominara al pensamiento de Helmholtz, Haym, Fortlage y Fischer, como una "filosofía kantiano-fichteana" (Kantisch-Fichtesche Philosophie). ${ }^{9}$

Marion Heinz ha hecho un aporte valioso respecto de la influencia de Fichte en la escuela del sudoeste alemán. ${ }^{10}$ Pero no se dispone aún de ningún estudio de conjunto sobre la presencia de la filosofía fichteana en la Escuela de Marburg, si bien algunos investigadores han señalado elementos en común. Solowiejczyk ha destacado algunos puntos de contacto entre la filosofía fichteana y la $\operatorname{LrE}$ de Cohen, tales como la eliminación de la cosa en sí, la unificación de la materia y la forma, con el consiguiente rechazo de lo a posteriori y de la intuición sensible, así como la deducción legal de todo el conocimiento a partir de un principio supremo (el yo de Fichte y el pensamiento puro de Cohen), y la concepción funcional de este principio supremo. ${ }^{11}$

En relación con el trasfondo fichteano de la $E r W$, Schmid sostiene que en ambos casos el yo no es concebido como si existiera de modo aislado de los demás, sino más bien como un ser social, involucrado siempre en una red de interrelaciones con los otros. ${ }^{12}$ Por otro lado, Stolzenberg considera que la relación intersubjetiva que está a la base de la relación legal en la $E r W$ es idéntica a la relación de mutuo reconocimiento de la exhortación del $G N R .^{13}$

Estos aportes de la investigación actual sobre el tema han abierto un camino en el que pretendo incluir este trabajo. El objetivo que aquí se persigue consiste en poner a prueba las afirmaciones de Gadamer, examinando las conexiones posibles entre la teoría que Fichte desarrolla en el Grundlage des Naturrechts y la filosofía moral de Cohen en su Ethik des reinen Willens.

\footnotetext{
${ }^{8}$ Köhnke, (1986), 188. Acerca del trasfondo político de los festejos en honor a Fichte, sobre todo en relación con la necesidad de unificar a Alemania bajo el imperio prusiano, Cfr. Köhnke, (1986), 188 ss.

${ }^{9}$ Köhnke, (1986), 193.

${ }^{10}$ Cfr. Heinz, (1997).

${ }^{11}$ Solowiejczyk, (1930), nota al pie de la p. 51.

12 "Con esto Cohen toma una posición fichteana. Él rechaza por cierto la concepción gnoseológica de la Teoría de la Ciencia de Fichte, pero sin embargo le concede que él ha realizado consideraciones absolutamente valiosas desde el punto de vista práctico. Es el caso de aquel lugar en el que descubre al yo como un yo social, que sólo puede constituirse en comunidad con un tú. Estas reflexiones se encuentran sobre todo en el 'Fundamento del derecho natural de acuerdo con los principios de la teoría de la ciencia', aparecido en 1796, que, junto con el 'Fundamento de la totalidad de la teoría de la ciencia' aparecido en 1794, persigue el objetivo de aclarar la libre autodeterminación y con ello el problema de la libertad."

("Damit nimmt Cohen eine fichtesche Position ein. Er verwirft zwar die erkenntnistheoretische Konzeption der Wissenschaftslehre Fichtes, gesteht diesem aber zu, dass er in praktischer Hinsicht durchaus bedenkenswerte Überlegungen angestellt habe. Dies etwa dort, wo er das Ich als soziales Ich entdeckt, als ein Ich, das sich nur in Gemeinschaft mit einem Du konstituieren kann. Diese Überlegungen finden sich vor allem in der 1796 erschienenen ,Grundlage des Naturrechts nach Prinzipien der Wissenschaftslehre', welche zusammen mit der 1794 erschienenen ,Grundlage der gesamten Wissenschaftlehre' das Ziel verfolgt, die freie Selbstbestimmung und damit das Problem der Freiheit zu klären“; Schmid, 1993, 60-61).

${ }^{13}$ Stolzenberg, (2002), 428-432.
} 
En primer lugar, examinaré el rol que juega la alteridad en la deducción de la autoconsciencia de las dos teorías. Si bien Cohen y Fichte sostienen concepciones diferentes de la autoconsciencia (en el primer caso es idéntica a la persona jurídica del Estado y en el segundo es la autoconsciencia del yo individual que somos cada uno de nosotros), coinciden en el rechazo de la concepción monológica de la subjetividad. Por eso, como dice Schmid en el texto citado más arriba, la subjetividad es pensada en ambos casos como una realidad social, en la que el sujeto está inserto desde el comienzo.

Pretendo demostrar que el rol fundante que tiene la alteridad para la constitución de la subjetividad es la razón por la cual Cohen y Fichte sostienen que la relación legal tiene una estructura dialógica. Pero esta coincidencia no significa que los dos conceptos de relación legal sean idénticos. Mi hipótesis es que el concepto de voluntad común que resulta de la relación legal en cada caso es diferente. En el caso de la $\operatorname{ErW}$ se trata de una voluntad ficticia que unifica los arbitrios individuales en una universalidad de orden superior, de la que participan todos los ciudadanos por medio de la actividad de la legislación. Por el contrario, siempre según mi hipótesis, en el GNR los individuos se comprometen simplemente a no interferir en la esfera de libertad del otro, para que el reconocimiento recíproco sea posible.

Considero que estas diferencias importantes en el concepto de relación legal tienen consecuencias de peso para sus respectivas teorías del Estado. Por eso me detendré en la propuesta de Cohen de una democracia deliberativa, donde todos los ciudadanos contribuyen a la tarea de la legislación por medio de sus representantes en el Parlamento. Pero el contraste entre ambas teorías quedará claro una vez que haya examinado la teoría fichteana del Estado justo, según la cual los ciudadanos deben ceder todo su poder a un tercero que garantice el respeto de la libertad y la propiedad de cada uno, reservándose para sí el control de sus actos de gobierno por parte de la institución del eforato.

A pesar de esta diferencia profunda que separa a las dos concepciones del Estado, es posible trazar un puente entre ambas a partir del rol que la corporalidad juega en ellas. Mi hipótesis es que en ambas propuestas, la existencia corporal del individuo es una condición de posibilidad fundamental del derecho y del Estado. Para fundamentar esta afirmación, reconstruiré en primer lugar la argumentación de Cohen, quien intenta demostrar que la autoconservación del individuo es indispensable para el ejercicio de la autonomía y la realización de la autoconsciencia en el Estado. En segundo lugar, seguiré la deducción del cuerpo propio en el $G N R$, como la esfera de acciones posibles del individuo y el ámbito sobre el que se ejerce la regulación del principio del derecho. 
La idea de la autoconservación de la $E r W$ tiene como consecuencia la exigencia de que el Estado garantice los derechos de existencia de los ciudadanos. Este es un punto de contacto con la teoría de Fichte, porque allí también el derecho a la existencia es el derecho básico, sin el cual no puede ser garantizado el imperio de la ley entre los ciudadanos. Para profundizar en esta idea, reconstruiré la idea fichteana de una economía planificada centralmente, orientada a la garantía de subsistencia de todos y cada uno de los miembros de la comunidad.

La búsqueda de afinidades y contrastes entre la $\operatorname{ErW}$ y el $G N R$ será entonces el hilo conductor de este trabajo, donde me propongo hacer un aporte a la cuestión de la presencia de Fichte en esta obra fundamental del neokantismo de Marburg. 
Capítulo 1: El rol de la intersubjetividad en la constitución de la autoconsciencia 


\section{Capítulo 1: El rol de la intersubjetividad en la constitución de la autoconsciencia}

\section{El problema de la autoconsciencia en Cohen y Fichte}

En este capítulo me propongo mostrar que las teorías de Cohen y de Fichte coinciden en un punto central, porque le otorgan un rol fundamental a la alteridad en la constitución de la autoconsciencia. Sin embargo, estos autores sostienen un concepto diferente de autoconsciencia.

En la teoría de Cohen, la autoconsciencia es la categoría fundante de la ciencia del derecho. Se trata de la consciencia de un tipo de subjetividad (Selbst), que está presente en ese ámbito de la cultura que es el sistema legal. Por lo tanto, se trata de una forma de la consciencia cultural (Kulturbewusstsein). El sistema filosófico de Cohen es un intento por integrar las tres dimensiones fundamentales de la consciencia cultural: la ciencia matemáticonatural (objeto de la filosofía teórica), la ciencia del derecho (tema de la filosofía práctica), y el arte en sus diversas formas (asunto de la estética). El concepto de la autoconsciencia es la condición de posibilidad de la legislación, o sea de la producción del derecho, porque es la voluntad que se expresa en el Estado, y lo convierte en persona jurídica. Esto significa que la autoconsciencia es la exteriorizacion de la voluntad de los ciudadanos como legisladores, a través de sus representantes en el Parlamento.

Por el contrario, Fichte defiende un concepto de autoconsciencia individual, entendida como la autoconsciencia de cada yo particular. Esta consiste en una actividad, en la que el yo se atribuye a sí mismo otra actividad en el mundo sensible, que es la tarea del conocimiento de un objeto. Esta atribución es posible a su vez gracias a otra actividad: la proposición del fin de esta acción (que es previa a su realización).

A pesar de esta diferencia, ambos pensadores coinciden en la fundamentación de sus respectivos conceptos de autoconsciencia a partir de una cierta relación intersubjetiva. Cohen deduce su concepto de autoconsciencia a partir de la concepción del derecho y el Estado como estructuras de tipo contractual. El contrato es, en esta teoría, la forma de toda relación legal, porque el Estado es una persona jurídica regida por un sistema legal, que ha sido consensuado por todos los ciudadanos. En la primera parte de este capítulo desarrollaré la crítica de Cohen 
al monologismo de algunas concepciones de la autoconsciencia y su discusión de la idea religiosa de la alteridad. Finalmente, reconstruiré la fundamentación de la autoconsciencia a partir de la relación intersubjetiva del contrato, que supone un concepto de alteridad jurídica.

En la segunda parte, intentaré trazar una analogía entre la idea de la alteridad en Cohen y en Fichte. Esta tarea exige previamente un recorrido por la deducción fichteana de la autoconsciencia. Comenzaré con la definición misma de la autoconsciencia, seguida por la tesis de la posición del mundo sensible. Para clarificar este último punto, reconstruiré los argumentos que Fichte esgrime para criticar el realismo dogmático del entendimiento humano común (das gemeine Menschenverstand). Luego, consideraré la explicación del círculo vicioso en la demostración de la autoconsciencia, donde el objeto se explica a través del sujeto y viceversa. Por último, expondré la solución del círculo vicioso por medio de la relación de exhortación y reconocimiento mutuo entre los yoes, que culmina con la deducción de la autoconsciencia. 


\section{El carácter dialógico de la autoconsciencia en la $E r W$}

\section{1. La vuelta a Kant}

La argumentación que desarrollan Cohen y Fichte para demostrar la realidad de la autoconsciencia coincide en la postulación del derecho como su condición de posibilidad. En el caso de Fichte, la relación de mutuo reconocimiento que hace posible la autoconsciencia es imposible si los yoes no respetan mutuamente sus esferas de libertad; es decir, que la autoconsciencia no puede pensarse sin la aplicación del principio del derecho. Cohen, en cambio, piensa que la ciencia del derecho no puede ser sistematizada y conocida si no se admite un sujeto colectivo o autoconsciencia, que es el fundamento de la universalidad de la persona jurídica del Estado. En la teoría de Cohen, la ciencia del derecho, y en especial sus avances en el terreno del concepto de persona jurídica, es indispensable para llegar hasta los conceptos de la ética.

Mientras que Fichte parte de un concepto metafísico de autoconsciencia y de reconocimiento, y luego deduce de allí la necesidad de un principio legal abstracto, Cohen enfoca su investigación en primer lugar en los resultados de la ciencia positiva del derecho, para sistematizarla en torno al eje del concepto de la autoconsciencia. Para fundamentar la ciencia del derecho, Cohen eligió el procedimiento del método trascendental, según su propia interpretación de la filosofía de Kant, desarrollada en sus tres obras: Kants Theorie der Erfahrung (La teoría de la experiencia de Kant, 1871), Kants Begründung der Ethik (La fundamentación de la ética de Kant, 1877), y Kants Begründung der Ästhetik (La fundamentación de la estética de Kant, 1889). De acuerdo con estos textos, el método trascendental consta de dos momentos: en primer lugar, se parte de un conjunto de conceptos sistematizados en un corpus científico o artístico, y luego se lo intenta explicar en base a determinadas categorías fundantes, entendidas como su condición de posibilidad.

Para comprender el trasfondo histórico de esta recepción de la filosofía de Kant, que está a la base del proceder argumentativo que Cohen sigue en su deducción de la autoconsciencia, es necesario retroceder unos años antes de la publicación de las primeras obras de Cohen sobre Kant, en concreto al fracaso de la revolución de 1848. 
Luego de la derrota de la Revolución del 48, se impuso en Alemania una política reaccionaria, que acarreó como consecuencia la salida del país de 750.000 emigrantes entre 1850 y 1855, la mayoría hacia los EEUU. En la universidad alemana dominaba un clima de mutua desconfianza y de vigilancia permanente. Muchos profesores que habían estado comprometidos con la revolución fueron separados de sus puestos. En particular, los profesores que pertenecían al hegelianismo de izquierda fueron blanco de persecuciones, como es el caso de Ludwig Feuerbach y Arnold Ruge, así como del teólogo Bruno Bauer. Todos ellos sufrieron bajo el "Sumpfluft der fünfziger Jahre" ("aire de pantano de los años 50”), según el decir de Friedrich Nietzsche.

Los hegelianos reaccionaron al fracaso de la revolución con una actitud pesimista, desesperando de la posibilidad de encontrar un sentido racional en la historia. El conocido biógrafo de Hegel, Karl Rosenkranz, llegó a afirmar que la lectura del periódico lo ponía "geschichtskrank" (“enfermo por la historia”). Desilusionado de la política, publicó en 1853 en Königsberg su Ästhetik des Häßlichen (Estética de lo feo). La represión en la universidad fue conduciendo de a poco al abandono de la dialéctica hegeliana. ${ }^{14} \mathrm{Si}$ bien el hegelianismo funcionó en algunos casos como legitimador de la monarquía prusiana, recibió su golpe de gracia a causa del escándalo generado por la obra de Bruno Bauer: Crítica de los evangelios sinópticos. Este episodio fue la causa de la disposición que permitía a los hegelianos solamente enseñar estética, cuando no eran despedidos a causa de la férrea política universitaria prusiana. Heine llegó a decir que no se sentía a salvo de los espías prusianos ni siquiera en su exilio en París. ${ }^{15}$

La caída de la dialéctica hegeliana dio lugar al auge de la metafísica de Schopenhauer, cuyo carácter pesimista estaba en consonancia con el espíritu de 1850. Rosenkranz se refirió al apogeo que conoció la filosofía de Schopenhauer como "una expresión de la desesperanza ya existente en las masas ante la vida" ("ein Ausdruck der schon in den Massen vorhandenen Verzweiflung am Leben"). ${ }^{16}$ Asimismo, su mística voluntarista correspondía con el intimismo de la época y la retracción de los ciudadanos a la esfera de la privacidad, producto del desencanto con el curso de la política, luego del fracaso de la revolución. Por otro lado, el ateísmo de Schopenhauer era bienvenido por una burguesía que abandonaba la fe cristiana, pero no quería caer en un materialismo poco refinado. Finalmente, dado que Schopenhauer no

\footnotetext{
${ }^{14} \mathrm{Sieg},(1994), 26-27$.

${ }^{15}$ Willey, (1978), 28.

${ }^{16}$ Köhnke, (1986), 115.
} 
enseñaba en la universidad, destinó sus obras al público culto, lo que explica la claridad de sus textos, que facilitó su popularidad. ${ }^{17}$

La caída de la filosofía hegeliana trajo aparejada también otra consecuencia: la valoración de la historia como una ciencia de referencia para la filosofía, como modelo de cientificidad. De allí la importancia que adquirió la historia de la filosofía en la obra de Eduard Erdmann, Kuno Fischer, Friedrich Ueberweg y Eduard Zeller. Edrmann, en su famoso Grundriss der Geschichte der Philosophie (Manual de historia de la filosofía), justificó a la investigación histórico-filosófica como un modo de filosofar y no como una mera forma de historiografía. $^{18}$

Pero el abandono de la dialéctica hegeliana abrió el camino a un positivismo creciente. Los métodos paradigmáticos de las ciencias del espíritu fueron sin duda los de las ciencias naturales, en especial de la física, la química y la fisiología. Este fue el terreno en el que arraigó la creencia de que la materia, tal como es conocida por las ciencias naturales, es la realidad última. Sobre ella se levantaron algunas teorías grotescas, como es el caso de la idea de Jakob Moleschott de que el cerebro secreta pensamientos, del mismo modo en que el hígado secreta bilis. O la reducción que hizo Ludwig Büchner de la consciencia a configuraciones moleculares, en Energía y materia (1855), un bestseller que conoció 19 ediciones hacia $1898 .^{19}$

En 1855, el físico y fisiólogo Hermann Helmholtz pronunció en Königsberg una conferencia que se tituló "Über das Sehen der Menschen" ("Sobre el acto de ver de los seres humanos"), con gran éxito. Rechazando la explicación materialista de la percepción, Helmholtz acentuó el rol que juega la organización física del órgano sensorial en dicho proceso. De allí su afirmación de que la luz es luz, sólo una vez que ha encontrado un ojo que pueda ver. Por esa puerta, la filosofía crítica de Kant ya se insinuaba como el remedio para el materialismo reinante. ${ }^{20}$ Helmholtz fue el primer científico que planteó la necesidad de volver a Kant, con el objeto de poner a la ciencia en armonía con la filosofía, del mismo modo en que el idealismo trascendental estuvo anteriormente en armonía con la física newtoniana. ${ }^{21}$

Un hito importante en el surgimiento del neokantismo fue el congreso que tuvo lugar en Göttingen hacia 1854, donde concurrieron tanto científicos neokantianos (con Helmholtz a la cabeza), cuanto materialistas (Büchner, Moleschott, etc.). El congreso de Göttingen puso sobre el tapete el debate en torno al materialismo, y hubo quienes buscaron aunar las

\footnotetext{
${ }^{17}$ Sieg, (1994), 31-32.

${ }^{18}$ Sieg, (1994), 33.

${ }^{19}$ Willey, (1978), 25.

${ }^{20}$ Sieg, (1994), 33-34; Winter, (1980), 77; Köhnke, (1986), 151-157.

${ }^{21}$ Willey, (1978), 26.
} 
voluntades de los partidarios del neokantismo. Entre ellos se contaban los científicos que apreciaban la teoría de las ideas metafísicas como ideales regulativos, porque implicaba la retirada de las ideas del yo, el mundo y Dios, del ámbito de la causalidad natural y mecánica. Estos cristianos encontraban en la filosofía de Kant una manera adecuada de salvar la ciencia y la fe, reservando el ámbito fenómenico y el nouménico para cada una respectivamente. De este modo, el dualismo kantiano salvaba la autonomía de la ciencia sin caer por ello en el materialismo escéptico. $^{22}$

Rudolf Hermann Lotze fue uno de los primeros neokantianos; se dedicó al estudio de la filosofía de Kant a instancias de su maestro en Leipzig, Christian Weisse. Este le recomendó, en una carta hacia 1847, cuando Lotze ya estaba en Göttingen, que analizara en profundidad la obra de Kant. Weisse era un hegeliano, pero consideraba que debía complementar su posición con la teoría kantiana de la libertad como una forma de causalidad, ya que las acciones espontáneas del hombre pueden ayudar al desenvolvimiento de la Idea en la historia. Por eso puede señalarse a la actitud de Weisse como un ejemplo del progreso gradual que se fue dando en muchos filósofos desde el hegelianismo al kantismo. ${ }^{23}$

En octubre de 1858, el príncipe Guillermo subió al trono de Prusia, acompañado de un intenso fervor popular. Su política liberal llegó pronto a las universidades y renovó la vida espiritual y académica, tan deprimida en los años precedentes. Pronto se despertó la necesidad de construir una identidad alemana, que fue puesta de manifiesto sobre todo en las fiestas en honor a Schiller, Fichte y Kant, quienes fueron celebrados como poetas y filósofos nacionales. ${ }^{24}$ La consagración de Kant como un filósofo de la germanidad es la causa de que más tarde algunos intérpretes, entre ellos Ernst Bloch, lo tacharan de un filósofo fascista, liberal y burgués. ${ }^{25}$

Fue Kuno Fischer el primero en sostener que la filosofía podría convertirse en una verdadera ciencia sólo cuando se construyera como una teoría del conocimiento, en busca de las condiciones de validez de la ciencia natural. Eduard Zeller lo siguió luego en su intento de refundar a la filosofía en términos de epistemología. ${ }^{26}$

Kant und die Epigonen (Kant y los epígonos, 1865), la obra de Otto Liebmann, un Privatdozent de 25 años y discípulo de Kuno Fischer, significó la culminación de la etapa programática del neokantismo (iniciada por las investigaciones de Helmholtz). En este texto,

\footnotetext{
${ }^{22}$ Willey, (1978), 26.

${ }^{23}$ Willey, (1978), 43-44.

${ }^{24}$ Sieg, (1994), 34.

${ }^{25}$ Köhnke, (1986), 12.

${ }^{26}$ Sieg, (1994), 36.
} 
Liebmann acusó a los filósofos postkantianos de no haber eliminado el supuesto de la cosa ensí, dejando al kantismo cargado con su último residuo de dogmatismo. Pero lo que confirió un carácter programático a su libro fue la afirmación, que se repetía al final de cada capítulo del libro, “also muß auf Kant zurückgegangen werden” (“entonces debe volverse a Kant”). ${ }^{27}$

Más tarde, Bismarck reemplazó a su ministro de educación, el conservador Heinrich von Müller, por Adalbert Falk, quien liberalizó notablemente el sistema educativo. A partir del año 1872, le quitó todo poder de inspección a la iglesia católica. El paquete de leyes de Falk para reformar el sistema educativo fue conocido como "Kulturkampfgesetze" ("leyes de la lucha cultural"). Estas decisiones motivaron la enérgica protesta del mundo clerical. La situación llegó a ser tan grave que, hacia 1876, todos los obispos de Prusia estaban ya sea en el exilio o presos. Durante la gestión de Falk, entre 1876 y 1878, fueron nombrados cuatro neokantianos a cargo de sendas cátedras en Prusia: Hermann Cohen, Otto Liebmann, Alois Riehl y Wilhelm Windelband. Pero Bismarck no pudo sostener su política anticlerical por mucho tiempo. Con la asunción del Papa León XIII, más flexible que su predecesor Pío IX, mejoraron las relaciones con la iglesia. Al abrirse un espacio de negociación en el manejo de la política educativa, y dada la presión que ejercía el clericalismo, Bismarck decidió separar a Falk de su cargo y frenar las reformas liberales. ${ }^{28}$

Volvamos a los años previos a la gestión de Falk, para seguir los pasos de Friedrich A. Lange, el maestro de Hermann Cohen y su predecesor en Marburg. Lange ocupó un puesto como Privatdozent en Bonn, donde fue introducido en la filosofía de Kant por Friedrich Ueberweg, y asistió a las lecciones de Helmholtz sobre fisiología y ciencias naturales. En 1858, decidió aceptar un puesto como profesor de un Gymnasium en Duisburg, a causa de lo insegura que se había vuelto la carrera académica en tiempos de la reacción conservadora. Lange debía alimentar a una familia de cuatro hijos, así que aceptó el cargo sin dudarlo. ${ }^{29}$

Pero en 1862, Lange firmó una petición de los liberales para un llamado a elecciones, y fue amonestado por el Consejo Escolar, prohibiéndosele toda actividad política en lo futuro. Indignado, renunció a su cargo como profesor del Gymnasium. Además dejó de pagar los impuestos, en señal de protesta contra la política militar de Bismarck. En ocasión de estas experiencias, Lange se fue radicalizando políticamente, e hizo propias muchas de las convicciones que luego formarían el corazón de la ética de Cohen. La participación en la Arbeitervereine puso a Lange en contacto con socialistas de la talla de August Bebel, Ferdinand Lasalle y Wilhelm Liebknecht. En 1865, fundó el periódico Der Bote vom

\footnotetext{
${ }^{27}$ Sieg, (1994), 37.

${ }^{28}$ Sieg, (1994), 79-80.

${ }^{29}$ Sieg, (1994), 87.
} 
Niederrhein (El mensajero del bajo Rin), donde se erigió en crítico acérrimo de la política de Bismarck y de la influencia de la iglesia católica en la política educativa. En un escrito anónimo, refutó en detalle las 80 tesis de la encíclica papal Syllabus errorum (1864). Desilusionado por el ambiente político e intelectual opresivo que se vivía en Alemania, emigró a Suiza en 1870, donde se desempeñó como profesor en la universidad de Zürich, retornando a su patria en 1871, como profesor de la universidad de Marburg. ${ }^{30}$

Lange se sintió a gusto en medio del ambiente liberal de Marburg, y vio con beneplácito la decisión de otorgar el título de Doctor Honoris Causa al Profesor Ignaz von Döllinger, quien enseñaba en Munich y había sido excomulgado por criticar el dogma de la infalibilidad papal. Más aún, Lange mismo se sumó a los argumentos de Döllinger en un escrito polémico. $^{31}$

Pero Lange dio una forma sistemática a sus ideas contestatarias por primera vez recién en Die Arbeiterfrage in ihrer Bedeutung für Gegenwart und Zukunft beleuchtet (El problema obrero iluminado a partir de su significado para el presente y el futuro, 1865). A pesar de su apreciación crítica del capitalismo, Lange dio forma en esta obra a una visión optimista de la marcha de la historia. Parte de esta atmósfera era la afirmación de que las condiciones para una solución de la cuestión social ya estaban dadas, porque eran el resultado de la evolución progresiva que había conseguido la consciencia humana a lo largo del tiempo. De allí que Lange creyera razonable apelar a la razón y la responsabilidad social de los capitalistas. Algunos elementos de la propuesta de Lange preanunciaban los temas que más tarde ocuparían la reflexión ético-política de Cohen.

Tal es el caso de las condiciones que Lange creía necesarias para una mayor justicia social. Estas eran, entre otras: la vigencia de las libertades individuales (de consciencia, expresión y reunión), la promoción de las cooperativas como modo de co-gobierno de los obreros, y la educación de las clases más desfavorecidas. Lange sostenía la necesidad de que el Estado se encargara de administrar un sistema de fábricas fundado en el co-gobierno de los obreros. Recibió fuertes críticas ya desde la primera edición de su obra: Marx y Engels cuestionaron su reformismo gradualista, y los liberales sus propuestas cooperativistas y de cogobierno de los obreros. ${ }^{32}$ Lo cierto es que Lange fue un crítico del materialismo dialéctico de Marx, en quien veía un residuo indeseable de la dialéctica hegeliana. ${ }^{33}$ Esta posición tuvo

\footnotetext{
${ }^{30}$ Sieg, (1994), 88-89.

${ }^{31} \mathrm{Sieg},(1994), 91$.

${ }^{32}$ Sieg, (1994), 95.

${ }^{33}$ Sieg, (1994), 97.
} 
importantes consecuencias históricas, ya que inspiró los argumentos de Bernstein contra el ala ortodoxa marxista del SPD. ${ }^{34}$

Lo cierto es que Lange rechazó desde el comienzo a la dialéctica hegeliana, calificándola de "monstruo conceptual" (Begriffs-Monstrum). Escribió en una carta a un amigo, que lo había saludado por su $30^{\circ}$ cumpleaños, que consideraba a la filosofía hegeliana como un retroceso a la metafísica escolástica y que, por el contrario, la filosofía debía levantarse por sobre el edificio de las ciencias exactas, que deben ser su "pan de cada día" (ihr tägliches Brot). ${ }^{35}$ Esta valoración crítica de la dialéctica hegeliana debe haber influido de alguna manera en la crítica posterior a que Cohen sometió a la afirmación de que todo lo real es racional, considerándola como la negación misma de la ética.

El rol central que Lange otorgó a las ciencias exactas y naturales lo llevó a rechazar la idea de la libertad de la voluntad o del yo como un mero constructo metafísico, a pesar de la inspiración claramente kantiana de su teoría política. ${ }^{36}$ Más tarde, Cohen también rechazará esta idea para su noción de autonomía, reemplazándola por la figura del ciudadano que se autolegisla, según las exigencias de su teoría del Estado, como se verá en un capítulo posterior.

Sin embargo, la valoración del aporte de las ciencias exactas y naturales no condujo a Lange a alguna forma de materialismo dogmático; más bien, él integró el idealismo trascendental kantiano en su enfoque biológico del conocimiento, en la línea de Helmholtz. ${ }^{37}$ Más aún, su recepción de Kant tiene la función de refutar al materialismo, tal como puede leerse en su Geschichte des Materialismus (Historia del materialismo, 1866), obra que tuvo mucha influencia en su época y conoció muchas ediciones. Parte del núcleo kantiano de la teoría de Lange es la idea de que el conocimiento que el hombre tiene del mundo no refleja la realidad tal como es, sino que revela la estructura fisiológica de su aparato cognitivo.

De allí que Lange reinterprete al idealismo trascendental en términos de un naturalismo. Esto significa que el modo en que conocemos el mundo puede ser establecido sólo en el laboratorio del psicólogo experimental, dado que nuestras representaciones son meros fenómenos fisiológicos. ${ }^{38}$ En consecuencia, rechazó la deducción kantiana de las categorías, porque las consideraba como pura metafísica, o como una forma de poesía. Lange era optimista respecto a la posibilidad de derrotar intelectualmente al materialismo. De hecho, esta postura fue desapareciendo progresivamente de la vida académica alemana, quizás

\footnotetext{
${ }^{34}$ Sieg, (1994), 98.

${ }^{35}$ Sieg, (1994), 100.

${ }^{36}$ Sieg, (1994), 101; Köhnke, (1986), 233.

${ }^{37}$ Sieg, (1994), 102.

${ }^{38}$ Köhnke, (1986), 251-252.
} 
porque el idealismo estaba demasiado enraizado en esta cultura, que valora tanto la interioridad y la profundidad espiritual. Lange graficó este rasgo con su afirmación de que Alemania es el único lugar en el mundo en el que el farmacéutico no puede leer una receta sin pensar en la conexión que existe entre su actividad y el fundamento del universo. ${ }^{39}$

Lange dio expresión a un pensamiento abierto, siempre susceptible de nuevas críticas y revisiones. Esta fue una de las causas de su influencia sobre quienes querían evitar todo dogmatismo, entre ellos el joven Hans Vaihinger. ${ }^{40}$ La capacidad de Lange para matizar sus juicios, e integrar parcialmente en su visión del mundo aquellas posturas que anteriormente había rechazado, puede apreciarse en su actitud frente a las ideas metafísicas. Si bien Lange había rechazado toda metafísica, consideraba que el ámbito dejado por Kant a lo nouménico o a la cosa-en-sí, debía ser rescatado, porque era el lugar propio de los sentimientos religiosos y estéticos, que pertenecen a las facultades espirituales y creativas del hombre, y deben ser desarrollados plenamente. ${ }^{41}$ Tampoco su crítica al dogmatismo de la iglesia católica fue un obstáculo para que considerara que había jugado en el pasado un rol importante en el progreso moral de la humanidad, y que, si se ocupara de la cuestión social, podría ayudar a frenar la expansión del materialismo. ${ }^{42}$

Como se dijo más arriba, más de un momento del sistema filosófico de Cohen delata la influencia de su maestro. Piénsese en su investigación filosófica de problemas sociales, su defensa del cooperativismo y su crítica del capitalismo, su discusión del absolutismo religioso (eco de las invectivas de Lange contra el dogma de la infalibilidad papal), o en su valoración del aporte de las ciencias naturales a la investigación filosófica. ${ }^{43}$ Sin embargo, Cohen rompió con la interpretación psicologista que hizo Lange del pensamiento de Kant, y devolvió a la epistemología kantiana al nivel trascendental del estudio de las condiciones del pensamiento. $^{44}$

A pesar de su rechazo posterior del psicologismo de Lange, Cohen se entregó en su juventud al estudio de la psicología. Luego de su doctorado, Cohen marchó a Berlín a estudiar con Heymann Steinthal y Moritz Lazarus, que habían fundado en 1859 el Zeitschrift für Völkerpsychologie und Sprachwissenschaft. En los escritos que Cohen publicó allí, siguió el método de Steinthal, que consistía en buscar las causas psicológicas de los fenómenos culturales, es decir las uniones causales que se dan en la consciencia. De este modo, se

\footnotetext{
${ }^{39}$ Willey, (1978), 98.

${ }^{40}$ Sieg, (1994), 106.

${ }^{41}$ Willey, (1978), 99.

${ }^{42}$ Sieg, (1994), 105.

${ }^{43}$ Sieg, (1994), 119.

${ }^{44}$ Willey, (1978), 102
} 
entendía a la psicología como una ciencia puramente empírica, en la línea de Herbart. Más tarde, se interesó por la filosofía de Kant, a partir del debate entre Fischer y Trendelenburg. ${ }^{45}$

Lange leyó con admiración la obra de Cohen Kants Theorie der Erfahrung (La teoría de la experiencia de Kant, 1871), y esto hizo posible que ambos se encontraran en Marburg. Cohen destacó que en esta reunión coincidieron en la idea de un monoteísmo fundamentado filosóficamente. ${ }^{46}$ Pronto entablaron una estrecha relación, que dio como resultado la habilitación de Cohen en Marburg hacia 1873. El escrito de habilitación fue su obra de 1871, acompañada por un escrito sobre Die systematische Begriffe in Kants vorkritische Schriften nach ihrem Verhältnis zum kritischen Idealismus (Los conceptos sistemáticos en los escritos precríticos de Kant, según su relación con el idealismo crítico).

Hacia 1874, Lange propuso a Cohen como su sucesor, y encontró obstáculos insalvables que obligaron a la postergación de su nombramiento. Uno de los principales problemas era la barrera puesta por el botánico Albert Wigland, quien objetó el nombramiento de un judío para una cátedra perteneciente a una universidad de larga tradición cristiana. ${ }^{47}$ En 1876, un año luego de la muerte de Lange, Cohen fue nombrado como su sucesor en la cátedra de Marburg, a causa no tanto de la memoria de su maestro, cuanto de la orientación científico-natural de su filosofía. ${ }^{48}$ A pesar de la continuidad clara que existía entre las teorías de Lange y las de su discípulo, la cuestión del rol que debía jugar la psicología abrió entre ellos una distancia insalvable. La crítica de Cohen al psicologismo de Lange es importante no sólo para comprender el contexto histórico que está detrás de la redacción de la $\operatorname{ErW}$, sino sobre todo para desentrañar las razones que movieron a Cohen a elegir a la ciencia del derecho como referente para deducir la autoconsciencia.

\section{2. La crítica de Cohen al psicologismo}

Uno de los primeros escritos de Cohen fue la "Introducción con un aporte crítico" para la Historia del materialismo de Lange, donde por primera vez tomó distancia respecto de la teoría de su mentor. ${ }^{49}$ El rechazo de Cohen del psicologismo de Lange se debió a una interpretación diferente de la teoría kantiana del conocimiento. Lange entendía a la gnoseología kantiana como una explicación del funcionamiento de nuestras facultades de

\footnotetext{
${ }^{45}$ Sieg, (1994), 108-110.

${ }^{46}$ Sieg, (1994), 114.

${ }^{47}$ Sieg, (1994), 116.

48 Sieg, (1994), 117.

${ }^{49}$ Cohen, (1914).
} 
conocimiento, es decir, como una cuestión de hecho. Por el contrario, Cohen se propuso desde el comienzo atender tan sólo a la quaestio iuris o cuestión de derecho, es decir a la investigación acerca de las condiciones bajo las cuales puede justificarse el conocimiento científico.

Para resolver la cuestión de derecho, se alejó del análisis del funcionamiento de las facultades de conocimiento del sujeto, y decidió considerar el corpus discursivo de la ciencia matemático natural, cuya universalidad y necesidad no creía que pudieran ponerse en duda. A partir de este factum científico, Cohen dedujo toda su filosofía teórica o lógica, entendida como la teoría de las condiciones de su justificación.

Cohen cambió de este modo radicalmente la concepción del sistema de las ciencias imperante en la academia alemana hasta ese momento. A partir de su distinción entre cuestiones de hecho y de derecho, colocó en el primer plano a la filosofía de la ciencia, como una teoría acerca de las condiciones de validez del conocimiento científico. De este modo, la psicología ya no podía cumplir el rol protagónico que le había correspondido anteriormente, porque ya no era necesario, para fundamentar el conocimiento científico, determinar el modo en que se producen los conceptos en la consciencia empírica. Cohen reconstruyó el sistema de las ciencias a partir de las categorías fundamentales de la filosofía teórica o lógica y de la filosofía práctica o ética. Las ciencias particulares podían ser justificadas como disciplinas sólo cuando se hubiera demostrado que hunden sus raíces en la lógica o en la ética.

Pero mientras que la lógica ya disponía de su ciencia de referencia en la ciencia matemático-natural, la ética debía todavía encontrar su punto de partida en alguna de las ciencias del espíritu. La psicología podría ser el punto de partida de la ética sólo si resistiera la evaluación crítica de su status epistémico.

\section{3. A la búsqueda de un punto de partida para la ética}

La ciencia de referencia de la ética, o Bezugsfaktum, debía tener la universalidad, necesidad y precisión necesarias para constituir un punto de partida confiable. Las candidatas para ser el punto de partida de la ética eran las ciencias del espíritu más desarrolladas en aquel momento: la historia, la sociología, la psicología y el derecho. En primer lugar, Cohen rechazó a la historia porque estudia las acciones de los grandes personajes que han conducido los pueblos y producido los acontecimientos más importantes. Este proceder acusa la 
influencia de categorías estoicas y cristianas, en la medida en que supone que la historia está determinada por la capacidad espiritual del individuo.

De acuerdo con esto, la moralidad se expresa sólo en pocos individuos, que son los héroes que dirigen la historia. Esto implica que se trata de una ciencia que tiene por objeto al sujeto tomado en sí mismo, aislado de las comunidades de las que forma parte. El individualismo metodológico que está detrás de esta postura inhabilita a la historia para dar cuenta del problema central de la ética, que es el de la relación entre el individuo y la universalidad.

Podría objetarse a este argumento que la historia muchas veces se ocupa no ya de los grandes individuos sino más bien de los pueblos. Es el caso de la historia de los procesos colectivos, tales como los movimientos sociales. Pero el pueblo no constituye una unidad apta para representar la universalidad moral con la que entra en relación el individuo. Más bien es una comunidad relativa e inestable, que integra a sus miembros a partir de criterios tales como el lugar de nacimiento o la pertenencia a una tradición determinada, o comunidad lingüística, cuando no por consideraciones de raza. Es decir, el pueblo es una unidad excluyente de la que no puede esperarse que integre de modo ilimitado a todos los miembros que quieran formar parte de él, sin establecer distinciones de ningún tipo. Como dice Dreyer:

El contenido de la moralidad, que de acuerdo con Cohen es el contenido constitutivo de la historia, es tan inagotable que no podría ser completado por ningún individuo o grupo particular. ${ }^{50}$

La única comunidad apta para representar la universalidad moral irrestricta que busca Cohen es el Estado. ${ }^{51}$

El tercer argumento contra la aceptación de la historia como Bezugsfaktum surge del status del Estado como formación cultural. Cohen se refiere a las relaciones entre las fuerzas materiales y las ideas morales, que tienen lugar en la formación cultural del Estado. La concepción materialista de la historia entiende al Estado como un mero producto de las

\footnotetext{
50 "Der Inhalt von Sittlichkeit, der nach Cohens der Konstituens von Geschichte ist, ist zu umfänglich, zu unerschöpflich, als dass ein Individuum oder eine Sondergruppierung ihn hinlänglich erfüllen könnte“. Cfr. Dreyer, (1985), 111.

51 "De allí que no pueda decirse que en última instancia el pueblo estaría en oposición al individuo. Porque el pueblo constituye para la antropología, en el mejor de los casos, un concepto uniforme a partir de fundamentos físicos, y con ello una universalidad. Contra esto, el Estado entra en la misión moral, en el sentido político de la historia, que es adjudicada de modo oculto al pueblo, con una ambigüedad funesta. (...) El concepto del Estado coloca por primera vez el concepto de universalidad en contra de esto, como una unidad vencedora, a la que deben ser sometidas todas aquellas particularidades".

("Man kann daher auch nicht sagen, dass in letzter Instanz das Volk den Gegensatz bilde zum Individuum. Denn das Volk bildet allenfalls für die Anthropologie auf physischer Grundlage einen einheitlichen Begriff, mithin eine Allheit. Im politischen Sinne der Geschichte dagegen tritt erst der Staat in die sittliche Mission ein, welche in einer verhängnisvollen Zweideutigkeit gemeinhin dem Volke zuerteilt wird. (...) Der Begriff des Staates erst stellt den Begriff der Allheit dagegen auf, als einer bezwingenden Einheit, welcher alle jene Partikularitäten unterworfen werden müssen“; $E r W, 33$ ).
} 
relaciones de poder de una comunidad dada. Esta idea no está exenta de problemas, toda vez que conlleva la negación misma de la historia. La historia es el producto de la acción del ser humano, lo que es decir que está orientada y producida por el espíritu humano, toda vez que el sujeto no es un animal movido solamente por instintos naturales.

Cohen considera que la mera existencia de hechos culturales tales como la ciencia natural matemática, las obras de arte más exquisitas, o el Estado democrático de derecho con su sistema legal, son la prueba inexcusable de que la cultura es la expresión del espíritu humano. El materialismo acarrea en última instancia la negación de la historia como disciplina científica. ${ }^{52}$ Por otro lado, si la historia necesita del concepto de ser humano para poder explicar los procesos de los que se ocupa, entonces es una ciencia que debe fundamentarse en la ética y no a la inversa. ${ }^{53}$ Esto significa que la historia no puede proporcionar a la ética el Bezugsfaktum a partir del cual deducir sus categorías fundamentales.

Otro posible candidato como Bezugsfaktum para la ética es la sociología. Cohen dirigió sus críticas sobre todo contra el organicismo de la sociología de su tiempo. De acuerdo con esta concepción, la sociedad es entendida como un sistema que funciona análogamente a como lo hace un organismo, entendido como la unidad de los órganos particulares. Del mismo modo en que la totalidad del organismo funciona correctamente en la medida en que cada órgano cumple con su función, la totalidad del sistema social existe sólo si cada institución cumple con el fin para el que ha sido establecida. La sociología supone entonces un normativismo tácito, es decir, parte de una serie de normas que deben cumplir las instituciones para mantener el todo social en funcionamiento.

Pero a la vez la sociología intenta criticar el status quo existente, promoviendo cambios o reformas. Se trata, sin embargo, de un intento condenado al fracaso, porque supone un funcionalismo que no puede ir contra sí mismo. Como puntualiza Günther,

El significado casi metafísico que recibe la naturaleza en la concepción de la sociedad como un gran cuerpo, conduce inevitablemente al doble sentido hipócrita, de impulsar la reacción, pero a la vez proclamar el progreso. ${ }^{54}$

\footnotetext{
${ }^{52}$ Por eso concluye Cohen: "Con esto (...) se revela esta concepción materialista y naturalista de la historia como la supresión de la historia. Porque la historia, como la historia de los seres humanos y sus obras y actos, es la historia del espíritu y las ideas; dicho de otro modo: no habría historia mundial, sino sólo historia natural“"

("Damit [...] enthüllt sich diese materialistische und naturalistische Geschichtsansicht als die Aufhebung der Geschichte. Denn Geschichte, als Geschichte der Menschen und ihrer Werke und Taten, ist Geschichte des Geistes und der Ideen; oder aber: es gäbe keine Weltgeschichte, sondern nur Naturgeschichte"; $\operatorname{ErW}, 39$ ).

${ }^{53} \mathrm{ErW}, 29,40$.

54 "Die quasimetaphysische Bedeutung, die die Natur bekommt, -in den Gedanken der Gesellschaft als einem großen Körper,- führt auch hier zu dem heuchlerischen Doppelsinn, die Reaktion zu betreiben und den Fortschritt zu proklamieren.“. Cfr. Günther, (1971), 96.
} 
Por eso la metáfora organológica de la sociedad permanece siendo una "comparación que tambalea" ("hinkendes Gleichnis"), y conduce a una concepción reaccionaria del cambio social. $^{55}$ Pero si bien la sociología debe suponer una serie de normas para explicar el funcionamiento del todo social, no puede fundamentarlas sin ayuda de la ética. Si la sociología es dependiente de la ética, entonces no puede constituir su Bezugsfaktum. Aún cuando la sociología pudiera dar cuenta de sus supuestos, no dispondría de ningún concepto de universalidad suficientemente incluyente a partir del que se pudiera deducir la universalidad irrestricta que necesita la ética.

\section{4. La ética y la psicología}

Cohen rechazó también a la psicología como Bezugsfaktum para la ética, en base a razones análogas a las esgrimidas para el caso de la historia. Cohen tenía en vista a la psicología de cuño biologista que estaba en boga en el momento en que escribió su Ethik. Como ya se dijo más arriba, la psicología era entendida entonces como una ciencia análoga a las ciencias naturales, porque tenía por cometido investigar las raíces orgánicas de los procesos mentales. El punto de partida de la psicología era, entonces, el individuo solo y aislado de los demás, pensado como un organismo cerrado a todo lo que le es externo. ${ }^{56} \mathrm{Al}$ igual que en el caso de la historia, Cohen consideraba que este enfoque no puede dar cuenta de la correlación entre el individuo y la universalidad, ya que sólo toma en cuenta al primero.

La ética no puede partir nunca del individuo aislado, como es el caso de las éticas perfeccionistas, que apuntan al desarrollo moral del individuo, en términos del logro de algún ideal de vida buena. Pero el individuo sólo podrá determinar su voluntad de acuerdo con la ley moral universal si entra en con los demás en un cierto tipo de relación intersubjetiva. Se trata de una correlación en la que el individuo se coloca en una posición de simetría con todos los demás, lo cual supone el reconocimiento de iguales derechos. Pero la psicología opera con un instrumental metodológico que no puede dar cuenta de esta correlación.

Tampoco puede admitirse la rama de la psicología que estudia las individualidades de los pueblos (Völkerpsychologie), porque estas comunidades particulares no tienen la universalidad necesaria para fundamentar la correlación entre el individuo y los demás de acuerdo con una ley moral que valga para todos. Las comunidades basadas en tradiciones, lenguas o rasgos étnicos compartidos son necesariamente excluyentes, porque no pueden

\footnotetext{
${ }^{55} \operatorname{ErW}, 41$.

${ }^{56} \mathrm{ErW}, 11$.
} 
aceptar como miembros a quienes no tengan estos rasgos en común. Por otro lado, la psicología comparte con la historia el problema de la dependencia respecto de la ética, dado que supone para su investigación el concepto de persona humana, pero no está en condiciones de tematizarlo. La psicología parte de la subjetividad como algo de antemano, cuya estructura debe determinar y explicar. Sin embargo, desde el punto de vista de Cohen, la subjetividad presupone el concepto de ser humano, que es una categoría de la ética. De este modo, la psicología debe pedir ayuda a la ética para fundamentarse, y no a la inversa.

Finalmente, la psicología no podría servir como Bezugsfaktum para la ética, porque no se desarrolla en el ámbito deóntico, sino más bien en el de la naturaleza. Es decir, es una ciencia que se ocupa de cómo es el hombre, pero no de cómo debe ser. Si la ética se fundara sobre ella, entonces perdería de modo inevitable su carácter deontológico. ${ }^{57}$ Dicho de otro modo, la ética tiene por cometido la fundamentación del concepto de una ley moral universal, es decir, de un enunciado con una estructura de tipo prescriptivo. La ética debe entonces argumentar en el plano normativo. Pero un enunciado de tipo prescriptivo no puede deducirse sin más de uno de tipo descriptivo o explicativo.

Dicho de otra manera, a partir del ser no puede deducirse el deber ser. Para poder dar este paso argumentativo, deben introducirse una serie de premisas intermedias. La ética no puede deducirse entonces a partir de la psicología, por lo que la psicología ya no puede permanecer como la ciencia fundante del ámbito de las ciencias del espíritu.

La conclusión de la investigación de Cohen es que el derecho es la única ciencia del espíritu que puede servir de punto de partida para la ética, por su precisión, universalidad y necesidad. El derecho fundamenta la ley moral universal en la voluntad común de la persona jurídica del Estado. La voluntad común se expresa por medio de la actividad de la legislación, de la que los ciudadanos son tanto los autores como los destinatarios.

El momento en el que la cooperación entre la ética y la ciencia del derecho se torna más evidente es la deducción de la autoconsciencia, en el capítulo cuarto de la $E r W$. En las páginas que siguen, reconstruiré la argumentación de Cohen para la fundamentación dialógica de la autoconsciencia, a partir de la figura legal del contrato. Esta es la primera parte de la investigación de Cohen sobre la autoconsciencia; restan aún la argumentación a partir de la persona jurídica de la cooperativa y del Estado, que se considerarán en los capítulos siguientes.

\footnotetext{
${ }^{57} \operatorname{ErW}, 12$ ss.
} 


\section{5. La alteridad y la autoconsciencia}

Cohen explica el primer paso de su deducción de la autoconsciencia diciendo que:

Se trata (...) del contenido de este concepto fundante mismo y de la disposición y la predisposición en la determinación de este contenido. ${ }^{58}$

Como ya se apuntó en la sección anterior, según Cohen es posible analizar el contenido de la autoconsciencia, es decir, el contenido del concepto del sujeto de la voluntad pura, o bien a partir del sujeto individual en sí mismo y aislado de los demás; o tomando como referencia su relación con los otros sujetos. A fin de dar cuenta del problema de la ética -la correlación entre el individuo y la universalidad- Cohen opta por el segundo camino. Y comienza con un interesante recorrido histórico, con el fin de poner en evidencia que el problema de la autoconsciencia ha sido frecuentemente mal planteado. Veamos sólo algunos de los hitos de su exposición.

El punto de vista del individuo está a la base de la teoría cartesiana del cogito, porque el individuo adquiere la certeza de su existencia como cosa pensante a partir de la reflexión sobre su acción misma de pensar. Leibniz dio un paso más, porque al postular que la apercepción es la diferencia característica de la consciencia respecto de toda materia, hizo entrar en juego la reflexividad, como una característica del yo, pero siempre desde el punto de vista del individuo. Lo mismo puede decirse de la idea kantiana de la apercepción, que garantiza la unidad de la consciencia, esto es de los juicios sintéticos a priori. Fichte, partiendo también del ego, definió a la autoconsciencia como el yo, es decir la espontaneidad originaria, por oposición al no-yo, entendido como la libertad del yo pero bajo la forma de la sujeción a las leyes de la naturaleza. El yo es el sujeto, que sólo puede ser pensado frente al no-yo, es decir al objeto de conocimiento. Cohen rechaza el punto de partida de Fichte, porque su intención no es ocuparse de la consciencia del sujeto individual, sino explicar las categorías fundamentales de la ciencia del derecho.

Sin embargo, Cohen considera que el procedimiento fichteano de contraponer el yo al no-yo, puede ser de ayuda en la investigación sobre el origen de la autoconsciencia desde el punto de vista moral, siempre y cuando se entienda correctamente el concepto del no-yo. ${ }^{59}$

La propuesta de Cohen es la siguiente. Si el no-yo se identifica con la humanidad, y de allí se concluye que el yo se relaciona con todos los demás sujetos en el no-yo, entonces podrá hacerse justicia al problema fundamental de la ética que, como hemos visto, es la correlación

\footnotetext{
58 "Es handelt sich (...) um den Inhalt dieses Grundbegriffs selbst und um die Disposition und die Anlage in der Bestimmung dieses Inhalts“ (ErW, 207).

${ }^{59} \mathrm{ErW}, 209$.
} 
entre el individuo y la universalidad. Utilizando el procedimiento fichteano, la ética podría liberarse del esquema monológico que ha dominado a la filosofía moderna, y lograr que el yo se abra a la perspectiva de la intersubjetividad.

Para explicar su propuesta, Cohen traza una analogía con el juicio del origen de la $\operatorname{LrE}$, esto es, la idea de que la identidad del objeto se determina por contraposición con aquello que el objeto no es. ${ }^{60}$ Sólo es posible la totalidad de la ciencia gracias a esta doble operación, en la que los conceptos se determinan por su distinción con los demás y, a su vez, son unificados en una unidad mayor. Es la unidad superior que integra a la pluralidad de los conceptos que surgen en virtud del procedimiento de sumación infinita, que es un producto del juicio de la universalidad. ${ }^{61}$ Cohen afirma, entonces, que ningún concepto debe ser considerado aisladamente, sino que debe ser pensado en un plexo de relaciones. Del mismo modo, el yo también necesita del otro para poder convertirse en un sujeto de derecho. La relación legal -

${ }^{60}$ Cohen busca establecer en el juicio del origen la constitución última de todo juicio de la ciencia. Remontándose al Sofista de Platón, considera que la negación relativa y no absoluta es la manera de romper la homogeneidad del ser parmenídeo y abrir el camino a la investigación científica, por medio de la distinción y la unión entre conceptos. El conocimiento científico, entonces, opera en última instancia por medio de discriminaciones, lo que sin embargo implica la necesidad de tomar en consideración un tercer elemento: la continuidad. No puede pensarse en un sistema de conocimientos científicos si no existe una continuidad entre todos ellos, lo que implica la ausencia de rupturas o agujeros en el corpus discursivo. Se trata de la continuidad de las operaciones que integran una teoría científica, toda vez que cada una debe seguir inmediatamente a la otra, sin que se interponga ninguna actividad extraña a la investigación $(\operatorname{LrE}, 91)$. En caso contrario, no se trataría del conocimiento puro, sino que podría estar contaminado por consideraciones de otra índole, como por ejemplo de tipo religioso o político. En este sentido la continuidad es una ley del pensamiento (Denkgesetz), y confiere unidad a todo el corpus de la ciencia natural. La ley de la continuidad pone en relación a cada uno de los juicios llevados a cabo con el origen a partir del cual surgieron.

${ }^{61}$ Siguiendo a Ferraro $(2000,86)$, traduzco Allheit como "universalidad" y no como "totalidad", porque esta expresión española le daría a Allheit un significado metafísico que no tiene en la obra de Cohen. Como bien señala Ferraro, en la $E r W$ (por ej. $E r W, 5$ ), aparece asociada también con "universidad" (Universität), pero esta palabra se usa en español más bien para hacer referencia a la institución académica.

La función del juicio de la universalidad es unificar y vincular en una unidad superior los números obtenidos por medio de la sumación del juicio de la pluralidad. La actividad sumatoria de la pluralidad no llega a establecer ninguna unidad permanente y estable, porque las unidades se derivan unas de otras únicamente en base al procedimiento mencionado. El tiempo deja a la unidad que forman los números siempre abierta al futuro, por lo que queda abierto el problema del establecimiento de una unidad que integre a todos los elementos $(\operatorname{LrE}, 178)$. Mientras que para el juicio de la pluralidad lo importante es la producción de cada miembro singular, en el juicio de la universalidad lo relevante es la unión de los miembros. El cálculo infinitesimal tiene la función de superar la unidad relativa y precaria del juicio de la pluralidad, introduciendo una dimensión nueva: la del espacio. Gracias a la ley de la continuidad, esta dimensión del espacio propia del juicio de la universalidad se integra exitosamente con la de la temporalidad, característica del juicio de la pluralidad. El cálculo infinitesimal logra producir la universalidad por medio del integral, que unifica la serie infinita de números con lo infinitamente pequeño (das Unendlichkleine) ( $r r E, 179)$. De este modo surge la universalidad de la sumación infinita. Es decir, ya no se trata del origen de cada número discreto y particular en virtud de la suma, sino de la síntesis de todos en la unidad ideal del cálculo infinitesimal. De este modo el objeto del conocimiento adquiere unidad y se ha dado un paso más en su determinación $(\operatorname{LrE}, 186)$. El juicio de la universalidad produce entonces el espacio por medio del cálculo infinitesimal, y de este modo se exterioriza la serie interna y puramente temporal del juicio de la pluralidad. Ya no se trata de que las unidades de la pluralidad aparezcan una después de otra (Nacheinander), sino más bien una junto a la otra (Beisammen). Las unidades son ubicadas una junto a la otra al mismo tiempo, constituyendo de este modo una unidad estable y completa ("Das Äußere ist in der Tat das Innere; aber das Innere verwandelt sich zum Äußeren in dem Fortschritt der Erzeugung von Zeit zu Raum“; $L r E$, 197). 
que es la forma que adquiere toda figura del derecho- supone siempre al yo y al otro, pero nunca considerados como dos términos aislados. ${ }^{62}$

A partir de la relación intersubjetiva en la que el yo incluye al otro, resulta una voluntad común, que los supera a ambos y adquiere autonomía respecto de sus voluntades individuales. La ciencia del derecho tiene un andamiaje científico preciso y universal, y apto para pensar la correlación entre el otro y el yo. Ahora bien, la adopción del enfoque de la ciencia del derecho exige el rechazo de otras concepciones de la alteridad, entre ellas, aquellas que provienen de la psicología y de la religión.

La deducción del otro a partir de la consciencia del yo es ilegítima, porque se trata de una deducción meramente psicológica, de una explicación sobre el modo en que el otro aparece a la consciencia del yo. Esta deducción no tiene nada que ver con el modo en que se expresa la voluntad pura en el derecho, ni tampoco con el concepto del sujeto de la voluntad pura. Es decir, la explicación psicológica del surgimiento de la consciencia del otro en el yo es moralmente neutra, y no aporta nada substancial a la investigación moral que Cohen intenta llevar a cabo.

I. 6. Autoconsciencia, alteridad y religión. El amor y la alteridad en la tradición judía profética

Cohen rechaza la concepción religiosa del amor al prójimo, aunque no niega de plano el aporte de la tradición religiosa en lo que hace al problema de la alteridad. Es por eso que Cohen rescata a la tradición judía profética, como una forma de proto-universalismo moral.

En efecto, Cohen reconoce como última fuente de su concepto de autoconsciencia, a la idea de la humanidad, tal como ha surgido del monoteísmo judío, que no es definido por contraposición con el politeísmo, sino más bien con la pluralidad de los hombres y los pueblos. Es decir, la idea del Dios único significa la exigencia de la unificación de la humanidad en una comunidad universal, constituida por los lazos morales de la justicia y la solidaridad. De allí la exigencia de extender el deber de la justicia hacia el extranjero, la viuda y el huérfano, que no son otra cosa que metáforas de la exclusión social. ${ }^{63}$

Cohen destaca especialmente el progreso moral que significó la adopción del deber de hospitalidad para con el extranjero en el monoteísmo judío, signado desde su origen por su carácter de religión nacional. Y se inspira en esta exigencia de universalidad, para elaborar el

\footnotetext{
${ }^{62}$ Ollig, (1979, a), 151.

${ }^{63} \mathrm{ErW}, 214$.
} 
concepto de la autoconsciencia a partir de la unificación del yo con el tú, en una voluntad común.

Cassirer dejó en claro esa influencia del mesianismo judío en Cohen, en las palabras pronunciadas frente a su tumba el 7 de abril de 1918:

Y cuando Moisés se coloca frente a Dios en la zarza ardiente, y le pregunta con qué nombre debe denominarlo a Dios, cuando el pueblo le pregunte cómo se llama el Dios que lo ha enviado, Dios le responde con las siguientes palabras: 'Yo seré, el que soy. Diles que 'yo soy' te ha enviado a ellos'. En esta alta abstracción del 'yo', en esta concepción de la persona apartada de toda cosificación, en esta superación de todo lo sensible y de toda figuración por medio del principio espiritual de la personalidad, se enraíza la fuerza auténtica del monoteísmo y su misión universal. ${ }^{64}$

Sin embargo, no debemos olvidar que Cohen también advirtió los peligros que la concepción religiosa del prójimo representa para la ética, puesto que, a su entender, la ética necesita emprender su propio camino, con independencia del discurso teológico al que ha estado íntimamente vinculada durante tanto tiempo. ${ }^{65}$

Para que la ética pueda preservar la pureza trascendental, es necesario, en primer lugar, someter a crítica el modo en que el yo entra en relación con el prójimo, en el discurso religioso. En tal discurso, la relación se da en base al "amor" (Liebe), entendido como afecto. Cohen rechaza la fundamentación de la voluntad pura en el afecto, porque supone que el yo está dado de antemano a la relación intersubjetiva. ${ }^{66}$ Se niega a aceptar, además, que el yo exista previamente a la acción, porque el sujeto de la voluntad pura -la autoconsciencia- es el objeto de la voluntad, es decir, el resultado de su acción. El punto de partida de la idea del amor al prójimo es, entonces, el de la psicología, pero de una psicología que aparece bajo la forma de la espiritualidad.

Cuando el yo se pone en relación con el tú por medio del amor, esta relación sólo alcanza a un grupo de individuos, pero nunca alcanza a la universalidad de la humanidad. La razón de esto es que el concepto de prójimo tiene un carácter excluyente, ya desde su misma definición. El prójimo implica el superlativo, pero también, por contraste, el comparativo y el diminutivo. Es decir, el prójimo es aquel con quien el yo se siente unido por un vínculo especial, en virtud de la posesión de determinadas características. Pero entonces quedan excluídas de esta relación las personas que no están en esa situación, o no presentan los rasgos

\footnotetext{
64 “Als Moses am brennenden Dornbusch vor Gott steht, und als er fragt, welchen Namen Gottes er nennen solle, wenn das Volk ihn frage, wie der Gott heiße, der ihn gesandt habe, da antwortet ihm Gott mit den Worten: 'Ich werde sein, der ich bin. Sage ihnen, der 'Ich bin' hat mich zu euch gesandt'. In dieser letzten und höchsten Abstraktion des 'Ich', in dieser vor allem Dinglichen abgewandten Erfassung der Person, in dieser Überwindung alles Sinnlichen und Bildlichen durch das reine geistige Prinzip der Persönlichkeit wurzelt die eigentliche Kraft des Monotheismus und seine weltgeschichtliche Mission."(Cassirer, 1918, 70).

${ }^{65}$ Görland, (1912), 241.

${ }^{66}$ Ollig, (1979, a), 151-152.
} 
del prójimo. Por eso, piensa Cohen, el concepto del prójimo ha sido utilizado para justificar las guerras de religión libradas contra el enemigo de la fe, contra aquél que está alejado de la comunidad religiosa. ${ }^{67}$

Queda claro, de este modo, que Cohen se niega a fundamentar el concepto del otro a partir de una determinada disposición afectiva del yo, porque el afecto siempre es excluyente y tiene un déficit de universalidad. El problema que presenta el concepto del amor al prójimo reside, en última instancia, en la perspectiva monológica que supone la fundamentación de la autoconsciencia en el afecto. El amor al prójimo consiste, en realidad, en la exaltación del yo como un sujeto privilegiado en relación con el otro, porque los elementos decisivos del afecto y las preferencias se ubican en el yo. Pero, según Cohen, sólo es posible lograr una fundamentación de la autoconsciencia, cuando el otro es puesto en una posición de simetría con el yo, y los intereses de ambos cuentan por igual.

Cohen encuentra otra objeción a la concepción religiosa del otro como prójimo, y la formación de una cierta comunidad espiritual entre los sujetos que están unidos entre sí por el lazo de un amor mutuo. Su idea es que, de este modo, ambos sujetos se despersonalizan, porque cada uno supera su individualidad para unirse espiritualmente con el otro. Cohen denomina a esta transformación de cada sujeto en el otro como una "mezcla" (Verschmelzung) de ambos, esto es, una situación en la que cada uno trasciende los límites de su identidad y se fusiona con el otro. Cada sujeto se niega a sí mismo, para superar su egoísmo y acceder al otro por medio de la compasión. El vínculo que ambos construyen los eleva por sobre su individualidad y los trasciende, modificando sus disposiciones afectivas. El sujeto de la voluntad pura, desde el punto de vista del amor al prójimo, consistiría entonces en una comunidad espiritual difusa donde la subjetividad de los individuos perdería sus contornos.

En la acción legal, en cambio, los sujetos constituyen una nueva voluntad que es independiente de ellos, aunque esto no significa que cada sujeto pierda su individualidad, sino que la voluntad común es la que garantiza el respeto de sus derechos y de sus intereses personales.

Ahora bien, la relación legal es un tipo de relación intersubjetiva diferente de la del amor al prójimo, porque los sujetos entran en ella sólo para proteger sus intereses. Por otro lado, la relación legal compromete las acciones de los sujetos sólo en la medida en que están tipificadas en las normas que la rigen. Es decir, que deja un ámbito libre para las acciones individuales que tienen lugar por fuera de la relación misma. Como dice Cohen:

\footnotetext{
${ }^{67} \operatorname{ErW}, 218$.
} 
La exigencia de la unificación se extiende y limita a la unificación para la acción legal; y, por lo tanto, para la producción de un contenido y una relación legales; pero no para algo así como la fusión anímica o espiritual de los sujetos. ${ }^{68}$

\section{7. Autonconsciencia, relación legal y contrato}

De lo expuesto hasta aquí, Cohen concluye que la interrelación entre el yo y el otro que es el origen de la autoconsciencia- debe ser pensada de acuerdo con los conceptos de la ciencia del derecho. De este modo, quedaría salvada la autodeterminación de los sujetos, y se ganaría en precisión y claridad. ${ }^{69}$

Sin embargo, en realidad Cohen no fundamenta la relación intersubjetiva entre el otro y el yo a partir del concepto abstracto y general de la relación legal, sino que centra su análisis en la figura del contrato. ${ }^{70}$ La razón de esto es que Cohen considera que toda relación legal puede ser entendida como una forma de contrato. En un capítulo posterior se explicará este principio a partir de la constitución del Estado como persona jurídica, pero aquí es necesario aceptarlo provisionalmente para los fines de la argumentación.

La figura legal del contrato supone que los contrayentes buscan ponerse de acuerdo en relación con un conjunto de normas, que luego regularán sus acciones. ${ }^{71}$ Pero la deliberación misma debe cumplir con la condición de que los contrayentes estén en posición de simetría el uno respecto del otro y que, por lo tanto, ninguno pueda coaccionar al otro para que consienta las cláusulas o los términos que le parezcan más convenientes. Como resultado del proceso de deliberación, los contrayentes acuerdan una serie de normas que regularán su comportamiento en el futuro y el contenido de dichas normas constituye una nueva voluntad.

Se trata de una voluntad común que, a pesar de que es el resultado de su declaración, trasciende sus voluntades particulares. Dicho de otro modo, la voluntad común que es el producto del contrato no puede ser modificada arbitrariamente si alguno de los contrayentes cambia de parecer. Por el contrario, sólo puede ser modificada de acuerdo con las cláusulas procedimentales que marcan el modo en que puede revisarse o rescindirse el contrato. El contrato, entonces, es vinculante incluso respecto de las condiciones bajo las cuales puede ser declarado como inválido o nulo. Por eso, la voluntad común producto del contrato unifica las

\footnotetext{
68 "Die Forderung der Vereinigung erstreckt sich und beschränkt sich auf die Vereinigung zur Rechtshandlung; also zur Erzeugung eines Rechtsinhalts, eines Rechtsverhältnisses; aber nicht etwa zur seelischen oder geistigen Verschmelzung von Subjekten." (ErW, 224).

${ }^{69}$ Winter, (1980), 286.

${ }^{70} \mathrm{ErW}, 247$.

${ }^{71}$ Winter, (1980), 283.
} 
voluntades de los contrayentes en una unidad superior y cualitativamente diferente. De este modo, las condiciones establecidas por la ley para celebrar los contratos, por un lado, y las cláusulas convenidas como resultado del mismo, por el otro, establecen con precisión y exactitud la relación que debe existir entre el tu y el yo.

El concepto de la acción legal, bajo la figura del contrato, hace innecesaria la explicación del modo en que se le presenta al yo el otro, porque en realidad el otro ya está contenido en ella. ${ }^{72}$ Sería absurdo pensar en una acción legal en la que estuviera involucrado sólo un sujeto, sin relación alguna con ningún otro. ${ }^{73}$ Por otro lado, la acción legal es universal, porque las normas que valen para cada uno de los sujetos -tomados individualmente- deben valer también para todos los demás por igual. Entonces, en la ética de Cohen el otro es el alter ego de la relación legal, con quien el yo se unifica en una voluntad común e independiente de sus voluntades fácticas. ${ }^{74}$

\footnotetext{
${ }^{72}$ Ollig, (1979, a), 154.

${ }^{73} \mathrm{ErW}, 224$.

${ }^{74}$ Winter, (1980), 292.
} 


\section{Autoconsciencia y reconocimiento en $G N R$}

\section{1. El concepto de autoconsciencia}

Hasta aquí ha quedado establecido que Cohen fundamentó la autoconsciencia a partir de la situación dialógica de la relación contractual. Fichte también dedujo la autoconsciencia a partir de una relación intersubjetiva, que consiste en el reconocimiento mutuo de los yoes como seres racionales. Esta sección del trabajo está orientada a reconstruir la deducción fichteana de la autoconsciencia, para finalmente establecer esta analogía entre las dos teorías. De este modo, creo que podría hacerse algún aporte al estudio de la presencia de la fílosofía de Fichte en al menos un representante del neokantismo de Marburg.

El objetivo del Fundamento del derecho natural (GNR) es la deducción de la relación legal a partir de la autoconsciencia del yo. Por esta razón, es necesario comenzar la investigación por la deducción de este último concepto. El significado del concepto de autoconsciencia está contenido en la siguiente afirmación de Fichte: "si un ser racional debe ponerse a sí mismo en tanto que tal, entonces debe atribuirse a sí mismo una actividad, cuyo último fundamento yace exclusivamente en él mismo". ${ }^{75}$ Es decir que el yo logra ser consciente de sí mismo cuando puede identificarse como el origen de una determinada acción. Se trata entonces de una acción reflexiva, porque permite que el sujeto vuelva sobre sí mismo.

Fichte la caracteriza como una "actividad que vuelve sobre sí misma" ("eine auf sich zurückgehende Tätigkeit"). Pero toda actividad reflexiva es necesariamente intencional, porque su sujeto se dirige a un objeto, que no es otro que el sujeto mismo. Pero, dado que la actividad reflexiva se refiere a otra actividad, que es aquella que el sujeto se atribuye a sí mismo, el concepto de autoconsciencia puede explicarse correctamente sólo si se toma en cuenta también la índole de esta última actividad.

La actividad que es objeto de la autoconsciencia es la que corresponde a todo ser racional, que según Fichte es el conocimiento de objetos del mundo sensible. ${ }^{76}$ El ser racional, en la teoría de Fichte, es un ser finito porque sólo puede reflexionar sobre un objeto limitado o determinado. ${ }^{77}$ Es decir, que la actividad de conocer se ejerce siempre sobre un objeto puesto

\footnotetext{
75 "Soll ein Vernunftwesen sich als solches setzen, so muss es sich eine Thätigkeit zuschreiben, deren letzter Grund schlechthin in ihm selbst liege“ (GNR, § 1; SW, III, 17; AA, I, 3, 329).

${ }^{76}$ Cfr. Neuhoser, F., (2001), 44-47.

${ }^{77}$ GNR, § 1; SW, III, 17; AA, I, 3, 329.
} 
como exterior al sujeto cognoscente, que limita su libre espontaneidad. ${ }^{78}$ Por ejemplo, cuando un sujeto percibe un objeto no puede decidir a su arbitrio los colores, formas, sonidos, olores o sabores que el objeto presentará a los sentidos, sino que más bien sus sentidos deben adaptarse a las cualidades del objeto. Tampoco puede conocerse un fénomeno determinado, si se inventan aleatoriamente las leyes naturales que lo rigen, tales como la ley de causalidad o de gravedad, etc. Por eso, Fichte concluye que los objetos no deben ser conocidos, "como son según nuestra opinión, sino sin añadidos nuestros, y nuestro representar debe regirse por su ser." ${ }^{79}$ No es posible conocer un objeto sin intervención de la actividad del sujeto, pero este objeto debe ser al mismo tiempo conocido como si existiera independientemente de dicha actividad de conocimiento.

Por estas razones, Fichte postula dos formas de actividad a la base del conocimiento de un objeto: una actividad libre y espontánea, y otra ligada a las leyes de la naturaleza. Según la primera forma, el sujeto pone el objeto, porque el conocimiento es un mero producto de la actividad libre del sujeto. Dicho de otro modo, el sujeto es el único origen del conocimiento. Pero el conocimiento también exige el sometimiento de la libertad del sujeto a la legalidad del mundo sensible. Es decir, que la libertad del sujeto no es algo anárquico e impredecible, sino que debe adquirir una determinada forma. Al carácter indeterminado de la actividad originaria del sujeto debe añadirse la actividad determinada por el contenido conocido en cada caso. La finitud del sujeto reclama que su objeto esté limitado y determinado, como se dijo más arriba.

Ahora bien, la actividad del conocimiento de un objeto en el mundo sensible no constituye la autoconsciencia misma, sino que es su objeto. Esta actividad constitutiva del yo es la libre proposición de un fin o una meta para la propia acción. Fichte fundamenta esta afirmación en el análisis de la estructura misma de la acción de conocer. Toda acción está precedida siempre de otra acción, por medio de la cual el sujeto se propone la meta de llevarla a cabo (o Zwecksetzung). A la hora de proponerse el fin de realizar la acción de conocer un objeto, el agente necesita elaborar un concepto de esta meta. En el concepto del fin debe estar contenida la acción de conocer un objeto del mundo sensible, con sus dos elementos: el sujeto y el objeto existiendo en el mundo sensible. Y por lo tanto deben estar representadas las dos formas que adquiere la libertad del sujeto, tanto la espontaneidad originaria cuanto la vinculación a las leyes naturales. Esto significa que el sujeto se verá a sí mismo como el autor de la acción futura de conocer un objeto en el mundo sensible. De este modo, la autoconsciencia consiste en la atribución a sí mismo de la acción de conocer un objeto en el

\footnotetext{
${ }^{78}$ Cfr. Düsing, (1991), 4.

${ }^{79}$ GNR, SW, III, 18-19; AA, I, 3, 330.
} 
mundo sensible, atribución que tiene lugar en la acción de proponerse el fin de llevarla a cabo. $^{80}$

De lo expuesto hasta aquí puede verse que la autoconsciencia no es un conocimiento especulativo y teórico que el yo tiene de sí mismo; por el contrario, se trata de una autoconsciencia práctica (praktisches Selbstbewusstsein). El yo es en última instancia un agente, lo que significa que es un sujeto que quiere realizar fines. Dicho de otro modo, es un yo volente (ein wollendes Ich). Por eso Fichte denomina a la voluntad como la "raíz más profunda del yo." ${ }^{, 1}$ Por lo tanto, la voluntad tiene prioridad por sobre la representación, es decir por sobre la facultad del conocimiento, que implica tanto la percepción cuanto la inteligencia. Este es la razón de la crítica de Fichte a Hume, quien habría intentado fundamentar al yo en la representación, entendiéndolo como una colección de percepciones. El argumento de Fichte contra Hume consiste en que las representaciones son el resultado de la actividad del yo, no su causa. Con palabras de Fichte: “¿cómo podría aceptarse que por medio de la unión de muchas representaciones, en ninguna de las cuales estaría el yo, surgiría el yo a causa de su agrupamiento?". 82

Si el yo es idéntico a la actividad misma de querer y de representar, no es una substancia dada de antemano, como podrían afirmar la metafísica dogmática o la psicología racional, defensoras de la posición del entendimiento humano común (das gemeine Menschenverstand). ${ }^{83}$ Este parte de la actitud natural o dogmática (die dogmatische oder natürliche Stellung), que implica un dualismo irreconciliable entre el sujeto y el objeto. Es decir, la actitud dogmática pone al sujeto y al objeto como existiendo independientemente el uno del otro. El sujeto conoce entonces al objeto tal como es en realidad, y accede a este conocimiento por medio de la sensibilidad. Esta es la posición que adopta el sentido común, lo que significa que es una actitud que encontramos frecuentemente entre los seres humanos. Este hecho amerita una crítica detallada, utilizando "el instrumento artificial de la reflexión filosófica." 84

\section{2. La crítica del entendimiento humano común}

\footnotetext{
${ }^{80}$ Cfr. GNR, § 1; SW, III, 20; AA, I, 3, 331.

81 “(...) die innigste Wurzel des Ich" (GNR, § 1; SW, III, 21; AA, I, 3, 332).

82 "wie konnte man doch annehmen, dass durch Verknüpfung mehrerer Vorstellungen, in deren keiner das Ich läge, wenn nur die mehreren zusammengesetzt würden, ein Ich entstünde?“ (GNR, § 1; SW, III, 21; AA, I, 3, 332 ).

83 "El intuir y el querer no preceden ni siguen al yo, sino más bien que eso mismo es el yo; este existe sólo en este poner y por medio de este poner" ("Das Anschauen und Wollen geht dem Ich weder vorher noch nachher, sondern es ist selbst das Ich; es geschieht nur in diesem Setzen und durch dieses Setzen $(\ldots)^{\text {““; }}$ GNR, $\S 1$; SW, III, 22; AA, I, 3, 333).

84 "des künstlichen Mittels philosophischer Reflexion“(Zöller, G., 2001, 98).
} 
El entendimiento humano común está preso de la ilusión de un realismo dogmático, cuya fuerza depende sobre todo del hecho de que la autoconsciencia no aparece a la consciencia empírica, puesto que en realidad constituye su condición de posibilidad. ${ }^{85}$ De allí la necesidad de ilustrar al entendimiento humano común, poniendo a prueba sus supuestos básicos. ${ }^{86}$ La posición dogmática o natural no ha estado siempre a la base de los juicios de los hombres a lo largo de la historia, sino que más bien es el punto final de un proceso histórico evolutivo que se remonta al animismo primitivo. Este se ubica en las antípodas del idealismo de Fichte, porque concibe a los objetos exteriores como causas libres, que no están regidas por ninguna forma de legalidad, sino que más bien son arbitrarias y azarosas.

Fichte desenmascara esta posición argumentando que en realidad esta libertad absoluta de los objetos exteriores no es otra cosa que la expresión de la libertad absoluta del sujeto cognoscente, que todavía no estaba en condiciones de sistematizar adecuadamente sus experiencias. El hombre en su estadio primitivo no podía regir sus representaciones por las leyes de la naturaleza porque sólo construía contenidos cognitivos en relación con sus necesidades presentes (alimentación, abrigo, etc.).

Luego pudo sistematizarlas de acuerdo a leyes tales como la de causalidad, pero sin lograr todavía reconocerse a sí mismo como el autor de estas representaciones. El hombre quedó preso entonces de la ilusión del realismo dogmático y no pudo acceder a la autoconsciencia, lo cual recién podrá ser garantizado por el idealismo de Fichte. Afirmar que el hombre no es el autor de la posición del mundo sensible “(...) significa decir lo mismo que diría un salvaje inculto, cuando afirmara: vuestra causalidad y vuestra influencia recíproca no tienen realidad alguna porque no se los puede comer." ${ }^{87}$ El entendimiento humano común entiende al concepto, que el sujeto se hace del objeto, como el resultado de un proceso que comienza por la percepción directa. Es decir, que el entendimiento humano común tiene la convicción de que el objeto le viene dado al sujeto en primer lugar por la sensibilidad. Pero esta es una afirmación circular, dado que se supone que el objeto existe con independencia de la actividad del sujeto, que es justamente aquello que se busca demostrar. Este supuesto no es sometido a crítica, y luego se apoyan todas las demás afirmaciones sobre estos cimientos.

El entendimiento humano común también se ve seducido a veces por la estabilidad de la constitución de los objetos del mundo sensible, que es la causa imperceptible de la ilusión

\footnotetext{
${ }^{85}$ GNR, § 2; SW, III, 25; AA, I, 3, 336.

${ }^{86}$ Cfr. Piché, (2001), 56-59.

87 “ (...) heisst dasselbe sagen, was ein ungebildeter Wilder sagen würde, wenn er spräche: eure Causalität und eure Wechselwirkung haben keine Realität, denn man kann sie nicht essen“ (GNR, § 2; SW, III, 26; AA, I, 3, $337)$.
} 
de su existencia exterior. Es decir, que apoya su realismo dogmático en el hecho de que los objetos se nos presentan constantemente con las mismas características identitarias, aún si los perdiéramos de vista para luego reencontrarlos después de un tiempo. Fichte considera que el idealismo absoluto puede proveer de herramientas conceptuales suficientes a quien esté en peligro de sucumbir a esta tentación.

Es decir, que si se consideran las condiciones mismas del proceso de conocimiento, no es necesario deducir la existencia independiente de los objetos a partir de la estabilidad de sus propiedades. En realidad, argumenta Fichte, esta estabilidad puede explicarse a partir de la necesidad que tiene el yo de respetar la ley de la coherencia en la construcción del objeto de conocimiento. Una vez que el sujeto ha determinado las características que definen al objeto en tanto que tal (por ej., aquellos rasgos que hacen que tal objeto sea un árbol y no otra cosa), la exigencia de la coherencia le prohíbe cambiarlas en lo futuro, o al menos hacerlo de modo arbitrario. Se trata del aspecto objetual que Fichte denomina como la "materia" (Materie). A partir de aquí, los cambios que el yo introduce en las representaciones sucesivas del mismo objeto estarán limitados o restringidos al marco de sus rasgos definitorios. Se trata de la "forma" (Form), que designa el aspecto dinámico en la construcción del objeto. ${ }^{88}$ Una vez superada la posición del entendimiento humano común, Fichte considera que está en condiciones de explicar el surgimiento de la autoconsciencia.

\section{3. La explicación de la autoconsciencia}

Los pasos argumentativos reconstruidos hasta aquí han apuntado a determinar el concepto de la autoconsciencia, pero no a demostrar su existencia, o sea a establecer sus condiciones de posibilidad. El punto de partida para la explicación de la autoconsciencia pareciera ser el análisis de la acción de proponerse el fin de conocer un objeto en el mundo sensible, porque esta acción es la puerta de acceso al concepto mismo de autoconsciencia, como se dijo más arriba. Fichte llega a esta conclusión luego de analizar tanto el yo como su objeto correlativo, que son los elementos contenidos en el concepto de fin o meta de la acción de conocer. El yo pareciera ser el punto de partida adecuado para la demostración, porque el objeto sólo puede ser explicado a partir de la actividad libre y originaria del yo. Sin embargo, el yo nunca puede ser tomado aisladamente del objeto, porque se trata de la libertad de un ser finito, que sólo puede ser ejercida si se la concretiza en un contenido determinado y limitado.

\footnotetext{
${ }^{88}$ GNR, § 2; SW, III, 29; AA, I, 3, 339.
} 
Es decir, que la libertad como espontaneidad del yo sólo puede ser realizada en cuanto que está sujeta a las leyes y las constantes del mundo sensible, según se dijo más arriba. Dicho de otro modo, no puede pensarse el objeto a partir de una actividad previa del yo. Por lo tanto, la única alternativa restante es la fundamentación de la libertad del yo a partir del objeto. Pero este es un camino sin salida, porque el objeto puede ser explicado sólo si se supone a la autoconsciencia como dada de antemano, lo que en realidad debería ser el objeto de la demostración y no su presupuesto. El yo se explica entonces a partir del objeto y el objeto a partir del yo, en una argumentación de tipo circular. En ambos casos, debe presuponerse que la autoconsciencia está en actividad antes de poder mostrar sus condiciones de posibilidad, lo que es inaceptable. Por eso Fichte dice que

cada momento posible de la consciencia está condicionado por otro momento previo, y la autoconsciencia es presupuesta como algo real en la explicación de su posibilidad. Se puede explicar sólo por medio de un círculo; no se puede explicar de ninguna manera, y parece algo imposible. ${ }^{89}$

Para salir de este círculo argumentativo, Fichte opta por abandonar el esquema hermenéutico sujeto-objeto, postulando otro correlato intencional para el yo. ${ }^{90} \mathrm{Si}$ el correlato del yo no puede ser un objeto, entonces debe ser otro yo. El procedimiento de Fichte consiste en presentar una disyunción exclusiva, y luego rechazar uno de los miembros de la misma. Finalmente, declara como válida sólo a la opción que ha quedado en pie. Pero la demostración no acaba aquí, ya que después Fichte desarrolla las consecuencias que se desprenden de este nuevo esquema interpretativo, a fin de mostrar su plausibilidad. La autoconsciencia es posible entonces gracias a una cierta relación entre el yo y otro yo, es decir, por medio de una relación intersubjetiva. ${ }^{91}$ Se trata de la unión sintética entre dos subjetividades o capacidades de ejercer una eficacia libre, o sea de conocer objetos del mundo sensible. Los dos sujetos se unen sintéticamente porque ambos forman una totalidad que va más allá de cada uno tomado por separado, y a la vez los incluye a ambos.

Sin embargo, la solución que Fichte propone parece contradictoria, porque el sujeto y el objeto deben tener rasgos bien marcados para hacer posible la autoconsciencia. Mientras que el sujeto debe limitar de alguna manera su espontaneidad originaria para poder realizar cualquier acción, porque se trata de un ser finito, el objeto es la instancia que pone las restricciones y encauza a la libertad del yo. Pero el otro es igual al yo, y no queda claro cómo

\footnotetext{
89 “ist jeder mögliche Moment des Bewusstseins, durch einen vorhergehenden Moment desselben, bedingt, und das Bewusstseyn wird in der Erklärung seiner Möglichkeit schon als wirklich vorausgesetzt. Es lässt sich nur durch einen Zirkel erklären; es lässt sich sonach überhaupt nicht erklären, und erscheint als unmöglich" (GNR, § 3; SW, III, 30; AA, I, 3, 340).

${ }^{90}$ Stolzenberg, J., (1995), 80.

${ }^{91}$ GNR, § 3; SW, III, 32; AA, I, 3, 342.
} 
podría ejercer la función de objeto sin perder su subjetividad..$^{92}$ Por otro lado, si la relación intersubjetiva está llamada a provocar la realización de la autoconsciencia, entonces el otro debe limitar la libertad del yo sólo de modo tal de poner en marcha al mismo tiempo toda su creatividad y libertad originarias. Es decir, debe tratarse de una limitación que en realidad desate y desencadene la libertad de acción ilimitada del yo.

Fichte intenta solucionar este problema determinando a la relación intersubjetiva, que constituye a la autoconsciencia, como una relación de exhortación (Aufforderung), en la que el otro insta al yo a la realización de su eficacia libre en el mundo sensible. ${ }^{93}$ Dicho de otra manera, la autoconsciencia es posible gracias a la determinación del otro a promover la autodeterminación del yo. El objetivo de la relación de exhortación es entonces que el yo pueda acceder a la autoconsciencia, sin la cual no es posible la acción. Pero el yo no puede acceder a la autoconsciencia luego de haberse determinado a la acción, porque en este caso debería presuponer una acción previa, acción que no es consciente de haber realizado, que es la proposición de la meta de llevar a cabo la acción. De este modo, el sujeto sería consciente de sí mismo como un sujeto que existe previamente a la acción, al modo del substancialismo dogmático mencionado más arriba.

Por lo tanto, el yo debe devenir autoconsciente en el momento mismo en que se está determinando a sí mismo a la acción. ${ }^{94}$ La relación de exhortación culmina justamente cuando el sujeto realiza la acción y toma consciencia de su racionalidad en ese momento. La exhortación se presenta bajo la forma de un deber (Sollen). ${ }^{95}$ Esto es experimentado por el yo como un mandato proveniente de afuera, de un impulso externo (Anstoß) que lo mueve a despertarse del estado de inacción. ${ }^{96}$ Crone grafica el concepto de exhortación a partir de dos situaciones de diálogo, como sigue:

\footnotetext{
${ }^{92}$ La tensión entre el punto de vista del sujeto y el del objeto se da también en el concepto de Aufgabe en la Wissenschaftslehre nova Methodo. Como bien apunta Crone: "La tarea puede entenderse por un lado negativamente como la exigencia de limitar la actividad subjetiva, y por el otro positivamente como la exigencia de realizar la libertad subjetiva, de iniciarla. Esta contradicción aparente retoma de nuevo el problema metodológico del círculo en sus acentos ya mencionados: la libertad subjetiva comprende tanto el momento genuinamente libre de lo incondicionado -entendido como independencia y eficacia espontánea-, cuanto el momento de la restricción y la específica orientación".

"Die Aufgabe ist einerseits negativ als Forderung zu verstehen, subjektive Tätigkeit zu beschränken, und andererseits positiv als Forderung, subjektive Freiheit zu vollziehen, diese zu initiieren. Dieser scheinbare Widerspruch greift das methodische Zirkelproblem in seinen bereits angesprochenen unterschiedlichen Akzentuierungen wieder auf: Subjektive Freiheit umfasst sowohl das genuin freiheitliche Moment der Unbedingtheit -als Unabhängigkeit und spontane Wirksamkeit gefasst- als auch das Moment der Beschränktheit und spezifischen Gerichtetheit" (Crone, 2005, 139).

${ }^{93}$ GNR, § 3; SW, III, 33; AA, I, 3, 342.

${ }^{94}$ GNR, § 3; SW, III, 33; AA, I, 3, 343.

${ }^{95}$ Oncina denomina a este fenómeno del deber como una "sincronía de lo diacrónico", esto es, un fenómeno que aparece en el presente pero que tiene una referencia intrínseca al futuro (Oncina, 1999, 223).

96 'Para que el ser racional sea consciente de su libertad, debe experimentar una 'exhortación', 'a decidirse a realizar su eficacia'. En una tal exhortación le viene a la consciencia la posibilidad de su libertad en tanto que
} 
Para ilustrar mejor el contenido conceptual de la exhortación, Fichte describe una situación de diálogo, que debe tener un carácter analógico. Supongamos que se le plantea a una persona una pregunta o se le pide un favor. Esta pregunta contiene una intención con un contenido determinado, que relaciona a la persona a la que se dirige la palabra con una acción posible. La persona interpelada está exigida entonces de realizar algo de acuerdo a ciertos fines. En tanto que la persona interpelada ha oído el pedido de favor y lo ha comprendido, tiene frente a si diversas posibilidades de reaccionar frente a él. La persona a la que se le ha preguntado o que se ha interpelado podría seguir efectivamente el contenido de la pregunta concreta o del pedido de favor, y realizar la acción exigida; más aún podría realizar la acción solicitada sólo parcialmente, pero sería también pensable el negarse a responder a la pregunta. $^{97}$

Este texto de Crone desarrolla claramente una condición de la exhortación, que consiste en la prohibición de coaccionar al otro. La coacción (Zwang) es lo contrario de la exhortación, dado que un sujeto no puede invitar al otro a realizar acciones libremente y a la vez coaccionarlo para que realice sólo un curso de acción. De este modo, el exhortante deja al exhortado libre para responder a la exhortación. Esto significa que puede responder o no a la exhortación, es decir que puede llevar a cabo o no una acción. Pero también implica que el yo tiene una variedad de cursos alternativos de acción positiva, dado que sólo dos alternativas constituyen una esfera pobre de acción. Este asunto se discutirá en detalle en un capítulo posterior.

Pero la causa última que produce en el sujeto la autoconsciencia es el reconocimiento que resulta de la exhortación. Si el otro exhorta al yo a la acción de conocer un objeto en el

objeto, como 'algo dado desde fuera'. Ella está determinada en tanto que objeto y es independiente de la eficacia del sujeto que experimenta- pero el sujeto está determinado a determinarse a sí mismo a la libre eficacia. En esta experiencia el sujeto se vuelve consciente 'de un golpe' de sí mismo, como sujeto de representaciones, determinado por un objeto, y como libre, como exhortado a la eficacia. Y como la exhortación justamente no exhorta a una acción determinada, sino más bien a ponerse un fin para sí mismo, ella posibilita una consciencia originaria de la libertad, que no procede de objetos exteriores y por lo tanto de representaciones objetuales."

"Damit das Vernunftwesen seiner Freiheit bewusst wird, muss es eine 'Aufforderung' erfahren, ,sich zur Wirksamkeit zu entschliessen'. In einer solchen Aufforderung kommt ihm die Möglichkeit seiner Freiheit als Objekt, als ,von außen gegeben' zum Bewusstsein. Als Objekt ist sie bestimmt und von der Wirksamkeit des erfahrenden Subjektes unabhängig -aber bestimmt ist das Subjekt nur dazu, sich selbst zur freien Wirksamkeit zu bestimmen. In dieser Erfahrung wird das Subjekt also ,in einem Schlage' seiner selbst als vorstellend, bestimmt von einem Objekt, und als frei, als aufgefordert zur Wirksamkeit bewusst. Und da die Aufforderung gerade nicht zu einer bestimmten Handlung aufgefordert, sondern dazu, sich selbst ein Ziel zu setzen, ermöglicht sie ein ursprüngliches Bewusstsein der Freiheit, das nicht von bestimmten Objekten bzw. Objekt-Vorstellungen herrührt" (Siep, 1979, 29).

97 "Um den Begriffsgehalt der Aufforderung besser zu verdeutlichen, beschreibt Fichte eine Dialogsituation, die Analogiecharakter haben soll. Angenommen, es wird von einer Person eine Frage oder Bitte an eine andere Person gerichtet. Diese Frage enthält eine bestimmte inhaltliche Absicht, die sich auf eine mögliche Handlung der angesprochenen Person bezieht. Der angesprochenen Person wird also eine zweckmässige abverlangt. Sofern die angesprochene Person die Bitte gehört und verstanden hat, gibt es für sie mehrere Möglichkeiten, hinauf zu reagieren. Die gefragte bzw. angesprochene Person könnte dem Inhalt der konkreten Frage oder Bitte tatsächlich nachkommen und die von ihr geforderte Handlung ausführen; ferner könnte sie die erbetene Handlung nur teilweise ausführen; vorstellbar wäre es aber auch, schon eine Antwort auf die Frage zu verweigern“" (Crone, K., 2005, 142). 
mundo, entonces supone al menos que el yo es un ser racional, en caso contrario la exhortación sería contradictoria. De este modo, el yo recibe del otro el concepto de sí mismo como ser racional y puede realizar su eficacia. ${ }^{98}$ Pero esta relación intersubjetiva no afecta solamente al yo, sino también al otro, porque le permite confirmar su concepto del yo como ser racional. Es decir, que el otro ha reconocido al yo como un ser racional en la medida en que lo ha exhortado a la acción, pero sólo lo ha reconocido hipotéticamente, hasta que respondiera o no a la exhortación. Cuando el yo actúe, entonces el otro podrá reconocerlo categóricamente como un ser racional.

A la influencia que el otro ejerce sobre el yo le corresponde una contra-influencia (Gegenwirkung) de este último sobre aquél, lo que constituye una forma de "eficacia recíproca libre“ (freie Wechselwirksamkeit). ${ }^{99}$ Esta idea fichteana puede encontrarse también en Schleiermacher, como puede verse en el siguiente fragmento, que ilustra la idea que Fichte tiene en mente cuando se refiere al carácter recíproco de esta relación intersubjetiva:

El objetivo de la sociedad no es pensado de ninguna manera como algo que resida fuera de nosotros; la eficacia de cada uno debe dirigirse a la actividad de los demás, y la actividad de cada uno debe ejercer su influencia sobre la de los demás. Ahora bien, no puede ejercerse un influjo sobre un ser libre de otro modo que motivándolo a la actividad propia, de modo tal que le sea ofrecido un objeto; y este objeto no puede ser, de acuerdo con lo dicho más arriba, otra cosa que un juego libre de los pensamientos y las sensaciones, por medio del cual todos los miembros se motivan y se estimulan mutuamente. De este modo, la influencia recíproca vuelve a sí misma y se completa. $^{100}$

\section{4. La deducción de la existencia del otro}

Una vez que Fichte ha demostrado que la autoconsciencia es posible sólo por medio de una relación intersubjetiva de reconocimiento, se pregunta cómo puede saber el yo que existe otro yo fuera de él, que es quien lo exhorta a la acción. Una vez solucionado este problema, podrá concluirse que esta relación es posible y por lo tanto, que la teoría fichteana del yo no implica caer en alguna forma de solipsismo.

\footnotetext{
${ }^{98}$ GNR, § 3; SW, III, 34; AA, I, 3, 343.

${ }^{99}$ GNR, § 3; SW, III, 34; AA, I, 3, 344.

100 "Der Zweck der Gesellschaft wird gar nicht als außer ihr liegend gedacht; die Wirkung eines jeden soll gehen auf die Tätigkeit der übrigen, und die Tätigkeit eines jeden soll sein seine Einwirkung auf die anderen. Nun aber kann auf ein freies Wesen nicht anders eingewirkt werden, als dadurch, daß es zur eigenen Tätigkeit aufgeregt, und ihr ein Objekt dargeboten wird; und dieses Objekt kann wiederum zufolge des obigen nichts sein, als die Tätigkeit des Auffordernden; es kann also auf nichts anderes abgesehen sein, als auf ein freies Spiel der Gedanken und Empfindungen, wodurch alle Mitglieder einander gegenseitig aufregen und beleben. Die Wechselwirkung ist sonach in sich zurückgehend und vollendet.“ En: Schleiermacher, (1980), 170.
} 
El punto de partida del argumento es la situación misma de exhortación. Fichte constata que, en la medida en que el yo entiende la exhortación, la concibe como un fenómeno que ocurre en el mundo exterior. Es decir, que la exhortación es puesta por el yo como un fenómeno recibido en primer lugar por la sensación (Empfindung). La exhortación debe aparecer ante el yo bajo la forma de las fuerzas naturales desencadenadas por el otro que ejercen influjo sobre las fuerzas naturales del yo. Es decir, que la exhortación es percibida por el yo ante todo como una relación de fuerzas aplicadas a sus órganos sensoriales. Si se trata de un gesto del otro, será captado por los ojos del yo, si es una frase o una palabra, por el oído, etc. Como toda relación exterior, es una interacción entre fuerzas del mundo natural o sensible.

Pero la sensación, al igual que todo conocimiento de un objeto en el mundo sensible, es una cierta restricción del yo, porque supone la limitación y la obstrucción de su espontaneidad originaria, según lo dicho más arriba. Pero cuando el yo admita que su libre eficacia ha sido restringida por una determinación externa (äußere Bestimmung), deberá aceptar al mismo tiempo que esta limitación fue causada por otro ser. La exhortación es una determinación causal que es ejercida sobre el sujeto, pero no una de tipo mecánico, porque en ese caso la fuerza externa habría provocado inevitablemente el efecto, es decir que el yo no hubiera podido elegir entre responder o no a la exhortación. Más bien se trata de una forma de causalidad orientada a que el yo reciba, por medio de esa configuración de fuerzas naturales, el concepto de sí mismo como un ser racional. De aquí se deriva la necesidad de que el autor de esta relación causal tenga, por lo menos, el concepto del otro yo como un ser racional.

La razón de esto es que, si el objetivo de la acción es despertar en el yo la consciencia de ser un ente de razón, entonces en el concepto mismo del fin de la acción debe estar contenido el concepto del otro como un ser racional. ${ }^{101}$ El efecto de una causa racional está

\footnotetext{
101 Crone comenta con este texto de Fichte, haciendo hincapié en el concepto de intencionalidad que está contenido allí:

"El pensamiento relevante de Fichte aquí es que el trato comunicativo entre individuos está signado por la estructura de la libre proposición de fines. Cuando un individuo se dirige a otro individuo, lo hace siempre con una intención determinada. Cuando los individuos se encuentran, dan expresión a la característica de la libre proposición de fines, que es característica de la autoconsciencia práctica. De este modo es realizado fácticamente el concepto de la libertad trascendental, que está a la base de la interacción práctica de los individuos y se vuelve la mirada a la consciencia concreta del individuo, que pudo ser desarrollada teóricamente en el último capítulo, pero que de momento sólo pudo ser postulada."

"Der hier relevante Gedanke Fichtes ist, dass der kommunikative Umgang zwischen Individuen von der Struktur der freien Zwecksetzung geprägt ist: Wenn ein Individuum ein anderes Individuum anspricht, dann geschieht dies immer mit einer bestimmten Intention. Wenn Individuen sich begegnen, dann verleihen sie dabei dem Merkmal der freien Zwecksetzung Ausdruck, dem Charakteristikum für praktisches Selbstbewusstsein. Auf diese Weise wird in der praktischen Interaktion von Individuen das zugrunde liegende Konzept transzendentaler Freiheit faktisch realisiert und in das konkrete Bewusstsein des Individuums gerückt, welches im letzten Kapitel theoretisch entwickelt, aber zunächst nur postuliert werden konnte" (Crone, K., 2005, 125).
} 
siempre precedido por un concepto de él mismo. ${ }^{102}$ Pero, ¿cómo puede saberse que un efecto determinado fue producido por un concepto previo? Esto puede concluirse si la multiplicidad (Mannigfaltigkeit) dada se puede sintetizar en una unidad de orden superior, que es el concepto de este efecto. Pero falta la garantía de que este efecto existe modo independiente de nuestro conocimiento de él, de que no se trata de una invención arbitraria de la imaginación. Es decir, que no se sabe todavía si la multiplicidad que se ha ordenado de este modo en una unidad, está configurada así también de modo objetivo. Para responder esta pregunta, debería postularse un fundamento racional de la exhortación, existente fuera del yo.

Este fundamento racional externo al yo debería ordenar la multiplicidad en una unidad de modo tal que el efecto sería explicable, sólo si este fundamento tuviera su concepto previamente a su realización. Si se identifica a este fundamento externo con la naturaleza, deberá afirmarse que ésta tiene razón y es libre, porque éstas son condiciones sine qua non para la elaboración de un concepto. Pero proponerse un fin es intentar producir un efecto fuera de uno mismo, y la naturaleza o el mundo sensible es el único ámbito donde puede producirse un efecto. Por lo tanto, la naturaleza no podría intentar producir un efecto fuera de sí misma, lo que implica que la naturaleza no es un ser racional y no puede ser el fundamento que Fichte está buscando. Fichte retoma la búsqueda de este fundamento a partir del análisis de la acción de la exhortación.

Si el efecto de la exhortación debió ser previsto por el fundamento de la acción de exhortación, en la medida en que este debió formarse el concepto de este efecto previamente a la acción, entonces esta acción es explicable sólo en términos de conocimiento y no puede ser explicada en base a juegos de fuerzas naturales. Pero una acción que puede ser explicada sólo en términos de conocimiento debe tener como causa necesariamente a un ser racional, que actúe del mismo modo que el yo. De este modo, el yo concluye que fuera de él existe efectivamente otro sujeto igual que él, y puede saberse reconocido como un ser racional. ${ }^{103} \mathrm{El}$ reconocimiento es una confirmación que uno recibe de otro que tiene al menos las cualidades que confirma en uno; por ejemplo, un premio otorgado a un científico es un reconocimiento a su labor si aquellos que integran el jurado y otorgan el premio tienen los méritos suficientes para darle el prestigio necesario.

\footnotetext{
${ }^{102}$ GNR, § 3; SW, III, 37; AA, I, 3, 345.

103 "La causa de la influencia sobre nosotros no tiene ante todo ningún otro objetivo, cuando no se propone ante todo que la debamos conocer como tal; por lo tanto debe admitirse que esta causa es un ser racional. Ahora se ha demostrado, lo que debía ser demostrado."

"Die Ursache der Einwirkung auf uns hat gar keinen Zweck, wenn sie nicht zuvörderst den hat, dass wir sie als solche erkennen sollen; es muss daher ein vernünftiges Wesen als diese Ursache angenommen werden. Es ist jetzt erwiesen, was erwiesen werden sollte“ (GNR, § 3; SW, III, 38; AA, I, 3, 347).
} 


\section{5. Conclusiones de la deducción de la autoconsciencia}

El yo aprende entonces que es un ser racional porque otro yo se lo ha enseñado. Dicho de otro modo, la autoconsciencia siempre está mediada por otra autoconsciencia. Por eso "el ser humano (y por lo tanto el ser finito en general), sólo puede ser humano entre seres humanos" ${ }^{\prime 104}$. Se trata entonces de una experiencia eminentemente pedagógica. ${ }^{105}$ Düsing ilustra esta idea con las siguientes palabras:

Justamente respecto de la educación puede y debe interpretarse la 'exhortación' como un intervalo de tiempo extendido, rellenado con interpelaciones continuas de las criaturas. En la medida en que la 'exhortación' es el título de un principio universal y necesario, y un concepto colectivo para una serie completa de acciones interpersonales concretas, que son necesarios sin excepción para la formación completa del individuo humano. ${ }^{106}$

De allí que Fichte rechace la idea de que los seres humanos aprendemos de las enseñanzas de la naturaleza. Los conocimientos que el ser humano extrae de la naturaleza son en realidad el producto de su observación e investigación, es decir, son una consecuencia de sus acciones y no alguna forma de revelación que la naturaleza le haga llegar. Cada conocimiento es obtenido por nosotros mismos, por lo cual es lícito decir que nos enseñamos a nosotros mismos. En realidad, dado que toda teoría científica presupone una cierta cooperación y trabajo conjunto entre los científicos, cuando el científico cree que aprende de la naturaleza en realidad está obteniendo ese conocimiento gracias a esta relación intersubjetiva fundante, que consiste en una forma de enseñanza mutua entre pares. De allí que Fichte exprese: "sólo la mutua influencia por medio de conceptos y de acuerdo a conceptos, sólo el dar y recibir de conocimientos, constituye el carácter propio de la humanidad (...)". ${ }^{107}$

Como se dijo anteriormente, Fichte considera que la idea del entendimiento humano común, de que el mundo fuera de nosotros existiría independientemente del conocimiento que

\footnotetext{
104 "Der Mensch (so also endliche Wesen überhaupt) wird nur unter Menschen ein Mensch“ (GNR, § 3; SW, III, 39; AA, I, 3, 347).

${ }^{105}$ En la idea de la función educativa de la Aufforderung puede verse claramente la influencia de la Ilustración en Fichte. A partir de esta relación intersubjetiva puede deducirse una concepción de la educación no como adoctrinamiento (Indoktrination), sino como Instruktion, esto es, orientada al mejoramiento moral del individuo. Las convicciones teóricas y prácticas deben surgir libremente en el individuo, a fin de valer como logros independientes de la razón (Zöller, 2004, 49).

106 "Gerade im Hinblick auf die Erziehung kann und muss man die ,Aufforderung' als ein ausgedehntes Zeitintervall, erfüllt von kontinuierlichem Ansprechen des Aufwachsenden, interpretieren. Insofern ist 'Aufforderung' der Titel für ein allgemeines und notwendiges Prinzip bzw. der Sammelbegriff für eine ganze Reihe von konkreten interpersonalen Handlungen, die allesamt notwendig sind für die vollständige Bildung des menschlichen Individuums“ (Düsing, E., 1986, 259).

107 "Nur freie Wechselwirkung durch Begriffe und nach Begriffen, nur Geben und Empfangen von Erkenntnissen, ist der eigenthümliche Charakter der Menschheit (...)“(GNR, § 3; SW, III, 40; AA, I, 3, 348).
} 
tengamos de él, es sólo una ilusión que debe ser disipada. El dogmatismo del entendimiento humano común es abandonado una vez que se ha considerado el proceso del conocimiento de un objeto, porque se constata que éste consiste simplemente en acciones del sujeto. El objeto conocido no es otra cosa que la libre eficacia del sujeto, que es abandonada libremente, a fin de someterse a las leyes del mundo. El mundo y el objeto son de este modo la libertad misma del sujeto, pero en su forma restringida. No podemos conocer aquello que existe fuera de nuestro conocimiento, por eso el mundo es simplemente un momento de la consciencia, que es indispensable para el yo finito, toda vez que sólo puede conocer objetos limitados y determinados. Por lo tanto, el sujeto no puede postular ningún mundo fuera de sí, sólo puede encontrarse con un ser racional igual a él, en una relación de mutuo reconocimiento. ${ }^{108}$ Por medio de la educación nos volvemos humanos, gracias a una relación intersubjetiva en la que somos conocidos por otro ser humano como seres racionales y nos transformamos en sujetos también capaces a su vez de conocer y captar por medio de conceptos. ${ }^{109}$ Somos invitados a cumplir con un deber, que consiste en la obligación de desarrollar y hacer uso de nuestra inteligencia. Pero esta exhortación misma puede ser entendida sólo cuando presuponemos que somos seres racionales.

La deducción de la autoconsciencia a partir de la exhortación ha recibido numerosas críticas de diversos intérpretes. Wood ha puesto en cuestión la coherencia lógica del argumento, planteando que Fichte en realidad supone aquello que quiere demostrar. ${ }^{110}$ Wood

\footnotetext{
${ }^{108}$ La Aufforderung implica la independencia y la irreducibilidad del otro, porque el otro no puede ser constituido por el sujeto, al modo en que pone el objeto de conocimiento. Por eso el otro es un Tatsache des Bewusstseins, que puede ser descripto pero no deducido trascendentalmente en el sentido kantiano de la palabra. Levinas critica a Fichte mostrando una contradicción en su sistema: la relación con el otro es previa a todo dato de consciencia, toda tematización o posición del sujeto, dado que hace posible la consciencia misma. Esto significa que no todo en la consciencia sería puesto por la consciencia, lo cual contradice uno de los principios fundamentales de la filosofía de Fichte (Williams, 1994, 145, 148).

${ }^{109}$ Crone, (2005), 146.

110 "El argumento trascendental de Fichte está acribillado de dificultades. Supongamos que garantizamos que la consciencia de un determinado yo presupone la consciencia de objetos externos que ya existen y resisten la actividad de uno. Está muy lejos de quedar claro que exista alguna circularidad viciosa en esto. Habría algo así si la presuposición provocara precisamente el mismo problema que ha sido invocada para resolver, pero esto está muy lejos de ser evidente. Si es que hay un problema envuelto en la presuposición de que cada momento de autoconsciencia está condicionado por la noción previamente existente de una 'exhortación', se trata sólo del problema de la Primera Antinomia de Kant, que nos es tan familiar. Es arbitrario invocar la noción de una 'exhortación' para resolver este problema; y además es algo condenado al fracaso. Si existiera algún problema relativo a una serie infinita de series regresivas de consciencia objetiva, ¿cómo podría ser una solución el introducir un tipo diferente de objeto que no produce el problema? Podría plantearse algo así, si vamos a reemplazar la presuposición de un mundo externo con la presuposición de una exhortación, la cual no es evidentemente la intención de Fichte."

"Fichte's transcendental argument is riddled with difficulties. Suppose we grant that awareness of a determinate self presupposes awareness of already existing external objects that condition and resist one's activity. It is far from clear that there is any vicious circularity or regress in this. There would be if the presupposition raised precisely the same problem that it was invoked to solve, but this is far from evident. If there is a problem involved in presupposing that every moment of self-awareness is conditioned by a previously existing moment, that is only the familiar problem of Kant's First Antinomy. It is arbitrary to invoke the notion of a 'demand' to
} 
argumenta que Fichte habría introducido arbitrariamente la afirmación de la exhortación como fundamento de la autoconsciencia, al verse imposibilitado de resolver el círculo vicioso de la explicación a partir del esquema sujeto-objeto. No estoy de acuerdo con esta objeción porque, como ya he dicho anteriormente, Fichte plantea una disyunción excluyente, según la cual el correlato del yo es otro objeto o bien otro yo. La razón de esta disyunción radica que, en su teoría, sólo hay dos modos de ser, a saber la objetualidad y la subjetividad. Una vez descartado el carácter de objeto del otro, sólo queda pensarlo como otro yo. La relación intersubjetiva que de allí se deriva no es una relación de conocimiento, sino más bien de exhortación a la acción libre. No puede ser una relación coactiva, porque sino el yo nunca se vería reconocido como un ser racional, o sea libre. Por lo tanto, debe ser algún tipo de invitación a la realización de la propia libertad. Sin embargo, debe tratarse de una invitación enérgica, porque está en juego la realización del ser mismo del yo. La exhortación no tiene pues un carácter arbitrario en la teoría de Fichte, sino que sigue una lógica estructurada y coherente.

También Düsing ha objetado la deducción del otro ser racional, pero se ha centrado en el modo en que se presenta la exhortación al yo. Como se dijo más arriba, este aparece al yo en primer lugar como un fenómeno del mundo exterior, bajo la forma de un impulso (Anstoß). Düsing cuestiona el paso que da Fichte entre la constatación de este hecho y la afirmación de que este impulso sea efectivamente la obra de un ser racional. Veamos cómo argumenta Düsing:

En la deducción que hace Fichte de la exhortación no puede divisarse ninguna prueba lógicamente concluyente de la realidad de la existencia del extraño; un impulso no puede ser una exhortación; más bien puede ser una afección sensible sin ningún significado formativo para el yo. Más aún, un impulso puede ser una exhortación -si bien no en orden a una primera toma de consciencia-, sin que venga de otro alter ego, sino por ejemplo de presiones naturales, tales como aquellas que provienen de animales vivos o de un paisaje sublime, que motivan al yo para ejecutar las acciones propias o reflexionar sobre sí mismo. No puede pretenderse que la exhortación misma -y con el dato de la exhortación al mismo tiempo la existencia de al menos un alter ego-, sea deducida de modo lógico y gnoseológico. Más bien el pensamiento de la posibilidad del ser exhortado, como fundamento de la existencia del yo volente, presupone en principio de facto la representación de la existencia de otro ser racional fuera de mi. ${ }^{111}$

solve that problem; and hoppeless besides. For if there were a problem about an endless regressive series of objective awareness, how would it be a solution to introduce a different sort of object that does not raise the problem? It might do so if we were going to replace the presupposition of an external world with a presupposition of a demand, but that is evidently not Fichte's intention" (Wood, 1990, 79).

111 "In Fichtes Deduktion der Aufforderung kann man wohl keinen logisch-stringenten Beweis für die Realität der Fremdenexistenz erblicken; ein Anstoß muss nicht Aufforderung sein; er kann einfache Sinnesaffektion ohne bildende Bedeutung für das Ich sein. Ferner kann ein Anstoß Aufforderung - wenn auch nicht zur ersten Bewusstwerdung - sein, ohne dass er von einem alter ego ausgeht, sondern z.B. von Natureindrücken, etwa von lebendigen Tieren oder von einer erhabenen Landschaft, die das Ich zu eigenen freien Handlungen oder zur 
Como puede verse, el problema que presenta la objeción de Düsing consiste en la mala interpretación del concepto de "impulso". Fichte no se refiere a un impulso meramente natural, aunque presenta en un primer momento la forma de una mera relación natural de fuerzas. Luego, apelando al principio de razón suficiente, Fichte argumenta que este efecto debe tener alguna causa proporcional. Es decir, que del hecho de que el yo se sepa reconocido por otro ser, se supone que este último debe ser al menos racional, porque necesariamente debe haber podido elaborar el concepto del yo como un ser racional.

\section{Conclusiones del Capítulo 1}

Luego de haber reconstruido la argumentación de Cohen y de Fichte, puede afirmarse que ambos pensadores le otorgan un rol constitutivo a la alteridad en la formación de la autoconsciencia. En las dos teorías, el yo es pensado siempre en correlación con otro, porque ambas suponen que el ser humano puede ser tal sólo cuando existe entre iguales. En Cohen, el yo necesita de otro que se comprometa con él en una relación legal creadora de normas que, una vez consensuadas, obligarán a los dos por igual. Del mismo modo, Fichte considera inevitable el encuentro con el otro yo, para despertar al sujeto a la consciencia de sí como un ser racional. Pero también en la teoría fichteana los yoes deben consensuar el modo en que regularán sus interacciones, y deben comprometerse a cumplir con la norma acordada. Se trata del problema de la relación legal, del que me ocuparé en el siguiente capítulo.

Reflexion auf sich selbst veranlassen. Man kann also nicht den Anspruch erheben, die Aufforderung selbst -und mit dem ,Faktum' der Aufforderung zugleich die Existenz von mindestens einem alter ego- sei logisch und erkenntnistheoretisch deduziert worden. Vielmehr setzt der Gedanke von der prinzipiellen Möglichkeit des Aufgefordertwerdens als Grund der ersten Bewusstwerdung des wollenden Ich de facto die Vorstellung vom Dasein eines anderen vernünftigen Wesen außer mir schon voraus“ (Düsing, E., 1986, 256). 
Capítulo 2: La estructura de la relación legal 


\section{Capítulo 2: La estructura de la relación legal}

En el capítulo anterior hemos indagado el procedimiento que Cohen y Fichte han seguido para deducir la autoconsciencia a partir de la alteridad. Pero en realidad esta deducción ha quedado incompleta, porque falta determinar otra condición sine qua non de la autoconsciencia. Se trata de la relación legal, que en ambos autores está a la base de esta forma de subjetividad. En este capítulo exploraremos este concepto y, fundamentalmente, sus características estructurales.

Cuando se considera la idea de relación legal, en primer lugar resulta evidente que hay una coincidencia entre Cohen y Fichte: en ambos la relación legal tiene una estructura dialógica. Esto no debería sorprendernos, dado que la autoconsciencia está estructurada de ese modo, según lo visto en el capítulo 1. Pero hay otro rasgo que también parece ser común al $G N R$ y la $E r W$. Se trata del carácter totalizante de la relación legal, es decir que la relación legal pareciera incluir y subsumir a sus miembros en una unidad superior. En la teoría de Cohen, la relación legal por excelencia es la persona jurídica, a punto tal de conferirle un carácter modélico para pensar el concepto mismo de Estado. La persona jurídica consiste en una voluntad común a sus miembros que, una vez expresada, tiene un rango legal y, por lo tanto ficticio. Esta voluntad acordada es independiente de las voluntades fácticas e individuales de quienes la han declarado. En este sentido, la voluntad de la persona jurídica incluye e integra a los arbitrios de sus miembros en una unidad superior.

En la teoría de Fichte, la relación legal constituye una comunidad regida por el principio del derecho, que prescribe a sus miembros limitar su libertad a favor de la de los demás. La comunidad legal tiene como eje la ley de la concordancia consigo mismo, a la que los sujetos deben someter sus decisiones y su voluntad. La comunidad legal de Fichte pareciera adquirir autonomía respecto de las voluntades fácticas de los sujetos e incluirlos en una unidad mayor, con la consecuencia de que sus miembros dejarían de ser individuos atomizados. Sin embargo, todavía no podemos saber si esta coincidencia entre los autores es algo más que una sospecha, porque en Fichte los individuos siempre se relacionan con los demás desde la consciencia de su yoidad. Para ello hará falta analizar con más detalle la argumentación de Cohen y Fichte. 


\section{La relación legal como una persona jurídica}

\section{1. Deducción de la autoconsciencia a partir del concepto de persona jurídica}

Si bien ya se mostrado el modo en que Cohen deduce la relación entre el yo y el otro a partir de la figura legal del contrato, queda por determinar aún el contenido de toda acción legal. Pero esto es posible sólo si se determina antes el tipo de subjetividad que en está en juego, porque la acción legal no es otra cosa que la expresión de una voluntad, es decir, del sujeto de una voluntad. ${ }^{112}$

Cohen toma como punto de partida para esta investigación la figura legal de la persona jurídica, porque es la realización de un tipo de subjetividad diferente del de la persona física. ${ }^{113}$ Cohen no puede partir de la persona física como sujeto de derecho para deducir la autoconsciencia, porque en ese caso quedaría preso del punto de vista individualista del sujeto aislado de los demás. En cambio, la persona jurídica parece más apta para dar cuenta de la autoconsciencia, por dos razones. En primer lugar, es una construcción ficcional $y$ normativa, porque es un ente abstracto que puede actuar análogamente al modo en que lo haría la persona física. ${ }^{114}$ Es decir, la persona jurídica puede endeudarse, pagar los impuestos, tomar decisiones relativas al funcionamiento de una empresa, etc. En segundo lugar, la persona jurídica se presenta como opuesta a los intereses meramente particulares de las personas que la integran, porque consiste en una voluntad que representa los intereses comunes. $^{115}$

Cohen inscribe su teoría de la personalidad jurídica en el debate relativo al status epistemológico de esta figura legal, que ya llevaba varias décadas en Alemania. En lo que sigue intentaré reseñarlo brevemente, a fin de hacer comprensible la teoría de Cohen sobre este trasfondo. ${ }^{116}$

Por un lado, Friedrich Karl von Savigny consideraba que sólo la persona física es capaz de derecho, mientras que la persona jurídica, en el sentido de las corporaciones o

\footnotetext{
${ }^{112}$ Winter, (1980), 285.

${ }^{113} \mathrm{ErW}, 229$.

${ }^{114}$ Cfr. Günther, (1971), 135. El concepto que se utilizaba para expresar esta idea en Europa antes del siglo XIX era el de persona moral (por ejemplo, en Puffendorf). Otras expresiones que se utilizaban para dar a entender la naturaleza no sensible de la persona jurídica corporativa eran: persona ficta, persona repraesentata, persona intellectualis, persona imaginaria, persona artificialis, persona mystica o persona composita (Winter, 1980, 318).

${ }^{115}$ Giesecke, (1990), 122-123.

${ }^{116}$ Para ello seguiré el análisis de Winter, (1980), 299-310, que aún no ha sido superado hasta el presente.
} 
instituciones, tiene una subjetividad legal ficticia. Bernhard Windscheid, en la misma línea de Savigny, sostenía que el hombre natural es el sujeto de derecho, mientras que las personas jurídicas, construidas por medio de operaciones del pensamiento, son sólo representaciones y personificaciones ficticias de sujetos de derecho. Otto von Gierke propuso -a diferencia de Savigny y Windscheid- una "teoría orgánica", porque suponía que tanto el individuo como las asociaciones son entidades vivas y en este sentido son sujetos de derecho. ${ }^{117}$ Gierke apoyaba su teoría en la idea de que la unión espiritual que tiene lugar en las asociaciones es producida por medio de la acción motivada psicológicamente. Rudolf von Ihering criticó las tesis de Savigny, Windscheid y Gierke, de que la voluntad de la persona jurídica no tendría otro contenido que el que se le otorgue en cada caso, es decir que no podrían determinarse de antemano las condiciones que deben cumplir los contenidos de la persona jurídica. La reacción de Ihrering contra esta posición se fundaba en su convicción de que llevaría inevitablemente al dominio de la mera fuerza natural y la arbitrariedad moral, dado que no permitiría poner límite a los abusos de poder de algunos miembros de la persona jurídica sobre otros

Como es sabido, Ihering buscó un contenido para la voluntad de la persona jurídica en los intereses, necesidades y objetivos del hombre, a los cuales debe servir el derecho. Los derechos son los intereses protegidos jurídicamente. En vez de partir del concepto de personalidad moral del individuo para determinar el de persona jurídica, Ihering sostenía una ética utilitarista para la cual el punto central es el destinatario del derecho (el sujeto que puede satisfacer sus preferencias). Por lo tanto, transformó al concepto de derecho en una categoría utilitaria y económica. Desde este punto de vista, entonces, la persona física es el individuo singular y la persona jurídica de la asociación es un producto ficcional, un mecanismo para facilitar las mediaciones legales para el logro de objetivos. Es decir, que la persona jurídica tiene un carácter ficticio y es un instrumento de la racionalidad con arreglo a fines.

Savigny, Windscheid y Gierke identificaban al sujeto individual como el sujeto de derecho (en el caso de Gierke, extendido a las asociaciones como organismos); pero ninguna de las tres teorías investigó cuál es la estructura legal del sujeto de derecho.

Paul Laband, por su parte, respondió a esta pregunta con su "método jurídico", intentando liberarse de toda apelación a las externalidades del derecho, tales como el sujeto concreto e individual, y manteniéndose únicamente en el medio legal. Desde este punto de vista, la persona jurídica es portadora de derechos y obligaciones, porque las condiciones y requisitos del sistema legal así lo han dispuesto. Laband se diferencia de las teorías anteriores,

${ }^{117}$ Cfr. ErW, 233. 
que postulan que sólo puede ser persona jurídica aquello que posee un carácter substancial, porque sostiene una teoría anorgánica que, si bien no excluye que la persona sea una substancia, tampoco lo exige. El problema de la teoría de Laband radica en que concibe a la persona jurídica como una representación obtenida por medio de la abstracción lógica y deja sin determinar su contenido específico. Dicho de otro modo, Laband se queda en la mera caracterización formal del concepto de persona jurídica.

Georg Jellinek intentó -al igual que Laband- superar el sincretismo metodológico y mantenerse en el ámbito estricto del derecho. Para ello, describió a la persona de la asociación como una voluntad uniforme y colectiva, una pluralidad unificada de voluntades. Pero esta voluntad unificada y completa es una proyección de la voluntad del individuo y permanece ligada al concepto psicológico de la voluntad.

\section{2. Persona jurídica y cooperativa: la voluntad común de los cooperantes}

\section{2. 1. La persona jurídica de la cooperativa}

Cohen entra en este debate sobre el concepto de persona jurídica, pero su investigación gira en torno a la persona jurídica de la cooperativa. No se detiene en la persona jurídica de las fundaciones (piae causae), porque en ellas se trata ante todo de la administración de bienes. ${ }^{118}$ Esto es, la fundación es una persona jurídica creada generalmente para destinar a obras de caridad los bienes dejados por un difunto. Lo importante en la fundación no es, entonces, el tipo de relación que se establece por su intermedio entre las personas, sino ante todo el modo en que los bienes deben circular entre los miembros de la persona jurídica, quiénes deben administrarlos, quiénes deben conservarlos hasta que sean utilizados, etc. ${ }^{119}$

Pero la autoconsciencia, en tanto que sujeto de la voluntad pura, debe representar la relación entre el individuo y la universalidad, que es característica de la ética. ${ }^{120}$ Es decir, debe dar cuenta de la relación entre el yo y los demás sujetos en tanto que está mediada por su voluntad común, o sea su voluntad pura. La persona jurídica de la cooperativa, a diferencia de

\footnotetext{
${ }^{118}$ La persona jurídica más antigua del derecho romano es la asociación de varias personas que tiende a un fin y que es reconocida como sujeto de derechos y obligaciones en su totalidad, independientemente de las personas que las componen y su renovación. Tal sujeto, cuya designación ordinaria en nuestro lenguaje es la corporación, puede decirse que tal vez tenga una existencia real y verdadera dada por el conjunto de los miembros asociados. Los romanos la asimilaban al hombre, atribuyéndole el titulo de persona (persona manicipii, coloniae, etc) aun cuando su capacidad jurídica sólo sea reconocida gradualmente. Las fundaciones son más artificiosas y de formación más reciente.

${ }^{119}$ Winter, (1980), 311.

${ }^{120}$ Kersting, (2002), 35-36.
} 
la fundación del derecho romano, tiene por finalidad la constitución de una voluntad común a partir de una cierta relación entre los cooperadores.

Cohen tiene, además, otra razón de peso para investigar la persona jurídica de la cooperativa: la promoción de la autodeterminación de los trabajadores. ${ }^{121}$ Se trata de una forma de organización del trabajo que permite a los obreros acceder al control del proceso de producción. ${ }^{122}$ En consecuencia, el trabajador es respetado en su persona como un fin en sí mismo, como un sujeto libre y activo, y no ya como un medio para la acumulación del capital en manos ajenas. ${ }^{123}$

El capitalismo, entonces, usa al obrero como medio para la acumulación del capital, por lo que su dominio sobre la fuerza de trabajo atenta contra la unidad de la persona. De este modo, en el sistema capitalista el obrero es dueño de sí y fin en sí mismo en la esfera privada, pero no lo es en la socioeconómica, donde, según Cohen, se convierte en un sirviente. ${ }^{124} \mathrm{La}$ forma de producción cooperativa entraña también la superación del carácter de mero instrumento del trabajador al servicio del progreso de la nación. ${ }^{125}$ De este modo, el capital no dominaría al trabajador, sino más bien a la inversa. ${ }^{126}$

Sin embargo, como apunta Giesecke,

Cohen ve en la propiedad de los medios de producción una relación de dominación que no se sostiene, que debe ser disuelta sólo por medio del modo de producción cooperativo, de acuerdo con el cual la unidad supraordenada del Estado debe impedir, que las cooperativas individuales entren en una lucha de competencia (ErW, 618 ff.). Cohen se declara a favor de una limitación de la propiedad, no de su total supresión $(\operatorname{ErW}, 620){ }^{127}$

En este fragmento, Giesecke aclara que Cohen no cree que la promoción del cooperativismo sea una panacea que fuera a dar por tierra con todos los males del capitalismo.

\footnotetext{
${ }^{121}$ Schmid, (1993), 78.

${ }^{122}$ Giesecke, (1990), 124-125.

${ }^{123} \mathrm{ErW}, 305$. Cohen retomó las reflexiones de su maestro Lange en torno a la importancia del cooperativismo. Lange había fundado en Duisburg una cooperativa de consumo, previendo la fundación más tarde de una cooperativa de producción. En su periódico, Lange abogó intensamente por un sistema estatal de créditos para financiar tanto las cooperativas obreras como las agrarias. Asimismo, exigió una reforma agraria, a partir de la división de los latifundios pertenecientes a los Junkers (Van der Linden, 1988, 295).Acerca de la influencia de Lange en Cohen en relación al cooperativismo, Cfr. Schwarzschild, (1956), 219.

${ }^{124}$ Van der Linden, (1994), 158-159; Lübbe, (1963), 244.

${ }^{125}$ Giesecke, (1990), 123.

126 Cfr. Giesecke, (1990), 122. No podemos dejar de advertir aquí una línea de interpretación del trabajo asalariado similar a la "esclavitud a tiempo parcial" de Marx, y con la idea del alieni iuris que Kant toma del viejo derecho romano para referirse a quienes no tienen otra cosa que ofrecer que su propia persona y, por eso mismo, se convierten en sujetos de derecho ajeno.

127 "Im Eigentum an Produktionsmitteln sieht Cohen ein ethisch nicht haltbares Herrschaftsverhältnis, das nur in der genossenschaftlichen Produktionsweise aufgelöst werden soll, wobei die übergeordnete Einheit des Staates verhindern soll, das die je einzelnen Genossenschaften in einen Konkurrenzkampf treten (ErW, 618 ff.) Cohen spricht sich für eine Beschränkung des Eigentums, nicht für dessen völlige Aufhebung aus (ErW, 620).“ (Giesecke, 1990, 125).
} 
En su propuesta, el Estado cumple el rol indispensable de regular la relación de las cooperativas entre sí, para evitar que reproduzcan el esquema capitalista de la competencia destructiva. Tampoco se trata meramente de distribuir la riqueza producida por el trabajador de un modo más justo, sino más bien de reformular el estilo de relación entre los integrantes del proceso de producción. ${ }^{128}$ El horizonte del cooperativismo de Cohen es, en última instancia, el de un socialismo ético. Este es el sentido de las siguientes afirmaciones de Cohen:

Por sobre todo se ha desprendido una conclusión a partir de toda esta consideración: que el problema no debe ser invertido y planteado de un modo nuevo para el trabajador. No puede ser un problema para el derecho, porque no lo es para la ética, la cuestión de convertir al trabajador en propietario del fruto de su trabajo y establecerlo en esa relación. No puede ser un problema de la cultura moral, el hacer accesible al obrero lo que el capitalista tiene por derecho. Esta accesibilidad sería un complemento peligroso del derecho. El producto del trabajo no debe ser un problema para el trabajador en el sentido de la propiedad. El problema de la propiedad no debe ser transferido de los hombros del empresario capitalista a los del trabajador asalariado. $^{129}$

Cohen le da un contenido concreto al imperativo categórico, y lo interpreta como la exigencia del establecimiento de una sociedad totalmente democrática en todos sus ámbitos. El respeto por las personas exige la protección y la optimización de las condiciones que hacen posible que cada ciudadano sea un legislador con pleno derecho. ${ }^{130}$ De acuerdo con este ideal, los cooperadores se convierten en miembros legisladores de la empresa para la que trabajan. ${ }^{131}$ Se trata de una democracia económica, que exige la participación de los trabajadores en cada estadio del proceso de producción. ${ }^{132}$ La cooperativa representa el interés

\footnotetext{
${ }^{128}$ Günther, (1971), 195-196.

129 "Vor allem hat sich eine Folgerung aus dieser ganzen Erörterung ergeben: dass nicht etwa das Problem umgekehrt werden und für die Arbeiter von neuem gestellt werden darf. Es kann nicht das Problem des Rechts, weil nicht das Problem der Ethik werden, den Arbeiter zum Eigentümer seines Arbeitsertrages zu machen, als solchen ihn einzusetzen und festzusetzen. Es kann nicht die Frage der sittlichen Kultur werden, beim Arbeiter billig werden zu lassen, was den Kapitalisten recht ist. Diese Billigkeit wäre eine gefährliche Ergänzung des Rechts. Der Arbeitsertrag darf für den Arbeiter nicht im Sinne des Eigentums zum Problem werden. Das Problem des Eigentums darf nicht von den Schultern des Kapitalunternehmers übertragen werden auf die des Lohnarbeiters" $(E r W, 612-613)$. Acerca la dimensión moral del muto reconocimiento de los cooperadores como co-legisladores, Cfr. Van der Linden, (1994), 157.

${ }^{130}$ Van der Linden, (1994), 158.

${ }^{131}$ Holzhey, (1994, c), 141.

${ }^{132} \mathrm{La}$ idea de una democracia económica ha ejercido influencia en algunos teóricos contemporáneos. Por ejemplo, Van der Linden considera pertinente la aplicación del imperativo categórico a la democratización de la toma de decisión en las empresas, en consideración de la eliminación de muchos de los males que provoca la estructura corporativa de las empresas. Por ejemplo, se solucionarían o mejorarían muchas situaciones que los obreros nunca consentirían, tales como un sistema de salud deficiente, los bajos sueldos, las políticas de privacidad invasivas, etc. Del mismo modo, las empresas deberían incorporar en su toma de decisiones a los miembros de la comunidad, en caso de que éstas afecten su vida, provocando contaminación ambiental, destruyendo el patrimonio histórico de la comunidad, así como otra clase de prejuicios (Van der Linden, 1998, 220-221). Otros beneficios que Van der Linden considera que se desprenderían de una democracia empresarial
} 
universal de la comunidad de cooperadores, es decir que elimina la mera competencia entre sus intereses individuales, que es uno de los pilares del capitalismo. ${ }^{133}$ Se trata de un intento de humanizar al capitalismo, si bien no de eliminarlo de raíz. ${ }^{134}$

En esta persona jurídica surgida en el seno del derecho alemán, los objetos o bienes que son utilizados pasan a segundo plano y son considerados sólo en la medida en que sirven de medios para la realización de la voluntad común de los cooperadores. Por eso apunta Cohen que "el fundamento del problema yace en la fuerza y la dirección de la voluntad". ${ }^{135}$ Es decir, el concepto de la cooperativa se determina exclusivamente en función de la voluntad que en ella se expresa, que es el producto de las voluntades declaradas de los cooperadores. ${ }^{136}$ De allí el carácter modélico de la persona jurídica de la cooperativa para la deducción de la autoconsciencia.

Este carácter modélico se funda en la universalidad de la voluntad de la persona jurídica de la cooperativa. En su Lógica del conocimiento puro, Cohen ha definido a la categoría lógica de la universalidad como la suma infinita, el integral, la esencia infinita y, en el caso del derecho, la reconoció en el concepto de la persona jurídica. ${ }^{137}$ Ahora bien, los cooperadores legales se definen como tales en virtud de su capacidad para producir una voluntad legal. Por eso, los cooperadores legales se califican como personificaciones de competencias para elaborar normas legales, como legisladores (Gesetzgeber). ${ }^{138}$

El concepto lógico de la universalidad, está relacionado con la voluntad unificada y legisladora, con el acuerdo y la unidad de la legislación. ${ }^{139}$ La universalidad significa aquí la voluntad universal, la esencia infinita de las voluntades plurales, es el acuerdo respecto de lo querido en común, del contenido de las acciones a legislar. ${ }^{140}$ Esta voluntad unificada representa la unidad de la persona jurídica -que si bien es representativa de las voluntades

serían el bajo incentivo que tendrían las empresas para expandirse continuamente, porque sus ganancias no aumentarían necesariamente, dado que la expansión implicaría la contratación de más empleados y la necesidad de repartir las ganancias con ellos. Esto implicaría que las empresas tendrían en realidad poco tamaño, lo cual es indispensable para la puesta en práctica de una democracia deliberativa en la institución que sea. La división de las ganancias entre los empleados disminuiría el afán de lucro de las empresas en general, y podría traer como consecuencia que los empleados se tomaran más tiempo libre y trabajaran un poco menos, lo que jamás se podría esperar en una corporación dirigida por algunos ejecutivos. Asimismo, las decisiones de la empresa tomarían en cuenta cada vez más las necesidades del ciudadano promedio, dado que serían hombres de esta clase social quienes tomarían las decisiones fundamentales. Es decir, si se contamina el medio ambiente las consecuencias no las sufrirá seguramente el ejecutivo que puede comprarse una casa en una zona de buena calidad de vida, sino más bien el empleado que no tiene mucho poder de decisión a la hora de elegir una vivienda (Van der Linden, 1998, 229-230).

${ }^{133}$ ErW, 619. Cfr. Günther, (1971), 196.

${ }^{134}$ Günther, (1971), 194; Günther, (1972), 31.

135“"Der Grund des Problems liegt in der Kraft und Richtung des Willens" (ErW, 230).

${ }^{136}$ Günther, (1971), 157-158.

${ }^{137}$ Müller, (1994), 129.

${ }^{138}$ Winter, (1980), 314-315.

${ }^{139} \mathrm{ErW}, 233$. Cfr. Günther, (1972), 17.

${ }^{140}$ Görland, (1912), 242. 
individuales de los cooperadores- de algún modo las ha substituido y se ha colocado en su lugar por medio del acuerdo (Beschluss). ${ }^{141} \mathrm{El}$ concepto de persona jurídica supone que la voluntad dividida y contradictoria de muchos puede ser superada por medio de un acuerdo entre todos. ${ }^{142}$ Este es el Estatuto de la cooperativa, que expresa una intención, "un hacer y un querer uniformes". La continuidad de la cooperativa como unidad de la persona jurídica exige que todos sus miembros posean el derecho de voto, a fin de determinar activamente la política y las acciones de la cooperativa dentro de los límites impuestos por sus Estatutos.

La voluntad común de los cooperadores -que es idéntica a la persona jurídica de la cooperativa- se expresa, entonces, de acuerdo con un procedimiento compuesto por ciertas reglas. Estas reglas están establecidas en el Estatuto de la cooperativa, que es fruto del acuerdo de todos los cooperadores fundadores, así como de los cooperadores que se van integrando luego a la persona jurídica. ${ }^{143}$ Se trata de las reglas según las cuales los cooperadores irán elaborando las normas que regirán las actividades de la cooperativa, o sea de las normas de la legislación. ${ }^{144}$

La actividad de la legislación es la expresión misma de la voluntad de la cooperativa, esto es la realización de la persona jurídica. ${ }^{145}$ La persona jurídica sólo existe entonces mientras se lleva a cabo la actividad de la legislación, es decir en tanto que los cooperadores elaboren sus propias reglas para el funcionamiento de la cooperativa. De este modo, la voluntad común de la cooperativa establece nuevas normas gracias al acuerdo al que arriban los cooperadores, pero siempre siguiendo una normativa previa que la condiciona, expresada en el Estatuto. ${ }^{146}$

Las normas que componen la voluntad común de la cooperativa son universales porque fueron elaboradas de acuerdo con un procedimiento universal, es decir, un procedimiento que garantiza que todos los legisladores las hayan acordado libremente y desde una posición de simetría. ${ }^{147}$ De este modo, la universalidad de las normas, que implica que se aplicarán a todos los cooperadores por igual, proviene del hecho de que aquellos que deben obedecer las normas son los mismos que las han elaborado. ${ }^{148}$ Dicho de otro modo, el ideal cooperativista de Cohen significa, como lo dice Schwarzschild, que "eventualmente la

\footnotetext{
${ }^{141}$ Kersting, (2002), 35.

${ }^{142}$ Schmid, (1993), 65.

${ }^{143}$ Van der Linden, (1994), 157.

${ }^{144}$ Günther, (1971), 157.

${ }^{145}$ ErW, 231.

${ }^{146}$ Günther, (1971), 157.

${ }^{147}$ Van der Linden, (1994), 156.

${ }^{148}$ Cfr. Holzhey, (1994, c), 142.
} 
distinción entre los que ponen las reglas y aquellos que las obedecen puede ser eliminada, que las personas pueden darse las reglas a sí mismas en una democracia completa." 149

La voluntad de la persona jurídica de la cooperativa constituye, entonces, un tipo de sujeto fícticio y abstracto, pero a su vez real y vinculante por su carácter jurídico. ${ }^{150} \mathrm{~A}$ diferencia del sujeto individual de la persona física, este sujeto puramente jurídico es universal y no ya particular. Se trata de un producto de la consciencia cultural, toda vez que es un producto exclusivamente de la ciencia del derecho y no se deriva de ningún dato natural dado de antemano. Es la consciencia de un sujeto universal, que consiste en un conjunto de normas vinculantes para quienes las han elaborado. ${ }^{151}$ Cohen denomina a esta consciencia de la subjetividad como autoconsciencia (Selbstbewusstsein).

La autoconsciencia es el sujeto de una voluntad puramente artificial, en cuanto que surgida de la tarea de deliberación y legislación de los cooperadores, y por lo tanto no se trata de una voluntad fáctica dada de antemano, ni tampoco de una mera suma de las voluntades empíricas de los cooperadores. ${ }^{152}$ Esta voluntad, que está constituida por las reglas del Estatuto de la cooperativa, no es entonces una voluntad empírica sino más bien una voluntad de carácter científico-legal, surgida exclusivamente a partir de la aplicación de las reglas inherentes al derecho. ${ }^{153}$ Dicho de otro modo, en la persona jurídica de la cooperativa, la autoconsciencia es el sujeto legal de una voluntad pura. ${ }^{154}$ Por eso dice Cohen que la persona jurídica de la cooperativa nos brinda un ejemplo claro para investigar el concepto de la autoconsciencia, en tanto que categoría fundamental con la que opera el derecho. ${ }^{155}$

Como veremos más adelante, Cohen aplica más tarde este mismo modelo, junto con el del contrato, a la deducción de la autoconsciencia en la persona jurídica del Estado. Sin embargo, para tratar la cuestión del Estado debe despejarse antes la objeción de que el concepto de comunidad es más apto que el de persona jurídica para explicar a este sujeto universal de la voluntad pura o autoconsciencia. ${ }^{156}$ Una vez que Cohen demuestre que el concepto de comunidad no puede ser un ejemplo de la autoconsciencia de la voluntad pura, quedará el camino despejado para demostrar el concepto de la autoconsciencia a partir de la persona jurídica del Estado. En efecto, Cohen utiliza el instrumental teórico, obtenido como

149 “(...) eventually the distinction between ruler and ruled will be obliterated, that the people will rule themselves in a complete democracy." (Schwarzschild, 1956, 219).

${ }^{150}$ Günther, (1971), 159.

${ }^{151}$ Günther, (1971), 196.

${ }^{152}$ Görland, (1912), 242-243; Winter, (1980), 315-316.

${ }^{153}$ Cfr. Günther, (1972), 17.

${ }^{154}$ Görland, (1912), 243-244.

${ }^{155} \mathrm{ErW}, 237$.

${ }^{156}$ Cohen entiende a la comunidad como la unión estrecha entre los miembros, constituida emocional-afectiva, biológico-orgánica o histórico-tradicionalmente. Tiene en mente comunidades tales como la comunidad eclesiástica de los creyentes, la familia, la clase social, el linaje, el pueblo, la raza o la patria (Winter, 1980, 320). 
resultado de su investigación sobre el concepto de comunidad, para discutir el concepto de nación y demostrar la necesidad del Estado democrático de derecho para la realización de la autoconsciencia.

Cohen rechaza el concepto de comunidad, como se verá más adelante, porque se trata de un modelo de integración en base a la posesión de ciertas características fácticas y, por lo tanto, conlleva la exclusión de quienes no comparten estos rasgos. El Estado democrático de derecho no puede ser pensado en base a un modelo tan deficitario de integración social, porque no puede dar cuenta de la relación entre el individuo y la universalidad, que constituye el problema de la autoconsciencia y de la ética. Recordemos que el trasfondo históricopolítico de la crítica al concepto de comunidad es la disputa del antisemitismo, que motivó varias intervenciones públicas de Cohen.

Cohen buscaba un modelo de Estado en el que todos los ciudadanos sean iguales ante la ley, $\mathrm{y}$, en última instancia, consideraba que la democracia representativa era la única posibilidad que permitiría a los judíos integrarse como ciudadanos de pleno derecho a la nación alemana, sin caer en la asimilación compulsiva al cristianismo o el "bautismo político". La posición de Cohen se comprende mejor si se tiene presente quiénes eran los actores políticos y académicos con quienes Cohen polemizó a lo largo de su dilatada historia intelectual, así como sus intervenciones públicas en tiempos de la Primera Guerra Mundial, donde matizó su crítica al concepto del nacionalismo y formó parte de la patriota "guerra de los espíritus". En lo que sigue, intentaré mostrar los aspectos complejos que presenta la relación de Cohen con la germanidad y el judaísmo.

\section{2. 2. La disputa del antisemitismo}

Cohen experimentó en carne propia los efectos de la furiosa ola de antisemitismo que se impuso en la Alemania de fines de 1870. El antisemitismo estaba en la atmósfera misma de la época, como lo demuestran los insultos que debían oír los miembros de la comunidad judía. Se decía que los judíos eran un elemento extraño en el cuerpo alemán, o que los judíos eran tan perezosos que habían huido de Egipto para no seguir trabajando allí, y que Moisés había querido sublimar el carácter haragán y delictivo de los judíos, denominándolo como el pueblo elegido. O que los judíos eran poco aptos para trabajar porque sus músculos eran débiles por naturaleza y sus huesos ya nacen torcidos. También que el ario tenía como meta la autorrealización, mientras que el judío buscaba sólo el enriquecimiento. 
Treitschke llegó a afirmar que le parecía indignante que continuamente llegaran judíos de Polonia que sólo se dedicaban a vender ropa, pero que con el tiempo llegarían a dominar los periódicos y las bolsas de valores del país. En consonancia con estos insultos, algunas organizaciones políticas pedían públicamente que se les quitara a los judíos el derecho al sufragio, se les examinara periódicamente para renovar su permiso de trabajo, se los obligara a bautizarse según el ritual cristiano, etc. ${ }^{157}$

Este odio fue tomando forma a partir de la acción de organizaciones políticas tales como el Christlichsoziale Partei, fundado por el predicador Adolf Stoecker. También en Marburg florecieron organizaciones estudiantiles antisemitas, tales como la Verein deutscher Studenten (fundada a fines de 1880), o la organización de Otto Böckels, sumamente poderosa en aquel entonces. Ejerció mucha influencia sobre los estudiantes la publicación del panfleto de Böckels Die Juden, die Könige unserer Zeit (Los judios, los reyes de nuestro tiempo), que fue distribuido por ellos mismos. ${ }^{158}$

Cohen mismo se vio obligado a participar, en calidad de perito, de un proceso judicial contra un acto de antisemitismo. Se trató de la demanda del rabino Leo Munk contra el docente Ferdinand Fenner, quien en una alocución de mitín afirmó que el Talmud exige a los judíos que traicionen a los cristianos. Del lado de los antisemitas fue convocado como perito el orientalista Paul de Lagarde (de Göttingen), mientras que por parte de la comunidad judía fue llamado Cohen. Contra la débil y poco informada argumentación de Lagarde, Cohen sostuvo, apoyándose en citas de los textos sagrados, que la religión judía es una religión de la humanidad y no ya de una nación particular. Por lo tanto, el Talmud jamás podría prescribir que se traicionara a los extraños, sean estos cristianos o de otra religión. El proceso culminó con la condena de Fenner a dos semanas de prisión más el pago de las costas del juicio. ${ }^{159}$

Como bien apunta Palmer, el caso de Fenner estuvo mal planteado judicialmente desde el comienzo. La cuestión no era si la religión judía permitía o no que se estafara o robara a los cristianos, sino más bien el problema consistía en si Fenner había insultado o no a la comunidad judía en su discurso. De allí la improcedencia de la consulta a Cohen y a de Lagarde, en calidad de peritos. ${ }^{160}$

Pero la cuestión judía alcanzó el status de debate académico recién con ocasión del artículo de Treitschke, "Unsere Aussichten" ("Nuestras perspectivas"), publicado en 1879 en

\footnotetext{
${ }^{157}$ Geismann, (1993), nota al pie de la p. 370.

158 Sieg, (1994), 154.

${ }^{159}$ Sieg, (1994), 156-157.

${ }^{160}$ Palmer, (2006), 50-53.
} 
los Preussische Jahrbücher (Anales prusianos). Allí Treitschke, preocupado por la masiva inmigración de judíos polacos, exigía la asimilación total de los judíos a la Alemania cristiana de la época. En este artículo llegó a afirmar que ellos son los causantes de todas las desgracias de la Alemania de la época (“die Juden sind unser Unglück") ${ }^{161}$. Pocos intelectuales tomaron posición contra Treitschke, lo cual puso en evidencia el rechazo que existía frente a las tradiciones y la cultura judía.

Cohen reaccionó con vehemencia al artículo de Treitschke con su "Bekenntnis in der Juden Frage" ("Declaración sobre la cuestión judía", 1880), donde negaba toda diferencia substancial entre el judaísmo y el cristianismo. La semejanza entre ambas religiones se fundaba, en opinión de Cohen, en su profesión de fe en un único Dios, garantía de la moralidad. El rasgo definitorio del judaísmo sería la legalidad inherente a su religiosidad, cuyo ejemplo paradigmático es la Torá misma. Justamente la valoración de la legalidad sería también, en opinión de Cohen, un elemento central de la tradición y la cultura alemanas. ${ }^{162}$ Cohen defendió la germanidad de los judíos y minimizó el peligro del antisemitismo, lo cual le valió el reproche de sus hermanos de fe. El ideal de Cohen de fusionar el judaísmo y el cristianismo puede verse claramente en su propuesta, hecha en un artículo sobre el descanso sabático, de pasar esta fiesta al día domingo. Esta propuesta provocó un enérgico rechazo en su comunidad. ${ }^{163}$

Contra la intención de Cohen de fusionar el judaísmo y la germanidad, Rosenzweig malinterpretó su Religion der Venunft aus den Quellen des Judentums (Religión de la razón a partir de las fuentes del judaísmo), afirmando que allí Cohen rompió con el velo del idealismo y abandonó la búsqueda de la sistematicidad, reemplazándola por los sentimientos nacionales y religiosos judíos. ${ }^{164}$ Por el contrario, Cohen intentó en algunos escritos de circunstancias, refutar la teoría de que los judíos alemanes pertenecerían a una raza diferente de las de sus conciudadanos, a partir de consideraciones tales como el efecto homogeneizante que tuvo sobre el organismo de todos los alemanes, incluidos los judíos, el hecho de haber vivido en las mismas condiciones climáticas durante tantos siglos. ${ }^{165}$

Pero es necesario admitir que Cohen nunca defendió la política de asimilación violenta que pedían los antisemitas. En un texto publicado en 1890, es decir 10 años después del Antisemitismusstreit con Treitschke, Cohen se oponía enérgicamente a la conversión compulsiva de los judíos al cristianismo. Esto significaría, argumentaba Cohen, una traición a

\footnotetext{
${ }^{161} \mathrm{Sieg},(1994), 148$.

${ }^{162}$ Wiedebach, (1997, a), 47-48.

${ }^{163}$ Sieg, (1994), 151-152.

164 Zank, (2006), 1-2.

${ }^{165}$ Wiedebach, (1997, a), 42.
} 
la fidelidad a la propia fe y a las propias raíces culturales. ${ }^{166}$ Su lucha por la preservación de la identidad judía no fue obstáculo para que se opusiera al sionismo de Buber. Contra éste, consideraba que la esencia del judaísmo es su carácter itinerante, que es la causa de su universalidad moral característica, e implica que la Palestina de todo judío es el mundo entero y no un territorio particular. ${ }^{167}$

Cassirer tuvo que enfrentar también una Antisemitismusstreit. El redactor responsable de los Kant-Studien, Bruno Bauch, publicó en 1917 en esta revista un artículo sobre el concepto de nación ("Über den Begriff der Nation"), donde advertía respecto del peligro que representaba la comunidad judía para el mantenimiento de la unidad de la cultura alemana. El carácter nacional, sostenía Bauch, se fija ante todo en el suelo y la sangre (Boden und Blut). Cassirer escribió un artículo polémico que no fue publicado en la revista, y por esta razón solicitó la retractación pública de Bauch.

Dado que la retractación nunca tuvo lugar, Cohen y Cassirer abandonaron la Sociedad Kant, a lo que le siguió la retirada de otros miembros. Finalmente, Bauch debió renunciar a su cargo en la revista, no sin antes victimizarse en una nota publicada en enero de 1917 en el periódico Panther, donde se presentó como el blanco de la censura judía. Bauch fue apoyado por varios colegas, y el mismo Heimsoeth le escribió a Hartmann en febrero de 1917 que opinaba que los Kant-Studien se habían finalmente judaizado. ${ }^{168}$

Además Cassirer tuvo serios problemas para ingresar a la carrera académica a causa de su condición de judío. Windelband decidió no apoyar su nombramiento en Strassburg precisamente por esta causa. De allí que Natorp le escribiera a Görland en 1902, que le parecía deprimente tener que dar la razón a Cohen acerca del antisemitismo imperante, cuando se esforzaba permanentemente por calmarlo, intentando convencerlo de lo contrario. $^{169}$

Pero la oposición de Cohen al nacionalismo extremo convivió en él con un ardiente patriotismo. En medio de la Primera Guerra Mundial tuvo lugar en Alemania un movimiento de ideas que legitimó la guerra en base a la superioridad cultural, política y moral alemana sobre los países aliados. Por eso se la denominó como la "guerra de los espíritus" (Krieg der Geister). Cohen participó activamente de este movimiento nacionalista, orientado a levantar el ánimo de la población sumida en la guerra, sobre todo con el dictado de una serie de

\footnotetext{
${ }^{166}$ Wiedebach, $(1997$, a), 44.

${ }^{167}$ Wiedebach, (1997, a), 35.

${ }^{168}$ Sieg, (1994), 400-402.

${ }^{169}$ Sieg, (1994), 335.
} 
conferencias en diversos centros intelectuales, inclusive en Marburg, de donde se había retirado ya en 1912 .

Entre ellas, fue famosa su "Über das Eigentümliche des deutschen Geistes" ("Sobre la particularidad del espíritu alemán”), pronunciada en la Sociedad Kant de Berlín en octubre de 1914. Las "ideas de 1914", como también se denominó a este movimiento, en realidad encerraban una notable heterogeneidad de puntos de vista. Estos iban desde la estimación de la "profundidad" de la cultura alemana (cimentada sobre el cultivo de la interioridad, desde Lutero en adelante), frente a la superficialidad de la cultura anglosajona (utilitarista y empirista), hasta la idea de la superioridad del socialismo alemán por sobre la democracia liberal de mayorías propia de los ideales del oeste.

En este último caso, se valoraba la idea socialdemócrata de la formación moral del ciudadano para una identificación con los objetivos del Estado, y la obediencia consciente y responsable de sus leyes, frente a la idea liberal de un egoísmo universal, con su pragmatismo consecuente en el ejercicio de la ciudadanía. ${ }^{170}$ Cohen, al igual que otros judíos, se entusiasmaba con la idea de que la participación activa de los judíos en la guerra fuera una muestra clara de patriotismo, que permitiera a la larga la supresión de las barreras que el antisemitismo había puesto a su integración a la vida de la nación. De allí su oposición decidida al sionismo, como una corriente que buscaba aislar a la comunidad judía del resto de los alemanes. En 1914 firmó junto con 300 notables judíos una declaración del "Comité Antisionista". Cohen estaba embargado de tal optimismo, que llegó a solicitar a la Oficina de Relaciones Exteriores en 1915 apoyo financiero para dictar una serie de conferencias en EEUU, con el fin de mejorar la imagen de Alemania en el extranjero, mostrando la civilidad, la libertad y la humanidad que reinaban en la nación. ${ }^{171}$

Cohen justificó también la participación de Alemania en la Primera Guerra Mundial, presentándola como una guerra para acabar con las causas de la guerra en general. Es decir, como una forma de establecer el reino de la razón sobre el mundo, misión que le estaba históricamente reservada a Alemania por su tradición humanista, de Lutero y Kant en adelante. Cohen veía a Alemania como la nación que puede realizar el ideal moral universalista kantiano, y estaba convencido de que esto la convertiría en la educadora de la humanidad. ${ }^{172}$

\footnotetext{
${ }^{170}$ Sieg, (1994), 375-377.

${ }^{171}$ Sieg, (1994), 394-397.

172 Wiedebach, (1997, a), 22, 129-131. Curiosa interpretación, por cierto, de los escritos de Kant sobre la Paz Perpetua y del abierto cosmopolitismo de su propuesta.
} 
Esta actitud positiva que Cohen demostró permanentemente frente a la nación alemana estaba acompañada del deseo de que su comunidad judía sea finalmente integrada como miembro de pleno derecho. De allí que su defensa de la idea de nación estuviera matizada con el rechazo de un nacionalismo excluyente que divorciara germanidad y judaísmo para siempre. Con estas salvedades, intento que resulte más clara la crítica de Cohen al concepto de comunidad, que reconstruyo a continuación.

\section{2. 3. La crítica del concepto de comunidad}

En primer lugar, el concepto de comunidad supone aquello que Cohen denomina como el prejuicio de la particularidad, es decir la afirmación de que lo particular puede ser conocido con independencia del concepto universal. ${ }^{173}$ Se trata de la tesis de que el concepto universal es, en realidad, el producto de la suma de los elementos individuales que, en primer lugar, se han observado empíricamente. Es decir que quienes defienden el concepto de comunidad como el medio para la realización de la autoconsciencia, en última instancia afirman que lo particular es lo único verdadero, y que lo universal es un mero derivado suyo.

La comunidad es el concepto de una totalidad, que no representa un salto cualitativo respecto de las particularidades que la integran, sino que es simplemente la unidad de la multiplicidad de todas ellas. Por ejemplo, el concepto de tal o cual nación como una comunidad, no es otra cosa, según Cohen, que el de un conjunto integrado por todos los individuos que tienen una cierta característica en común, tal como el lugar de nacimiento, el idioma, determinados rasgos étnicos o la pertenencia a alguna tradición cultural. La comunidad, entonces, es un mero conjunto que unifica la pluralidad de sus elementos, pero sin agregarles ningún rasgo nuevo que los constituya en una realidad autónoma e independiente de sus características fácticas.

Dicho de otra manera, Cohen sostiene que, sin el conocimiento previo del individuo en tanto que tal, no puede accederse nunca al concepto de la totalidad de los individuos, o sea a la idea de la comunidad. Pero el individuo sería accesible directamente por medio de la sensación. Por lo tanto, la sensación debe preceder y fundamentar al pensamiento. Esta es la raíz epistemológica del prejuicio de la particularidad, que Cohen quiere desarmar, para luego poder atacar el concepto de comunidad.

\footnotetext{
${ }^{173} \mathrm{ErW}, 234$.
} 
Ahora bien, para criticar el prejuicio de la particularidad, es necesario recurrir a la clasificación de los tipos de juicios en la $L r E$. En esos textos, Cohen intenta demostrar cuál es la relación que debe existir entre el pensamiento y la sensación, si lo que se busca es producir el conocimiento puro, o sea, la ciencia matemático-natural.

En realidad, la $\operatorname{LrE}$ defiende una relación entre el pensamiento y la sensación, que es inversa a la que se da en el prejuicio de la particularidad. Cohen identifica al conocimiento con el conocimiento puro, es decir, el conocimiento que es producido exclusivamente a partir de sí mismo, sin referencia a ninguna realidad dada de antemano. El conocimiento es pura actividad, y no puede contener en sí pasividad alguna. Pero, admitir que el conocimiento comienza con la sensación significaría afirmar que depende de una serie de objetos dados previamente e independientes de él, lo que es lo mismo que decir que el conocimiento no sería puro.

Por lo tanto, el conocimiento sólo comienza con el pensamiento. El último fundamento del conocimiento científico está constituido, en realidad, por los juicios de las leyes del pensamiento (die Urteile der Denkgesetze), el primero de los cuales es el juicio del origen. ${ }^{174}$

Los juicios de las leyes del pensamiento son juicios constitutivos del conocimiento puro, porque determinan la calidad del pensamiento científico, es decir, las reglas que debe cumplir para no dejar de ser tal. La sensación, en cambio, pertenece a la clase de los juicios de la metodología, que simplemente regulan los pasos que deben seguirse en el procedimiento de la investigación científica. ${ }^{175}$ Un momento fundamental de los juicios de la metodología es la medición de la magnitud intensiva, que es el objetivo del juicio de la realidad efectiva (Das Urteil der Wirklichkeit). ${ }^{176}$ Por lo tanto, la sensación juega un papel secundario en la teoría coheniana del pensamiento puro. Por esta razón, Cohen rechaza el prejuicio de la particularidad y con él el concepto de comunidad, porque éste se funda en aquél. Este es el motivo de la siguiente afirmación

La auténtica desgracia de la lógica consiste en que no se quiere dejar valer a la particularidad como un problema exclusivamente metodológico. Por eso se desliza subrepticiamente la particularidad y se desplaza al pensamiento del conocimiento. Por un lado, se plantea que el pensamiento no podría producir ni indagar la particularidad; por eso sería necesaria la sensación; por otro lado, se dice que la sensación no necesitaría del pensamiento para la particularidad; para ello estaría la sensación, y ella sería suficiente. Toda oposición contra el idealismo y su

\footnotetext{
${ }^{174}$ Cfr. $\operatorname{LrE}$,

${ }^{175} \operatorname{LrE}$, 404-616. Los juicios de la matemática y la ciencia matemático-natural contienen, en la terminología de Cohen, "naiven Kategorien", es decir, categorías que proveen de los fundamentos para la constitución del objeto de la experiencia científica $(\operatorname{LrE}, 431)$. Los juicios de la metodología, en cambio, permiten dar un paso más y establecer las condiciones de la tarea de la investigación científica ( $L r E, 429)$. Esto es, en los juicios de la metodología se trata del modo en que la ciencia obtiene nuevos conocimientos y amplía su horizonte.

${ }^{176} \operatorname{LrE}, 454-501$
} 
suficiencia se enraiza en este error; en la caracterización lógica de la particularidad. ${ }^{177}$

Este error metodológico cobra relevancia moral si se lo aplica a la discusión del concepto de comunidad, porque pone en evidencia su incapacidad para abarcar a todos los sujetos que quieran participar de ella. Si se aparta al pensamiento de su función fundamentadora y se coloca en su lugar a la sensación, entonces el concepto de comunidad puede sustituir al de persona jurídica, pero también desaparecerá la idea de una voluntad común a todos sus miembros, para dar lugar a una relación de mera adscripción. Es decir, los miembros de la comunidad no pertenecen a ella a causa de su cumplimiento de determinadas reglas comunes a todos, sino más bien en base a la posesión de ciertas características que pueden establecerse fácticamente.

Según Cohen, en el patriotismo es posible advertir "el déficit de universalidad" del concepto de comunidad, porque esta posición lleva a que el individuo se cierre en la particularidad de su nación, es decir, del conjunto de quienes comparten determinadas características, y excluye, como si fueran sus enemigos, a quienes no pertenecen a ella. ${ }^{178}$

Otro error que suelen cometer quienes defienden el concepto de comunidad frente al de persona jurídica, es afirmar que la comunidad es más apta para representar al sujeto universal de la ética, porque se funda en una relación fáctica entre los sujetos, que es armónica y los cohesiona fuertemente. ${ }^{179}$ En esta concepción juega un rol importante la analogía con la comunidad religiosa, signada por la armonía entre sus miembros, o sea la idea un regnum gratiae. ${ }^{180}$ Según Cohen, por el contrario, los grupos sociales caracterizados por la idea de la comunidad -tales como la familia, el pueblo, la clase social, etc.- suelen estar signados por el antagonismo y el conflicto.

Cohen piensa en las rivalidades entre las familias, o en las luchas de clase, o en los conflictos entre las mayorías y minorías raciales o religiosas, que conocía de cerca, por

\footnotetext{
177 "es ist das eigentliche Unglück der Logik, dass man die Einzelheit nicht lediglich als ein Problem der Methodik gelten lassen will. Daher schleicht sich die Empfindung ein und verdrängt das Denken der Erkenntnis. Einesteils meint man, das Denken könne die Einzelheit nicht ergeben und nicht ermitteln; dazu bedürfe es der Empfindung; andernteils meint man es aber so, dass es für die Einzelheit des Denkens nicht bedürfe; dazu sei eben die Empfindung da; und die allein zulänglich. So wurzelt aller Gegensatz gegen den Idealismus und seine Zulänglichkeit in diesem Fehler; in der logischen Charakteristik der Einzelheit.“ $(E r W, 234)$.

${ }^{178}$ Cfr. la cuestión del colectivismo en: Günther, (1971), 159.

${ }^{179}$ Estos argumentos de Cohen ganan mucha actualidad si se los considera en relación con el debate entre universalistas y comunitaristas morales. Adviértase que estas dificultades metodológicas que señala Cohen son comunes en algunas propuestas comunitaristas que, en los últimos años y especialmente en el mundo anglosajón, intentando superar el individualismo metodológico, mediante un concepto de comunidad ligado a la particularidad, que no alcanza a ni tampoco desea fundar propuestas de corte universal y que incluso ha llegado a cuestionar el papel de los derechos humanos universales como meras quimeras.
}

${ }^{180}$ Cfr. $\operatorname{Er} W, 238$. 
pertenecer a una familia judía de la Alemania decimonónica. ${ }^{181}$ La unidad de la comunidad está siempre en peligro por los enfrentamientos que su existencia misma conlleva. Cuando el individuo se integra en una comunidad no suele dejar de lado su egoísmo, para ponerse al servicio de objetivos comunes, sino que, antes bien, estos objetivos pretendidamente colectivos son, en realidad, una forma disfrazada de su autointerés.

El modelo de la comunidad se ha mostrado entonces poco idóneo para dar cuenta de la autoconsciencia, como una forma de subjetividad universal, que pone en relación a cada individuo con todos los demás por medio de ciertas reglas. De todo lo argumentado hasta aquí, Cohen concluye que el concepto de persona jurídica es el único capaz de realizar al sujeto universal de la voluntad pura, es decir, la autoconsciencia, con la precisión y la exactitud que sólo la ciencia del derecho puede conseguir. ${ }^{182}$

${ }^{181} \operatorname{ErW}, 241$.

${ }^{182}$ Ollig, (1979, a), 153. 


\section{La deducción de la relación legal en Fichte}

Como se desprende de lo argumentado hasta aquí, Cohen entiende a la relación legal como una estructura normativa que tiene una forma contractual. Dicho de otro modo, como una relación que se realiza gracias a ciertas reglas que facilitan la participación y el consentimiento de todos los involucrados en ella. Pero no se trata simplemente de que el consentimiento de los sujetos involucrados en ella legitime cualquier tipo de norma, sino que la relación legal se realiza según reglas que conforman una voluntad común, que trasciende sus voluntades empíricas y egoístas y constituye por lo tanto un fictio iuris universal. Es la voluntad de una persona jurídica que sigue el modelo de la cooperativa, lo que significa que está estructurada en base a una serie de reglas establecidas en el Estatuto. Estas reglas marcan las condiciones que deberán seguir las deliberaciones en el futuro. La autoconsciencia no es otra cosa que este sujeto ficticio y universal, que es el producto de la voluntad común y declarada de todos.

Como se adelantó a comienzos de este capítulo, Fichte ha elaborado también en GNR una teoría de la relación legal, como condición de posibilidad de la autoconsciencia. Este es otro punto en común entre Cohen y Fichte, además de la deducción de la autoconsciencia a partir de la alteridad, estudiada en el capítulo anterior. Pero también podría señalarse otro elemento compartido por ambas teorías: la idea de una relación legal que adquiere cierta autonomía respecto de los arbitrios de cada miembro de la relación legal. Un indicio claro de esta analogía pareciera ser la teoría fichteana de la estructura de la relación legal, como una comunidad regida por la ley de la coherencia consigo mismo, a la que deben someterse los sujetos si quieren existir como seres racionales. Veamos si este elemento es suficiente para hablar de una similitud estrecha entre lo expuesto en el parágrafo 4 de la $G N R$ y la idea de la personalidad jurídica en la $E r W$. 


\section{1. El mutuo condicionamiento y determinación de los sujetos involucrados en la situación de exhortación.}

Una vez que Fichte ha deducido la relación de reconocimiento mutuo que hace posible la autoconsciencia, da un paso más y concluye de allí que esta relación es posible sólo si los yoes están inmersos en una comunidad legal, regida por el principio del derecho. En el tránsito del $\S 3$ al 4, Fichte pasa de la necesidad de un reconocimiento mutuo de capacidades (esto, es, de la capacidad de autodeterminarse a la acción del conocimiento de un objeto), al reconocimiento del derecho de disponer de una igual esfera de acción para desarrollar estas capacidades. Wildt considera que el pasaje de un tipo de reconocimiento al otro no es conclusivo, porque una cosa es reconocer que el otro es capaz de algo (por ejemplo, de cometer un delito) y otra muy diferente es decir que tiene derecho a llevar a cabo aquello de lo que es capaz. ${ }^{183}$ En realidad, puede decirse, en contra de Wildt, que en el acto mismo de la exhortación está contenida la exigencia del reconocimiento del derecho a realizar las acciones correspondientes. Es un presupuesto pragmático de la misma, en cuanto que sería contradictoria la invitación y simultáneamente la prohibición de iniciar un determinado curso de acción.

Siep ha criticado en términos semejantes la deducción del reconocimiento de derechos a partir del reconocimiento de capacidades, argumentando que, por ejemplo, un alumno puede constituirse en un ser racional al invadir o agredir la esfera de acción del maestro. ${ }^{184}$ Pero aquí también se olvida que a fin de que el alumno aprenda algo del maestro, debe por lo menos reconocer al maestro como un ser racional y permitir que se comporte como tal. Por otro lado,

\footnotetext{
${ }^{183}$ Wildt, A., (1982), 276.

184 “De hecho Fichte dice más tarde (§ 6) que el ser educado presupone una forma de autolimitación, un 'guardar silencio', del lado del aprendiz. Pero esta autolimitación afecta en primer lugar a la posibilidad de percibir y comprender la exhortación del otro. Esta autorrestricción se funda en algo diferente de aquella autolimitación exigida por el reconocimiento de las esferas externas de acción. Obviamente no es necesario suponer un respeto tal en orden a la educación: su objetivo no debe ser realizado todavía en el comportamiento del aprendiz frente al educador. Pueden pensarse también éxitos parciales de la exhortación, en los cuales el exhortado pueda pensarse a sí mismo como el único autor de una eficacia en el mundo sensible, cuando él responda a la exhortación a la autoactividad no ya con respeto frente al educador, sino con un ataque a él."

"In der Tat sagt Fichte später (§ 6), dass das Erzogenwerden eine Art Selbstbeschränkung, ein, stille halten' von Seiten des Zöglings voraussetzt. Aber diese Selbstbeschränkung betrifft erst die Möglichkeit, die Aufforderung des Anderen wahrzunehmen und zu verstehen. Sie liegt auf einer anderen als die in der Anerkennung der äußeren Sphären des freien Handelns geforderte. Einen solchen Respekt braucht man offenbar für die Erziehung nicht voraussetzen: ihr Ziel muss durchaus noch nicht im Verhalten des ,Zöglings' gegenüber dem Erzieher realisiert sein. Es lassen sich sogar Teilerfolge der Aufforderung denken, in denen sich der Aufgeforderte auch dann als alleiniger Urheber einer Wirksamkeit in der Sinnenwelt erfahren kann, wenn er die Aufforderung zur Selbsttätigkeit nicht mit Respekt gegenüber dem Erzieher, sondern mit einem Angriff auf ihn beantwortet" (Siep, 1992, a, 49).
} 
Hösle ha admitido que el alumno debe reconocer al maestro como un ser racional, pero ha puesto en duda que esta exigencia de reconocer al maestro deba ser permanente. Hösle objeta que, si el alumno necesita ser reconocido por el maestro para adquirir autoconsciencia y convertirse en un ser racional, no se ve por qué seguirá necesitando de este reconocimiento, una vez que ha logrado aquel objetivo.

Mas aún, si no necesita seguir reconociendo al maestro una vez alcanzada su autoconsciencia, no se vería claro por qué debería respetar el derecho del maestro a una esfera de acción libre. En realidad, Hösle no toma en cuenta que Fichte no quiere decir que, una vez alcanzada la autoconsciencia, el sujeto la posea como algo estático para siempre. Por el contrario, Fichte argumenta que el sujeto puede adquirir la autoconsciencia, y seguir siendo consciente de sí mismo de allí en adelante, sólo en la medida en que esté actuando en un entramado de relaciones de reconocimiento recíproco. Esto quedará claro más adelante en la reconstrucción de la fundamentación de la relación legal.

Volvamos a la relación de reconocimiento recíproco analizada en el capítulo anterior, a fin de reconstruir la deducción fichteana de la relación legal. En primer lugar, puede decirse que, en la situación de exhortación, cada uno de los sujetos involucrados atribuye al otro el fundamento de sus acciones libres, en la medida en que el reconocimiento del otro es la causa de su autoconsciencia. Pero a la vez cada uno se atribuye a sí mismo este fundamento, porque es el autor de sus propias acciones. Esta doble atribución de la causa de las acciones libres a uno mismo y a la vez al otro es una paradoja. Pero, si se considera el modo en que los yoes han delimitado mutuamente sus esferas de acción, se concluirá que en realidad se trata de una paradoja aparente.

Como se dijo más arriba, el otro puede exhortar al yo sólo si le deja abierta una esfera de acciones libres, es decir una cantidad de cursos de acción posibles, porque en caso contrario se trataría más de una coacción que de una invitación al ejercicio de la libertad. ${ }^{185}$ La única manera en que el otro puede dejar una esfera libre de acción al yo es limitando su propia libertad, o sea reduciendo su conjunto de acciones alternativas posibles para no interferir en la libertad del otro. ${ }^{186}$ A su vez, el yo también debe limitar su esfera de acción

\footnotetext{
${ }^{185}$ Siep muestra que la renuncia a la coacción del otro no puede ser el único criterio de racionalidad. Más bien se trata de la autolimitación del sujeto en orden a la exhortación del otro y a la producción de un conocimiento en él. Si no, la renuncia a la coacción podría ser producto de una astucia del más débil o del desinterés por la libertad del otro, etc. (Siep, 1992, a, 48-49).

${ }^{186}$ Siep ha explicado con claridad y precisión este texto de Fichte. "Este paso sólo puede ser explicado, en mi opinión, de la siguiente manera: con la comprensión de la exhortación como un acto de educación y con su respuesta por medio de una acción libremente elegida yo sé: 1) lo que es un ser racional, es decir la autodeterminación a la acción; 2) que aquel que por medio de su acción busca (que yo obtenga) mi conocimiento
} 
para hacer posible la libertad del otro yo que lo exhorta a la libertad. Si no lo hiciera, no estaría respondiendo a la exhortación del otro, porque la comprensión de esta exhortación implica la aceptación de que el otro yo es también un ser racional.

Si el yo admite que el otro es un ser racional, debe aceptar entonces también que el otro es un ser libre, porque la racionalidad no es otra cosa que la realización de la libertad. Por lo tanto, el yo debe abstenerse de interferir en la libertad del otro yo que lo exhorta, si quiere responder a esta invitación. Esto significa a su vez que debe aceptar la esfera de acción que el otro le ha dejado abierta y confirmar de este modo el espacio de acción que el otro ha propuesto para ambos. ${ }^{187}$ La relación de reconocimiento recíproco implica entonces la mutua delimitación de las esferas de acción. Cada sujeto se determina a sí mismo como libre en la medida en que se puede atribuir a sí mismo una esfera de acción que le compete sólo a él, y de la que queda absolutamente excluido el otro. ${ }^{188}$

De allí concluye Fichte que los sujetos que intervienen en la relación de reconocimiento recíproco están contrapuestos por la determinación de una esfera de acción exclusiva para sí mismos, de la cual excluyen al otro. ${ }^{189}$ Esta contraposición hace posible su individualidad, a pesar de que una primera mirada produzca la impresión de que en realidad es una contraposición que homogeneiza a los sujetos y les hace perder su particularidad. ¿Por qué esta contraposición parecería borrar la individualidad de los sujetos involucrados en la relación de reconocimiento recíproco? La respuesta de Fichte es que la contraposición entre los sujetos surge del hecho de que poseen esferas iguales de acción, exclusivas y excluyentes, lo que implica alguna forma de comparación entre ellos. Pero comparar es equiparar los términos, que deben tener caracteres comunes para que sea posible la operación. De este

\footnotetext{
de mí mismo como un ser racional, él mismo debe ser un ser racional y 3) que el tipo de su acción frente a mí, esto es la autolimitación de su esfera de acción, era necesario para el logro de su intención. Dado que él me tomó como un ser racional, me trató como tal y por medio de esta acción quiso ayudarme a lograr la consciencia de mí como un ser racional, se limitó a sí mismo. Esta conclusión es lógica, dado que esta acción (de autolimitarse) está unida necesariamente con el concepto de razón no ya del filósofo, sino más bien de la consciencia ya exhortada, toda vez que la otra consciencia me ha tratado al menos hipotéticamente -es decir, hasta que se demuestre lo contrario- justamente de modo 'racional', por medio de la autolimitación."

"Dieser Schritt kann aber, so meine ich, nur folgendermaßen erklärt werden: mit dem Verstehen der Aufforderung als einem Erziehungsakt und mit seiner Beantwortung durch eine frei gewählte Handlung weiß ich: 1) was ein Vernunftwesen ist, nämlich Selbstbestimmung zur Handlung; 2) dass derjenige, der durch sein Handeln meine Erkenntnis von mit selbst als einem Vernunftwesen bezweckte, selber ein Vernunftwesen sein muss und 3) dass die Art seines Handelns mir gegenüber, nämlich die Selbstbeschränkung seiner Handlungssphäre, für das Erreichen seiner Absicht notwendig war. Weil er mich für ein Vernunftwesen hielt, mich als solches behandelte und durch dieses Handeln mir zum Bewusstsein meiner als Vernunftwesen verhelfen wollte, beschränkte er sich selbst. Da diese Handlung mithin nicht erst für den Philosophen, sondern bereits für das aufgeforderte Bewusstsein notwendig mit seinem Begriff von Vernunft verknüpft ist, ist es folgerichtig, wenn dieses Bewusstsein nur sein Gegenüber zumindest hypothetisch - d.h. bis zum Beweis des Gegenteils- ebenfalls „vernünftig“, durch Selbstbeschränkung, behandelt“(Siep, 1992, a, 51).

${ }^{187}$ Sobre la atribución de una esfera al otro, Cfr. Mather, (2003), 101.

${ }^{188}$ Siep, (1979), 33-34.

${ }^{189}$ GNR, § 4; SW, III, 42; AA, I, 3, 350.
} 
modo, la contraposición entre los sujetos pondría en relieve no sus diferencias o individualidades, sino sus elementos en común. Pero esta igualación permite que cada sujeto pueda elegir el curso de acción que desee, es decir que realice su individualidad. Por lo tanto, la objeción planteada arriba queda descartada. Este es el punto de partida de la demostración de la relación legal en el $\S 4$ del $G N R$, que tiene la forma de un silogismo, de la que nos ocuparemos en la siguiente sección.

\section{2. Demostración del principio del derecho (Rechtsatz)}

Fichte construye un argumento silogístico, encadenando una serie de afirmaciones que rezan como sigue:

Premisa mayor: "Yo puedo exigir a un determinado ser racional que me reconozca como un ser racional, sólo en tanto que yo mismo lo trato como tal." ${ }^{\text {190 }}$

Premisa menor: "Pero debo exigir a todos los seres racionales fuera de mí, en todos los casos, que me reconozcan como un ser racional."

Conclusión: "Yo debo reconocer al ser libre fuera de mí como tal en todos los casos, es decir limitar mi libertad por el concepto de la posibilidad de su libertad." 192

En lo que sigue, analizaré cada premisa por separado, para reconstruir el argumento en toda su complejidad.

\section{2. 1. Premisa mayor del silogismo}

Se trata de una premisa condicional que se compone de 3 partes: una condicionada, una condición y el fundamento de la unión entre ambos. Lo condicionado es el fin del individuo, es decir, el ser reconocido por los otros, la condición es el tratar al otro como un ser racional y el fundamento de su unión es la restricción de la fuerza natural del sujeto en virtud del concepto de los otros como individuos igualmente libres y racionales. Veamos cada elemento en particular. Lo condicionado en la premisa hace referencia a una forma de

\footnotetext{
190 "Ich kann einem bestimmten Vernunftwesen nur insofern anmuthen, mich für ein vernünftiges Wesen anzuerkennen, inwiefern ich selbst es als ein solches behandele“ (GNR, § 4; SW, III, 44; AA, I, 3, 352).

191 "Aber ich muss allen vernünftigen Wesen ausser mir, in allen möglichen Fällen anmuthen, mich für ein vernünftiges Wesen anzuerkennen“ (GNR, § 4; SW, III, 45; AA, I, 3, 353).

192 "Ich muss das freie Wesen ausser mir in allen Fällen anerkennen als ein solches, d.h. meine Freiheit durch den Begriff der Möglichkeit seiner Freiheit beschränken“ (GNR, § 4; SW, III, 52; AA, I, 3, 358).
} 
reconocimiento que no es de tipo moral, es decir que no se da en el foro interno de la consciencia, porque en caso contrario se caería en el solipsismo. Tampoco se trata de un reconocimiento de tipo político, que el sujeto recibiría por parte de la comunidad tomada como una totalidad.

Es una relación intersubjetiva que construye un pensar y un actuar comunes a los sujetos. Este nuevo nivel de consciencia compartida por ambos es la base de una forma de comunidad, que Fichte luego denominará como comunidad legal. El contenido de esta consciencia común (gemeinschaftliches Bewusstsein) es el concepto de ambos sujetos como seres racionales, y el reconocimiento de la necesidad consecuente de que se traten mutuamente como tales. ${ }^{193}$ Este es el fin entonces de la relación legal, o lo condicionado en la premisa mayor de silogismo. La condición de la premisa mayor del silogismo es la acción por medio de la cual se realiza el reconocimiento del otro. Es decir, que el reconocimiento está mediado por una acción en el mundo sensible.

La razón de que el reconocimiento tenga lugar por medio de una acción exterior es, como se dijo más arriba, que el reconocimiento del que se habla no es el mero conocimiento conceptual del otro como un ser racional, ya que éste tiene lugar sólo en el ámbito interno de la consciencia, al que el otro no tiene acceso. En este contexto vuelve Fichte sobre el problema del solipsismo, que ya fue tratado en el $\S 3$, si bien desde otro punto de vista. En el $\S 3$ se trataba del círculo vicioso, que surge cuando la autoconsciencia busca fundamentarse a sí misma en su foro interno. En el $\S 4$, por otro lado, se trata de la imposibilidad de alcanzar el ámbito de la intersubjetividad, desde un punto de vista solipsista. Como acentúa Honneth, Fichte abandona en el GNR el ámbito de la investigación monológica de la autoconsciencia y abre un nuevo horizonte: el de la fundamentación de los teoremas a partir del análisis de las condiciones de la acción intersubjetiva. ${ }^{194}$

El sujeto experimenta al otro sólo a través de sus acciones en el mundo sensible, mientras que este otro ser racional tiene un acceso exclusivo y excluyente a los contenidos de su consciencia. Como dice Fichte: "lo que yo pienso, el otro no puede saberlo". ${ }^{195}$ Una fundamentación monológica del reconocimiento recíproco fracasa inevitablemente, porque no permite investigar ninguna acción comunicativa. Si el ser racional no actúa en el plano intersubjetivo, el otro sujeto no puede ser afectado. Cuando el sujeto actúa en el mundo sensible, utiliza fuerzas naturales, y esto es lo que permite al otro tomar conocimiento de su acción. Una vez que se ha establecido que el reconocimiento del otro tiene lugar sólo por

\footnotetext{
${ }^{193}$ GNR, § 4; SW, III, 44-45; AA, I, 3, 352.

${ }^{194}$ Honneth, (2001), 76-80.

195 "was ich denke, kann der Andere nicht wissen" (GNR, § 4; SW, III, 45; AA, I, 3, 352).
} 
medio de la acción en el mundo sensible, queda por tratar el problema de la relación de esta acción con el concepto del otro como un ser igualmente racional.

Ante todo, la acción no debe contradecir el concepto del otro como un ser igualmente racional. Dicho de otro modo, no puede estar contenido en el concepto del fin de la acción ningún elemento que entre en contradicción con este concepto del otro como un ser racional. No debe suponerse en el concepto de la acción que, por ejemplo, el otro sujeto será tratado como un esclavo para satisfacer los propios intereses, porque se admitiría de este modo al mismo tiempo que él es menos libre que el sujeto que se propone este fin. En este caso, a pesar de que el yo sostendría el concepto del otro como un ser racional, se contradiría a sí mismo, atentando contra la coherencia lógica. Sin embargo, como dice Fichte: "la condición no es que yo no actúe en contra del concepto pensado, sino más bien que actúe realmente de acuerdo con él". 196

En este fragmento citado, Fichte enfatiza que, si el individuo cumple con la condición de no contradecirse en este sentido, gana en consistencia lógica y en racionalidad, pero esto no significa que la acción realizada sea mediadora del reconocimiento del otro. Para que esto se produzca, debe actuarse también de acuerdo con el concepto del otro en tanto que ser racional. Esto es, en el concepto del fin de la acción debe estar incluida una cierta relación con el otro. Se trata de relación fundada en la exigencia de que el yo sea tratado como un ser racional, siempre que él trate al otro de la misma manera. Esta influencia recíproca es la garantía de que el otro sujeto fue afectado por medio de la acción del yo. Es decir, que el otro ha abierto una esfera libre de acción para el yo, en tanto que ha elegido una alternativa en el seno de una esfera de acción que el yo le ha dejado abierta antes a él. En caso contrario, "permanecemos separados y no somos nada el uno para el otro". ${ }^{197}$ Podemos concluir, entonces, que la condición para lograr el reconocimiento, puede ser sólo una acción en el mundo sensible, esto es, un cierto manejo de fuerzas naturales de acuerdo con el concepto del otro como un ser racional, que Fichte denomina como Einwirkung (influencia). ${ }^{198}$

El tercer elemento que compone la premisa mayor es el fundamento de la relación entre la condición y lo condicionado, es decir la causa de que la acción de un individuo ejerza un influjo tal sobre el otro individuo, que se produzca la relación de reconocimiento. Como ya se dijo, la acción es la exteriorización de una fuerza. Pero ¿cómo podemos reconocer a aquellas acciones que no tienen como fin el tratamiento del otro como un ser racional? ¿O

\footnotetext{
196 "Die Bedingung ist (...) nicht dass ich nicht nur dem gefassten Begriffe entgegen handle, sondern, dass ich ihm wirklich gemäß handle" (GNR, § 4; SW, III, 45; AA, I, 3, 352).

197 "(...) bleiben wir geschieden und sind gar nichts für einander" (GNR, § 4; SW, III, 45; AA, I, 3, 352).

${ }^{198}$ GNR, § 4; SW, III, 45; AA, I, 3, 352.
} 
todas las acciones son meras relaciones de fuerzas, no importa cuál sea su fin? Fichte ve el criterio para enfrentar este problema en la configuración de las fuerzas puestas en movimiento.

En primer lugar Fichte constata que algunas exteriorizaciones de fuerzas tienen lugar gracias a las leyes mecánicas de la naturaleza. Este es el caso de los actos de los animales, cuya naturaleza instintiva impide que dejen alguna huella de libertad y razón tras de sí. El sujeto no puede delimitar su esfera de acción a partir de la experiencia de una acción realizada mecánicamente. Se trata de relaciones de fuerza y de poder, gracias a las que el sujeto es influenciado de cierto modo, y reacciona con otra exteriorización de fuerza. Frente a las fuerzas mecánicas, el individuo no tiene ningún alter ego, capaz de limitar su esfera de acción.

Pero cuando la exteriorización de fuerzas implica la acción de un ser racional, entonces el otro sujeto puede delimitar su esfera de acción y, a su vez, conocerse a sí mismo como ser racional. Si la acción ocurre de acuerdo con el concepto del otro como un ser racional, el sujeto afectado puede delimitar su campo de acción y finalmente actuar. Pero, ¿qué características tiene esta exteriorización de fuerzas? Se trata de la moderación (Mäßigung) de una fuerza por medio de un concepto, el concepto del otro sujeto como un ser racional. ${ }^{199}$ El individuo deduce, a partir de la de la acción del otro, que el otro es un ser igualmente racional, cuando las fuerzas son estructuradas de modo tal que se abre un campo de acción para él, que es tan amplio como el del otro. Esto lo lleva a Fichte a afirmar que "sólo la moderación de la fuerza por medio de conceptos es un criterio infalible y exclusivo de la razón y la libertad". ${ }^{200}$ Una vez establecido el contenido de la premisa mayor, podemos pasar a considerar a la premisa menor.

\section{2. 2. Premisa menor}

Para explicar la premisa menor del silogismo, debe aclararse en qué sentido el individuo necesita exigir a todos los demás seres racionales en todos los casos posibles, que lo reconozcan como un ser igualmente racional. La hipótesis de Fichte es que debe abandonarse el marco original de la relación de exhortación, para pasar a considerar una comunidad mayor de individuos interactuantes. De este modo, el individuo no puede ponerse como un ser

\footnotetext{
${ }^{199}$ Stadler, (2003), 43.

200 “nur die Mässigung der Kraft durch Begriffe ist untrügliches und ausschließendes Kriterium der Vernunft und der Freiheit"“ (GNR, § 4; SW, III, 45; AA, I, 3, 352).
} 
singular e irrepetible si no entra en relación con todos los otros individuos, no ya como una totalidad abstracta sino más bien concreta. ${ }^{201}$

El punto de partida de la argumentación es la comunidad que surge de la relación de reconocimiento recíproco, en la que cada acción depende de la acción previa del otro. El individuo confirmará su esfera de acción frente a la del otro, en la medida en que el otro le haya dejado esta esfera de acción disponible o abierta. Así se sigue la primera acción de esta última y luego al infinito, pero la cadena hubiera sido muy diferente, si uno de los sujetos no hubiera actuado frente al otro como individuo libre; por ahora no consideraré esta posibilidad, que será objeto de un análisis detallado más abajo.

En la relación de reconocimiento recíproco, cada sujeto actúa de modo tal que su acción responde, por decirlo así, a la del otro, por lo que ambos actúan en conjunto. La comunidad así constituida consiste en una serie de acciones mutuamente dependientes, que se siguen necesariamente las unas de las otras. El actuar común los obliga a orientarse a esta comunidad y respetar las consecuencias de este compromiso. ${ }^{202}$ Por lo tanto, en el seno de esta comunidad: "ambos estamos atados y unidos uno al otro por medio de nuestra existencia““ ${ }^{203}$ La necesidad vinculante de esta comunidad se funda en una ley, dado que sólo una ley puede ser el fundamento de que algunas acciones se deriven necesariamente de otras.

Esta ley debe ser aceptada y respetada por los individuos. Esto será posible sólo si los individuos tienen buenas razones para aceptar la ley. El motivo que debe llevarlos a someterse a ella debe fundarse en el motivo que los ha llevado a formar una comunidad legal. Los individuos están en relación mutua en virtud de que ambos quieren ponerse a sí mismos como seres racionales. El elemento nucleante de la comunidad, y el fundamento de la ley que la rige es la racionalidad. De allí que Fichte denomine a esta ley como la ley de la "concordancia consigo mismo" (Einstimmigkeit mit sich selbst) ${ }^{204}$ Se trata de la ley lógica de la coherencia o non contradictio de las propias acciones entre sí y con sus supuestos. Sin el cumplimiento de esta ley no puede hablarse de un comportamiento racional. La ley de la concordancia es el corazón de esta comunidad, en tanto que rige la interacción y con ello la influencia recíproca entre los sujetos. ${ }^{205}$

\footnotetext{
${ }^{201}$ GNR, § 4; SW, III, 46; AA, I, 3, 353.

202 Cfr. el resumen que hace Siep de la fundamentación de la relación legal en (1979), 32-33.

203 "wir sind beide durch unsere Existenz aneinander gebunden und einander verbunden" (GNR, § 4; SW, III, 48; AA, I, 3, 353).

${ }^{204}$ GNR, § 4; SW, III, 48; AA, I, 3, 354. Fichte habla también de esta ley en términos de "Consequenz". Ver Bartuschat, (1992), 187.

${ }^{205}$ Siep destaca que la ley que estructura las interrelaciones humanas no es de índole moral, sino más bien lógica (Siep, 1992, b, 86).
} 
La ley fichteana de la concordancia pertenece a una lógica para las acciones, lo que hoy se denominaría pragmática. Pero no se trata de un mero análisis de acciones sin tomar en cuenta concepto alguno. Por el contrario, el objeto de análisis son conceptos que sólo pueden ser transmitidos por medio de acciones. Por ejemplo, cuando alguien ejerce violencia sobre otro, el fin de su acción puede ser interpretado como suponiendo que el otro individuo no siempre tendría derecho a un conjunto de acciones libres, de modo tal que sus acciones podrían ser interrumpidas arbitrariamente. Este es el sentido de las palabras de Fichte:

Toda la unión de conceptos descripta era posible sólo en acciones y por medio de acciones: puede ser exigida y es exigida sólo para acciones. Las acciones valen aquí en lugar de los conceptos: y no se está hablando aqui de conceptos en sí, sin acciones, porque no puede hablarse de ellos. ${ }^{206}$

La ley de la concordancia consigo mismo exige, en primer lugar, que el yo reaccione frente a las acciones del otro sólo una vez que lo haya identificado como el autor de las mismas. Es decir, que el yo puede tratar al otro, sólo si lo puede entender como el punto de unión (Anknüpfungspunkt) de una serie de acciones. El yo identifica al otro como un punto de unión de una serie de acciones, en tanto que puede unir los predicados sensibles de la acción presente con los predicados sensibles de las acciones anteriores (por ej., determinadas características del cuerpo de quien las llevó a cabo, etc.).

En este sentido, el otro es reconocido por el yo como un ser sensible. Pero aún debe unir otro predicado del otro para poder reconocerlo como el autor de sus acciones, ya que también debe pensarlo como ser racional. ${ }^{207} \mathrm{Si}$ el yo no pudiera asegurarse de que el otro es un ser racional, entonces no tendría sentido entrar con él en una comunidad regida por la ley de la concordancia consigo mismo. Como se dijo más arriba, el yo reconoce al otro como un ser racional, cuando éste le deja una esfera libre de acción a su disposición, que es igual a su propia esfera de acción. Sólo cuando se logra esta doble identificación del otro, tiene sentido entrar con él en una relación de carácter racional.

Pero este doble reconocimiento de vuelve problemático cuando el otro no reconoce al yo como ser racional, por ejemplo, en el caso de que atente contra su propiedad o su integridad física. Si el otro individuo no reconoce al yo como un ser racional, entonces el yo sólo puede identificarlo como un ser sensible, análogo a un animal o una cosa. Sin embargo, Fichte considera que, aún en este caso, el yo se ve obligado por la ley de la concordancia

\footnotetext{
206 "Die ganze beschriebene Vereinigung der Begriffe war nur möglich in und durch Handlungen. Die fortgesetzte Consequenz ist es daher auch nur in Handlungen: kann gefordert werden, und wird nur gefordert für Handlungen. Die Handlungen gelten hier statt der Begriffe: und von Begriffen an sich, ohne Handlungen, ist nicht die Rede, weil von ihnen nicht die Rede seyn kann“ (GNR, § 4; SW, III, 48; AA, I, 3, 355).

${ }^{207}$ GNR, § 4; SW, III, 49; AA, I, 3, 355.
} 
consigo mismo a reconocer al otro como un ser racional, si bien de modo hipotético y problemático, y no categórico. Veamos con cierto detalle el recorrido argumental de Fichte.

En primer lugar, Fichte parte del concepto del otro individuo como un ser sensible. Es inevitable que el yo conceptualice siempre al otro como un ser sensible, porque esto no depende del modo en que el otro lo trate, dado que es un hecho de la naturaleza que cada acción esté determinada por los rasgos sensibles de la acción anterior. Pero ahora no se puede separar ambos predicados, sin caer en contradicción con el concepto previo, en el que ambos estaban unidos. En caso contrario, el yo habría elaborado un concepto del otro como un ser racional y la vez no-racional, lo cual es contradictorio. Fichte corrige este problema mostrando que el yo no necesita separar ambos predicados del mismo concepto una vez que el otro ha dejado de reconocerlo como un ser racional.

El yo puede mantener unidos los predicados de la sensibilidad y la racionalidad, si bien no se trata de una unión necesaria, sino más bien de una unión casual o fortuita. Esto implica que el yo no tratará de aquí en adelante al otro como un ser efectivamente racional, sino como un sujeto que puede comportarse como un ser racional, si decide retomar la relación de reconocimiento recíproco que se ha quebrado. Ahora, tanto como antes, sigue siendo posible que el yo trate al otro como un ser racional, cuando él a su vez lo trate también como tal.

En tanto que es un ser racional, el yo debe reconocer la contradicción en que ha caído el otro sujeto al no reconocerlo como tal. La contradicción en que ha entrado el otro consiste en que, por un lado, quiere ponerse a sí mismo como un individuo, toda vez que ha actuado; pero, para lograrlo, necesita de una libre esfera de acción, que sólo puede delimitar en relación con otra igual que pertenezca al yo. Pero no le ha dejado a este ninguna esfera de acción disponible, dado que ha interferido en su libertad. Por eso tampoco ha podido garantizarse una esfera de acción estable para sí mismo. Dicho de otro modo, si bien el otro ha ampliado su esfera de acción al avanzar sobre la esfera del yo, ha roto la relación legal que los unía y ya no puede estar seguro de que el otro no avanzará sobre el conjunto de libertad que él posee ahora.

Por lo tanto, el otro ha fracasado en su intento de ponerse a sí mismo como un individuo. Para ilustrar la posición del yo que actúa racionalmente, Fichte utiliza la metáfora del juez. El yo trata al otro racionalmente porque constata su incoherencia, por medio del criterio de la ley de la concordancia consigo mismo. Esto es, el yo actúa como un juez del comportamiento del otro, porque se coloca en un punto de vista superior, que es el de la racionalidad. 
La ley lógica de la coherencia trasciende por decirlo así la individualidad del yo, en tanto estructura su comunidad misma con el otro sujeto. De lo dicho hasta aquí se desprende "la superioridad, que cada uno se adjudica a sí mismo, frente a quien él tiene razón". ${ }^{208}$ El yo que juzga al otro como si fuera un juez debe suponer necesariamente que el otro siempre querrá ponerse a sí mismo como individuo, porque en caso contrario no habría entrado nunca con él en una comunidad legal, independientemente de que ahora haya quebrado la relación legal que los unía. Por lo tanto, si el otro sigue intentando constituirse como individuo, entonces el sujeto que se coloca en la posición del juez en realidad lo está exhortando a actuar racionalmente.

De este modo, tiene un sentido apelar al otro para que oriente su conducta por la ley de la coherencia consigo mismo, y vuelva a reconocer y a tratar al yo como un ser racional. Esta ley es vinculante para ambos, por eso el sujeto que lo juzga puede esperar del otro que no ponga resistencia al modo en que este sujeto lo trata. De esto se desprende que la comunidad de seres racionales permanece también cuando uno de ellos no reconoce al otro como un ser igualmente racional.

Si el yo se constituye como individuo, debe hacerlo como un individuo que se realizará siempre en el futuro en tanto que tal. En la medida en que se pone como individuo, pone a la vez su libertad como un rasgo central de su yo. Por lo tanto, debe ponerse como un ser libre para todo el futuro. De acuerdo con la ley de la concordancia consigo mismo, el yo debe ser consecuente, en todas las acciones siguientes, con el concepto de sí mismo, que puso en las acciones previas. Por ello, el yo debe exigir del otro que en el futuro siempre actúe según el concepto de este yo como un ser racional y que nunca le quite su esfera libre de acción. $^{209}$

Esta es una exigencia de coherencia, en tanto que si el otro sujeto ha reconocido al yo en una acción como un ser racional, no puede actuar contra tal concepto en las acciones siguientes, sin caer en contradicción consigo mismo. Esta contradicción radicaría en que, mientras que en la interacción previa el otro consideró a la libertad como un rasgo esencial del yo, en las posteriores este rasgo no tendría nada que ver con el mismo yo. La libertad sería, de acuerdo con esto, un rasgo esencial y no esencial del yo.

Pero también cuando el otro sujeto se ha puesto a sí mismo, ha puesto su libertad para todo tiempo futuro. Por esa razón puede exigirle al yo que sea consecuente y que limite su esfera de acción por la del otro para todo tiempo futuro. Por eso concluye Fichte que:

\footnotetext{
208 “(...) die Superiorität, die sich jeder zuschreibt, der Recht zu haben vermeint, über den, gegen welchen er Recht hat" (GNR, § 4; SW, III, 50; AA, I, 3, 356).

${ }^{209}$ Renaut, (2001), 87.
} 
(...) coloco sobre mí la misma consecuencia, y su actuar está condicionado por el mío. Estamos en la acción recíproca de la consecuencia de nuestro pensamiento y nuestro actuar consigo mismo y mutuamente entre nosotros. ${ }^{210}$

\section{2. 3. Conclusión}

De esto resulta que el yo debe reconocer a los demás sujetos, con los que establezca una relación, como seres igualmente racionales y libres, o sea que debe limitar su esfera de acciones libres, dejando espacio para que los demás dispongan de una esfera de acción igual a la suya. Este es el contenido del "principio del derecho" (Rechtsatz), que rige la relación legal entre los sujetos (Rechtsverhältnis). ${ }^{211}$ De lo argumentado hasta aquí se desprende el principio del derecho que, de acuerdo con su plan inicial, Fichte ha deducido a partir del concepto del individuo. $^{212} \mathrm{Si}$ la relación legal es una condición de la individualidad, y ésta a su vez lo es de la autoconsciencia, entonces la relación legal es también una condición de la autoconsciencia. $^{213}$

El principio del derecho no es un concepto a priori en el sentido de una forma vacía existente en el alma, y que fuera completada por la experiencia posterior. Más bien es una condición de la autoconsciencia, que es aplicada sólo con ocasión de cada relación intersubjetiva. Renaut hace referencia, con razón, a que aquí no se trata de una deducción tradicional del derecho natural. ${ }^{214}$ En una deducción tradicional, se establece en primer lugar la esencia del ser humano y de allí se concluye la legitimidad de sus pretensiones respecto de determinados derechos. La estrategia fichteana, en cambio, no supone que el sujeto sea la condición para la deducción del derecho, sino que más bien este último es lo que hace posible toda forma de consciencia humana.

Una vez clarificado el sentido que tiene el principio del derecho para Fichte y la estructura de la comunidad legal, que gira en torno al eje de la ley de la coherencia consigo mismo, existen suficientes elementos de juicio para resolver finalmente la cuestión de las semejanzas y las diferencias que pueden constatarse en este punto entre el GNR y la $E r W$.

\footnotetext{
210 "lege [ich] mir also die gleiche Consequenz auf, und sein Handeln ist bedingt durch das meinige. Wir stehen in Wechselwirkung der Consequenz unseres Denkens und unseres Handelns mit sich selbst und gegenseitig unter einander" (GNR, § 4; SW, III, 52; AA, I, 3, 358).

${ }^{211}$ Oncina, (1999), 215.

${ }^{212}$ Cfr. Siep, (1992, a), 74.

${ }^{213}$ Renaut, (2001), 94.

${ }^{214}$ Renaut, (2001), 91.
} 


\section{Conclusiones del Capítulo 2}

Como ya se dijo más arriba, Cohen y Fichte coinciden en adjudicar un rol constitutivo al derecho, como condición de posibilidad de la autoconsciencia. Es decir, la regulación de la libertad de cada miembro de la relación legal hace posible la forma de subjetividad que defiende cada teoría, tanto la idea de Cohen de la voluntad común expresa en la persona jurídica de la cooperativa, cuanto la autoconsciencia del yo individual que interesa a Fichte. Pero la estructura de la relación legal difiere en cada caso. Cohen concluye que la expresión de la voluntad común de los cooperadores da lugar a una voluntad artificial e independiente de los cambios y características de sus voluntades fácticas y particulares. Esta voluntad es idéntica a la persona jurídica y no puede ser modificada arbitrariamente por los cooperadores.

La comunidad legal que Fichte deduce no integra dentro de sí a sus miembros, como si se tratara de una unidad superior que los subsume. Si bien los sujetos de la relación deben someterse a la ley de la coherencia consigo mismos para sostener la comunidad legal, y no pueden traicionarla sin dejar de ser seres racionales, cada sujeto se relaciona con el otro desde su individualidad. La comunidad legal está orientada a proteger la esfera de libertad de acción de cada sujeto, y éste es el único objetivo de esta relación intersubjetiva. La comunidad legal no constituye un tipo artificial de subjetividad, independiente de la de cada uno de sus miembros.

Esta diferencia entre ambas teorías se traslada a la concepción que cada una sostiene del Estado. Mientras que Cohen concibe al Estado como una persona jurídica, y fundamenta de este modo una democracia deliberativa, Fichte defiende la necesidad de un gobierno sin un poder legislativo independiente. Este es el asunto que nos ocupará en el capítulo siguiente. 
Capítulo 3: La teoría del Estado 


\section{Capítulo 3: La teoría del Estado}

En el capítulo anterior nos hemos ocupado del concepto de relación legal en las teorías de Cohen y de Fichte. De lo argumentado allí se concluyó que ambas propuestas tienen un rasgo común: su estructura dialógica, que se funda en la deducción de la autoconsciencia a partir de la alteridad. Pero hay una diferencia importante entre ambas, que tiene también que ver con la estructura de la relación legal. Se trata de la voluntad común que resulta del acuerdo de quienes acepten entrar en esta comunidad legal.

Cohen le da un carácter ficticio, porque es la voluntad declarada y acordada de la persona jurídica, que unifica las voluntades de los individuos en una totalidad universal. De este modo, la voluntad común de la relación legal defendida por Cohen necesita de la participación permanente de sus miembros, en calidad de co-legisladores.

Fichte no propone una voluntad común que se construya en base a la legislación permanente de los miembros de la comunidad legal, porque su contenido ya está determinado desde el comienzo, y consiste en la limitación de iguales esferas de libertad para cada uno de los agentes de la comunidad. En realidad, los individuos nunca trascienden su individualidad para integrarse en una unidad mayor, aún cuando se sometan libremente a la ley de la concordancia consigo mismos, que de algún modo constriñe y encauza sus arbitrios.

Veamos si existe alguna conexión entre estas concepciones de la relación legal y las teorías del Estado de $\operatorname{Er} W$ y de GNR. De este modo, podremos constatar si la diferencia que encontramos entre sus concepciones de la relación legal se profundiza aún más hasta crear un abismo mayor entre las teorías, o si nos permite acercarlas y trazar una nueva analogía entre ellas. 


\section{I . La deducción de la autoconsciencia a partir de la persona jurídica del Estado}

Cohen ha propuesto la idea de un Estado socialista, fundado sobre la actividad parlamentaria y el sufragio universal. El horizonte de un socialismo ético, donde cada persona se autodetermina por medio de la autolegislación, motiva las fuertes críticas de Cohen al capitalismo, que ya hemos mencionado al hablar de la cooperativa. ${ }^{215}$ Es famosa su afirmación:

El carácter de fin en sí mismo produce y determina el concepto de persona, el concepto fundamental de la ética. La cosa es un mero medio en tanto que cosa del tráfico comercial. El trabajador no puede nunca ser confundido con una mera mercancía, aunque sea para los fines supremos de la riqueza nacional; él debe ser considerado y tratado 'en todo momento y al mismo tiempo como fin'.

Cohen ve en la ética kantiana la fuente de inspiración del ideal socialista, lo que convierte a Kant, en su opinión, en el verdadero fundador del socialismo alemán. ${ }^{217}$ Esta afirmación puede ser comprendida sólo en el plexo de relaciones del debate revisionista en el SPD alemán de fines del siglo XIX.

\section{1. El socialismo kantiano}

El debate sobre la relación entre la filosofía kantiana y la crítica del capitalismo puede remontarse por lo menos hasta Rudolf $\mathrm{H}$. Lotze, crítico de las formas de alienación y deshumanización del obrero en el modo de producción capitalista. Sin embargo, Lotze no abogó por las organizaciones obreras porque las consideraba factores de división. Por eso estaba a favor más bien de formas de corporativismo, en el marco de una monarquía limitada. ${ }^{218}$ Lotze consideraba que la monarquía era la forma más estable de gobierno, porque

\footnotetext{
${ }^{215}$ Günther, (1971), 188.

216 “Der Selbstzweck erzeugt und bestimmt den Begriff der Person, den Grundbegriff der Ethik. Bloßes Mittel ist die Sache, die als Sache des wirtschaftlichen Verkehrs die Ware ist. Der Arbeiter kann daher niemals bloß als Ware zu verrechnen sein, auch für die höheren Zwecke des angeblichen Nationalreichtums nicht; er muß 'jederzeit zugleich als Zweck' betrachtet und behandelt werden.“ (EmkN, 113). Cfr. Ollig, (1979, b), 127.

${ }^{217} \operatorname{EmkN}, 112$. Cfr. el comentario de Meyer en (1993), 261.

${ }^{218}$ Willey, (1978), 55.
} 
preservaba a la sociedad de las luchas entre los partidos y las diversas opiniones, y era por lo tanto la forma más apta para garantizar el bienestar general.

Si bien Lotze pensaba en una forma de monarquía hereditaria, sostenía que debía estar controlada por el parlamento. Se trataba de una forma de gobierno representativo, pero con voto calificado, sólo para aquellos ciudadanos que hayan gozado de una buena educación (Bildung), o que hayan logrado un éxito profesional o empresarial lo suficientemente importante como para dar fe de su relevancia social. Lotze creía que las masas eran por naturaleza inertes y necesitaban de un liderazgo, por lo que era poco razonable permitirles el acceso al derecho del sufragio universal. ${ }^{219}$

Otra fue la posición de F. A. Lange. En 1848, Lange dejó Zurich para pasar a enseñar en la Universidad de Bonn. En el camino, navegando por el río Rin, conoció a un joven obrero radicalizado que lo puso al tanto de las ideas revolucionarias de izquierda y despertó su interés por la cuestión social. ${ }^{220}$ Pero Lange no se quedó en la mera teorización de los problemas obreros, sino que pasó rápidamente a la acción, desplegando una actividad política notable. Es de destacar sobre todo su prédica incansable, de pueblo en pueblo, en búsqueda de la concientización de la clase obrera y campesina.

Lange era un enemigo acérrimo de la burocracia estatal, a grado tal que llegó a proponer un esquema de instituciones libres y autogestionadas en lo educativo, religioso, y en el ámbito de la producción, siguiendo el modelo del cooperativismo inglés. A diferencia de Marx, supo ver la importancia que tenían las clases obreras campesinas para luchar contra el capitalismo. ${ }^{221}$ Lange hizo mucho por la organización de cooperativas de consumo y de producción a lo largo del valle del Ruhr, en Mülheim, Essen y Elberfeld. Exhortaba permanentemente a los obreros a no aceptar todo "de arriba"; es decir del Estado, y a poner en juego la propia iniciativa. ${ }^{222}$

Lange fue el primer neokantiano que criticó al carácter absoluto de la propiedad privada, utilizando al imperativo categórico como herramienta conceptual. Consideraba que la propiedad privada hace imposible muchas veces que la libertad de cada sujeto permita una cantidad igual de libertad para los demás. ${ }^{223}$ La tercera edición de la obra de Lange Arbeitsfrage (La cuestión obrera) ejerció mucha influencia en el debate revisionista de comienzos del siglo XX. Bernstein tomó el ideal de Lange de un cientificismo sin prejuicios,

\footnotetext{
${ }^{219}$ Willey, (1978), 56.

${ }^{220}$ Willey, (1978), 85.

221 Willey, (1978), 91. El tratamiento por parte de Marx y Engels de la cuestión del campesinado, sin embargo, es complejo y sujeto a distintas interpretaciones. No estoy en condiciones de tomar posición definitiva, pero creo que es importante recordar cómo veían el tema filósofos como Lange y Eisner.

222 Willey, (1978), 92

${ }^{223}$ Willey, (1978), 94.
} 
como criterio para evaluar la teoría marxista de la crisis final de capitalismo. Sin embargo, el revisionismo de Bernstein no logró imponerse como el discurso oficial del SPD, ya que Bebel logró imponer la teoría de la lucha de clases, en el congreso celebrado en Dresden de 1903. No fueron pocos los miembros del partido que en ese congreso reprocharon a Bernstein su carácter burgués y su tibieza frente a la necesidad de una revolución inminente. Pero Bernstein no fue el único neokantiano comprometido en el debate revisionista. También Kurt Eisner, discípulo de Cohen, jugó un rol importante. Pero las partes del debate revisionista no lograron llegar a un acuerdo, de modo tal que Eisner debió abandonar en 1905 su puesto de redactor del Vorwärts, debido a diferencias insalvables de opinión con Bebel. ${ }^{224}$

La posición de Cohen se vio traducida claramente en la vida política de Eisner, sobre quien ejerció mucha influencia. Su pluma aguda y crítica puso en evidencia la corrupción de la monarquía prusiana, lo que le valió en 1897 una condena por ofensa a la majestad y 9 meses de prisión. En una carta escrita a Cohen durante el cumplimiento de la pena, declaró que la prisión lo había vuelto más decididamente "coheniano". Una vez que hubo salido de la prisión, se consagró a la tarea de redactor político del periódico socialista Vorwärts, guardando siempre una intensa relación epistolar con Cohen y los neokantianos de Marburg. ${ }^{225}$

El compromiso de Eisner en su lucha por los ideales socialistas hasta la prisión, llamó la atención de Liebknecht, quien le consiguió un puesto como redactor en Vorwärts, donde tuvo la tarea ardua de mediar entre los marxistas y los socialdemócratas, a pesar de las divergencias que a su vez él tenía con ambos. Por un lado, disentía con la afirmación de Bernstein de que la lucha de clases iba a ir perdiendo fuerza a lo largo del tiempo, y por el otro defendía contra los marxistas la idea de que el socialismo es una tarea moral. ${ }^{226}$ Más tarde tomó parte en la revolución de Munich en 1918 y formó parte de su gobierno, hasta que fue asesinado finalmente por un nacionalista fanático el 21 de febrero de $1919 .^{227}$

El debate acerca de la viabilidad y deseabilidad de un socialismo kantiano tuvo ribetes tanto teóricos cuanto de política práctica. Ya Schmidt había afirmado que, si bien es cierto que la ética kantiana es compatible al menos parcialmente con el socialismo, también lo es que existen otras éticas que están en la misma situación (por ejemplo, la cristiana). ${ }^{228}$ Por otro lado, Kautsky consideraba que la ética kantiana no es compatible con el socialismo, por diversas razones. En primer lugar, argumentaba que el imperativo categórico no es aplicable a

\footnotetext{
${ }^{224} \mathrm{Sieg},(1994), 231$.

${ }^{225}$ Sieg, (1994), 226.

${ }^{226}$ Van der Linden, (1988), 303.

${ }^{227}$ Van der Linden, (1988), 304-305.

${ }^{228}$ Schmidt, (1900), 106.
} 
las relaciones sociales, sino más bien al individuo tomado aisladamente. ${ }^{229}$ Desde su punto de vista, se trataría de una mera reacción burguesa contra el orden feudal, en el sentido de la revolución francesa, pero no tendría nada que ofrecer a la clase obrera. ${ }^{230}$ Kautsky, por su lado, vió en el kantismo una tendencia a reconciliar y armonizar los conflictos sociales, invisibilizando las luchas de clases, que en su opinión constituían el corazón mismo del modo de producción capitalista. ${ }^{231}$

Mehring -el gran jurista- consideraba que en realidad la ética kantiana no había ayudado históricamente al surgimiento del socialismo, sino que por el contrario había sido muy importante en el establecimiento del liberalismo más opuesto al movimiento obrero. ${ }^{232}$ Kautsky objetaba a los socialdemócratas su buena predisposición a tejer alianzas con los liberales. De hecho, muchos marxistas ortodoxos estaban de acuerdo con esas alianzas por razones de índole estratégica. Sin embargo, para los marxistas ortodoxos del SPD esta política de acuerdos resultaba de hecho muy difícil de justificar, en razón de la teoría de la crisis final del capitalismo y de la actitud hostil de muchos liberales hacia el movimiento obrero. ${ }^{233}$

Por el contrario, Franz Staudinger, profesor de un Gymnasium en Darmstadt, intentó sintetizar la ética de Kant y el materialismo dialéctico de Marx, pero fue deslizándose poco a poco hacia este último, considerando a la revolución violenta y a la lucha de clases como los únicos medios para cambiar el status quo. ${ }^{234}$ Staudinger consideraba que el obstáculo más importante de la ética de Kant para su integración con el socialismo es el supuesto metafísico de la libertad de la voluntad, que lo lleva a deducir al imperativo categórico a partir de esta abstracción sin realidad. De allí se desprenderían consecuencias que consideraba absurdas, tales como que la libertad consiste en la independencia respecto de los impulsos de la sensibilidad, sin relación alguna con su dimensión social. ${ }^{235}$

Staudinger buscaba rescatar el núcleo de la ética kantiana, que sería compatible con el socialismo, y que veía básicamente en la afirmación de que un hombre puede ser humano sólo cuando es libre, y es libre sólo cuando puede relacionarse racionalmente con otros hombres, lo que a su vez ocurre cuando quiere y actúa de modo racional. Esto último requeriría de una cierta igualdad legal, que excluya el derecho del más fuerte. Se trataría de una igualdad que es

\footnotetext{
${ }^{229}$ Kautsky, (1906), 209.

${ }^{230}$ Kautsky, (1906), 210.

${ }^{231}$ Kautsky, (1906), 217.

${ }^{232}$ Mehring, (1899/1900), 353. Sobre la controversia entre un Kant liberal y un Kant republicano-socializante, véase el trabajo de Bertomeu, (2005).

${ }^{233}$ Van der Linden, (1988), 302.

${ }^{234}$ Sieg, (1994), 233.

${ }^{235}$ Staudinger, (1901), 132.
} 
posible únicamente cuando se ha desarrollado una economía cooperativa, que impida que cada hombre le quite arbitrariamente su pan al otro. ${ }^{236}$

Adler creía que el kantismo era compatible con el socialismo por varias razones. En primer lugar, Adler reconocía dos semejanzas fundamentales en las filosofías de la historia de Kant y de Marx. Según su interpretación, ambos destacarían el rol fundamental que juega la economía en el devenir histórico. Esto se tornaría evidente si se considera el materialismo histórico de Marx, pero también, decía Adler, si se presta atención a la idea kantiana de la insociable socialidad, que lleva al hombre a entrar en sociedad con los demás por puro egoísmo, motivando la expansión del comercio y la inevitable desaparición paulatina de la guerra. Asimismo, en ambas teorías la historia adquiere un carácter supraindividual. ${ }^{237} \mathrm{En}$ segundo lugar, Adler sostenía que la ética kantiana no es una ética de la interioridad y la convicción, sino que se refiere al modo en que los hombres deben relacionarse socialmente. ${ }^{238}$ Finalmente, el concepto kantiano de independencia (Selbständigkeit) le brindaría al socialismo la clave para la aplicación del imperativo categórico a la economía. ${ }^{239}$

Vorländer encontró un punto en contacto entre Kant y Marx en el hecho de que ambos creían que la historia lleva en última instancia a una sociedad justa. ${ }^{240}$ También concordarían ambos en la necesidad de la independencia económica, como condición de la libertad política. ${ }^{241}$ Sin embargo, Vorländer veía en la ética kantiana las limitaciones de un pensamiento surgido antes del auge del capitalismo. Por eso Vorländer exigía el complemento del método crítico de Kant con el método histórico-económico del marxismo. ${ }^{242}$ Vorländer afirmaba que ambos pensadores sostienen una idea abierta de sistema, que consiste más bien en un método para llevar a cabo una búsqueda infinita y nunca completada, una tarea sin término. ${ }^{243}$

Como se dijo más arriba, la recepción del kantismo en el revisionismo de Bernstein tuvo que ver más con la lectura de Lange que de los neokantianos de Marburg. Bernstein valoraba sobre todo el cientificismo carente de prejuicios de Lange, como un arma para refutar el dogmatismo del ala marxista ortodoxa del SPD, que sostenía que el capitalismo inevitablemente iba hacia una crisis final por sobreproducción. También influyó en Bernstein la idea de Lange del socialismo como una tarea moral a realizar en la historia, la tarea de

\footnotetext{
${ }^{236}$ Staudinger, (1904), 153-154.

${ }^{237}$ Adler, (1904), 174-175.

${ }^{238}$ Adler, (1904), 179-180.

${ }^{239}$ Adler, (1904), 190.

${ }^{240}$ Vorländer, (1911), 283.

${ }^{241}$ Vorländer, (1911), 309.

${ }^{242}$ Vorländer, (1911), 310-311, 315.

${ }^{243}$ Vorländer, (1911), 335
} 
construir una sociedad en la que el obrero sea tratado como un fin en sí mismo y no como un medio para los fines del capitalista. ${ }^{244}$

Sin embargo, hay puntos en común entre los neokantianos de Marburg y el revisionismo de Bernstein, que permiten hablar de un socialismo kantiano en política. ${ }^{245}$ Tanto Bernstein como Cohen creían en la democracia como el camino y a la vez el objetivo del socialismo, y la importancia del cooperativismo como medio de emancipación de la clase obrera. Más aún, compartían la idea del socialismo no como la preparación para la crisis final del capitalismo y la revolución consecuente, sino más bien como una tarea infinita, abierta y siempre sujeta a nuevas revisiones y correcciones en base a la experiencia misma de la lucha social. $^{246}$

\section{2. La crítica del anarquismo}

Cohen se ocupa de la teoría del Estado para demostrar que la autoconsciencia es la categoría central de la ciencia del derecho. Dado que Cohen identifica al Estado con la totalidad del sistema del derecho, y de las condiciones de su producción y aplicación, es indispensable demostrar que el Estado no puede ser pensado sin el concepto de autoconsciencia, si se quiere concluir que el derecho no puede tampoco ser explicado sin esta idea. Es decir que podrá concluir que el sistema legal puede ser explicado únicamente a partir del concepto del sujeto de la voluntad pura. ${ }^{247}$

El sistema legal es idéntico al Estado mismo, porque el Estado es una persona jurídica y, por lo tanto, su existencia depende de la expresión de la voluntad común de los ciudadanos por medio de la legislación. ${ }^{248}$ Cohen recurre a sus investigaciones sobre la persona jurídica de la cooperativa, para determinar el tipo específico de persona jurídica que es el Estado. Pero si se quiere demostrar que el Estado supone necesariamente el concepto de "una voluntad común a todos los ciudadanos", entonces, en primer lugar, es indispensable despejar la objeción anarquista de que el Estado no es más que un instrumento de dominación.

Según Cohen, la fuerza que tiene muchas veces la concepción anarquista del Estado radica en que:

\footnotetext{
${ }^{244}$ Van der Linden, (1988), 298-299.

${ }^{245}$ La filosofía de Cohen influyó en el joven Ortega y Gasset, quien en su juventud adhirió a las ideas de Marburg y las difundió por medio de su labor periodística en sus escritos publicados entre 1902 y 1913 . En Latinoamérica el socialismo kantiano fue retomado por Alejandro Korn (Guariglia, 1992, a, 57).

${ }^{246}$ Van der Linden, (1988), 300.

${ }^{247}$ Cfr. Holzhey, (1993), nota al pie de la p. 30.

${ }^{248}$ Cfr. Holzhey, (1993), 27-28.
} 
Estamos acostumbrados a pensar el concepto del Estado bajo el concepto de la dominación, de acuerdo con el derecho romano estatal del imperium y dominium. Bajo este concepto fluyen, claramente, los límites del derecho público y privado, uno en el otro. Se trata tan frecuentemente, y con coherencia metodológica, de la dominación de la propiedad de las clases dominantes, quienes parecen formar el Estado, porque ellas son quienes lo rigen. ${ }^{249}$

Cohen contrapone a la concepción anarquista del Estado, su propia idea de un "Estado democrático de derecho". Se trata de una organización política estructurada a partir del imperio de la ley, razón por la cual el Estado democrático de derecho no puede nunca desligarse del todo de la obligación de guardar al menos una cierta imparcialidad en la aplicación de la justicia. Dicho de otro modo, el Estado no puede

(...) liberarse del todo de la tarea, que se designa con la fórmula pacta servare. Y esta fórmula significa, al mismo tiempo, fidem servare. ${ }^{250}$

El Estado democrático de derecho, entonces, no puede dejar de honrar los pactos a los que ha prometido fidelidad, ante todo el pacto social fundamental, que es el de hacer respetar la ley. Por lo tanto, el provecho que las clases dominantes pueden sacar del Estado, para servir a sus fines particulares, es limitado.

Frente al prejuicio anarquista, Cohen sostiene que el Estado democrático de derecho siempre conserva un núcleo de universalidad, toda vez que continúe existiendo como tal. El carácter universal del Estado se funda en la universalidad de su voluntad, que es producto de la deliberación y el consenso de todos los ciudadanos, por medio de sus representantes en el poder legislativo (elegidos por sufragio universal).

Sin embargo, la universalidad de la persona jurídica del Estado no quedará salvada hasta que Cohen haya analizado el procedimiento que rige la formación y expresión de la voluntad común de los ciudadanos en la persona jurídica del Estado.

Como es bien sabido, el anarquismo niega que la persona jurídica del Estado sea fruto de una voluntad efectivamente común a todos los ciudadanos, porque para que esto fuera así sería necesario que cada una de las voluntades individuales participara de hecho en su formación, lo cual es fácticamente imposible. Si al menos una de las voluntades individuales de los ciudadanos faltara en algún momento en el proceso de la deliberación, entonces se

\footnotetext{
249 "Wir sind gewohnt, den Begriff des Staates unter dem Begriffe der Herrschaft zu denken, gemäss dem römischen Staatsrechte vom imperium und dominium. Unter diesem Begriffe fliessen freilich die Grenze des öffentlichen und des Privatrechts gar oft und leicht ineinander über. Es handelt sich da nur zu oft und mit einer methodischen Konsequenz um die Eigentumsherrschaft der herrschenden Stände, die den Staat zu bilden scheinen, weil sie ihn regieren." $(E r W, 241-242)$.

250 “(...) sich dennoch grundsätzlich (...) der Aufgabe entschlagen, welche durch die Formel pacta servare bezeichnet wird. Und diese Formel bedeutet zugleich fidem servare.“ ( $\mathrm{Er} W, 242)$.
} 
trataría de una voluntad falsamente común, porque sería meramente la voluntad parcial de un grupo de ciudadanos. Y es esto lo que realmente ocurre, según la opinión anarquista mayoritaria, dada la imposibilidad de reunir a todos los ciudadanos para decidir sobre todos los asuntos de los que se ocupa el poder legislativo.

Pues bien, Cohen cree que es posible salvar esta objeción anarquista, si se considera el funcionamiento de la persona jurídica del Estado a la luz de los resultados de la investigación sobre la persona jurídica de la cooperativa. De allí se concluiría que la voluntad común que resulta del acuerdo de los cooperadores es independiente de sus voluntades fácticas, porque adquiere autonomía respecto de los cambios futuros en las preferencias y el parecer de los individuos que se han sometido a ella. ${ }^{251}$ Dicho de otro modo, los cooperadores ya no pueden decidir a cuáles normas obedecerán y a cuáles no, sino que deberán someterse de allí en adelante a las normas que ellos mismos han debatido y luego acordado. Lo mismo ocurre en la persona jurídica del Estado, donde los ciudadanos no podrán cambiar caprichosamente y a discreción las normas que no les convengan.

Ahora bien, la voluntad común del Estado se expresa cada vez que el poder legislativo proclama una nueva ley. ${ }^{252}$ Se trata de una voluntad declarada y expresa, pero que a su vez es el producto de la deliberación y la discusión previas. Es decir, se trata de una voluntad que tiene una unidad, porque se la ha moldeado a lo largo del debate y tiene una coherencia interna. En algunos puntos, seguramente esta voluntad que se ha proclamado discrepará al menos en parte con el parecer de muchas de las voluntades particulares que en ella tomaron parte, porque la homogeneidad de la voluntad común es el resultado de la deliberación y la negociación. Pero la voluntad común que se expresa en cada ley es diferente en cada caso, de acuerdo con el contenido del que se trate. Sin embargo, la voluntad que se expresa en cada acto de legislación es la expresión de una misma voluntad común, que no es otra que la voluntad del pueblo expresa en la constitución.

El contenido de la voluntad constitucional consiste en las reglas del procedimiento que debe seguirse en la legislación, para garantizar que ésta sea efectivamente democrática. Se trata de condiciones tales como la exigencia del sufragio universal para elegir a los legisladores, la igualdad de voz y voto en el parlamento, la ausencia de coacción sobre los representantes, su eventual inmunidad parlamentaria, etc. ${ }^{253}$

\footnotetext{
${ }^{251} \operatorname{ErW}, 243$.

${ }^{252}$ Ollig, (1979, a), 156; Lisser, (1922), 55.

${ }^{253}$ La impugnación de Cohen del sistema prusiano de votación por clases está motivada también por el reclamo de inclusión de la minoría judía en la vida estatal. "Como judío emancipado, Cohen reconoce al Estado como la única posibilidad para los judíos de convertirse en miembros valiosos de la comunidad constituida legalmente. El elogio que hace Cohen del Estado es el elogio de un Estado, en el cual las minorías étnicas y religiosas pueden
} 
Una vez que la voluntad común se ha expresado y fijado por escrito en la constitución, entonces bastará simplemente con que se controle el respeto de las normas allí establecidas, para que la voluntad estatal sea efectivamente una voluntad común y universal. ${ }^{254}$ La vigencia de la ley fundamental garantiza la universalidad de las normas promulgadas, sin necesidad de que todos los ciudadanos participen en cada momento en la tarea de la legislación. La personalidad jurídica del Estado consiste entonces en la expresión de la voluntad común, o sea en la construcción de un cierto tipo de subjetividad que, al igual que en el caso de la persona jurídica de la cooperativa, consiste en el sujeto de una voluntad ficticia y técnico-legal.

Dicho de otro modo, la persona jurídica del Estado es la expresión de una voluntad pura, que no depende de la voluntad fáctica y actual de cada ciudadano, ni tampoco de un grupo de ellos. ${ }^{255}$ Se trata del sujeto de una voluntad que surge a partir de sí misma, sin otra referencia que las reglas que la constituyen. El Estado es, entonces, un sujeto o una persona universal en virtud de su voluntad. ${ }^{256}$ El Estado constituye la autoconsciencia o, lo que es lo mismo, es el sujeto de la ética. ${ }^{257}$ Toda vez que el Estado es la expresión de la voluntad pura, y el contenido del movimiento de la voluntad pura es la tarea (Aufgabe), entonces el Estado mismo es la tarea de constituir el sujeto de la voluntad pura. ${ }^{258}$

Por lo tanto, el Estado es la tarea de la autoconsciencia. ${ }^{259}$ El Estado significa entonces la unidad del objeto y el sujeto de la voluntad, porque el objeto de la voluntad es la expresión de sí misma, es decir la exteriorización de sí misma, lo que implica que es la expresión del sujeto de la voluntad. ${ }^{260}$

\footnotetext{
convertirse en ciudadanos que tienen el mismo valor que los demás. Este Estado es el lugar de la emancipación precisamente de los judíos, porque 'sin ley no hay libertad, y sin una comunidad estructurada en base a la ley no hay ninguna personalidad libre’ $(E, 118)$. De allí que el Cohen judío pone su esperanza en el Estado de derecho prusiano y en su evolución, porque este mismo otorgó a los judíos la plena ciudadanía desde la misma fundación del reino." ("Als emanzipierter Jude erkennt Cohen im Rechtsstaat die einzige Möglichkeit der Juden, vollwertige Mitglieder der rechtlich verfassten Gemeinschaft zu werden. Cohens Staatslob ist das Lob für einen Staat, in dem die religiösen und ethnischen Minderheiten vollwertige Bürger werden können. Dieser Staat ist der Ort der Emanzipation gerade der Juden, denn ,ohne Gesetz keine Freiheit, und ohne die im Gesetz bestehende Gemeinschaft keine freie Persönlichkeit' (E, 118). Daher setzt der Jude Cohen seine Hoffnung auf den preussischen Rechtsstaat und auf dessen Entwicklung, weil dieser seit der Reichsgründung den Juden die volle Staatsbürgerschaft zugestand“; Schmid, 1993, 77). Cfr. Holzhey, (1993), 27-28; Winter, (1980), 333-334. Acerca de la superación de las pretensiones hegemónicas de la religión en la universalidad del Estado, Cfr. Lübbe, (1958), 234; (1963), 240. Para la cuestión de la neutralidad estatal, Cfr. Schwarzschild, (1956), 216.

${ }^{254}$ Cfr. la analogía entre la constitución y el Estatuto de la cooperativa en Schmid, (1993), 67-68.

${ }^{255}$ Giesecke, (1990), 119; Müller, (1994), 129; Natorp, (1918), 97.

${ }^{256}$ Cfr. Philonenko, (1989), 76-77.

${ }^{257} \mathrm{ErW}, 80$. Acerca del Estado como concepto modelo de la autoconsciencia, Cfr. Schmid, (1993), 69-70; Winter, (1980), 349; Görland, (1912), 240.

${ }^{258}$ Se trata de la persona jurídica como concepto conductor de la autoconsciencia (Schmid, 1993, 70-71); Günther, (1971), 117, 136. Cfr. Natorp, (1918), 98; Lisser, (1922), 56; Müller, (1994), 121-122.

${ }^{259} \mathrm{ErW}, 244$. Dreyer, (1985), 123.

${ }^{260} \mathrm{ErW}, 245$.
} 
Por otro lado, y nuevamente en contra de la afirmación del anarquismo, Cohen sostiene que las voluntades individuales y fácticas de los ciudadanos pueden ordenarse a la realización de la tarea de la autoconsciencia. ${ }^{261}$ Cada ciudadano se orienta a la constitución de la autoconsciencia en la voluntad común del Estado, en virtud de la actividad parlamentaria de sus representantes. ${ }^{262}$ Por medio del sufragio, cada ciudadano delega en los legisladores la representación de su voluntad. ${ }^{263} \mathrm{Si}$ no estuviera garantizado el sufragio universal, entonces la voluntad común sería una mera farsa, porque no unificaría e integraría a las voluntades individuales. $^{264}$

\section{3. La realización de la autoconsciencia en el Estado}

Otra cuestión importante que plantea la realización de la autoconsciencia en el Estado es el tipo de subjetividad del que aquí se trata. Dado que la autoconsciencia es el sujeto de la ética, puede ser pensada en analogía con el concepto del objeto de la naturaleza, del que se ocupa la lógica. ${ }^{265}$ No se puede llevar más lejos la analogía con la ciencia natural, afirmando que la autoconsciencia está constituida por las voluntades individuales de los ciudadanos, que están incluidas en ella, del mismo modo que los órganos lo están en el objeto de la naturaleza, o sea, en el organismo vivo. ${ }^{266}$ El problema radica en que el sujeto no puede ser dividido en partes, porque es espíritu expresado en la organización legal del Estado. Como dice Cohen: "la autoconsciencia se realiza en el contrato y está condicionada por él". ${ }^{267}$

No se trata del espíritu que se hace presente en la comunidad religiosa, entendido como una emanación de la divinidad. Ni tampoco puede pensarse la idea del espíritu en el

\footnotetext{
${ }^{261}$ Görland, (1912), 244. Acerca del concepto de Estado como instrumento metodológico para ejercer una crítica de las relaciones de dominación en los Estados existentes. Cfr. Holzhey, (1992), 40; (1993), 30; Lübbe, (1963), 241-242; Winter, (1980), 331.

${ }^{262}$ Cfr. Giesecke, (1990), 112; 120.

${ }^{263} \mathrm{ErW}$, 519. Cfr. Lübbe, (1958), 234-235; Lübbe, (1963), 242; Schmid, (1993), 67-68.

264 "Porque, como la universalidad del Estado, en tanto que unidad, y que tarea de la unidad, está condicionada por la voluntad particular, el particular debe tomar en sí esta tarea de la universalidad; debe ordenarse a esta unidad e integrarse en ella. Esta unidad es el contenido, con el que debe relacionarse su voluntad en todas sus acciones. Y la voluntad particular puede conseguir y afirmar su sujeto, su autoconsciencia, como tarea de su voluntad pura, sólo en este contenido, en este objeto. Contra esto se erizan sobre todo los impulsos del absolutismo religioso y la soberanía sobre todas las tendencias del espíritu humano." ("Denn wie die Allheit des Staates, als Einheit, und zwar als Aufgabe der Einheit, durch den Einzelwillen bedingt ist, so hat der Einzelne diese Aufgabe der Allheit auf sich selbst zu nehmen; dieser Einheit sich einzuordnen und einzugliedern. Diese Einheit ist der Inhalt, auf den er in allen seinen Handlungen seinen Willen zu beziehen hat, Und nur in diesem Inhalt, in diesem Objekte kann er sein Subjekt, sein Selbstbewusstsein, als die Aufgabe seines reinen Willens, erlangen und behaupten. Dagegen sträuben sich hauptsächlich die Regungen der religiösen Absolutheit und Souveränität für alle Richtungen des Menschengeistes. “; $\operatorname{ErW}, 245)$.

${ }^{265}$ Guariglia, (1992, a), 59.

${ }^{266}$ Günther, (1971), 137.

267 "Das Selbstbewusstsein (...) vollzieht sich in dem Vertrage und ist durch ihn bedingt." (ErW, 248).
} 
sentido de una formación de la consciencia cultural totalmente independiente del conocimiento científico-natural, al modo del espíritu que se expresa en el arte. Se trata, en realidad, del espíritu propio de la consciencia cultural manifestada por la ciencia del derecho, pero que se funda en los resultados de la ciencia natural, según la ley básica de la verdad.

El espíritu surge cuando los ciudadanos hallan la formulación escrita de una voluntad común a la que han llegado. ${ }^{268}$ Por lo tanto, supone siempre el acuerdo previo entre ellos. ${ }^{269}$ En este sentido, el contrato es el fundamento de la persona jurídica del Estado y, dado que el Estado es idéntico a la totalidad del sistema legal, es el fundamento del derecho mismo. ${ }^{270}$ Toda relación legal puede ser pensada bajo la forma del contrato, porque en realidad, la legislación es un acto de deliberación y acuerdo entre adultos consintientes en condiciones de simetría. ${ }^{271}$ Dicho de otro modo, "la autoconsciencia se realiza en el contrato y está condicionada por él". 272

La autoconsciencia hace posible una comunidad espiritual entre los ciudadanos, porque la forma contractual que adquiere la legislación en el Estado liga a los ciudadanos con los lazos del mutuo reconocimiento como sujetos de derecho. ${ }^{273}$ El otro deja de ser un extraño, porque participa en la empresa común de la legislación, y en la formación de la voluntad estatal por medio de la unificación de las voluntades particulares del otro y el yo. ${ }^{274}$ Los ciudadanos construyen la comunidad espiritual del Estado -la autoconsciencia- en la actividad legislativa. ${ }^{275}$ Los ciudadanos están interrelacionados en la voluntad común constituida por la ley. ${ }^{276}$

Cohen ejemplifica la relación intersubjetiva que la autoconsciencia instaura entre los ciudadanos, con el carácter de reclamabilidad judicial de la acción legal. Veamos de qué manera lo hace.

La relación legal es una actio, en el sentido de que contiene en sí no sólo las normas que deben cumplirse, sino también el procedimiento a seguir para denunciar y procesar a quien las transgreda. ${ }^{277}$ Una acusación penal (Anklage) sólo puede llevarse a cabo si se determinan con claridad al menos dos personas físicas: la del querellante y la del acusado. Es

\footnotetext{
${ }^{268}$ Cfr. Holzhey, (1994, c), 151. Ollig, (1979, a), 153.

${ }^{269}$ Figal, (1982), 175.

${ }^{270}$ Cfr. Winter, (1980), 346.

271 Philonenko, (1989), 79.

272 "Das Selbstbewusstsein (...) vollzieht sich in dem Vertrage und ist durch ihn bedingt." (ErW, 248).

${ }^{273}$ Cfr. Ollig, (1979, a), 154.

${ }^{274}$ Giesecke, (1990), nota al pie de la p. 118, 119-120; Dreyer, (1985),121-122.

${ }^{275}$ Cfr. Görland, (1912), 245; Holzhey, (1994/3), 151; Dreyer, (1985), 122-123.

${ }^{276}$ Giesecke interpreta erróneamente al concepto de Estado de Cohen como una forma de colectivismo, porque disolvería al individuo en la totalidad de la voluntad estatal (Giesecke, 1990, 129-130). Cfr. Günther, (1971), 156.

${ }^{277}$ Winter, (1980), 288-289.
} 
decir, que se trata de una relación entre un yo y un tú concretos y específicos. Como dice Cohen:

Pero allí yace al mismo tiempo la exigencia levantada: porque yo no puedo pensar en "Yo", sin pensar en ti. Así, el otro se ha transformado en la autoconsciencia en cierto modo en el Dualis del yo. En la medida en que la autoconsciencia debe significar la unidad de la voluntad, debe formar la unión de yo y tú. La voluntad me une a mi contigo; a ti conmigo. Esta unidad significa la tarea de la autoconsciencia. ${ }^{278}$

Cohen considera que esta característica intrínseca de la ley -que establece una correlación necesaria entre por lo menos dos sujetos- constituye un progreso de la relación intersubjetiva, que va desde una primera relación con un otro general y abstracto, hasta la correlación con un tú siempre concreto, sea en calidad de querellante o de acusado. Si el derecho no pudiera ser pensado bajo la forma del contrato, no estaría constituido en la forma de un sujeto colectivo, de la persona jurídica del Estado. Pero entonces tampoco sería la autoconsciencia la categoría fundamental del Estado, y la ética no podría deducirse a partir del derecho estatal. La autoconsciencia, entonces, supera la posición del yo aislado y separado de los demás, y lo lleva a convertirse en un tú. ${ }^{279}$ Dicho de otro modo, la autoconsciencia instituye una comunidad tan íntima entre el yo y el tú que no puede pensarse el uno sin el otro. $^{280}$

Cohen se apoya en el concepto de espíritu que ha resultado de su investigación en torno al problema de la autoconsciencia, para rechazar la teoría del Estado de Savigny y de la Escuela Histórica del Derecho.

En relación con Savigny -y a pesar de que ambos comparten ciertos supuestos fundamentales, puesto que afirman que el derecho se funda en el contrato, que el sistema legal tiene una forma contractual- ha dicho Cohen lo siguiente: En primer lugar, que la teoría del Estado de Savigny no se funda en el contrato, porque es diferente a la totalidad del derecho. En realidad, según Cohen, Savigny funda la voluntad del Estado en el "espíritu del pueblo", es decir de una comunidad prepolítica fundada en una tradición y cultura comunes, porque es la representación de este espíritu bajo la forma contractual del derecho. La diferencia entre la teoría de Cohen y la de Savigny, en síntesis, yace fundamentalmente en el concepto de espíritu que está a la base del Estado. En Cohen, ese espíritu es idéntico a la

\footnotetext{
278 “Aber es liegt darin zugleich die gesteigerte Forderung: dass ich auch nicht Ich denken kann, ohne dich zu denken. So hat der Andere im Selbstbewusstsein sich gleichsam in den Dualis des Ich verwandelt. Wenn das Selbstbewusstsein die Einheit des Willens zu bedeuten hat, so muss sie die Vereinigung von Ich und Du bilden. Der Wille vereinigt mich und dich; dich und mich. Diese Einheit bedeutet die Aufgabe des Selbstbewusstseins.“ $(\mathrm{ErW}, 249)$.

${ }^{279}$ Görland, (1912), 241, 244-245.

${ }^{280}$ Giesecke, (1990), 119-120.
} 
consciencia cultural del derecho, en tanto que autoconsciencia del Estado, mientras que en Savigny se trata un concepto místico, que en realidad sublima la idea naturalista del pueblo.

Cohen piensa que Savigny, en última instancia, confunde a la lógica con la ética, porque parte del concepto del pueblo como si fuera "una totalidad orgánica natural". El pueblo es fundamentado de modo descriptivo, por medio de la atribución a los ciudadanos de ciertos rasgos comunes. Por eso, Savigny usurpa al concepto del Estado el lugar que le corresponde en el reino de las ciencias del espíritu. Como dice el mismo Cohen: "la Escuela Histórica del Derecho echa sus raíces en un naturalismo, que se representa y se estructura de acuerdo con la forma usual del espiritualismo". ${ }^{281}$

Además, y siempre según Cohen, la propuesta de Savigny lleva, como consecuencia lógica, al nacionalismo, que no es otra cosa que una forma disfrazada de anarquismo. ${ }^{282} \mathrm{La}$ razón de esto es que el nacionalismo convierte a la realización de la voluntad del pueblo en un fin en sí mismo, y subordina la voluntad del Estado a este interés fundamental. ${ }^{283}$ De este modo, el Estado y el derecho pierden su carácter universal, que puede sólo puede estar fundado en la voluntad pura que se expresa por medio de la legislación, es decir en la autoconsciencia. $^{284}$

De lo argumentado hasta aquí, y retomando las conclusiones del capítulo 1 de este trabajo, puede derivarse que Cohen, a diferencia de Fichte, no opera con un concepto de autoconsciencia individual. Fichte entiende a la autoconsciencia como un tipo de relación consigo misma, en la que el sujeto individual puede atribuirse la causalidad en el mundo sensible. Por el contrario, en Cohen se trata de la consciencia de esa forma de subjetividad que Cohen denomina el "sí mismo" (Selbst), para diferenciarla de la autoconsciencia del yo. ${ }^{285}$

Cohen sospecha que el concepto de autoconsciencia individual está teñido de psicologismo. Es decir, que la autoconsciencia del individuo no es más que la consciencia empírica de sus estados internos. Pero no puede fundamentarse ninguna ciencia a partir de la supuesta evidencia de estados internos de consciencia, a los que sólo el sujeto puede acceder. El yo sólo es una parte de la voluntad pura, que unifica el querer del yo y del tú. Si el yo y el tú no son pensados juntos y correlativamente, la idea misma de voluntad pura carece de sentido. Como dice el propio Cohen:

\footnotetext{
281 "Die historische Rechtsschule wurzelt in einem Naturalismus, der sich nach der üblichen Art des Spiritualismus als solchen ausstattet und darstellt.“ $(\mathrm{Er} W, 252)$.

${ }^{282} \operatorname{ErW}, 255$.

${ }^{283}$ Cfr. Giesecke, (1990), 121-122.

${ }^{284} \mathrm{ErW}, 256$.

${ }^{285} \mathrm{ErW}, 258$.
} 
El sí mismo no es algo así como la fuerza natural dada psicológicamente, que es quien produce la voluntad; y en este caso sería pensada como un poder natural y una disposición garantizados; pero más bien es siempre sólo la tarea quien constituye, en tanto que tal, tanto al sujeto cuanto al objeto del querer puro. ${ }^{286}$

Cohen estructura el concepto de la autoconsciencia en base a la tarea, en tanto que es el motivo de la voluntad pura. Pero la voluntad pura se expresa como autoconsciencia en la voluntad estatal, que dota al Estado de personalidad jurídica. ${ }^{287}$ Por lo tanto, la autoconsciencia es la realización de la voluntad pura en la acción legal, que incluye tanto a la tarea de la legislación cuanto de la aplicación de la ley. ${ }^{288}$ Como dice Cohen,

El concepto de ley, al que aquí se está haciendo referencia, no tiene que ver con la unidad y la esencia de la leyes, que son establecidas por la ley fundante, la constitución; sino más bien con las leyes particulares, en las cuales se atestigua y se realizan las tareas de la voluntad estatal. Sin ley no hay voluntad, y por lo tanto tampoco una autoconsciencia del Estado. Este concepto estatal de la ley debe convertirse en el concepto guía para la autoconsciencia personal. ${ }^{289}$

La tarea de la autoconsciencia en la voluntad estatal es el objetivo último de la moralidad que, a su vez, es el norte de la vida política. Nunca puede decirse que se ha completado la tarea de la autoconsciencia, porque es infinita y está siempre abierta al futuro. ${ }^{290} \mathrm{La}$ autoconsciencia es el sujeto de la voluntad pura sólo en la medida en que actúa. $^{291}$ De allí se desprende la necesidad de analizar más en detalle la acción de la autoconsciencia, para completar la determinación de su concepto.

\section{4. La acción de la autoconsciencia}

Cohen emprende el análisis del concepto de la acción, con el propósito de liberar definitivamente a la autoconsciencia del prejuicio psicologista, y desvincularla de toda

\footnotetext{
286 "Das Selbst ist nicht etwa die psychologisch gegebene Naturkraft, welche den Willen hervorbringt; und wäre sie noch so primitiv als eine verborgene Naturmacht und Anlage gedacht; sondern es ist immer nur die Aufgabe, welche, als solche, so das Subjekt, wie das Objekt des reinen Wollens bildet.“ (ErW, 259).

${ }^{287}$ Dreyer, (1985), 122.

${ }^{288}$ Görland, (1912), 244; Ollig, (1979, a), 156.

289 "Bei dem Gesetze, wie es hier gemeint ist, handelt es sich aber nicht um die Einheit und den Inbegriff der Gesetze, den das Grundgesetz, die Verfassung ausmacht; sondern um die einzelnen Gesetze selber, in denen die Aufgaben des Staatswillens sich bekunden und betätigen. Ohne Gesetz kein Wille, also auch kein Selbstbewusstsein des Staates. Dieser Staatsbegriff des Gesetzes muss der Leitbegriff werden für das persönliche Selbstbewusstsein.“ $(E r W, 262)$.

${ }^{290}$ Para el Estado como Zielbegriff de la autoconsciencia, Cfr. Schmid, (1993), 72-73; Lisser, (1922), 56-57.

291 "El producto y el testimonio de la voluntad pura es la acción. A ella corresponde y de ella surge la autoconsciencia. La acción representa mejor y con más claridad la producción de la autoconsciencia." ("Das Erzeugnis und das Zeugnis des reinen Willens ist die Handlung. Ihr entspricht, ihr entspringt das Selbstbewusstsein. Mehr und deutlicher als der Wille stellt die Handlung die Erzeugung des Selbstbewusstseins dar.“; $E r W, 259)$.
} 
fundamentación en el yo empírico. La autoconsciencia puede ser demostrada de manera adecuada, sólo una vez que se ha establecido su realización por medio de las leyes particulares en el Estado. ${ }^{292}$ Sin embargo, puede surgir un conflicto entre las convicciones morales del individuo y el contenido de la ley. Es decir, que puede aparecer una tensión entre la particularidad del ciudadano y la universalidad de la ley. Por ejemplo, podría impugnarse cierta ley particular, por considerarla injusta en relación con otras leyes naturales o leyes noescritas, que operarían de este modo como criterio moral frente al derecho positivo.

Sin embargo, Cohen piensa que no puede justificarse la moralidad o la inmoralidad de las leyes positivas en base a una legalidad natural previa al Estado, sino que debe serlo simplemente en virtud de las disposiciones mismas establecidas en la constitución, que marcan cómo debe legislarse y aplicarse la ley para constituir el sujeto colectivo de la autoconsciencia. La autoconsciencia es entonces el concepto guía para juzgar la moralidad de las leyes del Estado, por lo que se trata de un criterio inmamente al sistema legal mismo.

Es en este contexto que Cohen remite al ejemplo histórico de Sócrates, quien reconoció la majestad del Estado en la ley injusta que lo condenaba a muerte. ${ }^{293}$ Sócrates prefirió la vigencia de una ley injusta, a la ausencia total de leyes y a la destrucción del Estado. Por eso no juzgó a sus jueces de acuerdo con leyes naturales, independientes de la legislación estatal, sino que más bien decidió aceptar su veredicto y se rehusó a seguir la sugerencia de Critón de sobornar a los guardias, a fin de escapar y marchar al destierro. ${ }^{294}$ Sócrates comprendió, entonces, que es preferible una vida injusta como ciudadano de un Estado democrático, que una vida por fuera de la comunidad estatal.

La razón de esto es que Sócrates entendió que la participación en la comunidad espiritual de la autoconsciencia es la condición necesaria para llevar una vida moral. Es decir, que el ciudadano puede superar el punto de vista egoísta del sujeto aislado, y ponerse en correlación con la universalidad de los demás, sólo cuando acepta y cumple la ley dictada por el Estado. La ética -que tiene por objeto la correlación entre el individuo y la universalidadsólo puede ofrecer a cada ciudadano el concepto guía de la autoconsciencia, que se realiza en el Estado.

Como es evidente, a partir de su análisis del concepto de autoconsciencia, Cohen concluye que existe una identificación íntima entre la ética y el sistema legal. Mejor dicho, que la ética provee al sistema legal de las categorías fundamentales para explicar su constitución última, lo que vale tanto para los conceptos de voluntad pura y autoconsciencia,

\footnotetext{
${ }^{292}$ Winter, (1980), 349.

${ }^{293}$ Cfr. Schmid, (1993), 71-72.

${ }^{294} \operatorname{ErW}, 264-265$.
} 
como para el concepto de acción. Por eso rechaza la división tajante de Kant entre ética y derecho. ${ }^{295}$ Cohen consideraba que la ética kantiana no podía unificar a la ética con el derecho, porque no disponía de un factum científico como punto de partida. ${ }^{296}$

Según Cohen, el derecho kantiano, a diferencia de la ética, tiene un fundamento externo de determinación de la voluntad. Pero Cohen considera que la reclusión de la ética en el foro interno de la consciencia, y su consiguiente fundamentación en la convicción (Gesinnung), abren el camino para el imperio de la religión en un ámbito de la consciencia cultural, que debería confiarse solamente al conocimiento científico del derecho. ${ }^{297}$

A fin de colocar sobre fundamentos firmes el vínculo íntimo que reclama para la ética y para el derecho, Cohen investiga el rol que juega la coacción en la realización de la autoconsciencia en el Estado. Si consigue mostrar la relevancia moral de la coacción legal, podrá superar entonces la división kantiana entre la ética y el derecho, y demostrar el carácter trascendental de la ética respecto del sistema jurídico. Veamos si cumple con su cometido.

Según Cohen, la función que cumple la coacción desde el punto de vista legal, no es la mera imposición arbitraria de la autoridad del Estado, sino más bien la garantía de la conciliación de las voluntades o los arbitrios del yo y del tú. ${ }^{298}$ Es decir, el derecho está allí para llevar a buen término los conflictos entre los ciudadanos, sobre determinados privilegios, recursos, etc. ${ }^{299}$ Sin la coacción, la ley que rige el derecho no puede ser aplicable y el Estado pierde toda realidad histórica, porque deja de ser una persona jurídica.

Pero el problema de la ética no es otro que el de la conciliación de la libertad del yo y del tú según leyes universales. ${ }^{300}$ Por esta razón, Cohen sostiene que el carácter coactivo del derecho, en vez de separar al derecho de la ética, los une íntimamente. La coacción no es otra

\footnotetext{
${ }^{295}$ Cfr. Winter, (1980), 253. Obvio es decir que esta particular interpretación de Cohen de la relación entre ética y derecho en Kant podría ser refutada y de hecho lo ha sido. Aunque no es mi objetivo entrar en cuestiones interpretativas de la filosofía práctica kantiana.

${ }^{296}$ Guariglia, (1992, a), 58.

${ }^{297} \mathrm{ErW}, 269$.

298 "¿Qué significado puede tener la coacción para el derecho? Para dar cuenta de esta reflexión no se toma en cuenta el éxito de la coacción; este éxito no es algo esperado. Se trata exclusivamente de la característica que de este modo debe recibir el concepto del derecho, para unificar la arbitrariedad de uno con la del otro. Se trata fundamentalmente también de mediar en el conflicto entre el uno y el otro." "Welche Bedeutung kann nun aber der Zwang für das Recht haben? Auf den Erfolg des Zwanges, um diesen Gedanken zunächst abzufertigen, ist es keineswegs abgesehen; der wird nicht erwartet. Es handelt sich lediglich um das Merkmal, welches der Begriff des Rechtes dadurch empfangen soll, um die Willkür des Einen mit der Willkür des Andern zu vereinigen. Es handelt sich also im Grunde nur um den Gegensatz des Einen und des Andern, der geschlichtet werden soll."; ErW, 269).

${ }^{299}$ Winter, (1980), 255.

${ }^{300}$ Aquí resuena el eco de la definición kantiana del derecho, en la Metafisica de las Costumbres, que reza: "Una acción es conforme a derecho (recht) cuando permite, o cuya máxima permite a la libertad del arbitrio de cada uno coexistir con la libertad de todos según una ley universal" "'Eine jede Handlung ist recht, die oder nach deren Maxime die Freiheit der Willkür eines jeden mit jedermanns Freiheit nach einem allgemeinen Gesetze zusammen bestehen kann") (AA, VI, 230). Cito por la trad. esp. de Adela Cortina Orts y Jesús Conill Sancho, en Kant, (1997), 39.
} 
cosa que la aplicación consecuente de la ley, que ha sido promulgada por los mismos sujetos a los que es aplicada. ${ }^{301}$ Por eso Cohen rechaza la teoría de los imperativos de Bierling, según la cual la ley tiene la forma de una prescripción impuesta por el legislador al pueblo, que podría formularse como la oración "yo quiero, tu debes". En realidad la autoconsciencia del Estado nos señala más bien que la legislación no es el producto de un grupo social particular, sino del "nosotros" que unifica al yo y al tú en una misma voluntad. ${ }^{302}$ Dicho de otro modo,

Y puede hacerse llegar a cada uno el llamado: tú debes; y no se debe para ello tomar por separado al yo del legislador. En el reconocimiento exigido se manifiesta una atribución para la prescripción. En la tarea de su autoconsciencia, podremos decir, yace el fundamento legal de la norma. ${ }^{303}$

Las teorías de Cohen y de Bierling coinciden en que las normas legales tienen la forma de un imperativo o de una prescripción. Por esta razón se apartan de la teoría de Zittelmann, quien considera que las normas legales son en realidad juicios descriptivos sobre el funcionamiento de las instituciones. Es decir, Zittelmann entiende a las normas legales no ya como enunciados prescriptivos, sino más bien de tipo indicativo. Sin embargo, objeta Cohen, las normas legales exigen el cumplimiento de determinadas conductas, que son los efectos legales que se espera que ocurran. ${ }^{304}$

Es decir, dado que las normas legales son prescripciones que reclaman cumplimiento perentorio, están orientadas a la producción de determinadas consecuencias. Las leyes de la ciencia natural, en cambio, no acarrean otras acciones en términos de efectos, sino que más bien se limitan a explicar y describir cómo de ciertos fenómenos se siguen otros de acuerdo a regularidades. ${ }^{305}$ Zittelmann funda su teoría en un elemento común a las normas legales y las leyes naturales, que induce a una identificación de ambos tipos de legalidad. Se trata del concepto de la condición. El problema radica en que los dos tipos de leyes aparentemente no podrían distinguirse, porque ambos contienen en sí las condiciones de su aplicación.

Cohen sostiene que las leyes naturales están formuladas correctamente, cuando es posible identificar cada caso particular que cae bajo cada ley. Sólo de este modo puede llevarse a cabo una explicación nomológico-deductiva, porque esta tarea consiste en la derivación del caso particular a partir de una ley y de ciertas condiciones iniciales. La norma

\footnotetext{
${ }^{301}$ Este punto de la teoría de Cohen tiene notables semejanzas con la teoría pura del derecho de Kant, como puede constatarse leyendo $M d S$, AA, VI, 335.

${ }^{302}$ Cfr. Winter, (1980), 365.

303 "Dann kann aber auch jedermann an sich selbst den ruf ergehen lassen: du sollst; und er braucht dazu nicht erst das Ich des Gesetzgebers hinzuzunehmen. In seiner Anerkennung, die erfordert wird, gibt sich eine Befugnis zur Verordnung kund. In der Aufgabe des Selbstbewusstseins, werden wir sagen dürfen, liegt der Rechtsgrund der Norm.“ (ErW, 271).

${ }^{304}$ Winter, (1980), 369.

${ }^{305} \operatorname{Er} W, 272$.
} 
legal también contiene en sí las condiciones que deben cumplir los casos particulares para quedar tipificados en la ley particular y por lo tanto garantizar su aplicación. Sin embargo, hay una diferencia substancial en las dos formas de razonamiento condicional.

Las normas legales se fundan sobre una serie de condiciones, que son las exigencias estipuladas por la constitución para regular la actividad de la legislación. Asimismo, las normas legales también establecen una serie de reglas para sancionar las transgresiones a la ley que están tipificadas en ellas. Las condiciones legales prescriben entonces la ejecución de ciertas acciones, tanto en lo relativo al cumplimiento cuanto a la transgresión de la ley.

La categoría de la condición confiere a las leyes del derecho su universalidad, esto es su aplicabilidad a todos los casos que tipifican, sin excepciones. La universalidad de la ley no resulta de su mera forma, con abstracción de su materia, sino que más bien se trata de un concepto modal. Es decir, la universalidad es “(...) un estadio en el camino de la investigación, el hallazgo, la formación, el desarrollo y la realización ampliada de la ley". 306

Por lo tanto, para determinar la universalidad de la ley, es de enorme importancia la cuestión de su aplicabilidad exhaustiva. De este modo, se vinculan indisolublemente la forma de la ley, es decir, su aptitud para ser aplicable a cada caso, con la materia, o sea el contenido que adquiere la ley en cada aplicación particular. Sin aplicabilidad no hay contenido, pero sin contenido tampoco hay aplicación y, por lo tanto, universalidad en sentido estricto.

Cohen rechaza de este modo la objeción de que la ley sería un mero formalismo, mostrando la relación dialéctica que existe entre forma y contenido, desde el punto de vista de la universalidad. ${ }^{307}$ Desde el punto de vista metodológico, la universalidad no puede ser pensada sin considerar al mismo tiempo el carácter necesario de la ley. Una característica conlleva la otra, porque la ley es aplicable a todos los casos en ella tipificados, siempre y cuando contenga en sí las indicaciones metodológicas para encontrarlos. Si la ley tipifica correctamente los casos que entran en su órbita, entonces es aplicable con necesidad lógica.

\footnotetext{
306 “(...) eine Stufe auf dem Wege der Forschung, der Findung und der Ausbildung und Ausdehnung und erweiterten Durchführung des Gesetzes.“ $(E r W, 275)$.

307 "A partir de esto resulta de nuevo comprensible que nadie puede darse por satisfecho con esta determinación de la ley a partir de la metodología de la forma, porque se extrañaría el contenido (que es en realidad una expresión incorrecta) en esta forma universal; mientras que con razón, como veremos, lo que se debería extrañar es la relación con el contenido y la transición en cierto modo de la forma en el contenido. No basta con decir, que el concepto de la ley exigiría la universalidad; sino que lo válido es enseñar expresamente que la universalidad tiene el sentido metodológico más preciso: el hacer deducible toda particularidad, que forma parte del problema que nos ocupa, a partir de sí misma. Este es el sentido modal de la universalidad." ("Daraus wird es aber wiederum verständlich, dass man mit dieser Bestimmung des Gesetzes aus der Methodik der Form heraus sich nicht zufrieden geben mochte, dass man in einem falschen Ausdruck des gefühlten Mangels den Inhalt in dieser allgemeinen Form vermisste; während man mit Recht, wie wir sehen wollen, den Zusammenhang mit dem Inhalt und den Übergang gleichsam der Form in den Inhalt vermissen durfte. Es genügt nicht zu sagen, dass der Begriff des Gesetzes die Allgemeinheit fordere; sondern es gilt ausdrücklich zu lehren, dass die Allgemeinheit den prägnanten methodischen Sinn hat: alle Einzelheit, die dem betreffenden Problema angehört, aus sich ableitbar zu machen. Das ist der modale Sinn der Allgemeinheit“; ErW, 276)
} 
Cohen define el procedimiento de aplicación de la ley como un razonamiento silogístico, cuya necesidad se funda en la corrección misma del argumento. Se trata de un silogismo cuya premisa mayor es la ley a aplicar, la menor es el caso particular que se considera y la conclusión es la aplicación misma, con ciertos matices sobre el carácter de la premisa inicial, pero con un eco del silogismo práctico aristotélico. La necesidad es la consumación y la certificación de la universalidad misma de la ley. Por eso, Cohen se niega a admitir que el derecho tenga lagunas, que impedirían su aplicación en determinados casos. En sus propias palabras:

La validez objetiva de esta universalidad de la norma se muestra en el principio fundamental del derecho, de que el juez no puede decir que la ley tendría una laguna, y que le impediría encontrar el derecho. Esta afirmación está prohibida para el juez; contradice el concepto de la norma legal, que el juez debe cumplir, administrar e interpretar. Él es juez y no legislador. La ley le ha sido dada; y la ley es universal. ${ }^{308}$

Es decir, el trabajo del juez en la aplicación de la ley no es otro que construir el silogismo deductivo que permita identificar el caso en cuestión, como un ejemplo más que está contenido en la norma. Este es el significado de la hermenéutica jurídica. De este modo se desarrollan las virtualidades inagotables que contempla la ley. Por esta razón, el juez no puede excusarse de la tarea hermenéutica y demostrativa a la que está obligado por su cargo, con el pretexto de que ninguna ley contempla el caso que le ha sido confiado, y que por lo tanto se trata de una laguna del sistema legal. ${ }^{309}$ La universalidad de la ley implica una necesidad apodíctica, porque consiste en una serie de instrucciones para la elaboración de los silogismos deductivos que permiten su aplicación. ${ }^{310}$

Otra diferencia importante entre las normas legales y las leyes naturales tiene que ver con el valor del tiempo como categoría modal. Se trata de la dimensión temporal de ambas formas de legalidad, pero de acuerdo con la peculiaridad y especificidad de su estructura lógica. El análisis de la estructura de las normas legales nos permite concluir que están referidas necesariamente al futuro, porque prescriben una serie de acciones a realizar, tanto para cumplir con ellas como para sancionar a quienes no lo hagan. ${ }^{311}$ Es decir, las normas legales están orientadas a producir determinadas consecuencias en el futuro. ${ }^{312}$

\footnotetext{
308 "Die tatsächliche Geltung dieser Allgemeinheit der Norm zeigt sich in dem Grundsatze des Rechts, dass der Richter nicht sagen darf, das Gesetz habe eine Lücke, und er könne das Recht nicht finden. Dieser Spruch ist der Richter versagt; er widerspricht dem Begriffe der Rechtsnorm, die er zu befolgen, zu verwalten und auszulegen hat. Er ist Richter und nicht Gesetzgeber. Das Gesetz ist ihm gegeben; und das Gesetz ist allgemein." (ErW, 277).

${ }^{309}$ Winter, (1980), 351, 382-384.

${ }^{310} \mathrm{ErW}, 278$.

${ }^{311}$ Dreyer, (1985), 124.

${ }^{312} \mathrm{ErW}, 279$.
} 
Si no se hace referencia a esta dimensión temporal, no puede siquiera hablarse con sentido de normas legales. Las leyes naturales, en cambio, son intemporales, porque explican la ocurrencia de fenómenos según regularidades que deben ser válidas para todo tiempo. En esto radica la universalidad y necesidad de las leyes naturales, a diferencia de la universalidad y la necesidad apodíctica de las normas legales que se ha analizado más arriba. De este modo, hemos retornado a la objeción de Zittelmann, basada en la consideración de las normas legales como una forma de las leyes naturales.

Desde el punto de vista de Cohen, una concepción de este tipo, implicaría la negación de la autoconsciencia, porque la voluntad del Estado no sería la expresión de una voluntad pura, resultado de la deliberación y la legislación de los representantes de todos los ciudadanos, según el procedimiento establecido en la constitución. Pero el carácter temporal de las normas legales -o sea su referencia interna al futuro- las diferencia claramente de las leyes naturales. Entonces, la ética también encuentra su justificación en la estructura lógica de las normas legales. ${ }^{313} \mathrm{Si}$ la ley es la tarea de la autoconsciencia, entonces pierde sentido la concepción psicologista y naturalista de la autoconsciencia del individuo, en tanto que sujeto de la moralidad. ${ }^{314}$

La orientación al futuro es la fuente del carácter progresista del socialismo y de la resistencia contra las tendencias políticamente reaccionarias presentes en todo Estado. Si el valor modal del futuro permite fundamentar la autoconsciencia universal, entonces también es determinante para la realización del carácter moral del Estado. De allí toma su fuerza la virtud de la valentía, que sostiene el optimismo en la lucha histórica por el establecimiento del Estado democrático de derecho. Este es el sentido de las siguientes afirmaciones de Schmid:

Frente a la realidad llena de sufrimiento el hombre está llamado a alcanzar el ideal con su trabajo y a no desesperar. El optimismo es la salida de la virtud de la valentía (...) Para el socialismo, la virtud política de la valentía significa ahora que no deben ser elegidos el camino de la revolución y de la mala utopía, sino más bien aquél de la reforma. La virtud de la valentía hace posible la creencia en la capacidad de reforma de la realidad llena de sufrimiento. Ella hace posible una visión optimista del mundo $y$ de este modo le abre al hombre la esperanza en un futuro mejor, es decir la esperanza en la realización del fin de la historia mundial, que es el Estado como el Estado de la humanidad. De este modo, la virtud de la valentía se convierte en una 'virtud de la historia mundial' (ErW, 558). ${ }^{315}$

\footnotetext{
${ }^{313} \operatorname{ErW}, 281$.

${ }^{314} \operatorname{ErW}, 282$.

315 “Angesichts der leidensvollen Realität ist der Mensch dazu angerufen, das Ideal zu erarbeiten und nicht zu verzweifeln. Der Optimismus ist der Ausfluss der Tugend der Tapferkeit (...). Für den Sozialismus bedeutet die politische Tugend der Tapferkeit nun, dass nicht der Weg der Revolution und der schlechten Utopie gewählt werden soll, sondern derjenige der Reformation. Die Tugend der Tapferkeit ermöglicht den Glauben an die Reformfähigkeit der leidensvollen Realität. Sie ermöglicht eine optimistische Weltsicht und eröffnet so dem Menschen die Hoffnung auf eine bessere Zukunft, d.h., die Hoffnung auf die Realisierung des Ziels der
} 
Weltgeschichte, des Staates als Staat der Menschheit. Dadurch wird die Tugend der Tapferkeit zur, Tugend der Weltgeschichte“ (ErW, 558)“, Schmid, 1993, 83-84). 


\section{EI Estado como garante de la libertad y la propiedad del individuo}

A diferencia de Cohen, Fichte no propuso una democracia deliberativa. Esto puede parecer sorprendente a primera vista, porque el principio del derecho tiene una estructura dialógica, como ya se dijo en el capítulo anterior. De esta relación legal podría derivarse la necesidad de que todos los miembros del Estado tomen parte en las decisiones que hacen a la vida común. Sin embargo, como se verá más adelante, Fichte exige que todos los ciudadanos le cedan su libertad y su propiedad a un tercero, para que pueda aplicar imparcialmente la ley y hacer respetar el derecho. Este cambio se debe, entre otros motivos, a la adopción del supuesto antropológico del egoísmo universal por parte de Fichte.

Pero puede señalarse además otro factor de una importancia determinante en la teoría fichteana del Estado. Se trata de la experiencia de la revolución francesa, que despertó en el joven Fichte la búsqueda de una sociedad donde se realizara la libertad del individuo. Para comprender el sentido que tienen para Fichte las ideas de la libertad, el gobierno representativo, o la soberanía popular, considero que es imprescindible rastrear cuáles son los aspectos de la revolución francesa que más influyeron en sus reflexiones tempranas sobre filosofía política.

\section{1. Los escritos de Fichte sobre la revolución francesa}

El primer artículo de la Declaración de los derechos del hombre y el ciudadano dice "los hombres nacen y permanecen como libres e iguales en sus derechos. Las distinciones sociales no pueden estar fundadas sino en la utilidad común" (les hommes naissent et demeurent libres et égaux en droits. Les distinctions sociales ne peuvent etre fondées que sur l'utilité commune). En esta declaración están presentes los principios que Fichte toma de la Ilustración para su filosofía del derecho:

1) El principio de que el hombre posee determinados derechos naturales ;

2) La idea de un contrato social; 
3) La equiparación del Estado con la Gemeinnutzen (utilité commune, utilidad común). ${ }^{316}$

El 2 de junio de 1793 los jacobinos subieron al poder y establecieron un gobierno revolucionario y democrático. Este hecho impactó profundamente a Fichte. Ya Benjamin Constant señaló con acierto que el sistema propuesto por Fichte en Der geschlossene Handelstaat tiene muchos puntos en común con la política de Robespierre. ${ }^{317}$ El núcleo de los planteos revolucionarios del joven Fichte es la afirmación de que "el hombre no puede ser heredado, vendido o regalado" ("Der Mensch kann weder ererbt, nocht verkauft, noch verschenkt werden”). Es decir, que el hombre es un fin en sí mismo. Por eso la autonomía y el progreso cultural del individuo, conculcados por el gobierno bárbaro del feudalismo, deben ser puestos en el centro de la vida estatal. ${ }^{318}$

De acuerdo con Robespierre, Fichte sostenía que hay un derecho a y un deber de hacer una revolución, porque los contratos y acuerdos del gobierno con la nobleza y la burguesía deben ser anulados de inmediato. En caso de que los grupos privilegiados optaran por la resistencia armada, Fichte consideraba legítimo tomar a su vez las armas contra ellos. Inclusive preveía la aplicación de la pena capital, porque los crímenes de la nobleza atentaban contra la humanidad misma del pueblo. ${ }^{319}$

En sus escritos sobre la revolución francesa, Fichte sostuvo que para cada sujeto sólo tiene carácter vinculante la norma que él puede darse a sí mismo. Por lo tanto, las decisiones del soberano (der Fürst) son vinculantes sólo si pueden ser acordadas por cada miembro de la comunidad política. Si el ciudadano no acuerda la ley dictada por el soberano, tiene derecho a dar el contrato social por anulado. ${ }^{320}$

También es de inspiración jacobina la tesis del GNR de que sólo el pueblo puede rebelarse, en tanto que el poder le pertenece originariamente. Por eso la constitución debe prever el derecho de revocación del poder de un gobierno injusto, que Fichte va a corporizar en el eforato, como se verá más adelante. Pero esta idea de Fichte delata también la influencia de los girondinos quienes, encabezados por Condorcet, proponían una constitución en la que estuviera protegido el derecho del pueblo a peticionar al gobierno que tome determinadas

\footnotetext{
${ }^{316}$ Hammacher, (2004), 183.

${ }^{317}$ Constant, (1919), pp. 52 ss. (Citado por Buhr, 1991, 10).

${ }^{318}$ Buhr, (1991), 20 - 25.

${ }^{319}$ Buhr, (1991), 25 - 32.

${ }^{320}$ Rametta, (2004), 230.
} 
medidas, y a litigar cuando sospeche que el accionar del gobierno atenta contra la constitución. $^{321}$

Pero los escritos fichteanos de 1793 y 1794 no sólo contienen una teoría de la revolución o de la desobediencia civil, sino que también delinean los rasgos fundamentales de un Estado justo. En estos textos, Fichte defendió el derecho inalienable de los ciudadanos a obedecer a su propia ley moral, y el derecho alienable a la acción externa (äussere Handlung), que sin embargo debe ser cedido libremente por el individuo en el acto del contrato social y no puede ser usurpado por la fuerza. ${ }^{322} \mathrm{El}$ contrato social consiste, en la primera teoría de Fichte, en la cesión libre de los derechos alienables de cada uno de los ciudadanos. Pero cada uno cede sus derechos sólo a condición de que los demás también lo hagan. Si un individuo no cumple con su contrato, la sociedad está autorizada a castigarlo. Al suscribir el contrato social, el ciudadano también acepta las penas previstas para los casos en que él no cumpla con sus cláusulas.

Pero esto no significa que Fichte proponga en estos escritos la idea de una democracia directa, porque la considera más problemática que ventajosa. Por el contrario, Fichte sostiene que el poder debe cederse a un ciudadano o al menos a un grupo de ellos. En este último caso, se denomina príncipe (Fürst), quien no recibe sus atribuciones por sucesión hereditaria, sino por transferencia de la sociedad. ${ }^{323}$ El príncipe es en realidad una máquina animada por la ley, porque no obedece a su voluntad particular, sino a la de la comunidad. Por lo tanto, para aplicar la ley con imparcialidad, debe cuidar de evitar los favoritismos. Fichte no aprueba que los nobles tengan acceso a los cargos públicos, porque sospecha que entonces gobernaría sólo su voluntad caprichosa y cambiante. ${ }^{324}$

Si bien no se opone a que un príncipe gobierne el Estado, esto no implica que abogue por la supresión de la libertad de expresión. Por el contrario, somete a crítica la afirmación de que la libertad de expresión sería perjudicial porque, en un Estado donde cada uno pudiera decir lo que desee, aquellos que no acuerden con las opiniones vertidas se sentirían heridos en sus convicciones. Contra esto, Fichte responde que aquellos que piensan diferente no tienen razón alguna para sentirse ofendidos, porque siempre pueden negarse a aceptar como válidas a las ideas que los demás expresan. ${ }^{325}$ Aún si estas opiniones encerraran verdades provechosas, nadie puede obligarnos a tomar lo que es mejor para nuestro desarrollo físico, intelectual y moral. Por ejemplo, no puede forzarse al vagabundo a tomar el pan que se le

\footnotetext{
${ }^{321}$ Buhr, (1991), 34 - 39.

${ }^{322} \mathrm{ZDF}$, SW, VI, 12-13; AA, I, 173-175.

${ }^{323} Z D F$, SW, VI, 13; AA, I, 174-175.

${ }^{324} B B U$; SW, VI, 243; AA, I, 369-370.

${ }^{325} \mathrm{ZDF}$, SW, VI, 15; AA, I, 176-177.
} 
ofrece. Del mismo modo, no puede obligarse a los individuos, a consecuencia del contrato social, a tomar ninguna verdad o pensamiento que se les ofrezca, aún cuando redunde en su beneficio espiritual o cultural.

Otro motivo para garantizar la libertad de expresión es que, dice Fichte, la comunicación de los pensamientos y consideraciones intelectuales y morales a los demás es indispensable para el desarrollo de la personalidad. Por lo tanto, la libertad de pensamiento y expresión es un derecho inalienable y no puede ser cedido en el contrato social. ${ }^{326} \mathrm{~A}$ diferencia de las tesis de posteriores de $G N R$, Fichte creía en sus escritos revolucionarios que la educación política de los ciudadanos puede ayudar a avanzar desde un Estado que puede ser concebido como una máquina, donde los ciudadanos obedecen a la ley a causa de las sanciones penales, hacia otra forma de organización estatal, en la que el ciudadano se gobierne a sí mismo por la legislación de su propia razón. ${ }^{327}$

Los escritos revolucionarios de juventud motivaron las investigaciones posteriores de Fichte sobre la idea de voluntad común de los ciudadanos en un Estado justo. No se trata de consideraciones meramente especulativas, porque están marcadas por el acontecimiento histórico de la revolución francesa, que dejó una huella profunda en el pensamiento de Fichte. ${ }^{328}$ Veamos en detalle las consecuencias que sacó de estas primeras reflexiones para su teoría más sistemática de la GNR.

\section{2. La necesidad del Estado en la teoría del GNR}

El primer elemento de los escritos revolucionarios que Fichte retoma en su GNR, es la idea del Estado como mediación indispensable para la protección y la realización de la libertad del individuo. Pero la libertad debe ser pensada en relación estrecha con la propiedad, como veremos en el capítulo 5 de este trabajo, que estará dedicado al derecho a la existencia en la teoría del GNR.

Fichte comienza su teoría del Estado a partir de una tarea que dejó abierta la deducción del principio del derecho, analizada en el capítulo anterior. Este problema puede ser formulado como sigue: "realizar un poder, por medio del que pueda ser impuesto, entre las

\footnotetext{
${ }^{326} Z D F, \mathrm{SW}, \mathrm{VI}, 15-17$; AA, I, 176-178.

${ }^{327}$ Rametta, (2004), 231.

${ }^{328}$ Pueden consultarse algunas cartas de Fichte, donde expresa su admiración por la Revolución Francesa (Buhr, 1991, 55 - 62). Es posible que haya habido alguna influencia de Babeuf sobre Fichte, dada la semejanza entre ambos planteos. Sin embargo, aún no se ha logrado una demostración concluyente de la hipótesis, que Marianne Weber defendió enérgicamente (Buhr, 1991, 39 - 42).
} 
personas que viven juntas, el derecho o aquello que todos necesariamente quieren. "329 Pero no se trata de una potencia ciega o mecánica, sino del resultado de la unificación de la potencia de los contrayentes, de acuerdo con su voluntad común de garantizarse recíprocamente la seguridad de su propiedad. ${ }^{330}$ El supuesto motivacional del derecho de coacción es el egoísmo o autointerés (Eigenliebe). Dicho de otra manera, se parte del hecho de que todas las personas buscan sólo la conservación de su propiedad, en una condición de egoísmo generalizado.

Fichte se ve obligado a recurrir a esta psicología moral, una vez que ha separado tajantemente el ámbito del derecho del de la moralidad, y ya no puede contar con que los contrayentes tienen una voluntad buena. Pero la coacción debe operar sobre la voluntad, determinándola a buscar la seguridad de la propiedad de los demás. Por lo tanto, el mecanismo coactivo actuará sobre la voluntad de modo tal que ésta quiera la seguridad de la libertad y propiedad de los demás, pero sólo en tanto que es un medio necesario para proteger y garantizar la propia.

De este modo, la voluntad de cada persona subordina su interés particular al interés general, sus metas individuales al objetivo común de garantizar la propiedad de todos. ${ }^{331}$ Así se llega a la constitución de una voluntad común a los contrayentes, a partir de su autointerés. Pero esta voluntad común debe tener un status diferente al de cada voluntad particular, porque no se puede aplicar sobre ella la misma coacción que se ejerce sobre las voluntades individuales. Mientras que cada voluntad debe ser coaccionada por medio del ejercicio de una potencia superior a ella, la voluntad común dispone de la mayor potencia posible en la comunidad legal, porque es el resultado de la unión de las potencias individuales. Por lo tanto, debería ejercerse sobre ella la potencia suprema, que es ella misma, lo que es imposible.

Otra razón que impediría pensar en una voluntad que se obligue a sí misma, es que en este caso ya estaría determinada de acuerdo al derecho, y no habría en realidad necesidad de coacción alguna. Basta pensar, por ejemplo, en un ladrón que se decidiera a coaccionar por sí mismo su propia voluntad de acuerdo con la ley; es obvio que no robaría y no sería un ladrón, lo que haría innecesaria la coacción misma. Por lo tanto, la voluntad común que resulta del acuerdo de las personas afectadas no puede ser objeto de coacción, sino que esta voluntad común puede ser sólo el sujeto que aplica esta coacción. En consecuencia, la unificación o síntesis entre el interés individual y el común, que es el objetivo del derecho de coacción, no

\footnotetext{
329 "Eine Macht zu realisiren, durch welche zwischen Personen, die bei einander leben, das Recht oder das, was sie nothwendig alle wollen, erzwungen werden könne" (GNR; § 16; SW, III, 150; AA, I, 3, 432).

${ }^{330}$ Hammacher, (2004), 187.

${ }^{331}$ Cfr. Batscha, (1970), 157
} 
puede ser el resultado de ningún mecanismo externo, sino que más bien deben estar dados desde el momento mismo en que esta voluntad común es constituida. El interés individual y el común deben estar identificados y unificados indisolublemente en esta voluntad colectiva. Cada individuo acuerda entonces subordinar su propio interés al de la comunidad legal, pero sólo si todos los demás lo hacen. En caso contrario, estaría poniendo en peligro su propiedad, lo que atentaría contra el derecho.

Pero no ha sido aún resuelto el problema de la realización efectiva de esta voluntad común en el mundo sensible, porque esto sólo es posible en una res publica. ${ }^{332}$ Fichte explica la constitución del Estado a partir del contrato de ciudadanía y de la legislación civil y penal. Las personas, reunidas en un determinado momento del tiempo, deberán declarar de cuáles objetos quieren apropiarse exclusivamente, y la parte de tierra en la que quieren vivir. Una vez que su declaración de propiedad haya sido reconocida por los demás, se habrá constituido el contrato de ciudadanía. Este acto establece una voluntad inalterable y permanente para todo el futuro de la comunidad legal. Sin esta voluntad, la comunidad pierde la estabilidad necesaria para mantenerse unida.

De allí la necesidad de la institución de la ley, que tiene dos momentos fundamentales: en primer lugar, se determina el alcance de los derechos de cada ciudadano (momento de la legislación civil). En un segundo momento, se establece el modo en que se castigará a quien haya violado los derechos establecidos en la legislación civil (momento del derecho penal). El derecho penal determina el monopolio de la fuerza por parte del Estado en la forma del derecho de juzgar (poder judicial), y de ejecutar este veredicto.

\section{3. La autoconservación de la voluntad común}

En principio parece ser suficiente con el derecho de coacción, para que la voluntad común se conserve a sí misma y tenga la estabilidad que la comunidad legal necesita. Por medio del derecho de coacción, cada persona subordina su voluntad particular a la voluntad común por miedo a perder la seguridad de su propiedad. Cada uno teme a la potencia común y unificada de todos, porque es mayor que la potencia propia. Por eso el equilibrio del derecho es mantenido a pesar del estado de incertidumbre en que se hallan las personas respecto de las intenciones de las demás. Cada una confía en el autointerés de las demás, y esto les permite

\footnotetext{
${ }^{332}$ Según Fichte nunca pudo haber existido el hombre en estado de naturaleza (Philonenko, 1997, 428), ya que el hombre se constituye como tal en el seno de una comunidad donde está siempre en relaciones de reconocimiento recíproco con los demás. Cfr. Lasson, (1863), 170; Philonenko, (1999), 64.
} 
proponerse fines y realizarlos en el mundo sensible. Pero todavía es necesario introducir una tercera condición de la estabilidad de la comunidad legal, que consiste en la delegación de la fuerza coactiva en un tercero, que aplique imparcialmente la ley. ${ }^{333}$

Veamos las razones de Fichte para afirmar que el derecho de coacción debe ser ejercido sólo por un tercero, que no sea ni delincuente ni víctima de un delito. Fichte parte de la premisa de que, cuando un individuo agrede a otro, se excluye a sí mismo de la voluntad común, porque ha desvinculado a su voluntad particular de los intereses de todos. Entonces el criminal debe sufrir la coacción sobre su voluntad, pero esto no significa que la coacción deba ser aplicada por la víctima del delito sobre su agresor. Si la víctima pudiera castigar a su agresor, entonces no habría garantía de que se respetará la ley, porque la víctima podría aplicar la coacción de modo indebido (movida por el resentimiento, el deseo de venganza, etc.), y la comunidad legal se hundiría en la desconfianza recíproca. Por lo tanto, es necesario que la potencia unificada de las personas esté en manos de un tercero, que pueda, por lo tanto, preservar el equilibrio del derecho.

Sin embargo, esta solución es problemática. El requisito fundamental para el éxito de este mecanismo es que la voluntad del tercero desginado para coaccionar no esté interesada o implicada en el conflicto. Pero, en el caso de que el tercero tuviera algún interés, este mecanismo no podría evitar que actúe parcialmente, y esta tercera persona podría aliarse con alguno de los litigantes contra el otro y fallar a su favor. O, peor aún, el tercero designado para aplicar la coacción podría aliarse con un grupo social para oprimir a otro. Esto provocaría la formación de una nueva voluntad, que sería común sólo a los miembros del grupo opresor, dado que los oprimidos no han consentido subordinar sus fines particulares a los de sus dominadores.

Esta voluntad opresora atentaría contra la ley y resultaría, paradójicamente, efectiva, porque sería más poderosa que la voluntad de los oprimidos. Pero esta situación no sería conveniente ni siquiera para los miembros del grupo opresor, dado que, al transgredir el principio del derecho, estarían poniendo en peligro la seguridad de la propiedad de todos, inclusive la de ellos mismos. Esto es, si la potencia unificada de todos en este tercero no aplicara la ley, aún cuando esto sucediera una sola vez, las personas estarían obligadas, por la ley de la coherencia consigo mismas, a defender su propiedad de los ataques de los demás y a abandonar el estado legal, por el estado de guerra o de desconfianza mutua. De este modo, cualquiera podría formar parte del grupo de los oprimidos tarde o temprano, y esta

\footnotetext{
${ }^{333}$ Cfr. Gueroult, (1974), 65.
} 
eventualidad por sí misma debería disuadir a los opresores de continuar con su comportamiento ilegal.

Ahora puede darse el paso final de la argumentación y responder a la pregunta por la autoconservación de la voluntad común a todos los individuos. La voluntad común será estable no sólo cuando la facultad de coaccionar la ejerza un tercero, sino cuando éste aplique la ley de modo permanente e infalible, todo el tiempo que exista la comunidad legal. ${ }^{334}$ La ley debe estar regida entonces por otra ley que determine el modo en que aquella debe aplicarse, y que prescriba que la ley se haga respetar con eficacia. Se trata de la ley fundamental o constitución, que debe reglamentar la actividad judicial, de modo tal que ningún ciudadano sea juzgado por una ley, si antes no lo han sido igualmente aquellos que también la han transgredido, siempre y cuando hayan sido denunciados o acusados.

\section{4. La forma de gobierno más justa}

Hasta ahora se ha demostrado que sólo bajo la condición de que la ley sea aplicada eficazmente por medio de un poder público, y de acuerdo con una constitución, puede garantizarse la propiedad de las personas. Sin embargo, queda abierto el problema de cuál es la constitución que mejor garantice este orden legal. Fichte rechaza de plano las formas de gobierno despóticas, entre ellas la democrática. La constitución despótica presenta el problema de que el depositario de la facultad de coaccionar no debe rendir cuentas de sus acciones de gobierno a ninguna instancia fiscalizadora. En las formas despóticas de gobierno el poder de coacción es abandonado a sí mismo, y esto hace imposible que aplique la ley con eficacia.

El despotismo acarrea la disolución del orden legal mismo, porque no permite juzgar las acciones de gobierno según una constitución. El gobernante no puede controlarse a sí mismo, porque si no sería juez y parte, y entonces se trataría de una voluntad privada y no de una voluntad pública. Por esta razón, Fichte defiende la institución del eforato, un cuerpo estatal encargado de fiscalizar la constitucionalidad de los actos de gobierno, según se verá más adelante.

Veamos cuáles son los argumentos con los que Fichte rechaza el tipo de constitución democrática, donde toda la comunidad ejerce el poder coactivo sobre cada criminal. En primer lugar, afirma que el riesgo de parcialidad y de negligencia en la aplicación de la ley no

\footnotetext{
${ }^{334}$ GNR; § 16; SW, III, 157; AA, I, 3, 437.
} 
puede ser evitado en un sistema democrático, porque no hay ninguna instancia de control suprema a la comunidad misma, que castigue los actos ilegales. Fichte apoya su argumentación con consideraciones de tipo consecuencialista, imaginando el escenario que podría producir un gobierno democrático. Si la comunidad no debe rendir cuentas de su acción a nadie más que a ella misma, hipotetiza Fichte, no podrá hacer respetar la ley sin interrupciones, lo que provocará una sensación de impunidad en los criminales. Esto los volverá cada vez más audaces en sus intentos de transgredir la ley.

Probablemente el crecimiento descontrolado de la criminalidad no podría ser contenido por la comunidad, quien necesitaría redoblar la violencia contra los criminales. Se produciría de este modo una escalada simétrica de violencia, que en algún momento forzaría a la comunidad a trasgredir la ley para poder frenar la criminalidad. Luego, atemorizado el pueblo por la represión descargada sobre él, podría quizás gozarse de una paz precaria, pero sin garantía alguna de que el caos no vuelva a apoderarse del Estado.

Tampoco se solucionaría este problema si la comunidad recurriese a un juez consultivo, para que la ponga en sobreaviso cuando se transgreda la ley. El problema que presenta la estrategia de introducir un juez consultivo para llamar al orden a la comunidad, es justamente el carácter consultivo y no ejecutivo de esta figura. Es decir que la comunidad mantendría de todos modos el poder de coacción en sus manos y simplemente podría optar por no seguir los consejos de este juez. Por lo tanto, la constitución democrática no estaría en condiciones de garantizar el derecho de coacción y no podría construir una comunidad regida por el principio del derecho. ${ }^{335}$ Esto implica que toda forma de gobierno que se ajuste al derecho debe ser representativa, esto es, debe ser el resultado del acto por el que la comunidad delega su poder en un solo hombre o en un grupo.

A fin de solucionar el problema del control de los actos de gobierno, Fichte aboga por la separación de dos poderes: el poder ejecutivo y el poder de inspección y control del poder ejecutivo, o eforato. ${ }^{336}$ Sin embargo, como puede verse, Fichte unifica los poderes ejecutivo, legislativo y judicial en la función ejecutiva en general, ya que considera innecesario el sistema de controles mutuos entre los tres poderes. ${ }^{337}$ Pueden distinguirse en GNR dos argumentos a favor de esta tesis.

\footnotetext{
${ }^{335}$ GNR; § 16; SW, III, 159; AA, I, 3, 439.

336 Para poder separar el derecho de la moral y darle autonomía, debemos suponer metodológica- e hiperbólicamente que los hombres pueden obrar de mala fe y ser infieles al derecho, por lo cual la voluntad general no podría ser juez de sí misma, ya que podría incurrir en error sobre lo que más conviene al bien común y lo que corresponde al derecho (Cfr. Renaut, 1986, 377).

${ }^{337}$ Dicho de otra manera, Fichte considera que el acto de gobernar es un acto indiviso (Cfr. Merle, 1991, 25).
} 
El primer argumento parte de la relación que existe entre la constitución y las leyes particulares, de acuerdo con la estructura del orden legal. Fichte escribe que, cuando una persona decide ser ciudadano de un Estado, se compromete a someterse a todas las leyes que en él rigen y que a futuro se promulgarán, porque en realidad se somete a la ley fundamental del Estado. ${ }^{338}$ Esta es su constitución, que prescribe que en el Estado debe reinar el derecho entre los ciudadanos, esto es, el mutuo respeto de la propiedad de cada uno, y que la ley debe ser aplicada infaliblemente por un poder ejecutivo constituido de tal o cual manera. Las demás leyes deben en realidad limitarse a aplicar esta ley fundamental y no son leyes en sentido estricto, sino más bien decretos. ${ }^{339}$ Por lo tanto, no hay ninguna razón para separar el poder legislativo, el ejecutivo y el judicial. ${ }^{340}$

El segundo argumento de Fichte consiste en un análisis de la relación que debe darse entre el poder ejecutivo y el judicial. Mientras que el juez determina el modo concreto en el que debe aplicarse la ley, el poder ejecutivo debe simplemente garantizar que esta orden del juez se cumpla. De allí deriva Fichte la necesidad de suprimir la división de poderes a fin de optimizar la aplicación del derecho, o sea de efectivizar la restricción de las libertades de cada ciudadano en función de la libertad de todos los demás. ${ }^{341}$ Podría trazarse una analogía entre esta relación y la que existe entre una fuerza física y la voluntad externa a ella, que la determina completamente. ${ }^{342}$

A pesar de la unificación de los tres poderes en el ejecutivo, el eforato debe funcionar con independencia del gobierno, porque es responsable de velar por la constitucionalidad de su administración. ${ }^{343}$ Una constitución garantiza el derecho sólo cuando cumple con estas tres condiciones: haber sido declarada y reconocida por la voluntad unificada de una comunidad, prever un mecanismo de representación del pueblo en un gobernante o en varios, y contener la institución del eforato. ${ }^{344}$ La comunidad delega toda su facultad de coaccionar en el poder

\footnotetext{
${ }^{338}$ Batscha, (1970), 159.

${ }^{339}$ A diferencia de los representantes del contractualismo clásico (Rousseau, Kant y Locke), no hay en Fichte una instancia por medio de la cual el pueblo elija a sus representantes en el poder legislativo y, de este modo, sea autolegislador a través de sus representantes. En este sentido, se trata en Fichte sobre todo de una expertocracia en lo que al poder legislativo respecta (Maus, 2001, 143 - 145).

${ }^{340}$ Lasson, (1863), 170.

${ }^{341}$ Oncina Coves, (2004), 214.

${ }^{342}$ Cfr. Renaut, (1986), 380.

${ }^{343}$ GNR; § 16; SW, III, 161; AA, I, 3, 441.

${ }^{344}$ Fichte recomienda para aquellos Estados en los que no ha sido introducido el eforato un gobierno hereditario, porque en tal caso el gobernante se cuidará de ser muy injusto con la comunidad, aunque sea por temor a la venganza de la misma contra sus descendientes.

"Cuando el eforato todavía no ha sido introducido, o no puede ser introducido porque la mayoría son todavía bárbaros, la representación hereditaria es la más adecuada, de modo tal que el detentador del poder que actúe de modo injusto, que no tema a Dios ni a ningún tribunal humano, tenga miedo aunque sea de la venganza, que se
} 
ejecutivo, pero retiene el poder de control de los actos de gobierno en el eforato. La voluntad común se expresa en primer lugar al delegar el poder ejecutivo en el gobernante, pero luego deja de ser una voluntad común y se somete a sus órdenes.

Sin embargo, la voluntad de los ciudadanos conserva el derecho de seguir expresándose luego de haber delegado la autoridad, no por medio del poder ejecutivo, porque justamente le ha transferido su poder de decisión, sino por medio del eforato. ${ }^{345}$ La ciencia del derecho natural puede establecer simplemente estas condiciones generales, que todo Estado debe cumplir para garantizar la legalidad, y no puede ir más allá. Por esta razón, Fichte no considera que el establecimiento de la mejor forma de gobierno sea un problema propio de la ciencia del derecho natural; se trata en realidad de un asunto de política empírica, que debe resolverse atendiendo a las características de cada Estado en particular.

Sin embargo, Fichte realiza una serie de sugerencias de orden político práctico, para facilitar la aplicación de su teoría. Por ejemplo, afirma que no es practicable una monarquía absoluta, ya que la tarea del gobierno es tan compleja que nunca podrá llevarla a cabo una persona sola. Por eso el poder ejecutivo debe estar siempre en manos de un grupo de administradores. Eventualmente puede aceptarse una monarquía de acuerdo al derecho, pero siempre y cuando los conflictos entre los administradores del gobierno, en torno a decisiones controvertidas, sean resueltos de manera inapelable por un presidente vitalicio, y no por el monarca. La otra constitución posible de acuerdo a derecho es la republicana, que prevé el gobierno de un cuerpo estructurado por una constitución.

Otro problema es el modo en que los gobernantes serán elegidos por el pueblo. De acuerdo con la teoría fichteana del contrato social, podría esperarse que Fichte sea un defensor del sufragio universal. Sin embargo, no lo admite necesariamente y sin restricciones; por el contrario, contempla casos en que los miembros del poder ejecutivo no sean elegidos directamente por la comunidad, sobre todo cuando esta es la única manera de proteger la propiedad de todos y de cada uno. Fichte acepta que recaiga sobre el pueblo tanto la elección

acumule a causa de sus delitos sobre su progenie quizás inocente, y que según las leyes de la naturaleza caerá sobre su cabeza."

"Wo das Ephorat noch nicht eingeführt ist, oder, weil die mehreren noch Barbaren sind, nicht eingeführt werden kann, ist sogar die erbliche Repräsentation die zweckmässigste, damit der ungerechte Gewalthaber, der Gott nicht scheuet und kein menschliches Gericht zu scheuen hat, wenigstens die Rache fürchte, die durch alle seine Vergehungen sich über seine vielleicht schuldlose Nachkommenschaft häuft, und dem nothwendigen Gange der Natur nach ganz sicher auf ihr Haupt fallen wird" (GNR; § 16; SW, 163; AA, I, 3, 442-443).

${ }^{345}$ Por eso Renaut considera que Fichte arriba a una síntesis republicana de tres momentos: un momento rousseauniano: el pueblo es el poder supremo y origen de todo poder, por lo cual afirmación de la soberanía de la voluntad general; un momento lockeano: la crítica de la democracia directa como una forma de despotismo y defensa de la democracia representativa; y un momento hobbesiano: la unidad de los poderes legislativo, ejecutivo y judicial (Renaut, 1986, 378 - 379). 
directa del cuerpo entero de gobierno (democracia pura), cuanto la elección de sólo una parte del poder ejecutivo (democracia mixta).

Pero también podría elegirse simplemente a algunos miembros del cuerpo de gobierno, los cuales funcionarían como electores y completarían a los demás miembros (aristocracia mixta) o los miembros del poder ejecutivo podrían elegir ellos mismos a todos sus sucesores (aristocracia pura). Fichte tampoco niega la legalidad de una aristocracia hereditaria, o de una aristocracia en la que el poder ejecutivo sea elegido por electores que hayan recibido sus atribuciones por herencia. ${ }^{346}$

De lo argumentado hasta aquí queda claro que Fichte está lejos de la idea que tiene Cohen de la ciudadanía como autolegislación, y del Estado como la tarea de la conformación de una voluntad común expresa en la actividad del Parlamento. La razón de esto reside en que Fichte no confiere autonomía al poder legislativo y, por lo tanto, no puede construir un espacio público de debate y de toma de decisiones, porque considera que los ciudadanos no pueden legislar de acuerdo con la constitución. Fichte supone que, si se deja a los ciudadanos a su libre arbitrio, entonces perseguirán implacablemente su autointerés y sabotearán la estabilidad de la comunidad legal, poniendo en peligro la propiedad y la libertad de todos los demás. Por lo tanto, la exigencia de imparcialidad en la legislación y la administración de justicia requiere que estas funciones sean la prerrogativa de un tercero, que no esté vinculado estrechamente con la vida del pueblo.

\section{5. La constitución}

La constitución debe ser inalterable y permanente, porque constituye el mecanismo de acuerdo con el que funciona todo el Estado, a fin de garantizar la vigencia del derecho. ${ }^{347}$ Por esta razón, debe aprobarse una reforma de la constitución sólo cuando hay una unanimidad absoluta. ${ }^{348}$ La unanimidad relativa es aquella en la que la minoría se adhiere a la mayoría, o en caso contrario debe abandonar el Estado. ${ }^{349}$ En el caso de una reforma constitucional, no puede obligarse a ningún ciudadano a que acepte una propuesta sólo porque un grupo de

\footnotetext{
${ }^{346}$ GNR; § 16; SW, III, 161-163; AA, I, 3, 441-442.

${ }^{347}$ Los ciudadanos no deben ser consultados cuando se incorporan al Estado respecto de si aceptan o no la constitución, ya que con el mero hecho de que viven dentro del Estado se da este asentimiento por supuesto (Maus, 2001, 154).

${ }^{348}$ GNR; $§ 16$; SW, III, 184; AA, I, 3, 458.

${ }^{349}$ Lasson, (1863), 172.
} 
conciudadanos estén de acuerdo, porque la importancia misma del asunto no permite este tipo de soluciones de compromiso.

Dentro de los límites establecidos por la constitución, la ley civil puede ser modificada al infinito, en razón de las circunstancias nuevas que así lo exijan (nuevos oficios o ramas industriales que aparezcan, etc.). ${ }^{350}$ Pero las personas que estén dispuestas a entrar en una comunidad legal no pueden aceptar de ninguna manera una constitución que transgreda el derecho natural (por ej., que no garantice la propiedad a todos los sujetos, etc.). Si reconocieran una constitución contraria al derecho natural, estarían aceptando que el principio del derecho sea transgredido en el mismo acto en el que buscan que este principio sea respetado, lo que atentaría contra la ley de la concordancia consigo mismo.

\section{6. El contrato de transferencia (Übertragunscontract)}

Si bien no puede coaccionarse a una comunidad para que adopte tal o cual constitución concreta, cada persona tiene derecho a obligar, a quien quiera entrar en una relación legal con ella, a prestar su consentimiento para la determinación de una constitución en general con arreglo a derecho. El útlimo fundamento de este derecho de coacción es, según el $\S 4$, la ley de la coherencia consigo mismo. Sin embargo, cada persona queda en libertad de acordar la constitución concreta que mejor le parezca.

Lo mismo ocurre con la elección de los representantes del poder ejecutivo. Cada persona tiene derecho a coaccionar a las demás para que elijan al candidato que quieran de entre una lista, pero no para que se decidan por éste o por aquél, porque esto no entra en las competencias del derecho natural. Tampoco los representantes elegidos por la comunidad pueden ser obligados a aceptar el cargo en cuestión, porque este cargo trae aparejado un lugar determinado en la distribución social de la propiedad. Pero la declaración de la cantidad de propiedad que cada persona desee para sus fines, así como el rol que ella quiera jugar en la división social del trabajo, queda librada a su decisión individual, porque constituye el contrato de ciudadanía mismo. Para un análisis detallado de esta cuestión, remito al último capítulo de este trabajo, dedicado al derecho a la existencia.

Ahora bien, los ciudadanos deben aclamar necesariamente por unanimidad relativa a sus representantes, porque en caso contrario serían obligados a poner su libertad y su propiedad en manos de alguien en quien no confían. Esto es, serían coaccionados a poner en peligro su propiedad, lo que sería un atentado contra el derecho originario y el principio

\footnotetext{
${ }^{350}$ GNR; § 16; SW, III, 185; AA, I, 3, 459.
} 
mismo del derecho. Fichte intenta mostrar que es posible lograr la unanimidad relativa en el reconocimiento de los representantes elegidos por el pueblo, imaginando el escenario que se daría si ellos ganaran la elección por mayoría y no por unanimidad relativa. Supongamos que no hay unanimidad relativa, entonces al menos debería haber una mayoría a favor de tales o cuales candidatos, porque en caso contrario se generaría un estado de anarquía y no podría reinar el derecho. ${ }^{351}$

La minoría que no quisiera reconocer a los representantes elegidos, se vería obligada a hacerlo, si quiere seguir viviendo en el territorio ocupado por este Estado. ${ }^{352}$ La razón de esto es que, si la minoría no acepta ser gobernada por los representantes elegidos por la mayoría, no está dispuesta a formar una comunidad legal y política con los demás. Dicho de otro modo, si no hay otra manera de elegir a los representantes del poder ejecutivo que por una unanimidad relativa, entonces, si se rechaza el resultado de la elección, se está empujando a la comunidad al camino de la anarquía y de la disolución. Pero nadie tiene la obligación de aceptar en el Estado a quien no esté interesado en formar una comunidad legal, que es el último fin del Estado. Por lo tanto, los ciudadanos que queden en minoría pueden ser coaccionados a aceptar la voluntad de la mayoría o abandonar el Estado. De este modo, se garantizaría el reconocimiento unánime de los representantes elegidos. ${ }^{353}$

Una vez que los representantes han sido elegidos o han asumido el poder según lo marca la constitución, puede realizarse el contrato de transferencia, por medio del cual la potencia unificada de los ciudadanos es transferida a los gobernantes. ${ }^{354}$ Se trata de un contrato con una cláusula especial, que consiste en que no puede ser rescindido unilateralmente ni por los gobernantes ni por la comunidad. La razón de esta cláusula es que, si se diera una interrupción arbitraria y no prevista del contrato de transferencia, entonces se interrumpiría la aplicación de la ley. Si la ley dejara de aplicarse, entonces cada ciudadano estaría autorizado para defender su libertad y su propiedad con todos los medios a su alcance. Con la interrupción de la legalidad, se disolvería inmediatamente la comunidad legal. El contrato de transferencia puede ser disuelto sólo como resultado del interdicto dictado por el eforato, y el juicio popular posterior al gobierno. Esto se tratará en detalle en el apartado sobre el eforato.

\footnotetext{
${ }^{351}$ La decisión por mayorías garantiza además la estabilidad del gobierno, porque los ciudadanos cooperarán con el gobierno que ellos mismos han elegido (Braun, 1991, 141 - 142).

${ }_{352}$ Braun destaca la territorialización de la ciudadanía en Fichte (Braun, 1991, 140).

${ }^{353}$ GNR; § 16; SW, III, 164-165; AA, I, 3, 443.

${ }^{354}$ El pueblo, como comunidad autodeterminada, deja de ser tal a consecuencia del contrato de transferencia. El poder ejecutivo, por su parte, deja de ser parte del pueblo, para no volver a pertenecer más a él. Si los miembros del poder ejecutivo son destituidos a consecuencia de un interdicto, les cabrá la pena de muerte, pero no volverán a ser parte de la comunidad (Cfr. GNR; § 16; SW, III, 177; AA, I, 3,453).
} 
Fichte recomienda que los gobernantes sean elegidos de modo vitalicio dado que, una vez que han sido elegidos para esos cargos, han sido apartados del pueblo y nunca podrán volver a fomar parte de él. Si los gobernantes pudieran volver a formar parte del pueblo luego de finalizado el ejercicio de sus funciones, entonces no estaría garantizada su imparcialidad en la aplicación de la ley. Dicho de otro modo: si los representantes supieran que más tarde formarán parte del pueblo, podrían aliarse con algunos ciudadanos y aplicar la ley parcialmente y en su favor, para garantizarse a su vez determinados privilegios o favores especiales luego de finalizado su ejercicio de la función pública. ${ }^{355}$

De este modo, los gobernantes serían juez y parte en los conflictos legales que deben resolver, lo que obstaculizaría la aplicación eficaz del derecho de coacción. ${ }^{356}$ Los gobernantes deben centralizar todo el poder de la comunidad en sus manos, menos el poder de fiscalización y control de su gestión. El contrato de transferencia les ha delegado el poder de dictar y aplicar la ley y, por lo tanto, de distribuir la propiedad y la libertad entre los ciudadanos, según el principio del derecho. Para garantizar la aplicación de la ley, los gobernantes deben evitar la más mínima excepción a la misma, y por esta razón disponen de todo el poder de policía y vigilancia de los ciudadanos. ${ }^{357}$

El contrato de transferencia debe incluir cláusulas relativas a los requisitos a cumplir por el poder ejecutivo, a fin de garantizar el imperio de la ley en el Estado. Estas condiciones están orientadas a coaccionar a la voluntad de los gobernantes, esto es, a determinarla de modo tal que sólo puedan alcanzar sus fines individuales si a la vez cuidan de los fines colectivos o del bien común. Estos requisitos son, en primer lugar, el dictado de las sentencias de modo tal que se juzgue la acción no según su contenido material, sino en relación a su concordancia con la mera forma de la ley. También deberá cuidarse que los administradores del poder ejecutivo reciban un ingreso lo suficientemente alto como para que sean inmunes a los sobornos. En vistas de la imparcialidad, debe controlarse que ellos tengan pocas amistades y pocos vínculos en general con el pueblo.

Otra condición importante es que la aplicación de la ley siga la sucesión temporal, esto es, que se resuelvan primero los casos más antiguos y luego los más recientes. En caso contrario, el trancurso de un lapso de tiempo excesivamente largo entre el delito y la sentencia

\footnotetext{
355 Este aspecto de la teoría de Fichte es claramente republicano, si bien no incluye la necesidad de la automodelación del carácter o de la virtud política, por su concepción estrecha y monológica de los móviles morales.

${ }^{356}$ GNR; § 16; SW, III, 180; AA, I, 3, 455.

${ }^{357}$ GNR; § 16; SW, III, 166; AA, I, 3, 444.
} 
puede dar lugar a una sensación de impunidad y quebrar la comunidad legal. ${ }^{358}$ Para evitar esto, debe fijarse un plazo para la resolución de los casos en proceso y cumplirlo escrupulosamente, ya que sólo de este modo los ciudadanos sabrán que se ha respetado el derecho, y no atentarán contra la comunidad legal. También los gobernantes deben ser coherentes en sus sentencias, fallando del mismo modo en los casos semejantes, ya que, si ellos se vieran obligados a contradecir sus propias sentencias previas para hacer justicia al caso presente, será obvio que han transgredido el derecho y entrará en peligro la estabilidad del orden legal. A fin de poder aplicar todos estos criterios sobre el proceder del poder ejecutivo, debe garantizarse la publicidad de todos los actos de gobierno, lo que a su vez permitiría fortalecer la confianza de los ciudadanos en el imperio de la ley.

\section{7. El eforato como poder negativo}

Una vez establecidas las condiciones que debe cumplir el poder ejecutivo para hacer prevalecer el derecho, resta conocer el mecanismo de coacción que se aplicará sobre los gobernantes cuando no cumplan con sus obligaciones. En la teoría de Fichte se trata de un problema complejo, dado que la facultad de coaccionar es propia del poder ejecutivo, quien detenta la suma de la potencia de los ciudadanos. Por esta razón, es imposible que cada ciudadano en privado tenga éxito al coaccionar al poder ejecutivo, dada la diferencia obvia de fuerzas. No se podría justificar, por otro lado, que el pueblo coaccione a los gobernantes para que cumplan con la constitución, porque se atentaría contra la comunidad legal misma y se destruirían las condiciones de la aplicación del derecho, al ponerse en cuestión la inapelabilidad de las sentencias del poder ejecutivo, que es la garantía de la aplicación eficaz del derecho.

Al menos tres violaciones claras de la constitución justifican, desde el punto de vista de Fichte, que los gobernantes sean sometidos a juicio político. Fichte se refiere a situaciones tales como que los gobernantes hayan postergado el dictado de una sentencia luego de transcurrido un lapso considerablemente largo de tiempo desde la acusación, que el poder

\footnotetext{
${ }^{358}$ Fichte admite, sin embargo, que este principio puede ser legítimamente dejado de lado, si la administración eficaz de la justicia así lo exige. Algunas causas son más fáciles de resolver que otras, por lo cual es recomendable muchas veces comenzar por ellas, en vez de hacerlo por las más antiguas, por razones de manejo racional del tiempo. "Luego de que se haya encontrado una institución judicial regular que esté ocupada permanentemente, quizás con muchos asuntos; muchas disputas legales deberían ser más fáciles de resolver que otras, y esto reside sobre todo en que no se pierda tiempo (...).”

"Nachdem jetzt eine regelmässige Justizeinrichtung getroffen, die stets, und vielleicht mit mehreren Dingen zugleich, beschäftigt ist; manche Rechtsstreitigkeiten leichter $\mathrm{zu}$ entscheiden seyn dürften, als andere, und überhaupt alles daran liegt, dass keine Zeit verloren gehe (...).“ (GNR; § 16; SW, III, 167; AA, I, 3, 445).
} 
ejecutivo se contradiga a sí mismo en sus sentencias, o que se vea obligado a cometer injusticias flagrantes (para no contradecirse en sus sentencias).

El pueblo, como tal, no puede llamar a una asamblea popular para enjuiciar y destituir al poder ejecutivo, en cuyas manos se ha entregado el poder. La razón de esto es que el pueblo desaparece como comunidad a consecuencia del contrato de transferencia y queda convertido en un simple agregado de individuos, a merced del poder centralizado en el gobierno. ${ }^{359}$ Pero no se ve cómo el pueblo podría constituirse otra vez y llamar a la asamblea popular. En realidad, el pueblo recién volvería a tener entidad en el acto de constitución de la asamblea, lo que implica que, al convocar a la asamblea, se estaría constituyendo como pueblo antes de constituirse como tal, lo cual es contradictorio. ${ }^{360}$

No sería de esperar que el poder ejecutivo llame a la asamblea popular para que lo someta a juicio, por dos razones. En primer lugar, si está convencido de que ha actuado con justicia, entonces no querría interrumpir y obstaculizar la administración del Estado, porque el llamado a la asamblea conlleva la suspensión de su facultad de coacción. De allí que podría justificar su renuencia a llamar a la asamblea popular en el mandato que ha recibido del pueblo, quien le ha ordenado ante todo que cuide de la aplicación constante del derecho y no la interrumpa jamás, para no poner en peligro la existencia de la comunidad.

En segundo lugar, si el poder ejecutivo fuera consciente de haber cometido una injusticia, querría escapar de toda sanción. Dado que que ya ha desvinculado su voluntad privada de la voluntad común, puede preverse con certeza que no llamará a la reunión de una asamblea popular soberana para que lo someta a juicio político. Por lo tanto, pareciera que no puede ejercerse coacción alguna sobre el poder ejecutivo, y que no se podría garantizar la determinación de su voluntad privada para conformarla con la voluntad común. Pero al mismo tiempo se impone necesariamente la implementación de un mecanismo coactivo sobre el gobierno.

La solución que Fichte propone para este problema puede sintetizarse como sigue: "el pueblo es declarado de antemano como comunidad por la constitución en un determinado caso. ${ }^{361}$ Esto es, la constitución deberá prever un mecanismo para constituir al pueblo en asamblea, pero sólo cuando la gestión del gobierno no cumpla con las condiciones ya mencionadas. No se trata de la reunión periódica de una asamblea popular, para controlar la

\footnotetext{
${ }^{359}$ GNR; § 16; SW, III, 177; AA, I, 3,452.

360 En la Grundlage des Naturrechts "comunidad" es idéntica a "sociedad". En otros textos tiene un carácter étnico, idéntico al de Nación. Un tercer significado es aquel grupo social que no ha sido educado ni es culto, que no pertenece a la clase de los Gelehrte (como en el Deduzierter Plan) (Batscha, 1970, 229).

361 "Das Volk wird durch die Constitution im voraus, auf einen bestimmten Fall, als Gemeine erklärt" (GNR; $\S$ 16; SW, III, 170; AA, I, 3, 447).
} 
rendición de cuentas del gobierno. Si el pueblo se reuniera periódicamente, el poder ejecutivo se vería obligado a retrasar la aplicación del derecho y se perdería en eficacia y en legalidad. Esta rendición de cuentas periódica dejaría el camino abierto a la acción de grupos intrigantes, que intentarían manipular la asamblea popular a favor de sus intereses particulares. La implementación misma de este mecanismo en un Estado de magnitud moderada sería imposible o sumamente difícil. Esta es la razón del principio enunciado por Fichte: "la comunidad no debe ser convocada sin necesidad; cuando haya necesidad, debe ser reunida inmediatamente y debe poder y querer hablar. ${ }^{, 362}$

La asamblea debe ser llamada de acuerdo con la constitución, pero el problema es quién podrá convocarla. No puede ser el pueblo, porque antes de la asamblea no puede constituirse como tal; ni tampoco el poder ejecutivo, porque, en tanto que acusado, sería juez y parte. Por lo tanto, debe facultarse por medio de la constitución a una institución especial para realizar este llamado, que ha sido denominada por Fichte como el eforato (Ephorat). ${ }^{363}$ El eforato no puede tener facultades ejecutivas, esto es, compartir las responsabilidades con el gobierno, porque dejaría de ser un organismo de contralor y fiscalización, lo que significa que sería juez y parte en el juicio político que debe llevar a cabo. ${ }^{364}$

El eforato no está facultado para someter a juicio al poder ejecutivo por sí mismo, ni para dictar sentencia en casos de reconocida importancia pública, o suspender tal o cual sentencia del poder ejecutivo. La razón de esto es que las sentencias del poder ejecutivo deben ser inapelables, a fin de que la ley sea aplicada permanentemente y con eficacia. ${ }^{365}$

A diferencia del poder ejecutivo, los éforos no necesitan ser separados del pueblo, dado que no deben juzgarlo, sino más bien controlar al gobierno en nombre del pueblo. Por lo tanto, su cargo no debe necesariamente ser vitalicio, y el eforato puede ser renovado

\footnotetext{
362 "Die Gemeine muss nie ohne Noth zusammengerufen werden; sobald es aber Noth thut, muss sie sogleich beisammen seyn, und sprechen können und wollen“ (GNR; § 16; SW, III, 170-171; AA, I, 3, 448).

${ }^{363}$ Fichte reconoce que el eforato podía encontrarse ya en Esparta, pero la institución más semejante al mismo son los tribunos populares de la república romana (nota al pie de GNR; § 16; SW, III, 171; AA, I, 3, 449) (Cfr. Batscha, 1970, 19).

En cuanto a la historia filosófico-política de la institución del eforato, recordemos que Aristóteles discutió la pertinencia de esta institución en el siguiente pasaje de su Política: "es más, incluso la institución del eforado está mal. Esta es su magistratura soberana en los asuntos más importantes, pero todos los éforos proceden del pueblo, de modo que muchas veces acceden al poder hombres muy pobres, que a causa de su indigencia son venales. Esto ya se vio muchas veces antes y hace poco en la cuestión de Andros, donde algunos, corrompidos por el dinero, hicieron cuanto dependía de ellos por destruir la ciudad. Por ser una autoridad con tan enorme importancia y de poder tiránico, hasta los reyes se veían forzados a tratarlos con demagógicos halagos, de forma que de esta manera se causaba la decadencia del régimen político, ya que de aristocracia pasaba a ser democrático" (Pol. 1270 b) (Cito por la traducción española en: Aristóteles, 1993, 94-95). Recuérdese, además, que según Aristóteles la democracia era el gobierno de los pobres, que por ser tales no eran capaces de virtud.

Esta institución espartana fue valorada por Calvino (en su Insitution chrétienne) como una instancia que permitió luchar contra los excesos del despotismo. En la Politica de Althusius, el eforato juega un papel importante en orden a mantener el pacto entre el príncipe y el pueblo (Cfr. Renaut, 1986, 382; Maus, 2001, 151).

${ }^{364}$ Cfr. Braun, (1991), 143.

${ }^{365}$ GNR; § 16; SW, III, 171; AA, I, 3, 449.
} 
periódicamente. Cada eforo deberá fiscalizar al éforo saliente y, si encuentra que ha cometido alguna falta que todavía tiene consecuencias en el presente, debe denunciarlo ante la asamblea y proceder al juicio político. Si se lo hallara culpable del cargo presentado, sería condenado por alta traición. ${ }^{366}$ Dado que cada éforo deberá juzgar al saliente, no es razonable que esté facultado para elegirlo, pero tampoco es lógico que lo designe el poder ejecutivo, que deberá ser controlado y juzgado por el nuevo éforo.

Lo más razonable sería que los éforos fueran elegidos por el pueblo, toda vez que representan su voluntad, en tanto que fiscalizadores del gobierno. En tanto que representantes del pueblo, no es razonable que ellos mismos se propongan como candidatos. Lo más recomendable, desde el punto de vista de Fichte, es que el pueblo elija a aquellos cuya sabiduría y prudencia despierten espontáneamente su confianza. ${ }^{367}$ De todos modos, no queda claro en el GNR el modo en que serán elegidos los éforos, dado que Fichte desplaza esta cuestión del ámbito legal y la deja en manos de la política empírica. ${ }^{368}$

Lo que sí queda fuera de toda duda en esta teoría es que el poder del eforato no será ejecutivo, sino más bien prohibitivo. Por medio de la figura del eforato, Fichte introduce un poder absolutamente negativo frente a otro absolutamente positivo (correspondiente al poder ejecutivo). ${ }^{369}$ Dicho de otro modo: los éforos no tienen ningún poder de coerción sobre el gobierno, lo que implica que la fuente de su poder debe provenir de otro lado. ${ }^{370}$ Fichte encuentra el fundamento del poder de los éforos en su capacidad misma para detener el funcionamiento de todo el orden legal por medio de la declaración del interdicto. ${ }^{371}$

\section{8. El ejercicio de la soberanía popular}

La teoría de Fichte ha mostrado hasta aquí ser muy diferente de la democracia deliberativa de Cohen. Mientras que Fichte sostiene que el pueblo debe entregar toda su

\footnotetext{
${ }^{366}$ Es razonable otorgar inclusive distinciones vitalicias a los éforos luego de su salida (GNR; § 16; SW, III, 181; AA, I, 3, 456).

367 "No debe detenerse al eforato, sobre el cual recae el ojo y la confianza del pueblo, quien, justamente en vistas de esta voluntad sublime, se fija continuamente en sus hombres más conservadores y grandiosos, éstos mismos deben ser un éforo."

"Man darf um das Ephorat nicht anhalten; auf wen das Auge und das Zutrauen des Volks fällt, welches, gerade um dieser erhabenen Wahl willen, auf seine biederen und grossen Männer fortgehend aufmerken wird, derselbe wird Ephor“ (GNR; § 16; SW, III, 181; AA, I, 3, 456).

${ }^{368}$ Cfr. Oncina Coves, (2004), 216.

${ }^{369}$ Verweyen, (1975), 135.

${ }^{370}$ Cfr. Vincenti, (1997), 258.

${ }^{371}$ Dicho de otra manera, el eforato es un contra-poder del tipo de un consejo constitucional (Philonenko, 1984, 42).
} 
libertad a un tercero para que mantenga el orden en la comunidad, Cohen considera que cada ciudadano debe ser tratado por el Estado como un fin en sí mismo, o sea que deben garantizarse las condiciones para que pueda participar en la actividad legislativa del Parlamento y de las diferentes instituciones sociales (entre ellas, las cooperativas). En la $\mathrm{ErW}$ la tarea de la autoconsciencia, que es la expresión de la voluntad común que hace posible la persona jurídica del Estado, es la unificación permanente de las voluntades individuales en la universalidad de la ley.

Pareciera que entre ambas teorías se yergue un abismo infranqueable, porque una niega toda participación al pueblo en la tarea del gobierno y la legislación, mientras que la otra se funda sobre el concepto de soberanía popular mismo. Pero en la teoría de Fichte hay un momento donde el pueblo parece emerger y apropiarse de la palabra, erigiéndose en juez del gobierno y del eforato, las dos instancias fundamentales en las que ha delegado su poder. Aquí parece quebrarse el aislamiento en que quedaron los ciudadanos luego del contrato de transferencia, y de su desaparición como pueblo. Veamos si la teoría fichteana de la soberanía popular se acerca un poco o se aleja de la democracia deliberativa de Cohen.

La interrupción del orden legal y la emergencia del pueblo en la vida pública tiene lugar ante todo luego de que el eforato ha declarado el interdicto. Se trata de un procedimiento previsto por la constitución, que consiste en la acusación pública al poder ejecutivo, del cargo de haber gobernado en contra de la constitución. ${ }^{372}$ El eforato tiene la obligación de denunciar las irregularidades que detecte en el funcionamiento del gobierno, y llamar a una asamblea popular para presentar los cargos, las pruebas y los alegatos contra el gobierno. ${ }^{373}$ Dado que el poder del gobierno resulta de una mera transferencia del poder del pueblo, sólo éste puede decidir si el poder ejecutivo ha violado el contrato de transferencia, y declarar nula la acusación si no lo ha hecho. ${ }^{374}$ Cuando el eforato suspende la legalidad del poder ejecutivo, todas las sentencias que dicte de allí en adelante pierden su validez y se vuelven subversivas contra la voluntad común, que ahora se expresará sólo por medio del eforato. ${ }^{375}$ De este modo, los ciudadanos no se ven ya más obligados a someterse a las sentencias y a la coacción del poder ejecutivo, porque ya no representa al derecho. ${ }^{376}$

\footnotetext{
${ }^{372}$ Aquí se inspira Fichte en el interdicto eclesiástico, que prevé la suspensión de las funciones de un cargo, a fin de asegurarse la obediencia que necesita (GNR; § 16; SW, III, 172; AA, I, 3, 449).

${ }^{373}$ Batscha, (1970), $170-171$.

${ }^{374}$ Maesschalk, (1996), 128 - 129.

${ }^{375}$ Vincenti, (1997), 257

${ }^{376}$ El eforato permite, de esta manera, la vigencia del principio de la soberanía popular (Renaut, 1986, 383):
} 
Una vez que las sentencias del poder ejecutivo han perdido toda legalidad, los gobernantes se verán obligados por el eforato y responderán a su orden de someterse al juicio político del pueblo. El poder ejecutivo no puede escapar de todos modos a los dictados del eforato porque, si se rebelara contra el interdicto, estaría inevitablemente condenándose a la pena de muerte. Pero, si se somete al interdicto, puede demostrar todavía en el juicio político su inocencia, esgrimiendo las pruebas y argumentos de que dispone.

Pero no puede descartarse que el poder ejecutivo intente corromper al eforato con bienes y privilegios; por eso, el eforato debe estar tan bien remunerado como el poder ejecutivo. Sin embargo, el eforato también puede ser coaccionado por el poder ejecutivo por las armas, de allí la necesidad de que la constitución también declare y garantice la inviolabilidad de las personas de los éforos, quienes deben ser protegidos como sacrosanti. ${ }^{377}$ Esto significa que el ataque a sus personas debe ser considerado como un delito de alta traición (Hochverrath).

El interdicto, entonces, tiene como fin inmediato la convocatoria a una asamblea popular. ${ }^{378}$ El pueblo concurrirá con seguridad, porque, si su derecho ha sido violado de modo flagrante, querrá hacer justicia y restablecer el derecho, a fin de conservar su propiedad y libertad. Fichte admite que la organización de la asamblea popular es una tarea compleja, porque resulta impracticable la idea de que todo el pueblo se reúna de hecho en el mismo lugar y exprese su veredicto respecto del litigio. ${ }^{379}$ Este es, sin embargo, un problema de la política práctica y no de la ciencia del derecho natural.

El derecho natural debe limitarse a mostrar la necesidad e inevitabilidad de un juicio popular en casos de interdicto. Sin embargo, en el concepto mismo de asamblea popular está contenida la exigencia de que el pueblo se reúna en lugares físicos concretos, y allí exprese su voto. ${ }^{380}$ Pero no queda claro de qué modo la asamblea popular será coaccionada para que se comporte de acuerdo con la voluntad común del derecho y no se haga prevalecer tal o cual voluntad privada. Si el pueblo es el juez del poder ejecutivo y del eforato, entonces no tendrá ninguna instancia ni poder superior a él mismo que determine su voluntad. ${ }^{381}$

Fichte responde a este problema recurriendo a su supuesto motivacional del egoísmo racional. Los ciudadanos, argumenta Fichte, querrán asegurar su propiedad y su libertad de acción, porque por ese motivo han firmado anteriormente el contrato de transferencia con los

\footnotetext{
${ }^{377}$ GNR; § 16; SW, III, 177; AA, I, 3, 453.

${ }^{378}$ Renaut, (1986), 385.

${ }^{379}$ En su Rechtslehre de 1812, Fichte pone en cuestión la capacidad del pueblo como totalidad para juzgar la justicia o injusticia de los actos de gobierno (SW, X, 632 ff.). Cfr. Braun, (1991), 146; Verweyen, (1975), nota al pie de la p. 138.

${ }^{380}$ GNR; § 16; SW, III, 173; AA, I, 3,450.

${ }^{381}$ El pueblo conserva de este modo su derecho original a la autodeterminación (Braun, 1991, 145).
} 
representantes en el poder ejecutivo. Pero, si juzgaran las acciones injustas, denunciadas por el eforato en el interdicto, como si fueran acciones justas, entonces luego de haberse restituido el poder a los gobernantes, deberán someterse a las sentencias injustas que se dicten de allí en adelante. Pero acordar esto es lo mismo que provocar la disolución de la comunidad legal, lo que ningún ciudadano quiere, toda vez que ya ha entrado en esta comunidad, y la ley de la concordancia consigo mismo prohíbe la contradicción entre las acciones de una misma persona. De ahí concluye Fichte que "ellos sin duda reflexionarán sobre este asunto con madurez, y se cuidarán de una sentencia injusta. „382

El pueblo atenderá entonces a los argumentos y pruebas del poder ejecutivo y del eforato. Luego decidirá si la acusación es fundada o no. Si lo es, el poder ejecutivo es declarado culpable de alta traición, ya que ha violado las cláusulas del contrato de transferencia y ha oprimido a los ciudadanos. ${ }^{383}$ Pero lo mismo ocurrirá con los éforos si su acusación es infundada, ya que han obstaculizado la aplicación de la ley y han puesto en peligro a la comunidad legal misma. No puede aducirse a su favor el hecho de que hayan actuado movidos por una recta intención y quizás en un exceso de celo por el derecho, ya que la mala voluntad es tan perjudicial para el funcionamiento estable de una comunidad legal como la negligencia, porque ambas ponen en peligro la propiedad de los ciudadanos del mismo modo. ${ }^{384}$

La condena por alta traición es necesaria también para coaccionar a los éforos, dado que los motivará a extremar los cuidados antes de declarar un interdicto, a advertir a los gobernantes de la acusación que podría pesar sobre ellos, etc. Las conversaciones e intimaciones previas al poder ejecutivo les permitirá revisar los fundamentos de su acusación, relevar más pruebas, etc. Pero el poder ejecutivo podría llegar a amenazar a los éforos con armas, para que desistan de sus propósitos. En ese caso, el pueblo seguramente saldrá en su defensa, porque los éforos son el portavoz de la voluntad común y del derecho. Debe prevenirse la eventualidad de que el poder ejecutivo se alce en armas contra el pueblo, para escapar del juicio político. Esta reacción podría significar el establecimiento de una tiranía o la reducción del pueblo a la esclavitud. Por esta razón, a fin de garantizar la aplicación del interdicto, Fichte defiende la formación de fuerzas populares, no sólo en las grandes ciudades,

\footnotetext{
382 "Sie werden sonach ohne Zweifel die Sache reiflich überlegen, und sich vor einem ungerechten Spruche hüten."(GNR; § 16; SW, III, 174; AA, I, 3,451).

${ }^{383}$ Verweyen, (1975), $136-137$.

${ }^{384}$ Para minimizar este peligro se debe tomar la siguiente precaución en la elección misma de los éforos: "Los más sabios de entre el pueblo deben ser elegidos como magistrados, y muy en particular deben ser elegidos como éforos aquellos hombres de edad más avanzada y que sean los más maduros".

"Die Weisesten unter dem Volke sollen zu Magistratspersonen, und ganz besonders alte, gereifte Männer zu Ephoren gewählt werden.“(GNR; § 16; SW, III, 175; AA, I, 3,451).
} 
sino también en las provincias. ${ }^{385}$ De este modo, el pueblo podrá protegerse de posibles abusos de sus representantes. ${ }^{386}$

Una vez constituida la asamblea soberana, debe preverse el mecanismo que se utilizará para la decisión colectiva. Dado que se trata de la determinación de un hecho, esto es, de si el gobierno ha actuado contra la constitución o no, cada ciudadano deberá responder meramente con un voto positivo o negativo. La gravedad de la decisión exige que el pueblo se expida por unanimidad. Pero esta condición no se cumple normalmente, y esperarlo en este caso sería poco razonable. De lo que se trata en realidad es del logro de una mayoría tan considerable (Fichte habla de siete octavos), que la minoría se encuentre en una desventaja manifiesta en la relación numérica. Si se debe contar siempre con una mayoría y no se puede esperar una unanimidad, entonces permanece abierto el problema de cómo lograr ésta a partir de aquella.

Fichte confía en que la mayoría se logrará con relativa facilidad, porque los ciudadanos son egoístas racionales y buscan asegurar su propiedad. Simplemente se les deberá preguntar si ellos aceptarían seguir siendo gobernados en adelante de la misma manera en que lo ha hecho el poder ejecutivo en el caso que se juzga. La mayoría, por lo tanto, considerará a la minoría que ha votado de modo diferente ya sea como falta de sentido común, o como reacia a determinar su voluntad privada por el bien común.

En primer lugar, dado que el fin supremo es preservar la comunidad legal, es aconsejable que los más inteligentes entre la mayoría intenten persuadir argumentativamente a la minoría, haciéndoles ver lo poco razonable de su posición. En el caso de que no cambien su voto, deberán abandonar el territorio, porque no están dispuestos a vivir según las leyes y la voluntad común. Dada la magnitud del riesgo que corren, los ciudadanos disidentes considerarán muy bien el asunto, y votarán en contra sólo cuando estén convencidos en consciencia de que un voto afirmativo atentaría contra la seguridad común y, de este modo, contra la propia. Una vez eliminado el disenso, ya sea por la integración a la opinión mayoritaria o por abandono del Estado, resultará necesariamente la unanimidad en el voto y podrá decidirse el litigio. ${ }^{387}$

Aún habiendo tomado todas las precauciones anteriores, puede ocurrir que los éforos se alíen con el poder ejecutivo para oprimir al pueblo. Fichte considera que es poco probable que se llegue a este extremo, porque esto sería posible sólo si todos los éforos estuvieran corruptos desde la asunción de su cargo. Fichte sostiene que, si todos los éforos son elegidos

\footnotetext{
${ }^{385}$ Verweyen considera insuficiente este recurso para asegurar la aplicación del interdicto, lo cual incrementa el riesgo de una guerra civil (Verweyen, 1975, 137 - 138).

${ }^{386}$ GNR; § 16; SW, III, 178; AA, I, 3, 453-454.

${ }^{387}$ GNR; § 16; SW, III, 179-180; AA, I, 3, 454-455.
} 
cuidadosamente por el pueblo, este difícilmente se equivocará, dado que debe tratarse de hombres de moral probada. Por lo tanto, lo más probable es que un eforato sumamente corrupto sea producto de la elección de un pueblo tan depravado como él, sobre quien recaería la responsabilidad de su propia elección. En este caso, el eforato no proclamaría el interdicto y, por supuesto, tampoco el poder ejecutivo lo haría.

Si el eforato fuera tan corrupto, entonces la comunidad misma se vería obligada a rebelarse contra el poder ejecutivo y, de esta manera, a dictar el interdicto. ${ }^{388}$ Pero la comunidad todavía no ha sido constituida en pueblo, puesto que no se ha llamado a la asamblea. Por eso se rebelarán individuos o grupos a título particular, quienes convocarán a la comunidad a sumarse a su acción. ${ }^{389}$ Pero esto conlleva un problema de suma gravedad, dado que por el momento rige el derecho presuntivo y la comunidad funciona suponiendo la legitimidad del poder ejecutivo. Se presupone que sus sentencias son justas y que responden a la voluntad común, por lo que toda rebelión contra el gobierno no es más que la expresión de una mera voluntad individual que no quiere determinarse por esta voluntad común.

Pero el pueblo es la fuente de todo poder, y por eso no podría rebelarse contra sí mismo, ya que querría un orden de cosas y a la vez no lo querría, lo que es contradictorio. Esto significa que el pueblo siempre estaría facultado a pedir cuentas al gobierno, a quien le ha transferido el poder. De allí que, si la injusticia reina en todos lados y la opresión se ha vuelto insoportable, no sea problemático que la comunidad misma se levante espontáneamente contra el poder ejecutivo y los éforos. Se trataría de una rebelión legítima, porque los ciudadanos deben velar por la seguridad de la propiedad de todos. De este modo, el derecho presuntivo caería por sí solo, y el pueblo dejaría de ser rebelde para recuperar el poder que le pertenece legítimamente.

Pero pareciera que, si una persona o grupo de personas se alzaran contra el poder ejecutivo, en razón de injusticias flagrantes, tendrían pocas razones para esperar un resultado exitoso. Fichte enfrenta este problema recurriendo de nuevo a su supuesto motivacional del egoísmo racional universal. Si el poder ejecutivo es evidentemente injusto, entonces pone en peligro permanentemente la seguridad de los ciudadanos. Pero estos le obedecerán sólo en la medida en que cumpla con el contrato de transferencia, y determinarán su voluntad según sus leyes sólo bajo la condición de que el gobierno represente la voluntad común de garantizar la seguridad de todos. Entonces, difícilmente el poder ejecutivo tenga la fuerza necesaria para

\footnotetext{
${ }^{388}$ En estos casos excepcionales se da el ejercicio de la soberanía popular, que para el contractualismo clásico es el elemento esencial del funcionamiento cotidiano del Estado (Maus, 2001, 153).

${ }^{389}$ Fichte desconfía en sus últimos escritos del poder regenerador de las revoluciones, porque normalmente están comandadas por líderes que sólo buscan hacerse con el poder (Cfr. SW, X, 633 ff.). (Cfr. el comentario de Verweyen, 1975, 139). Acerca del derecho de revolución en GNR, Cfr. Philonenko, (1997), 415.
} 
aplicar la coacción sobre los rebeldes, ya que lo más probable es que el pueblo le haya retirado antes su apoyo y su cooperación, y sin duda también se habrán alejado muchos de sus colaboradores más cercanos. Por lo tanto, los rebeldes seguramente podrán escapar de la coacción del poder ejecutivo, y su levantamiento será exitoso.

Ahora bien, todavía no queda claro el modo en que se resolverá la rebelión. Si la comunidad responde a la convocatoria de los rebeldes, se constituirá en asamblea soberana, a fin de escuchar los argumentos de los rebeldes y del poder ejecutivo, y dar un veredicto respecto de la acusación. Si la comunidad falla a favor de los rebeldes, entonces la voluntad de este grupo se verá confirmada en dos aspectos: en el material, esto es, el contenido de la acusación (que se ha cometido tal y tal injusticia, etc.), y en el aspecto formal o procedimental, gracias al veredicto de la comunidad, quien es la única que puede instaurar el derecho. ${ }^{390}$ En consecuencia, los rebeldes se convertirían en éforos naturales, legitimados por la comunidad misma. ${ }^{391} \mathrm{Si}$ la asamblea popular fallara en contra de su acusación, entonces serían condenados como meros rebeldes por alta traición, y el orden legal resultaría inmediatamente restablecido.

Si la comunidad no aprueba la rebelión de este grupo, esto puede deberse a dos razones: o bien a que la injusticia no es tan flagrante y grave como para justificar la interrupción del orden legal, y correr los riesgos que esta conlleva para la seguridad de la población. O bien puede ocurrir que la comunidad no esté lo suficientemente madura o esclarecida para hacer valer sus derechos y luchar por ellos. ${ }^{392}$ En este último caso, los rebeldes, a pesar de llevar toda la razón consigo, no son reconocidos como éforos naturales por su comunidad y se convierten en víctimas de su irracionalidad. Como dice Fichte, deben ser considerados más bien como mártires del derecho, que han cometido el único error de no conocer bien a su comunidad y actuar esperando una respuesta racional de su parte. ${ }^{393}$ De todos modos, una comunidad de este tipo no está en condiciones de constituir una comunidad legal, lo que la coloca fuera del ámbito de la ciencia del derecho natural, que supone esta condición como dada de antemano.

\section{9. Balance de la teoría fichteana de la soberanía popular}

\footnotetext{
${ }^{390}$ En realidad lo único que queda en la teoría de Fichte es la democracia carismática, en la cual los éforos naturales o rebeldes se arrogan la facultad de representar al pueblo. Los éforos naturales actúan materialmente de modo correcto, pero formalmente incorrecto (esto es, atentan contra la ley) (Cfr. Oncina Coves, 1997, 84).

${ }^{391}$ Cfr. Vincenti, (1997), $259-260$.

${ }^{392}$ Cfr. Renaut, (1986), 397 - 398.

${ }^{393}$ GNR; § 16; SW, III, 184; AA, I, 3, 458.
} 
La teoría fichteana del derecho de rebelión del pueblo es problemática, porque restringe la participación popular sólo a los estados de excepción. En primer lugar, el pueblo ejerce su soberanía en tanto que firma el contrato de sumisión y, en ese momento, renuncia al ejercicio cotidiano de la misma. Esto es, el pueblo delega todas las facultades de gobierno (aún la legislación) en el poder ejecutivo, y sólo retoma su soberanía en caso de necesidad, cuando los éforos declaren el interdicto y convoquen al pueblo para que haga de juez entre ellos y el soberano. Si los éforos traicionaran al pueblo, éste podría levantarse y seguir a los éforos naturales, a esos sujetos que se rebelan en nombre del pueblo, pero que no tienen status ni protección constitucional alguna.

El derecho de participación del pueblo, entonces, es el derecho del no derecho. Dicho de otro modo, la democracia deliberativa puede ser ejercida sólo en casos de necesidad extrema, lo que significa que está ausente del funcionamiento normal del Estado. Si los éforos naturales logran imponer su poder, serán vistos como los "sostenedores de la nación" ("Erhälter der Nation"), si no lo logran, serán los mártires y los rebeldes. Esto lo decide el mero juego de fuerzas entre ellos y la policía, o lo que es lo mismo, el destino ciego. ${ }^{394}$

De lo argumentado hasta aquí puede concluirse que Fichte permite sólo excepcionalmente el ejercicio de la soberanía popular, que no está incluida en el funcionamiento cotidiano del Estado justo. Las propuestas de Cohen y Fichte divergen entonces en su idea misma del Estado y del rol que debe jugar la ciudadanía en su estructura. En lo que sigue intentaré vincular esta diferencia con los diferentes conceptos de relación legal que cada uno sostiene, estudiados en el capítulo 2 de este trabajo.

\footnotetext{
${ }^{394}$ Cfr. Oncina Coves, (2004), 224 - 225.
} 


\section{Conclusiones del Capitulo 3}

De lo argumentado hasta aquí, se pueden constatar diferencias importantes entre la concepción del rol que debe cumplir la ciudadanía en la $\operatorname{Er} W$ y en el GNR. Estas diferencias se derivan de la estructura que tiene la relación legal en cada teoría. Como se dijo en el capítulo anterior, Cohen entiende a la relación legal como la integración de sus miembros en una unidad superior, que es la voluntad declarada y acordada por todos. Se trata del producto de la deliberación de todos y es idéntica a la persona jurídica, un sujeto legal de carácter ficticio. La persona jurídica representa los intereses de todos sus miembros, por eso Cohen la opone a la figura legal de la persona física, que hace referencia a los intereses del individuo particular, tomado aisladamente de su relación con los demás.

La persona jurídica necesita entonces de la participación de sus integrantes en la elaboración de sus reglas, en calidad de co-legisladores. De este modo, Cohen considera que podría aplicarse el imperativo categórico de Kant al funcionamiento de las instituciones, y por lo tanto, del Estado. La persona jurídica de la cooperativa es el modelo que sirve a Cohen de inspiración para construir su teoría del Estado. Esto no debe sorprendernos, dado que la persona jurídica tiene la estructura de toda relación legal y el Estado es el conjunto de todas las relaciones legales, así como de las condiciones de su producción. Por lo tanto, el Estado se funda sobre la actividad de co-legislación de los ciudadanos en el Parlamento, y en las diversas instituciones que gobiernan la vida social (entre ellas, las cooperativas).

Por el contrario, Fichte ha deducido la necesidad de una relación legal que garantice la relación de mutuo reconocimiento, que es a su vez la condición de posibilidad de la autoconsciencia del yo. Dicho de otro modo, Fichte arguye que es contradictorio que un yo reconozca al otro como un ser libre y a la vez le quite su esfera de acciones posibles. La razón de esto es que el reconocimiento es una práctica social, y presupone cierta coherencia entre la idea que se quiere comunicar por medio de la acción y la forma de la acción misma. La relación legal está orientada entonces al reconocimiento de la libertad del otro para que se constituya como autoconsciencia, es decir para que sea libre. Esto significa que la deducción de la relación legal está orientada al reconocimiento de la libertad del otro como un fin en sí mismo.

Pero luego Fichte advierte que no es posible garantizar la esfera de acciones libres del otro si no es en una organización política que haga realidad la voluntad común de hacer 
respetar el derecho. La razón de esto es que la comunidad legal no queda garantizada por la mera sumisión voluntaria de sus miembros al principio del derecho y a la ley de la coherencia consigo mismo. De allí la necesidad de introducir el derecho de coacción, para la eventualidad de que alguno de los miembros abandone su compromiso de cumplir con el principio del derecho. Pero el derecho de coacción presupone el egoísmo universal, porque está orientado a utilizar el autointerés de cada ciudadano para determinarlo en orden a la voluntad común. De este modo, cada ciudadano reconocerá en el otro la libertad no ya como un fin en sí mismo, sino más bien como un medio para proteger la propia esfera de acción. Pero no puede confiarse en que estos ciudadanos egoístas vayan a aplicar la ley con imparcialidad. Por eso es necesario que deleguen toda su libertad en un tercero, que unifique los poderes ejecutivo, legislativo y judicial en sí mismo.

Al final de la investigación de Fichte, desaparece aquella relación dialógica de la comunidad legal y queda sólo una multitud disgregada y sometida al arbitrio de un gobierno integrado por unos pocos. En realidad se trata de una consecuencia lógica de la estructura de aquella relación legal, cuya razón de ser era limitar las libertades de cada uno sus miembros en favor de una cantidad igual de libertad para los demás. De aquella relación legal no surgió ninguna voluntad común autónoma respecto de sus voluntades individuales, que exigiera su participación permanente en su conformación, porque su contenido ya estaba dado exhaustivamente desde el comienzo. Es decir, que el espacio público se convirtió en algo superfluo.

De este modo, hemos encontrado una diferencia fundamental entre las dos teorías del Estado, que se desprende de sus concepciones de la relación legal, y nos abre la pregunta de si no trae aparejadas aún otras diferencias importantes. Sin embargo, en el capítulo siguiente veremos que hay un elemento que permite trazar una analogía entre Cohen y Fichte: se trata del rol fundamental que la corporalidad del individuo juega en estas teorías. 
Capítulo 4: El rol de la corporalidad del individuo en la fundamentación del sistema legal 


\section{Capítulo 4: El rol de la corporalidad del individuo en la fundamentación del sistema legal}

La ética de Cohen y la teoría del derecho natural de Fichte contienen dos teorías diferentes del Estado, en las que la idea de la soberanía popular tiene un significado opuesto. Sin embargo, en ambas el "cuerpo" es la condición sine qua non del derecho y del Estado. En este capítulo intentaré mostrar en qué sentido esta idea es común a la $E r W$ y al GNR. En el capítulo siguiente examinaré las consecuencias que de ello se desprenden para la discusión en torno al derecho de los ciudadanos a la existencia. 


\section{La autoconservación como condición del derecho}

En la teoría de Cohen, el ciudadano adquiere realidad gracias a su corporalidad. Recién cuando el ciudadano está en condiciones de conservar su existencia por sí mismo, se convierte en un individuo de carne y hueso. La autoconsciencia es una subjetividad ficticia y universal que adquiere realidad solamente cuando los individuos concretos pueden actuar y participar de la actividad estatal. La idea de la autonomía en la forma de autoconservación es un punto central de la teoría, porque implica la entrada efectiva de los sujetos en la historia. Sin embargo, la idea de la autoconservación sólo tiene sentido si se la coloca en un plexo de relaciones con los demás aspectos de la autonomía. En lo que sigue reconstruiré el proceder argumentativo que sigue Cohen para fundamentar la corporalidad de los ciudadanos como una exigencia para la realización de su autonomía.

\section{1. La libertad como autonomía}

Una vez que Cohen ha demostrado que la autoconsciencia es la tarea de la voluntad pura en el Estado, queda por establecer qué reglas pautan las condiciones que debe cumplir la legislación y la aplicación de la ley, para realizar la autoconsciencia en el Estado. La actividad de la legislación presupone el ejercicio de ciertos derechos. Los ciudadanos, en tanto que legisladores, fundan todos sus derechos en el derecho a la libertad. Ésta se realiza bajo la forma de la autonomía, en sus cuatro aspectos: la autolegislación, la autodeterminación, la autorresponsabilidad y la autoconservación. Las reglas que debe seguir la legislación, para realizar la autoconsciencia, consisten en la puesta en práctica de la autonomía en sus cuatro formas. Dado que los ciudadanos sólo son autónomos cuando además son libres, es necesario en primer lugar explorar la idea misma de la libertad.

Ante todo, el concepto de la libertad debe ser pensado en relación con el ideal del Estado socialista, que Cohen fundamenta por medio de la deducción de la autoconsciencia. Sin embargo, no parece ser una tarea fácil, porque el socialismo ha sido entendido históricamente como una forma de materialismo. Es decir, como una respuesta a la Magenfrage (problema del estómago), al problema de la mera satisfacción de las necesidades 
biológicas del hombre. El materialismo histórico, desde el punto de vista de Cohen, supone que el hombre está condicionado por su entorno material y económico, de modo tal que el cambio de sus condiciones materiales es la única manera de mejorar la situación social y política de los trabajadores.

Contra el materialismo, Cohen afirma:

Puede comenzarse con el problema del estómago; pero el centro debe estar constituido desde el comienzo por el problema del espíritu; el problema de la libertad espiritual y, por lo tanto, moral. ${ }^{395}$

Dicho de otro modo, si el hombre es el producto de las relaciones económicas, en las que entra para transformar la naturaleza por medio del trabajo, entonces no tiene sentido mejorar su situación cultural. Contra el materialismo histórico, Cohen sostiene que no es posible fomentar el progreso moral de la humanidad por medio de la transformación de las relaciones económicas, porque en realidad la moralidad es producto de la consciencia cultural del derecho, y no se funda en el modo de producción vigente en cada sociedad.

Si esto último fuese verdadero, argumenta Cohen, entonces el derecho no tendría cientificidad alguna, toda vez que el sistema legal se funda en la persona jurídica del Estado, que se realiza gracias a la deliberación y al acuerdo permanente de los ciudadanos. Esto es, el derecho ya no sería producto de la acción de los hombres, que produce contenidos culturales y es, por lo tanto, una realidad humana autónoma. Por el contrario, el derecho sería una sublimación de procesos de índole económica. De este modo, junto con el concepto del derecho, caería el de acción y, en última instancia, la idea misma de autoconsciencia.

Si Marx convierte al hombre en un producto de su entorno, entonces le ha quitado la autoría de sus actos y la responsabilidad, por lo que resulta contradictorio su llamado a los obreros a transformar de la historia. "Cuando el socialismo de un Marx quiere, desde su puesto elevado de observación, volver influyente al poder coactivo de las relaciones materiales, se convierte de pronto en un satírico. ${ }^{396}$ De este modo, el materialismo supone que la idea moral de la libertad no sería realizable en la historia, porque no tendría poder alguno para mover a los hombres a actuar de acuerdo con su contenido. Por lo tanto, la fuerza motora del comportamiento humano sería de índole puramente material y quedaría despojada de todo contenido moral.

\footnotetext{
395 "Mit der Magenfrage soll man anfangen dürfen; aber das Zentrum muss von allem Anfang an die Frage des Geistes bilden; die Frage der geistigen, also der sittlichen Freiheit." $(E r W, 311)$.

396 "Wenn der Sozialismus eines Marx von seiner hohen geschichtlichen Warte aus die zwingende Macht der materiellen Verhältnisse eindringlich machen will, so wird er unversehens zum Satyriker.” ( $\mathrm{ErW}, 312)$.
} 
Cohen sostiene que el idealismo ha sido frecuentemente malinterpretado por el materialismo, dado que éste le ha atribuido una idea de la libertad que en realidad no le corresponde. De acuerdo con esta interpretación, la libertad no sería una idea moral, sino más bien una fuerza o un poder inteligible con repercusiones en el mundo fáctico, en el sentido de la causalidad por espontaneidad de Kant. Contra esto, Cohen aclara que la idea de la libertad como causalidad por espontaneidad es propia del espiritualismo, que defiende la existencia de una fuerza de orden inmaterial, que es la causa de cambios efectivos en la serie de procesos causales mecánicos de la naturaleza.

Este es el error que Cohen señala en el tratamiento kantiano del problema de la libertad. Kant ha fundamentado, desde el punto de vista de Cohen, la idea moral de la libertad en la legalidad del carácter inteligible de la persona moral. De este modo, la idea de la libertad deja de ser una regla para la acción y se convierte en la manifestación de la causalidad espontánea de la persona, que influye de este modo en los procesos causados mecánicamente en el mundo sensible. ${ }^{397}$ En última instancia, la idea del carácter inteligible no sería otra cosa que un residuo de la metafísica dogmática de la cosa en-sí.

Pero Kant ha rechazado explícitamente la psicología racional en los paralogismos de la razón pura. Cohen afirma que esta consecuencia se debe a una ambigüedad en su pensamiento. Al deslizarse inadvertidamente el concepto del homo noumenon, la idea de la libertad pierde su carácter puro y trascendental y queda atada al concepto de un yo dado de antemano a la acción. De este modo, la acción sería un mero desarrollo del homo noumenon. Pero entonces el nivel del ser y el del deber se confundirían, y con ello el ámbito de la lógica y el de la ética. De allí concluye Cohen que

La libertad no debe estar vinculada con el carácter. Aquí se muestra la repercusión negativa de la explicación errónea de la cosa en sí. El homo noumenon había sido fijado en una cierta cosidad. ${ }^{398}$

Pero Kant considera a la libertad no sólo en relación con el origen de la acción, sino también como la causa de la ley. Esto convierte al problema de la libertad en el problema de la autonomía. En la filosofía teórica se explica el origen absoluto de la acción por medio de la causalidad espontánea de la libertad. En la filosofía práctica, por otro lado, la libertad aparece tematizada en conexión con el problema de la ley moral. Cohen considera que el tratamiento

\footnotetext{
${ }^{397} \operatorname{ErW}, 317$.

398 "Die Freiheit darf nicht mit dem Charakter in Verbindung gebracht werden. Hier zeigt sich die ungünstige Nachwirkung der mangelhaften Klärung des Ding an sich. Im Charakter war der homo noumenon doch in einer gewissen Dinglichkeit festgehalten“ ( $E r W, 317)$.
} 
kantiano del problema de la libertad recién aquí gana en cientificidad, porque el problema de la legalidad es la cuestión capital de la ciencia, como ya se dijo en los capítulos anteriores.

La libertad se convierte entonces en la autonomía, entendida como la autolegislación. De acuerdo con lo visto en el capítulo 3, Cohen encuentra en las formulaciones del imperativo categórico la clave del socialismo ético, porque su principio fundamental es el tratamiento de la humanidad en cada ciudadano siempre como un fin en sí mismo, de allí la exigencia de la co-legislación en todas las instituciones.

Como se dijo en el capítulo 2, Cohen aplicó el imperativo categórico tanto al análisis de la estructura de la persona jurídica de la cooperativa, como a la crítica del capitalismo. Pero también lo aplicó a la persona jurídica del Estado, como una comunidad de legisladores. Por eso afirma enfáticamente Cohen: "Con estas palabras se ha expresado el sentido más profundo y poderoso del imperativo categórico; ellas contienen el programa moral del nuevo tiempo y todo el futuro de la historia mundial", 399

Cohen ha hecho el mismo movimiento que, de acuerdo con su interpretación, es característico de la ética de Kant. Se trata de un desplazamiento en el planteo del problema de la libertad, desde la búsqueda inicial de una causa absoluta del movimiento espontáneo, hasta la pregunta por el último objetivo de la acción humana, que es la humanidad como fin en sí mismo. De acuerdo con esto, la libertad es la meta de todas las acciones del Estado. Dicho de otro modo, la libertad es el contenido de la tarea de la autoconsciencia. Pero el concepto de la libertad sólo podrá determinarse luego de haber investigado el concepto de autonomía en sus cuatro dimensiones.

\section{2. La autonomía como autolegislación (Selbstgesetzgebung)}

La autoconsciencia se realiza por medio de la tarea de la legislación en el Parlamento, siempre y cuando la legislación cumpla con ciertos requisitos. En primer lugar, los ciudadanos deben autolegislarse, es decir, dictarse a sí mismos las leyes que se promulgan en el poder legislativo. En caso contrario, no se realizaría la autoconsciencia por medio de la voluntad estatal, porque faltarían las voluntades individuales que deben acordar las normas públicas.

Cohen recrea la oposición kantiana entre autonomía y heteronomía, a partir de los resultados de la investigación en la $L r E$. En este sentido, interpreta el concepto de heteronomía a partir de la categoría de la sensación, que tiene una función meramente

\footnotetext{
399 "In diesen Worten ist der tiefste und mächtigste Sinn des kategorischen Imperativs ausgesprochen; sie enthalten das sittliche Programm der neuen Zeit und aller Zukunft der Weltgeschichte" $(E r W, 320)$.
} 
metodológica. Se trata del juicio de la realidad efectiva, cuya aplicación supone que previamente el objeto de conocimiento ya ha sido constituido por el pensamiento.

Como se dijo en el capítulo 2 (con ocasión de la crítica de Cohen al concepto de comunidad), en la $\operatorname{LrE}$ la sensación no tiene ninguna función trascendental o constitutiva, sino más bien meramente instrumental. Cohen critica el concepto de comunidad, mostrando que supone el prejuicio de la particularidad. Es decir, que la idea de comunidad se funda en la creencia de que el conocimiento se origina en la sensación y no en el pensamiento. En este sentido, la heteronomía es análoga a la sensación. La heteronomía, en tanto que pone el origen de la acción en un objeto exterior a la voluntad y no en la fuerza creadora de la voluntad misma, tampoco puede ser justificada desde el punto de vista trascendental. Veamos la argumentación detenidamente.

Cohen sostiene en su $\operatorname{LrE}$ que los contenidos de la ciencia sólo pueden ser fundamentados en base a las leyes y categorías fundamentales de la ciencia misma, pero nunca a partir de objetos externos que estén dados de antemano a la actividad científica y la condicionen. En caso contrario, se trataría de una forma de dogmatismo. Análogamente, Cohen denomina a la heteronomía como patología, porque fundamenta la acción de la voluntad en el afecto, y no ya en la voluntad misma. Este aspecto de la heteronomía no puede ser rechazado de plano porque el afecto cumple un rol en la actividad de la voluntad, si bien subordinado a la fuerza creadora de esta última.

En analogía con el concepto de la sensación en la filosofía teórica, el afecto entra en juego sólo una vez que la voluntad se ha puesto el motivo de la acción, que es la tarea. De este modo, el afecto pasa a ser un mero motor de la acción. De allí su carácter meramente instrumental, aunque indispensable, análogo al carácter subsidiario de la sensación en la $\operatorname{LrE}$. De allí la afirmación de Cohen: "El afecto es un elemento de la voluntad, pero él mismo no es la voluntad". 400

El concepto de heteronomía tampoco permite responder al problema fundamental de la ética, que es el de la correlación entre el individuo y la universalidad. La heteronomía no puede superar el punto de vista del individuo aislado de los demás, porque se funda en la exigencia de satisfacer los deseos sensibles del sujeto. De este modo, no puede realizarse la autoconsciencia por medio de un concepto como el de la heteronomía, porque no puede fundar la legalidad universal que ésta requiere.

La heteronomía significa en última instancia la idolatría de la naturaleza, es decir, la creencia de que las fuerzas exteriores a la voluntad tienen más poder sobre ella que ella

\footnotetext{
400 "Der Affekt bildet ein Element des Willens; aber er ist nicht Wille" $(\mathrm{ErW}, 326)$.
} 
misma. Esto significa la sacralización de las relaciones sociales tal como se presentan, porque son consideradas como si fueran naturales. La heteronomía es entonces reaccionaria e impide la crítica y la transformación de las instituciones, porque no está en condiciones de proponer un criterio racional y trascendente a ellas. En este sentido, Cohen valora el trabajo pionero de Rousseau, quien separó a la historia de la naturaleza, y juzgó la inhumanidad e injusticia de la civilización y la técnica, tomando como herramienta al criterio de lo natural. ${ }^{401}$

Otra forma de heteronomía es aquella que parte de la relación metafísica entre el sujeto y el mundo. Este es el caso de la metafísica de Spinoza, donde la ley de la voluntad se deriva de la relación entre el espíritu humano y la substancia, de la cual aquél es un atributo. De este modo, este tipo de teorías le niegan al sujeto el carácter de principio de la legislación. De aquí deriva Cohen su crítica a la filosofía del derecho de Hegel, sobre todo en relación a su principio "lo que es real, es racional" ("was wirklich ist, das ist vernünftig"). Se trata también de la idolatrización de la historia. Por lo tanto, la realidad histórica pasa a ser el criterio de la razón moral. Pero esto es la negación misma de la moralidad, que no se funda en el ser sino en el deber ser. Por eso Cohen reformula el principio hegeliano de la siguiente manera: “(...) lo que es racional, no es real, sino que debe ser realizado”. ${ }^{402}$ Es decir, las instituciones del derecho positivo vigentes no deben dictar a la razón práctica los contenidos de sus juicios morales; por el contrario, la razón moral debe recuperar su trono perdido y enjuiciar con soberanía al status quo.

La teología también es otra forma de heteronomía, porque el fundamento de la ley tampoco es el sujeto sino más bien la voluntad de Dios, expresada por medio de su palabra. El punto de partida de la teología puede formularse como sigue: dado que Dios trasciende el pensamiento humano, su voluntad no puede ser demostrada ni fundamentada por la razón. El único camino que queda es el estudio de la revelación que Dios hizo de su pensamiento en los textos sagrados. Cuando Dios se ha manifestado por medio de la precisión de su pensamiento en palabras, la teología se ha convertido en la ciencia rectora de la ética.

Se trata de una actitud arrogante que ahoga la originalidad y espontaneidad del espíritu humano. Cohen la considera como una blasfemia contra la auténtica religión, que predica la inefabilidad de Dios. Esta forma de fundamentalismo aparece cuando la religión es reemplazada por la teología.

No se habría permitido nunca que quedara un resto de libertad religiosa de espíritu, que pudiera reconocer en esta pretensión a una forma de autotiranización; la gente se hubiera escandalizado ante la blasfemia que subyace a esto, dado que la teología no marcharía junto con la religión. Pero esto se retrotrae especialmente al mito. La

\footnotetext{
${ }^{401} \mathrm{ErW}, 329$.

402 “(...) was vernünftig ist, das ist nicht wirklich; sonder es soll wirklich werden.” (ErW, 331).
} 
revelación, la emanación, y todas las expresiones del autodesarrollo del absoluto, permanecen en el fondo como algo que no es para nada extraño ni escandaloso, porque se exige el autodesarrollo y la autorrepresentación del absoluto. (...) Pero el carácter compulsivo de la heteronomía no yace todavía en ello. Este surge por primera vez por medio de la precisión del pensamiento en palabras. La palabra de Dios se convierte en el documento del pensamiento de Dios. ${ }^{403}$

Por esta razón, en la heteronomía, bajo la forma de la teonomía, se desemboca siempre en alguna forma de fundamentalismo. Dado que los teólogos sostienen que la palabra de Dios debe ser coherente e inalterable, se ven obligados a forzar los textos sagrados, corrigiendo aquello que no encaje en su interpretación unilateral del mensaje divino. Cohen condena la teonomía como una forma de intolerancia, que acarrea graves consecuencias para la vida comunitaria. Por ejemplo, la religión suele ser una de las causas determinantes en la constitución de las literaturas nacionales, y por lo tanto de la cerrazón de los Estados sobre sí mismos, en una actitud de hostilidad creciente hacia el exterior.

Frente a la parcialidad del cultivo unilateral de la literatura nacional, Cohen rescata el desarrollo que ha tenido la ciencia de las literaturas comparadas a partir de Herder. El cultivo de esta disciplina ha abierto, constata Cohen, la mentalidad cerrada de los nacionalismos hacia un creciente multiculturalismo, y ha despertado la simpatía por los demás pueblos. ${ }^{404}$ Gracias a la literatura comparada se ha fomentado a su vez la ciencia de las religiones comparadas, que ha abierto las puertas al diálogo interreligioso. Cohen otorga mucha importancia a estos esfuerzos por desarrollar la tolerancia entre las diferentes culturas y religiones, porque la autoconsciencia es una comunidad espiritual que une a todos los ciudadanos por los lazos de las leyes universales promulgadas por ellos mismos. De lo argumentado hasta aquí, Cohen concluye que la religión, en su forma de nacionalismo, es un obstáculo insalvable para la realización de la autoconsciencia, porque resiente el imperio de la ley entre los ciudadanos.

Otra forma que adquiere la teonomía es el panteísmo, que Cohen encuentra ejemplarmente representado en Schiller. Se trata de la elevación de la voluntad por medio de la recepción de la divinidad en el interior del hombre. El camino para la elevación del alma es la educación estética, entendida como el desarrollo de deseos nobles. Sin embargo, no quedan claros en esta teoría los límites entre la divinidad y la humanidad, porque se funden en una

\footnotetext{
403 "Es wäre niemals der religiösen Freigeisterei überlassen geblieben, in dieser Anmassung die Selbstironisierung zu erkennen; man würde an der Blasphemie, die darin liegt, Anstoss genommen haben, wenn hier nicht die Theologie mit der Religion zusammenginge. Diese aber geht hier besonders auf den Mythos zurück. Offenbarung, Emanation und alle die Ausdrücke der Selbstentfaltung des Absoluten bleiben innerlich unbefremdlich und unanstössig; denn man fordert die Selbstentfaltung, die Selbstdarstellung des Absoluten. (...) Darin liegt in der Tat noch nicht der Zwang der Heteronomie. Dieser entsteht erst durch die Präzisierung des Denkens zum Worte. Das Wort Gottes wird zum Urkunde vom Denken Gottes“ (ErW, 333).

${ }^{404} \mathrm{ErW}, 334$.
} 
sola substancia; ni tampoco entre la humanidad y la animalidad, a causa de la ambigüedad del concepto de deseo que Schiller utiliza. De acuerdo con lo dicho en los capítulos anteriores, no puede fundamentarse la voluntad pura ni, por lo tanto, la autonomía, a partir del concepto del deseo, por noble que sea este deseo, porque se ataría de este modo la voluntad a un elemento dado de antemano y perdería en pureza trascendental.

La voluntad pura no es entonces la voluntad sublime que defiende Schiller. Pero también es necesario tomar recaudos respecto de otra forma de educación estética, que consiste en el desarrollo de la autonomía moral a partir del estudio de obras literarias. En esta propuesta pedagógica, se acentúa la importancia de aquellos textos literarios donde pueden encontrarse ejemplos de comportamientos moralmente edificantes. Cohen encuentra a la base de esta propuesta la idea socrática de que la virtud es aprendible, y por lo tanto es enseñable. El problema que plantea este tipo de educación moral a partir del arte es que no logra trascender el nivel de los ejemplos de comportamientos morales, y no llega nunca a considerar sistemáticamente el problema filosófico de la autonomía moral. ${ }^{405}$

Más bien, dice Cohen, esta propuesta consiste usualmente en una búsqueda vana de originalidad y novedad, que deja intactos los prejuicios del alumno y las contradicciones morales que afectan su vida cotidiana. Con otras palabras,

De este modo seríamos llevados por ella [la búsqueda de novedades] hacia el camino de la obstinación y la oscuridad, en orden a la elucubración de una ley moral solamente propia; o, en la medida en que esto fuera difícilmente realizable, a la conformación de algunas (leyes morales) antiguas en base a una nueva. En los ejemplos de nuestro tiempo puede verse justamente esta falsa originalidad, que conduce a una ética falsa, vacía e intimamente errada en cuanto a su contenido, porque contradice todas las líneas rectoras naturales e históricas de la moral. ${ }^{406}$

Esta idea de educación moral apunta al desarrollo de la convicción interior en el individuo, pero no toma en consideración la dimensión social de la subjetividad. Este es el problema que Cohen señala también en el pietismo, que lleva a una exaltación unilateral de la individualidad, a expensas de la vida común en el Estado. Se trata de la búsqueda de alguna forma de iluminación interior, que puede llegar a entrar en conflicto con los derechos y las exigencias de los demás ciudadanos. Pero la autolegislación es la realización de la autoconsciencia, como la comunidad espiritual de los ciudadanos en torno al imperio de la

\footnotetext{
${ }^{405}$ En este punto Cohen se hace eco del rechazo de Kant de la idea de la educación moral por medio de ejemplos $(M d S, \mathrm{AA}, \mathrm{VI}, 479-480)$.

406 "Dann würde man auf die Bahn des Eigensinns und des Dünkels durch sie geleitet werden, ein eigenes Sittengesetz sich auszutüfteln; oder aber, wofern dies doch eben schwerlich auszuführen ist, eines der vielen alten mit einem neuen, soweit es angeht, auszustatten. An Beispielen fehlt es gerade unserer Zeit am wenigsten für diese falsche Originalität, welche inhaltlich zu einer falschen, hohlen, innerlich unwahren, weil allen natürlichen und geschichtlichen Leitungslinien der Moral widersprechenden, angeblichen Ethik führt" $(\mathrm{ErW}$, $338)$.
} 
ley. Por lo tanto, es necesario despojarse de toda forma de individualismo que pueda estar latente en el concepto de la autonomía.

La idea de la autonomía como mero desarrollo de la individualidad, sin consideración para con la dimensión social del individuo, no puede ser sometida a crítica adecuadamente si antes no se considera un supuesto básico con el que opera. Se trata de la idea del yo como un objeto dado de antemano a la acción. Si se exige el desarrollo de la autonomía en términos de educación de las capacidades morales de un yo dado previamente, entonces la autonomía pierde su relación constitutiva con la voluntad pura, que exige el concepto de un sujeto puramente legal, y por lo tanto constituido sólo por la acción y en tanto que actúa. Es decir, que

El sí mismo de ningún modo está dado de antemano y ni en ninguna estructura tan ideal, antes de que se exponga, y no tiene sólo que exponerse; sino que tiene más bien que producirse. Y sólo puede producirse en la legislación. ${ }^{407}$

La autolegislación por medio de la actividad parlamentaria permite la superación de la perspectiva egoísta e individualista de la heteronomía fundada en el deseo, porque cada ciudadano construye de este modo la voluntad común que se expresa en la ley, y entra en la comunidad espiritual de la autoconsciencia. Así quedan excluidas del ámbito de la autonomía la apelación a Dios, la naturaleza o la historia como las fuentes profundas de la subjetividad. Si cada ciudadano no se autolegisla por medio de su participación en la actividad parlamentaria, no puede realizarse la autoconsciencia de la voluntad pura en el Estado; por lo tanto, tampoco puede fundamentarse la ética a partir del derecho. Pero la legislación es siempre una acción particular que tiene un contenido específico según cada caso. Por esta razón, Cohen agrega a la autolegislación el momento de la autodeterminación.

\section{3. La autonomía como autodeterminación (Selbstbestimmung)}

La autodeterminación es la exigencia de que los ciudadanos se autolegislen sin sufrir ningún tipo de coacción, ya sea externa, es decir por parte de otros ciudadanos o grupos de poder o el partido gobernante mismo, o interna, o sea proveniente de los propios afectos y prejuicios. La autodeterminación (Selbstbestimmung) se presenta como un concepto opuesto a la determinación (Bestimmung), que significa que el sujeto no puede generar la acción a partir

\footnotetext{
407 "Das Selbst ist keineswegs und in keiner noch so idealen Gestalt vorher vorhanden, bevor es sich darlegt, und es hat sich keineswegs nur darzulegen; sondern es hat sich erst zu erzeugen, Und es kann sich nur erzeugen in der Gesetzgebung." (ErW, 339).
} 
de sí mismo. El agente puede estar determinado por ciertas disposiciones afectivas o por el destino y la fatalidad. Por el contrario, la autodeterminación es una forma de la autonomía porque, a diferencia de la determinación, pone el destino en manos del sujeto que actúa. Dicho de otro modo, la autodeterminación convierte al hombre en dueño de su propia historia. $^{408}$

Si bien el concepto de autodeterminación está vinculado con el de autolegislación, no es compatible con la idea de un yo dado de antemano a la actividad de la legislación, que se desarrollaría y realizaría por medio de ella. La razón de esto es que, si el yo se diera de antemano a su actividad, como una substancia fija y permanente, entonces la actividad misma estaría condicionada por un elemento exterior a ella. Dicho de otro modo,

(...) debe tenerse por seguro que no existe ningún sí mismo como algo dado, ni en la consciencia moral ni en la religiosa; y asimismo tampoco en la jurídico-estatal; más bien hay por todos lados sólo principios que deben surgir y a los cuales debe estar unida; en los cuales se establece la tarea. ${ }^{409}$

En caso contrario, la voluntad del Estado dejaría de ser una voluntad jurídica, o sea una voluntad que surgiera a partir de sí misma o una voluntad trascendental. Cada ciudadano debe realizar la acción de autolegislarse únicamente a partir de sí mismo, de sus propias decisiones, intereses y apreciaciones.

Dado que la autonomía como autodeterminación está orientada a explicar la realización de la acción particular, plantea problemas metodológicos diferentes de los de la autonomía como autolegislación. La razón de esto radica en que la autolegislación hace referencia más bien a las condiciones formales de la legislación en el Estado. Por eso está en íntima relación con el concepto de autoconsciencia. Pero en la autodeterminación es el individuo particular quien pasa a primer plano, o sea el sujeto que realiza esta o aquella acción concreta. Esto exige la consideración de la categoría de la particularidad, propia de los juicios metodológicos de la $\operatorname{LrE}$. Cohen trata la cuestión de la particularidad en la acción a partir del concepto de la determinabilidad (Bestimmtheit).

La determinabilidad no es sólo la condición de la particularidad, sino que al mismo tiempo significa la precisión, la claridad y la seguridad que son los signos característicos, infalibles y seguros de la acción pura. Allí no permanece ninguna vacilación, de la cual pendiera la acción. Allí no permanece ninguna elección

\footnotetext{
${ }^{408} \mathrm{ErW}, 345$.

409 “(...) ist festzuhalten, dass es kein Selbst als ein vorhandenes gibt, weder im sittlichen, noch im religiösen Bewusstsein; und allerdings ebenso auch nicht im rechtlich-staatlichen; überall vielmehr sind es nur Ansätze, welche voraufgehen müssen, am welche angeknüpft werden muss; an welchen die Aufgabe einsetzt." (ErW, $351)$.
} 
inquieta; sino que la determinabilidad de la acción surge de la precisión de la elección. ${ }^{410}$

Dicho de otro modo, la determinabilidad de la acción depende de la claridad de la intención del agente. La intención es la anticipación del resultado de la acción en la consciencia individual del agente. Por lo tanto, la acción será realizada con más precisión cuanto mejor definido esté el concepto de la meta a lograr. Se trata del concepto de la tarea, o sea del motivo de la acción.

La particularidad es el contenido concreto de la acción de producir esta o aquella ley individual. Entonces la particularidad no puede desligarse del concepto de la autoconsciencia, porque el contenido de la acción de la legislación es siempre la realización de la voluntad pura en el Estado. Esta es la tarea de la voluntad pura, y es el último objetivo de la autodeterminación. De este modo, la autodeterminación logra una síntesis entre la particularidad de la acción realizada y la universalidad de la autoconsciencia. Este es el aporte de la autodeterminación a la autonomía de la voluntad pura. La autodeterminación dota de realidad por primera vez a la autoconsciencia, al producirla en el mundo sensible por medio de la acción concreta de la legislación.

La determinabilidad evita entonces que la acción y, por lo tanto la voluntad pura y la autoconsciencia, acaben siendo una pura ilusión. La apelación a la autodeterminación le permite a Cohen disipar el malentendido que ha sufrido el concepto kantiano de autonomía, interpretado frecuentemente como un formalismo vacío. Esta interpretación de la ética de Kant, se funda en la idea de que la autolegislación es la producción de una ley universal, pero ayuna de todo contenido particular. Cohen arguye en defensa de la ética kantiana, en el capítulo quinto de la $E r W$, que en realidad la ley universal no excluye los contenidos particulares de cada ley, sino que más bien los contiene en sí misma, como virtualidades que pueden deducirse de ella misma. El contenido particular es derivable de la ley universal por medio del silogismo deductivo (estudiado en el capítulo 3 de este trabajo), que aplica la ley a cada caso.

Pero la mediación entre la ley universal y el contenido particular no sólo es pertinente en orden a la aplicación de ley, sino también a la elaboración de la ley, que constituye el problema específico de la autonomía. A la hora de explicar el proceso de la legislación, Cohen recurre a otro tipo de mediación entre la universalidad y la particularidad, que consiste en la

\footnotetext{
410 "Die Bestimmtheit ist nicht nur die Bedingung der Einzelheit; sondern sie bedeutet zugleich die Präzision und die Klarheit und die Sicherheit, welche die Kennzeichen, die unfehlbaren und untrüglichen der reinen Handlung sind. Da bleibt kein Schwanken, in dem die Handlung hängen bliebe. Da bleibt keine bange Wahl; sondern aus der Präzision der Wahl geht die Bestimmtheit der Handlung hervor.“ (ErW, 346).
} 
relación entre la ley general establecida en la constitución, relativa al modo en que debe legislarse, y su mediación por las leyes concretas y particulares que son promulgadas por los legisladores en cada caso. Por eso dice Cohen,

La autodeterminación representa esta relación de la tarea del sí mismo con la tarea de la legislación en relación con la ley particular, y en relación con el desarrollo del sí mismo en la acción particular. Ella conduce a la libertad frente a la elección de la determinabilidad. En la determinabilidad se realiza el sí mismo. ${ }^{411}$

La autodeterminación implica que el sujeto realiza en cada acción un nuevo contenido, una nueva tarea. De este modo, queda garantizada la realización ininterrumpida de la autoconsciencia por medio de la autolegislación. La autoconsciencia no es otra cosa que esta actividad incesante de promulgación y aplicación de la ley. Es decir, que la autoconsciencia está condicionada por la actividad siempre concreta de la autonomía como autodeterminación.

El concepto de autodeterminación está en relación también con el concepto de causalidad. La determinabilidad de la acción es imposible sin el conocimiento causal de los medios que conducen a la realización del fin que el agente se ha propuesto llevar a cabo. Por lo tanto, la libertad como tarea a realizar necesita del conocimiento científico. El concepto jurídico de la acción supone necesariamente que el agente conoce el fin de su acción y los medios que conducen a este fin. Esta condición debe cumplirse necesariamente, por ejemplo, en la acción de celebrar un contrato, o en la comisión de algún delito, porque en caso contrario la acción no podrá ser imputable. Pero a pesar de que Cohen le otorga un lugar fundamental al pensamiento causal en la autodeterminación, rechaza el intelectualismo jurídico, que considera que el pensamiento causal es el elemento más importante de la acción.

Supongamos que alguien fuera imputado por haber accionado un aparato que produjo luego una explosión. Esta acusación tiene sentido sólo si el imputado tenía un conocimiento claro de la relación causal que existe entre la presión de la mano sobre el aparato y el desencadenamiento de la explosión.

Pero no es suficiente para imputar a un sujeto una explosión por medio de un aparato, con invocar el hecho de que haya conocido la relación causal que existe entre la presión sobre el aparato y la explosión, sino que además tiene que haber decidido llevarla a cabo. Esto es independiente de que él mismo haya provocado la explosión, o se lo haya encargado a otra persona, o lo haya delegado en un dispositivo mecánico. En los tres casos, su intención unifica a la acción, integrando el conocimiento causal de los medios para lograr el fin

\footnotetext{
411 "Diesen Zusammenhang der Aufgabe des Selbst mit der Aufgabe der Gesetzgebung in Bezug auf das einzelne Gesetz, und in Bezug auf die Entfaltung des Selbst in der einzelnen Handlung stellt die Selbstbestimmung dar. Sie führt die Freiheit vor die Wahl der Bestimmtheit. In der Bestimmtheit realisiert sich das Selbst.“ $(E r W, 348)$.
} 
propuesto con la toma de decisión y las acciones posteriores que culminan con el desencadenamiento final de la explosión. ${ }^{412}$

Pero la autodeterminación no es simplemente la condición de la acción individual, sino que además está referida necesariamente a los otros sujetos, toda vez que la acción legal supone la pluralidad de la comunidad estatal. Volviendo al ejemplo de la explosión, si el sujeto acciona el aparato con la finalidad de matar a otra persona, la consciencia de la víctima queda incluida de alguna manera en la consciencia del agente de la acción. La autodeterminación tiene lugar siempre en la esfera intersubjetiva que constituye la autoconsciencia. Por eso agrega Cohen,

Tampoco se querrá discutir a nivel psicológico que, en la intención de esta autodeterminación, el hombre que se busca matar por medio de la explosión, late junto con la propia consciencia; se oirá su respiración; se presentirá su grito de muerte. $^{413}$

Este fragmento de Cohen pone en primer plano la cuestión de la responsabilidad que tiene el delincuente por el sufrimiento de la víctima. Pero la autorresponsabilidad que debe asumir todo agente frente a los demás, cuando se autodetermina a la acción, nos conduce al tercer aspecto de la autonomía.

\section{4. La autonomía como autorresponsabilidad (Selbstverantwortung)}

La autodeterminación dejó abierta la cuestión de la autorresponsabilidad, es decir, la atribución del sujeto a sí mismo de la autoría de la acción legal. No se trata entonces simplemente de que el sujeto sea el autor fáctico de la acción de la autolegislación, sino además de que pueda reconocerse a sí mismo como tal. La cuestión de la autorresponsabilidad tiene diversos aspectos, según se considere su dimensión afectiva o cognitiva. Cohen dirige sus críticas en primer lugar contra quienes intentan explicar sólo en términos cognitivos aquellas situaciones en las que el agente se ve imposibilitado de actuar. Según esta posición, la causa de que el sujeto no pueda actuar reside en que ha deliberado durante demasiado tiempo antes de decidirse a llevar a cabo la acción y, por lo tanto, ha anulado la fuerza y el impulso espontáneo de la voluntad.

\footnotetext{
${ }^{412} \operatorname{ErW}, 354-355$.

413 “Auch psychologisch wird man es nicht bestreiten wollen, dass in dem Vorsatze dieser Selbstbestimmung der durch die Explosion zu tötende Mensch in dem eigenen Bewusstsein mitpulsiert; man wird seinen Atem hören; seinen Todesschrei vorausvernehmen." (ErW, 356).
} 
Contra esta hipótesis, Cohen argumenta que, si la deliberación es demasiado rápida y precipitada, puede ocurrir que el sujeto no haya podido madurar su decisión y también se vea imposibilitado de actuar. Aunque una deliberación rápida no necesariamente obstaculiza la acción, que muchas veces surge de una intuición rápida y acertada del agente. Pero Cohen encuentra problemas también en la tesis fundamental del intelectualismo, que consiste en que el afecto no juega ningún rol en el desencadenamiento de la acción, porque esta depende únicamente del conocimiento adecuado de las circunstancias que la rodean.

Es decir, el intelectualismo parte del supuesto de que, una vez que el sujeto disponga del conocimiento causal pertinente para la acción, será inevitable que el afecto coopere para su realización. Cohen argumenta contra el intelectualismo a partir de ejemplos en los que el afecto es demasiado débil para realizar el fin propuesto o tan fuerte que se desvía de los mandatos del pensamiento y sigue su propio camino. Sin embargo, el afecto suele cooperar con el pensamiento en la acción, salvo en excepciones ${ }^{414}$.

Cohen considera que también es necesario despejar la objeción escéptica de que el pensamiento causal no sería el producto de la acción libre del sujeto, sino que más bien sería él mismo el resultado de alguna fuerza mecánica, que obliga al sujeto a desarrollar el conocimiento científico. Si esta objeción estuviera en lo cierto, entonces no podría explicarse la acción en base al concurso del pensamiento causal, porque él mismo no sería producto de la autodeterminación del sujeto.

Si la precisión, la exactitud y la claridad del pensamiento causal son sólo una ilusión de la actividad propia, si fueran sólo la obra de un reloj de música en nosotros, entonces las fundamentaciones que crea la lógica a fin de asegurar su cuerpo doctrinal, serían en los hechos sólo intentos de esbozar y proyectar el fundamento objetivo incognoscible de su superestructura. ${ }^{415}$

Es decir, si el pensamiento causal no es producto de la acción libre del sujeto, pierden cientificidad tanto la lógica cuanto la ética, porque en realidad lo que es puesto en cuestión es la ciencia misma como producto cultural. Cohen se apoya en los resultados de su investigación en la $\operatorname{LrE}$ para rechazar de plano el escepticismo. Apela fundamentalmente a la tesis de que todo conocimiento tiene su origen en la espontaneidad originaria del pensamiento. Una vez que ha quedado fuera de duda la libertad del pensamiento causal, Cohen decide dar otro paso más y preguntarse por las consecuencias que acarrea esta

\footnotetext{
${ }^{414} \operatorname{ErW}, 359$.

415 "Wenn die Genauigkeit, die Gründlichkeit und die Klarheit des kausalen Denkens nur eine Illusion selbsteigener Tätigkeit, wenn sie vielmehr nur das Werk einer Spieluhr in uns wäre, dann wären die Grundlegungen, welche die Logik sich ausdenkt, um ihr Lehrgebäude zu sichern, in der Tat nur subjektive Nachversuche, das unerkennbare objektive Fundament aus seinem Überbau heraus zu zeichnen und abzubilden.“ $(E r W, 360)$.
} 
conclusión para la autodeterminación a la acción y, por lo tanto, para la autonomía como autorresponsabilidad.

Pero Cohen considera primero la cuestión de cómo debe formularse la pregunta acerca de la influencia de la libertad del pensamiento causal en la autodeterminación a la acción. En primer lugar, rechaza la formulación de la pregunta a partir de las acciones malas, es decir de las acciones que transgreden la ley. La pregunta debe ser formulada de modo positivo, porque debe investigarse el papel que juega la libertad del pensamiento en las acciones que dan lugar a la ley o que la ponen en cumplimiento. En realidad, la pregunta por la producción del mal es la pregunta por las excepciones a la ley, que no puede conducir nunca a la fundamentación de la legalidad jurídica y moral. ${ }^{416}$

De acuerdo con el análisis de Cohen, el pensamiento mítico ha tenido históricamente un interés especial en la explicación del origen del mal y ha contribuido mucho a desviar la correcta formulación del problema de la autorresponsabilidad. El pensamiento mítico es más propenso a las ideas conmovedoras que a la meditación serena de los grandes problemas teóricos. Por eso el pensamiento mítico no suele ser movilizado por el problema del bien, dado que el bien es lo natural, resulta del orden y el encadenamiento armónico del cosmos y de las acciones humanas. El mal, en cambio, es la irrupción del caos en el ordenamiento armónico y coherente del bien, una ruptura de la legalidad que funda la cultura y la vida humana. El surgimiento del mal pone al pensamiento mítico frente a la difícil pregunta de cómo a partir de este ordenamiento originario puede proceder el desorden y la ilegalidad.

El pensamiento mítico griego encontró la respuesta en el concepto del destino trágico. Se trata de la idea de la culpa, pero no de la culpa del pecador como individuo, sino más bien de la culpa heredada de padres a hijos. Dicho con más precisión, es la culpa que reciben todos los seres humanos cuando nacen por el mero hecho de pertenecer al mismo género. La tragedia griega echó alguna luz sobre este concepto ciego de la culpa, porque en ella el héroe se libera de la culpa al enfrentar al destino con su propia virtud. El espectador a su vez se libera también del miedo al destino por medio de la catarsis y accede a una comprensión de la realidad, en la que el individuo empieza de a poco a dibujarse sobre el trasfondo del determinismo natural.

Cohen ve a la segunda ruptura con el pensamiento mítico en el surgimiento de la religión monoteísta. Los textos sagrados del judaísmo ya reconocían dos formas de mal: una que no es responsabilidad del individuo, porque se trata de una culpa ontológica que causa inevitablemente el mal en el sujeto. Esta forma del mal moral es remediable sólo por medio de

\footnotetext{
${ }^{416} \operatorname{ErW}, 361$
} 
las ofrendas a Dios en el templo. Junto a esta noción está la concepción de una forma del mal que es producto de la debilidad humana, y por lo tanto debe ser juzgada por el juez en lo criminal. Se trata de un asunto puramente humano y está en manos del hombre el acabar con ella.

Puede verse que la religión recorre un camino inverso al de la poesía. La tragedia produce al individuo en el héroe, en el semidios; y ella produce y transfigura su culpa por medio de su sufrimiento heroico. En cambio, la religión produce al individuo en el alma humana y en sus pecados. Pero ella trae la redención en el conocimiento de la debilidad humana; la debilidad se convierte en el atributo de la moralidad humana. ${ }^{417}$

Pero recién con la aparición de la ciencia emerge en la historia humana la libertad del pensamiento, y se pone sobre el tapete la cuestión de la responsabilidad. En particular, es el derecho quien ha planteado con claridad científica este problema y ha liberado definitivamente al individuo de todo residuo de los conceptos míticos de la culpa y el destino. Dicho de otro modo, es el derecho quien puede plantear y tratar la pregunta por el rol del pensamiento en la autorresponsabilidad de un modo positivo y no ya negativo. El derecho retrotrae toda la cuestión de la responsabilidad al concepto de imputación $\mathrm{y}$, por su intermedio, al de autodeterminación.

La discusión en torno a los conceptos de dolo y culpa pone de relieve la complejidad de la acción legal y la interrelación del afecto y el conocimiento causal en la acción. Es decir, se trata de la cuestión relativa, por un lado, a si el sujeto se propuso cometer el crimen de modo consciente y de si tenía un conocimiento claro de las circunstancias conducentes a la realización de este fin. Si el sujeto se ha propuesto la meta de cometer el crimen, se puede hablar de dolo. Si el agente persigue otro fin y el crimen ocurre contra sus previsiones, entonces se trata de la categoría legal de la culpa. También puede hablarse de culpa cuando el sujeto no tenía un conocimiento claro de las circunstancias y creía que el crimen no tendría éxito, si bien se había propuesto llevarlo a cabo. Si la acción tuvo lugar a pesar de las estimaciones previas del sujeto, se trata de un caso de culpa consciente.

El dolo conlleva una imputación plena del crimen al delincuente, porque integra las tres dimensiones características de la acción jurídica: la intencionalidad del acto, el conocimiento claro de los medios para llevarlo a cabo, y finalmente la decisión y ejecución del mismo a causa de la fuerza motriz del afecto. Por eso Cohen se opuso al intelectualismo de Liszt, quien reduce la intencionalidad del criminal al conocimiento causal de las

\footnotetext{
417 "Man sieht, der Religion geht den umgekehrten Weg von dem der Poesie. Die Tragödie erzeugt das Individuum im Helden, im Halbgott; und sie erzeugt und verklärt seine Schuld durch sein heroisches Leiden. Die Religion dagegen erzeugt das Individuum in der Menschenseele und in deren Sünde. Aber sie bringt die Erlösung in der Erkenntnis der Menschenschwäche; die Schwachheit wird das Attribut der menschlichen Sittlichkeit.“ $(E r W, 366)$.
} 
circunstancias del crimen, dejando afuera la dimensión afectiva. Según Liszt, el juez entonces podría imputar al acusado sólo cuando ha podido comprobar que tenía una clara consciencia de los medios necesarios para realizar la acción.

Pero de este modo el derecho quedaría desconectado de la ética, y ya no tendría la finalidad de reformar moralmente al criminal e integrarlo de nuevo a la vida social y estatal. $^{418}$ El crimen consistiría entonces en un mero error del pensamiento causal; por lo tanto, la ética se diluiría en la lógica. Cohen rechaza de plano la estrategia argumentativa del intelectualismo, ante todo porque atenta contra la ley fundamental de la verdad, que exige la independencia y autonomía de los ámbitos de la lógica y la ética. De este modo, la acción moral sería idéntica a la acción de conocer la naturaleza, lo que choca contra las conclusiones de la investigación de Cohen en la $\operatorname{LrE}$.

Pero el intelectualismo jurídico acarrea también otra consecuencia decisiva, porque niega la cualidad moral misma del ciudadano. Al quitar toda relevancia al afecto para la producción de la acción, el agente queda desposeído de voluntad y en última instancia de toda capacidad de decisión libre. Se convertiría en una "máquina de pensar" (Denkmaschine), lo que significa la negación misma de la autonomía. ${ }^{419}$

Contra el punto de vista intelectualista, Cohen argumenta que la culpa tiene que ser pensada necesariamente como una forma de dolo. Dicho de otro modo, si el sujeto actuó a pesar de su ignorancia respecto de las consecuencias de la propia acción, su crimen debe ser catalogado como una forma de negligencia. La culpa es el resultado de una acción que debe ser explicada haciendo apelación no sólo al pensamiento, es decir a la ignorancia del agente, sino que debe incluir necesariamente también a la dimensión afectiva, porque el afecto es el motor de toda acción.

De todos modos, el criminal debe cargar con la responsabilidad, tanto en el caso de que haya realizado una acción dolosa cuanto una culposa. La pregunta por la responsabilidad, es decir, la cuestión de si el sujeto puede reconocerse a sí mismo o no como el autor de sus acciones, atraviesa y fundamenta todos los ámbitos de la cultura humana, porque la cultura es el producto de las acciones del hombre.

El veredicto del juez acerca de la culpabilidad del imputado no puede agotar todo el proceso de asunción de la propia responsabilidad, que debe recorrer el criminal mismo. La sentencia del Estado no puede reemplazar la imputación que cada criminal debe hacerse a sí mismo, porque en caso contrario el concepto mismo de autonomía carecería de sentido. Si el ciudadano no se hiciera responsable de su transgresión a la ley, entonces no se habría

\footnotetext{
${ }^{418} \mathrm{Er} W, 368$.

${ }^{419} \operatorname{ErW}, 369$.
} 
autolegislado y no habría participado en la actividad de la legislación parlamentaria por medio de sus representantes. La autoconsciencia, como el sujeto de la voluntad común de los ciudadanos, implica necesariamente la identificación del autor y el destinatario de la ley. Por lo tanto, cada ciudadano queda sujeto a la misma ley que ha acordado. En este sentido, el contrato es la forma de toda relación legal y el fundamento del Estado, como se argumentó en el capitulo 3 de este trabajo.

De este modo, la ética puede liberarse del resabio mítico de la culpa y el pecado original gracias al concepto de autonomía. Por lo tanto, la categoría de la autorresponsabilidad permite el desprendimiento absoluto de la ética respecto de la religión. De allí Cohen concluye que

El sí mismo se carga con la consciencia de la culpa porque reconoce que en caso contrario debería renunciar a sí mismo. Él no puede recurrir a los medios para interpretar a su infracción como una equivocación y, en virtud de esta interpretación, por medio de la ofrenda liberarse de esta consciencia de culpa. No puede tampoco ser reconocida como purificación moral, la liberación de la culpa por medio de la creencia en un Dios, que se ha ofrecido él mismo por mis pecados. Sólo puedo buscar y querer encontrar mi salvación en el juicio del conocimiento moral. Y no puedo dispensarme de este juicio del conocimiento moral por ningún medio del cielo o el infierno. En caso contrario, perdería mi punto medio y mi peso moral. ${ }^{420}$

Las teorías deterministas, que entienden a la criminalidad como una forma de enfermedad psicológica, son en realidad otra forma más de intelectualismo. El criminal, sin embargo, no debe abandonar la autorresponsabilidad bajo el pretexto de que ha cometido el crimen por causas que están fuera de su control, porque esto significaría el abandono de su humanidad. Más aún, la aceptación de esta forma de determinismo atenta contra el concepto mismo de Estado y de autolegislación, como ya se dijo más arriba. Por lo tanto, se trata en última instancia de una forma de suicidio moral. Este es el sentido de las afirmaciones siguientes de Cohen:

Y cuando la culpa se vuelve una ilusión, no ocurre menos con la virtud; porque el enfermo seguramente puede hacer el esfuerzo que es necesario para el trabajo de lentejuelas de la virtud; tal como puede medirse con hombres normales en el juego de la sagacidad y la gracia. ${ }^{421}$

\footnotetext{
420 "Das Selbst belastet sich mit dem Bewusstsein der Schuld, weil es erkennt, dass es sonst sich aufgeben müsste. Es kann nicht mehr zu dem Mittel greifen, sein Vergehen als ein Versehen zu deuten, und durch das Opfer auf Grund dieser Deutung von diesem Schuldbewusstsein sich zu befreien. Es kann auch nicht als sittliche Reinigung anerkannt werden, durch den Glauben an einen Gott, der sich selbst für meine Sünde geopfert habe, meine Erlösung von der Schuld zu erlangen. Nur im Urteil der sittlichen Erkenntnis kann ich mein Heil suchen und finden wollen. Und dieses Urteil der sittlichen Erkenntnis darf ich durch kein Mittel des Himmels oder der Hölle mich entheben lassen. Ich würde sonst meinen Mittelpunkt verlieren und mein sittliches Gewicht.“ (ErW, 370-371).

421 "Und wenn der Schuld zur Illusion wird, so wird es nicht minder auch die Tugend; denn der Kranke kann sich sicherlich auch den Karftaufwand leisten, der zu dem Flitterwerk der Tugend nötig ist; wie er sich auch in den Spielen des Scharfsinns und des Witzes mit manchem normalen Menschen messen kann.” (ErW, 372).
} 
Pero el juez no debe ni puede entrar en el santuario de la consciencia moral del criminal, sino que más bien debe limitarse a emitir un juicio sobre la autoría objetiva del crimen. La autorresponsabilidad queda en manos del criminal, de su autoconocimiento y sus deseos de superación. Se trata de la propiedad más íntima del ciudadano, que no puede nunca serle arrebatada por nadie en un Estado democrático de derecho. Cohen pone entonces al individuo en primer plano, tanto en la autonomía como autodeterminación, cuanto como autorresponsabilidad. Winter ha objetado este paso argumentativo, afirmando que no logra integrar los planos de la individualidad y la universalidad, como veremos en la siguiente sección.

\section{5. La crítica de Winter a la teoría de la autonomía moral de la ErW}

Winter ha intentado mostrar que el concepto de autonomía de Cohen es inconsistente con su teoría de la autoconsciencia. La razón de ello reside, según Winter, en que Cohen retoma, en su teoría de la autonomía, el punto de vista del sujeto en su individualidad, lo que entra en tensión con el punto de vista de la universalidad, propio de la autoconsciencia. Winter considera que este error es evidente en el tratamiento del problema de la autodeterminación, donde ya no se trata de la producción de la ley particular, sino de cualquier acción como un fenómeno real.

Cohen somete a crítica al concepto metafísico de libertad, esto es a la idea del origen absoluto de la acción en las facultades del sujeto individual, y propone en su lugar el de autonomía como la producción de la ley. Sin embargo, argumenta Winter, Cohen no explica la autodeterminación a partir de la acción de la legislación, sino más bien de la intencionalidad como fenómeno psicológico del agente. De este modo, Cohen confunde a la persona moral con el individuo natural, de modo tal que ya no sería posible establecer de qué modo aquella ejerce una influencia sobre este último. ${ }^{422}$

De acuerdo con Winter, Cohen se saldría del punto de vista moral e ingresaría inesperadamente en el de las determinaciones científico-naturales y empíricas, porque simplemente se limitaría a explicar y describir cómo es que la acción particular tiene lugar. Pero este es un salto ilegítimo de la ética a la lógica, que va contra la ley fundamental de la verdad. Por otro lado, Cohen explica la libertad del agente en base a su capacidad para el

\footnotetext{
${ }^{422}$ Winter, (1980), 398
} 
conocimiento científico o pensamiento causal, lo que tiene poco que ver con la determinación a la acción de la legislación.

Winter señala un problema análogo en la investigación de Cohen sobre la autorresponsabilidad. En vez de analizar los supuestos normativos de la acción de legislar, Cohen se adentra en investigaciones fenomenológicas acerca del surgimiento del sentimiento de culpa como resultado del autoconocimiento del criminal. ${ }^{423}$ Dicho de otro modo, Winter afirma que Cohen se mantiene en el plano de la introspección fenomenológica, donde concibe a la autorresponsabilidad como dada de antemano en el sujeto concreto. Por lo tanto, Winter considera que Cohen se habría alejado de su ética jurídica y se acercaría a una ética fenomenológica del tipo de la de Scheler. ${ }^{424}$

Al final de esta investigación sobre el concepto de autonomía estamos en condiciones de refutar la tesis de Winter, ya que ha quedado claro que Cohen no fundamenta el concepto de autonomía en ninguna teoría del individuo que sea independiente de la idea de autoconsciencia del Estado. Por el contrario, Cohen deriva los diferentes momentos de la autonomía de las condiciones que debe cumplir la acción de la legislación en el Estado para realizar la autoconsciencia. Como ya se dijo, en primer lugar debe tratarse de una forma de autolegislación, porque en caso contrario el individuo no entraría en relación con la universalidad de la autoconsciencia y no tendría sentido la teoría moral de la $\operatorname{ErW}$. En segundo lugar, la autolegislación es siempre la producción concreta de tal o cual ley, lo que supone la capacidad del individuo para autodeterminarse.

Pero la autodeterminación no tiene sentido si el individuo no puede hacerse cargo de las consecuencias de la promulgación de la ley, lo que constituye el momento de la autorresponsabilidad. Por lo tanto, no es necesario apelar a ninguna fenomenología de la consciencia individual, o a ninguna teoría psicológica, como sugiere Winter, para explicar el concepto de autonomía.

Ahora bien, hay una cuarta dimensión del concepto de autonomía que tiene que ver con la autoconservación del individuo, y que es la última condición de la autolegislación y la participación en la tarea de la autoconsciencia. Veamos en detalle este nuevo significado que ha adquirido la autonomía, y su relación con los restantes niveles.

\footnotetext{
${ }^{423}$ Winter, (1980), 410

${ }^{424}$ Winter, (1980), 424.
} 


\section{6. La autonomía como autoconservación (Selbsterhaltung)}

El problema de la autoconservación es el último momento de un proceso que comienza con el sujeto abstracto que tiene sólo la competencia de autolegislarse, y va concretizándose e individualizándose de a poco hasta ser capaz de identificarse con la acción que ha realizado. Pero, a pesar de que el sujeto autorresponsable tiene un sentido de la identidad personal y es capaz de identificarse con las leyes y cumplirlas, o de asumir sus transgresiones, no es todavía un individuo de carne y hueso.

Dicho de otro modo, para que el sujeto pueda actuar a partir de sus propias decisiones y por lo tanto hacerse cargo de ellas, debe tener necesariamente un cuerpo. El sujeto podrá realizar su autonomía sólo en la medida en que simultáneamente lleve a cabo una serie de acciones para mantenerse en la existencia, tales como alimentarse o hidratarse. De allí deriva Cohen la exigencia de la autoconservación. Sin embargo, su argumentación es más compleja, porque está íntimamente entrelazada con los resultados obtenidos en su investigación sobre la autorresponsabilidad. Veamos cómo procede Cohen en su demostración de la dimensión moral de la corporalidad.

Cohen trata la cuestión de la autonomía como autoconservación a partir de la respuesta a una objeción que puede surgir frente al concepto de autorresponsabilidad. Este argumento parte del análisis del proceso de individualización, que permite que el sujeto se atribuya a sí mismo el crimen y finalmente decida resocializarse. La objeción plantea que este proceso de individualización estaría en contradicción con la universalidad de la autoconsciencia, a la que debe servir la autorresponsabilidad. Es decir, dado que la autorresponsabilidad debe descansar en el conocimiento de sí mismo y exige la reflexión del criminal sobre los motivos de su acción, llevaría al abandono de la perspectiva de la intersubjetividad e implicaría una recaída en la perspectiva individualista, que Cohen intentó superar en su teoría del derecho estatal. ${ }^{425}$

Sin embargo, a pesar de que la sentencia del juez no puede suplantar a la autorreflexión del individuo, tiene un aspecto objetivo e insoslayable desde el punto de vista legal, que es el de la condena y la determinación de la pena. La necesidad de establecer un castigo para el criminal es una refutación clara del intelectualismo, porque supone que el crimen es algo más que un mero error del pensamiento. Si el crimen fuera el resultado de un mero error cognitivo, sería suficiente entonces con una compensación por los daños y perjuicios objetivos que resultaron de la acción delictiva. Sin embargo, la ley prevé una serie

\footnotetext{
${ }^{425} \mathrm{ErW}, 373$.
} 
de normas que apuntan a la transformación y modelación del carácter y de la constelación de valores que orientan a la acción del sujeto.

Es decir, la sentencia supone una relación lógica entre el concepto del crimen y el de la pena, porque ambos están tipificados y definidos en el Código Penal. Toda vez que el derecho sólo puede ser comprendido bajo la forma del contrato, debe contener necesariamente también el momento de la reparación o del resarcimiento, para la eventualidad de que uno de los contrayentes no haya cumplido con las normas contraídas. Con otras palabras,

Su culpa legal es su culpabilidad, que él no sólo debe sentir, sino también reparar. El juicio del juez sobre el hecho objetivo de un crimen es, de acuerdo con esto, al mismo tiempo un juicio sobre el criminal, gracias a la necesidad lógica de la restricción deducida. Y este juicio sobre el criminal se convierte, en virtud de la necesidad lógica, en un juicio sobre su culpabilidad; este es su pena. ${ }^{426}$

La determinación de la pena es el resultado de la aplicación del silogismo deductivo por parte del juez, quien interpreta la ley y establece su vigencia para el caso particular. Pero la ley es la expresión de la voluntad pura y la autoconsciencia. Por lo tanto, el concepto de la pena pone en relación íntima al sujeto individual de la acción con la comunidad de los colegisladores. Es decir que el concepto de la pena hace posible la relación objetiva que existe entre la autorresponsabilidad del individuo y la universalidad de la autoconsciencia. Esta conclusión arroja luz sobre otro error, que consiste en separar a la pena de la culpa en el sentido moral, y rechazar a esta última del ámbito del derecho. Esta es la concepción de la responsabilidad propia de quienes piensan al derecho como una mera técnica y lo desvinculan de la ética. Contra la reducción de la responsabilidad al cumplimiento exterior de la pena, Cohen exige que el criminal restaure su relación con la comunidad legal, a fin de que pueda volver a ser un co-legislador en el Estado.

Sin embargo, esto es posible sólo una vez que haya cumplido con la pena objetiva que se le ha fijado.

La pena lo eleva sobre la culpa. La culpa le da sólo el medio de liberación de la penitencia. Pero está la pregunta de si la penitencia en sentido moral puede liberarlo de la culpa. Probablemente su arrepentimiento se vuelva tan amargo que él permanezca fijado a la autoacusación, la compunción, la desesperación. Debemos dejar aqui fuera de consideración otros pensamientos, tales como los de la religión, que podrían proporcionar un complemento a la penitencia, porque se trata sólo de la autoconsciencia en base a la autolegislación y sus desarrollos. 427

\footnotetext{
426 "Seine juristische Schuld ist seine Schuldigkeit, die er nicht allein zu fühlen, sondern einzurichten hat. Das Urteil des Richters über den Tatbestand eines Verbrechers ist demnach kraft logischer Notwendigkeit in der gezogenen Einschränkung zugleich ein Urteil über den Verbrecher. Und dieses Urteil über den Verbrecher wird daher kraft logischer Notwendigkeit zu einem Urteil über seine Schuldigkeit; diese ist seine Strafe.“ $(E r W, 374)$. 427 "Die Strafe hebt ihn dann sogleich über die Schuld hinaus. Die Schuld gibt ihm nur das Befreiungsmittel der Busse. Aber es ist die Frage, ob die Busse im ethischen Sinne ihn von der Schuld zu befreien vermag. Vielleicht
} 
Como sostiene Cohen en este fragmento, el concepto de pena, como determinación objetiva de la compensación que el criminal debe pagar por el daño producido, consuma la liberación de la ética respecto de la religión, porque supera el concepto de la penitencia como la expiación por los pecados y la idea consiguiente de purificación moral.

Hay quienes afirman que el criminal, una vez sentenciado, dejaría de ser un ciudadano, y se convertiría de nuevo en un co-legislador sólo una vez cumplida su pena. Pero esta afirmación es incorrecta porque, en la medida en que el criminal acepta sobre sí la pena y la cumple, se encuentra en continuidad con su actividad previa de legislación y promulgación de la ley. Este es el sentido de las siguientes palabras de Cohen:

Cuando luego de la expiación puede lograrse la restitución de un hombre íntegro, allí debe dominar el presupuesto de que este resultado no aparece luego de la expiación conseguida, sino que ya se establece durante la expiación y con la toma de posesión de la pena. ${ }^{428}$

La legislación sólo tiene sentido si el autor de la ley es el mismo sujeto que luego se somete a ella, lo que implica el cumplimiento de las sanciones que ha consentido de antemano para los casos de desviación de la ley. En el caso del delito de hurto, la compensación que debe garantizar la pena puede ser determinada de muchas maneras. Sin embargo, el asesinato presenta el problema insalvable de que no hay compensación posible para quien ha perdido la vida por culpa del criminal. Para resolver este problema, Cohen debe en primer lugar considerar la legitimidad de la pena de muerte como compensación proporcional al delito de homicidio.

En este caso, parecería razonable la sanción con la pena de muerte, porque quien ha destruido intencionalmente a otro ciudadano no puede pensarse de ninguna manera como un posible cooperador y co-legislador en el Estado. Por lo tanto, no tendría ningún sentido la aplicación de una pena con el objetivo de devolver al criminal al ejercicio pleno de la ciudadanía. Sin embargo, la gravedad de la pena de muerte exigiría que el juez pueda emitir un juicio exhaustivo e infalible acerca de las intenciones del criminal. Pero sólo el criminal puede saber si efectivamente ha querido matar o no, porque sólo él tiene acceso a su consciencia moral.

wird seine Reue so bitter, dass er in der Selbstanklage, in der Zerknirschung, in der Verzweiflung hängen bleibt. Andere Gedanken, etwa die der Religion, die ihm eine Ergänzung der Busse verschaffen möchten, müssen hier ausser Betracht bleiben, wo es sich nur um das Selbstbewusstsein auf dem Grunde der Selbstgesetzgebung und ihrer Entwickelungen handelt.“ $(\operatorname{Er} W, 377)$.

428 "Wenn nun aber nach der Abbüssung die Restitution zu einem integern Menschen erfolgen kann, so muss dabei die Voraussetzung obwalten, dass diese Wirkung nicht erst nach erfolgter Abbüssung eintritt, sondern während der Abbüssung und mit dem Antritt der Strafe bereits einsetzt.“ (ErW, 378). 
Por lo tanto, la aplicación de la pena capital significaría en la práctica la extralimitación de las atribuciones del juez. Dada la imposibilidad de dictaminar concluyentemente sobre la culpa del delincuente, implicaría también la instauración del derecho de la venganza o de la compensación simétrica de un asesinato con otro. La única alternativa que quedaría para poder aplicar la pena correspondiente a este delito, sin violar la autorresponsabilidad del criminal, es dejar en sus manos la decisión de suicidarse en el caso de que considere que tuvo la intención firme y clara de cometer el homicidio. Pero puede verse claramente lo absurdo de una tal pena, y por lo tanto su inaplicabilidad. ${ }^{429}$

Cohen esgrime aún un argumento adicional para rechazar la pena de muerte, que surge de la fundamentación misma de su teoría. El Estado consiste en la realización de la tarea de la autoconsciencia moral, lo que no es posible si todas las voluntades individuales de los ciudadanos no participan en la constitución de la voluntad común de la ley. Se trata entonces de la tarea de la legislación, que nunca debe darse por concluida, porque constituye la esencia misma del Estado como persona jurídica. Es una tarea infinita, porque siempre está abierta al futuro. Pero, si la pena de muerte se aplicara sobre cualquier ciudadano, entonces su voluntad particular dejaría de participar en la tarea de la autoconsciencia, lo que contradice el concepto mismo del Estado.

Por otro lado, en la medida en que la tarea es infinita, nunca se puede dar a un ciudadano por perdido o etiquetarlo como un ciudadano ejemplar, ya que la ciudadanía es una tarea que se construye día a día. Es decir, que

La tarea no puede nunca lograr su solución adecuada; pero tampoco puede ser arrancada del corazón de un hombre. De alli se sigue que, como ningún hombre es bueno, tampoco ningún hombre es malo. ${ }^{430}$

Por lo tanto, debe renunciarse a pronunciar cualquier tipo de juicio moral definitivo sobre los ciudadanos, lo que deja sin fundamento la aplicación de la pena de muerte.

La autonomía como autorresponsabilidad no puede realizarse sin el cuidado por la autoconservación porque, si el ciudadano muere, desaparecen con ello todas las condiciones para la realización de la autoconsciencia. De allí que Cohen afirme de modo concluyente:

La autoconservación tiene como supuesto indeleble ante todo al individuo natural [...]. Con el alma del ser humano no puede comenzarse legalmente nada, ni conseguir

\footnotetext{
${ }^{429} \operatorname{ErW}, 380$.

430 "Die Aufgabe kann niemals zur adäquaten Lösung kommen; aber sie kann auch niemals aus dem Herzen eines Menschen herausgerissen werden. Daraus folgt; dass, wie kein Mensch gut ist, auch kein Mensch böse ist.“ $(E r W, 381)$.
} 
nada, cuando ella es el alma del hombre asesinado. El alma puede tener un sentido ético, desde el punto de vista legal, sólo como el alma de un hombre vivo. ${ }^{431}$

La objeción religiosa a favor de la pena de muerte, que sostiene que la existencia más allá de la muerte permite al individuo continuar con su progreso moral, no tiene sustento alguno en la teoría de Cohen, porque la ética no puede realizarse fuera del Estado. Por lo tanto, la autoconservación es la forma fundamental de la autonomía, porque es la condición sine qua non del progreso moral. Pero, dado que la ética es una forma más de la consciencia cultural, y la cultura es el producto de la acción humana, la autoconservación es en realidad la condición y el supuesto básico de la cultura humana. Por eso Cohen afirma,

la autoconservación, este es el A y el O. El aseguramiento de la cultura, es decir la elevación de la cultura, tiene como supuesto imprenscindible a la autoconservación realizada sin excepciones. ${ }^{432}$

De este modo, Cohen concluye que la existencia de los ciudadanos debe ser preservada celosamente por el Estado democrático de derecho, para garantizar su universalidad moral. Cohen da respuesta a lo que considera como el problema fundamental de la ética, esto es la correlación entre el individuo y la universalidad. Esta es posible sólo cuando cada ciudadano, sin excepciones, puede participar en la elaboración de la ley. Si cada ciudadano es el autor de la ley, entonces la ley se aplicará del mismo modo para todos. Si la universalidad de la ley se realiza en la autoconsciencia del Estado, el otro término de la relación, es decir, el individuo, existe cuando se garantizan las condiciones de la autonomía. El individuo puede relacionarse con la universalidad cuando su existencia corporal es un asunto de Estado.

\footnotetext{
431 "Die Selbsterhaltung hat aber, wie das Selbst überhaupt, das natürliche Individuum zur unauslöschlichen Voraussetzung. Mit der Seele des Menschen ist rechtlich nichts anzufangen, und nichts auszurichten, wenn sie die des getöteten Menschen ist. Die Seele kann einen ethischen Sinn rechtlich nur haben, als die Seele des lebendigen Menschen." (ErW, 382).

432 "Selbsterhaltung, das ist das A und das O. Die Sicherung der Kultur, das ist die Erhöhung der Kultur, sie hat zur unerlässlichen Voraussetzung die ausnahmslos durchgeführte Selbsterhaltung.“ (ErW, 387).
} 


\section{La deducción del cuerpo a partir del principio del derecho}

De lo argumentado en la sección anterior puede concluirse que en la $\operatorname{Er} W$ la corporalidad del individuo es la condición sine qua non del sistema legal entero y, por lo tanto, del Estado. Esto implica que la autoconsciencia no puede realizarse si no se garantiza la existencia de los ciudadanos. Es decir que la autoconsciencia exige que los ciudadanos puedan satisfacer sus necesidades básicas, y que su integridad psico-física esté protegida contra el robo, la violación, la tortura o el asesinato. De este modo, Cohen se ha ido deslizando desde la subjetividad ficcional de la autoconsciencia hasta la individualidad concreta de los ciudadanos de carne y hueso.

En la segunda parte de este capítulo intentaré mostrar que en la teoría de Fichte también la corporalidad es la última condición de posibilidad del derecho. Sin embargo, ya no se trata de la autoconservación, que en el GNR es parte de la teoría de la propiedad, de la que me ocuparé en el capítulo siguiente. En el nivel de la fundamentación del GNR la corporalidad significa la atribución de un cuerpo a sí mismo (Leib), como la esfera de acciones que son posibles para el yo. Para establecer con claridad las diferencias entre el concepto de la corporalidad de la $\operatorname{Er} W$ y el correspondiente al GNR, es necesario en primer lugar reconstruir la teoría de Fichte. Este es el objetivo de las páginas siguientes. 


\section{1. La atribución a sí mismo del propio cuerpo}

Ya ha quedado establecido en el capítulo 2 que, si los sujetos quieren ponerse a sí mismos como individuos, esto es, como seres racionales que coexisten con otros seres racionales, deben respetar el principio del derecho. Pero aún resta saber si puede cumplirse el principio del derecho. Dicho de otra manera, deben deducirse las condiciones de aplicación del principio del derecho en el mundo sensible.

En primer lugar, debe determinarse si la autoconsciencia puede realizar sus fines en el mundo sensible. Fichte parte de la hipótesis de que el sujeto puede atribuirse un cuerpo a sí mismo y, de este modo, realizar su eficacia en el mundo. Esta hipótesis reza como sigue: “el ser racional no puede ponerse como individuo operante sin atribuirse un cuerpo material y de este modo determinarlo". 433

Dado el carácter deductivo de la argumentación de Fichte, este paso no puede comprenderse si no se retoman las conclusiones inmediatamente anteriores. Los resultados de la investigación previa pueden sintetizarse de este modo: la relación legal permite explicar la constitución del sujeto en un individuo, o sea, el pasaje desde un yo aislado y cerrado en sí mismo a un yo en interacción permanente con los demás. Para explicar la transición desde el mero concepto de un sujeto que establece una relación intersubjetiva con los demás a un yo que actúa de tal modo determinado, es necesario demostrar las condiciones de posibilidad de la acción individual.

La primera condición de una acción individual es la constitución de la persona, esto es, de un sujeto que actúa de esta o de aquella manera concreta. La persona se pone a sí misma al atribuirse una esfera exclusiva de acción, o sea un conjunto de acciones alternativas, de la que excluye a todas las demás. Una vez definido el concepto de persona, es necesario analizar la estructura misma de la acción que realiza. ${ }^{434} \mathrm{El}$ yo meramente formal se convierte en una persona por medio de la atribución a sí mismo de una esfera concreta de acción, porque de esta manera limita y determina su libertad.

Se trata de una atribución en el sentido de la posición de la esfera de acciones posibles para la persona, como si existiera independientemente de esta actividad misma de posición. La persona pone a la esfera como si existiera fuera y totalmente separada de ella porque, en

\footnotetext{
433 "das vernünftige Wesen kann sich nicht, als wirksames Individuum, setzen, ohne sich einen materiellen Leib zuzuschreiben, und denselben dadurch zu bestimmen" (GNR, § 5; SW, III, 56; AA, I, 3, 361).

${ }^{434} G N R, \S 5$; SW, III, 56-57; AA, I, 3, 361.
} 
caso contrario, no podría restringir su libertad para llevar a cabo sus fines. Si la esfera de acciones posibles fuera puesta como dependiente de la actividad de posición de la persona, se trataría de una esfera de acciones indeterminada y sin existencia objetiva.

Dicho de otra manera: si la persona pudiera crear arbitrariamente su esfera de acciones, entonces no dispondría en realidad de esta esfera de acciones, sino que más bien creería o imaginaría que dispone de ella. Pero aquello que el yo pone como existiendo independientemente de sus acciones, esto es, con validez objetiva, es justamente el "mundo", según lo demostrado en el $\S 2$. Por lo tanto, la persona pone su esfera de acciones posibles como una parte del mundo.

El yo es una actividad pura (sin mezcla alguna de pasividad), que vuelve a sí misma cuando puede atribuirse la actividad de la posición del objeto, según lo demostrado en el $\S 1$. La actividad de la posición de un objeto se puede definir como la intuición del objeto. Pero para entender el modo en que funciona la intuición de un objeto, debe prescindirse de la concepción del entendimiento humano común, que es el blanco de las críticas de Fichte en el $\S 2$.

Como ya se dijo en el capítulo 1, el entendimiento humano común explica a la intuición como una forma de conocimiento que se dirige a un objeto que existe realmente fuera del sujeto. En contraposición con la concepción del entendimiento humano común, Fichte sostiene que la intuición del objeto es un proceso dinámico explicable sólo por la actividad del yo. El ejemplo del trazado de una línea (ein Linienziehen), de la cosecha del propio Fichte, puede servir como ilustración de su punto de vista. Cuando trazamos una línea, dice Fichte, estamos realizando ante todo una acción, y es en función de esta acción que luego ponemos el tiempo y la extensión.

El tiempo y la extensión son más bien condiciones del trazado de la línea, y son puestos por el yo simplemente con el objeto de realizar la acción. Por lo tanto, el tiempo y la extensión no preexisten a la acción, sino que son una parte suya. ${ }^{435}$ Otro ejemplo de Fichte es la actividad del pintor, que ve, por así decirlo, la pintura antes de plasmarla en la tela. ${ }^{436}$ Cuando intuyo un objeto, estoy llevando a cabo una acción que, en realidad, se deriva de otra acción previa, en la que me propuse el fin de intuir este objeto. En el concepto del fin de la acción de intuir este objeto, yo he debido incluir también el tiempo y la extensión, porque son los medios indispensables para intuir cualquier objeto. La razón es imaginación productiva (productive Einbildungskraft), porque tiene la estructura del yo volente, o sea que actúa en

\footnotetext{
${ }^{435}$ Acerca de la utlización por Fichte del ejemplo del trazado de una línea en la Wissenschaftslehre nova Methodo (AA, IV, 2, 110 ss), Cfr. Siep, (1993), 113.

${ }^{436}$ GNR, § 5; SW, III, 57-58; AA, I, 3, 362.
} 
vista de determinados fines. Intuir es, según Fichte, Hinschauen, es decir, ver el producto de la acción antes de llevarlo a cabo ${ }^{437}$.

Análogamente, la persona pone su esfera de acciones posibles como algo determinado en la extensión. Un objeto determinado debe tener sus límites, por lo que el entendimiento fija y establece la esfera de acciones posibles como un todo completo y delimitado respecto de lo demás. Dado que la persona se define por su esfera de acciones, existe todo el tiempo en que ésta también existe. Pero, según lo argumentado en el $\S 4$, el individuo se pone a sí mismo como existiendo idéntico a sí mismo para todo tiempo futuro. Esto es, se pone a sí mismo como algo permanente e inmodificable. La esfera de acciones posibles también debe ser puesta, entonces, como algo permanente e inmodificable.

Pero la extensión inmodificable y determinada para todo futuro es lo que llamamos una extensión en el espacio (Ausdehnung im Raume). ${ }^{438}$ Aquello que es puesto por la persona como el conjunto de acciones que puede realizar en el mundo sensible, pero existiendo de modo permanente y limitado en la extensión, es lo que Fichte denomina como cuerpo. ${ }^{439} \mathrm{El}$ cuerpo es definido, entonces, por el concepto de la esfera de acciones de la persona. ${ }^{440}$ Para decirlo con Fichte: "El cuerpo material deducido es puesto como el ámbito de todas las acciones libres de la persona y nada más. En esto únicamente consiste su esencia “ 441

El yo es voluntad, como dice el $\S 1$; esto es, consiste en la posibilidad de proponerse fines y de ponerlos en práctica. Por lo tanto el yo es causa de los objetos en el mundo sensible que corresponden a sus fines. Pero la persona puede ejercer su causalidad en el mundo sensible sólo por medio del cuerpo, según lo argumentado hasta aquí. ${ }^{442}$ Por lo tanto, la voluntad debe tener una influencia directa sobre el cuerpo, por lo que todo cambio en la

\footnotetext{
${ }^{437}$ Zöller puntualiza en este respecto: "Según la teoría trascendental del objeto de Fichte, la intuición no es algo receptivo frente a un objeto dado de antemano, sino que produce antes de todo este objeto suyo. De este modo, intuir es en realidad Hinschauen" ("Nach Fichtes transzendentaler Gegenstandstheorie ist die Anschauung nicht etwa rezeptiv gegenüber einem vorgegebenen Gegenstand sondern produziert diesen ihren Gegenstand allererst. Anschauen ist so eigentlich Hinschauen" (Zöller, 2001, 98).

${ }^{438}$ GNR, § 5; SW, III, 59; AA, I, 3, 363.

${ }^{439}$ El cuerpo es, entonces, el modo en que podemos pensarnos a nosotros mismos, como apunta Siep. "Sin embargo, Fichte no es ni un dualista ni un 'fenomenalista' del cuerpo. Él no discute que tengamos un cuerpo, ni que éste sea real y material. Esta no es tampoco ninguna propiedad exterior, sino que es inseparable de nuestra autoconsciencia: no podemos pensarnos más que como 'corporales' “

("Dennoch ist Fichte weder Dualist noch 'Phänomenalist' des Leibes. Er bestreitet weder, dass wir einen Leib haben, noch dass dieser real und material ist. Dies ist auch keine äußerliche Eigenschaft, sondern von unserem Selbstbewusstsein unabtrennbar: Wir können uns gar nicht anders als 'leibhaft' denken“; Siep, 1993, 108).

${ }^{440}$ La materialidad del yo "(...) entra en juego por primera vez en la experiencia de los propios límites prácticos como reflejos de un mundo exterior, en el que los cuerpos materiales reciben influencia unos de otros" ("[...] kommt erst in Spiel bei der Erfahrung der eigenen praktischen Grenzen als Wiederspiegelungen einer Außenwelt, in der materielle Körper auf einander Einfluß nehmen“; Zöller, 1998, 649). Cfr. también Zöller, (2001), 98-100.

441 "Der abgeleitete materielle Körper ist gesetzt, als Umfang aller möglichen Handlungen der Person; und nichts weiter. Darin besteht sein Wesen“ (GNR, § 5; SW, III, 59; AA, I, 3, 363).

${ }^{442}$ Cfr. Giassi, (2000), 155.
} 
voluntad debe tener su correspondiente en el cuerpo. ${ }^{443}$ Lo querido se produce en el cuerpo y sólo por su medio. ${ }^{444} \mathrm{El}$ concepto de la persona, al igual que el de su cuerpo, se agota en las acciones que se propone y lleva a cabo la voluntad. ${ }^{445}$

Pero parece que la voluntad está en contradicción consigo misma, dado que debe poner el cuerpo, como se dijo más arriba, como algo invariable y permanente y, sin embargo, modificable al infinito por sus diferentes acciones. El carácter invariable del cuerpo es la "materia". El concepto de materia ya fue tratado en el capítulo 1, donde se concluyó que todo objeto sensible en general debe ser puesto como permanente e inmodificable. La posibilidad de transformar el cuerpo, es, es por otro lado, su "forma".

Fichte sostiene que todo objeto sensible en general tiene una forma, esto es, puede sufrir modificaciones al infinito, porque es puesto siempre por el yo, que es libre y tiene un movimiento indeterminado. Es decir que el cuerpo, al igual que todo objeto sensible, puede sufrir infinidad de alteraciones, porque la voluntad también puede modificarse al infinito. Las partes deben permanecer en tanto que cumplen una función en un plexo de relaciones cambiantes. La materia, entonces, es el conjunto de partes que integran el cuerpo, mientras que la forma está constituida por las relaciones que la persona establece entre ellas al ponerlas en movimiento para realizar el concepto del fin que se ha propuesto. ${ }^{446}$

Las partes que integran la materia son denominadas por Fichte como los "miembros" (Glieder) del cuerpo. El concepto del fin que se ha propuesto la persona se expresa por medio del cambio de la posición recíproca de los miembros entre sí. Pero los fines propuestos pueden ser infinitos y, como ya se dijo, no deben ser impedidos por el cuerpo, sino más bien realizados por su medio, en la medida en que el cuerpo contiene la esfera de sus acciones posibles. Por eso cada miembro debe poder siempre cambiar su posición respecto de las demás, con un movimiento que sea propio sólo de él. La persona establece relaciones entre los miembros (mayor y menor, etc.) y los vincula a una totalidad, cuya unidad se corresponde con la unidad del concepto del fin a realizar en ese caso.

La totalidad conseguida de este modo puede, a su vez, concebirse como miembro de una totalidad mayor, etc. Y viceversa, la persona puede entender a cada miembro de la unidad como otra unidad que, a su vez, está compuesta por otros miembros. Esto es:

El cuerpo debería estar dispuesto de modo tal que cada vez dependiera de la libertad pensar la parte como mayor o menor, más compuesta o más simple; y de nuevo pensar cada conjunto de partes como un todo, y por tanto a éste como una parte de un

\footnotetext{
${ }^{443}$ Siep, (1993), 116.

${ }^{444}$ Cfr. López-Domínguez, (1999), 281.

${ }^{445}$ Zöller, (1998), 647.

${ }^{446}$ GNR, § 5; SW, III; 60-61; AA, I, 3, 364.
} 
todo mayor; $y$ en este respecto volver a dividir todo lo pensado como una unidad desde este punto de vista. ${ }^{47}$

A los fines del análisis, distingue Fichte entre el movimiento de cada miembro en particular y el del todo. Pero en realidad, cada miembro se mueve sólo cuando los demás lo hacen coordinadamente, dentro de la unidad que les confiere el concepto del fin que expresan. Esta propiedad del cuerpo es lo que Fichte denomina como la "articulación",448.

\section{2. La influencia de la otra persona como condición de la atribución del propio cuerpo}

Este es el asunto del $5^{\circ}$ Teorema ( $\left.§ 6\right)$, que dice: "La persona no puede atribuirse un cuerpo sin ponerlo como si estuviera bajo el influjo de una persona fuera de ella, y sin determinarlo ulteriormente de este modo". ${ }^{449}$ Es decir, la siguiente argumentación apunta a demostrar que la atribución del propio cuerpo a sí mismo tiene como condición necesaria la acción de otra persona sobre el propio cuerpo. El punto de partida es el $2^{\circ}$ Teorema ( $\left.§ 3\right)$, ya demostrado, según el cual el sujeto se vuelve autoconsciente si es exhortado por otro ser racional a la acción libre. Pero los Teoremas $3^{\circ}$ y $4^{\circ}(\S \S 4$ y 5 , respectivamente) han dejado sentado que el otro sujeto no actúa sobre un ser racional en abstracto, sino más bien sobre una persona, esto es, un individuo que se realiza por medio de acciones concretas. Según el $4^{\circ}$ Teorema $(\S 5)$, el individuo se constituye como tal en virtud de la determinación de una esfera de acciones posibles, cuya totalidad existe como un cuerpo propio.

La exhortación de la otra persona conlleva una restricción de la propia libertad, en tanto que es puesta como una operación que viene causada por otro sujeto que existe fuera del yo. Como se dijo en el capítulo 1, la razón de esto es que el yo no puede poner ningún objeto como existiendo fuera de él mismo, sin restringir su libertad para adecuarla a las características del objeto puesto. De este modo, la posición del otro sujeto encauza y limita la libertad del yo. Dicho de otro modo, exige que el yo ponga su libertad como parcialmente suprimida, porque se reserva una porción de libertad ilimitada y absoluta para poder dar origen a la actividad de la posición del otro sujeto. Al menos una acción, de entre las que

\footnotetext{
447 "Der Körper müsste so eingerichtet seyn, dass es jedesmal von der Freiheit abhinge, den teil grösser oder kleiner, zusammengesetzter oder einfacher zu denken: hinwiederum, jede Menge von Theilen zu denken, als ein Ganzes: mithin selbst als Ein Theil in Beziehung auf das grössere Ganze; jedes in dieser Rücksicht als Eins gedachte wieder zu theilen“ (GNR, § 5; SW, III; 60-61; AA, I, 3, 364).

${ }^{448}$ Cfr. Gueroult, (1974), 64.

449 "Die Person kann sich keinen Leib zuschreiben, ohne ihn zu setzen, als stehend unter dem Einflusse einer Person ausser ihr, und ohne ihn dadurch weiter zu bestimmen" (GNR, § 6; SW, III, 61; AA, I, 3, 365).
} 
integran la esfera de acciones posibles de la persona, debe ser puesta como impedida. Pero el cuerpo es la esfera de las acciones posibles, por lo cual el cuerpo mismo debe ser puesto como influenciado por la acción de la otra persona.

O sea que al menos uno de los movimientos posibles del cuerpo debe ser frustrado, para hacer posible la relación entre el yo y el otro. La influencia de la otra persona sobre el yo debería ser atribuida, en buena lógica, a esta otra persona. Pero, si adoptamos el punto de vista de la filosofía trascendental, la situación parece ser otra. La influencia de la otra persona sobre el yo se origina en la otra persona, pero la consciencia de esta influencia tiene lugar en el yo; es decir, es una actividad más de la autoconsciencia. Por lo tanto, deber ser puesta por el yo mismo, como todos los objetos que se presentan a su consciencia.

Dicho de otro modo: dado que la influencia de la otra persona sobre el cuerpo del yo es una influencia sobre su esfera de acciones posibles, toda vez que impide que el yo elija una de ellas. Si la esfera de acciones posibles es puesta exclusivamente por el yo, puede concluirse que la influencia de la otra persona sobre el yo es puesta exclusivamente por el yo mismo.

Fichte no quiere decir que la autoconsciencia, en primer lugar, se constituye como tal $\mathrm{y}$, luego, toma conocimiento de que uno de sus cursos posibles de acción ha sido suprimido. Por el contrario, la actividad de la constitución de la autoconsciencia tiene como rasgo central la limitación de una alternativa posible de acción. De lo cual se desprende que “(...) la misma actividad determinada de la persona tiene que ser suprimida y no suprimida al mismo tiempo y en el mismo momento indiviso, si ha de ser posible una consciencia”, ${ }^{450}$

Es decir que una determinación imposible del cuerpo debe ser puesta como si esta acción fuera posible, como si perteneciera a su esfera de acción. La acción imposible es producida por la voluntad y al mismo tiempo es suprimida por la influencia externa de otra persona. El paso siguiente de la deducción de Fichte consiste en la explicación de esta posición paradójica de la acción como existente y como suprimida. Veamos cómo procede Fichte para aclarar esta idea.

En primer lugar, la posición de esta acción como suprimida debe ocurrir, según lo demostrado en el $\S 1$, de modo tal que la voluntad del yo conserve el poder de liberar esta obstrucción en caso de que así lo quiera. Como ya se dijo, toda acción supone una cierta articulación del cuerpo. Dado que la posición de una actividad como existente y a la vez como suprimida por la influencia de otra persona consiste en realidad en dos acciones, debe consistir entonces en una doble articulación.

\footnotetext{
450 "Es muss sonach dieselbe bestimmte Tätigkeit der Person zugleich, in demselben ungetheilten Momente, aufgehoben seyn, und nicht aufgehoben seyn, wenn ein Bewusstsein möglich seyn soll“" (GNR, § 6; SW, III, 63; AA, I, 3, 366).
} 
Esta doble articulación toma las formas de un órgano superior y uno inferior ${ }^{451}$ Fichte los caracteriza como

dos órganos, que se relacionan entre sí del siguiente modo: el primero, en el que la persona produce el movimiento suprimido, y al que llamaremos el órgano superior; puede ser modificado por la voluntad sin que por eso también lo sea el otro, al que llamaremos el órgano inferior. ${ }^{452}$

\section{3. Los órganos superior e inferior y las materias dura y sutil}

El órgano inferior es una articulación del cuerpo en la que la voluntad pone una influencia como si no fuera producida por su propia eficacia (aunque de hecho lo es), sino más bien por otra persona externa a ella. Esto es, la voluntad podría suprimir esta influencia libremente, pero la retiene a fin de poder recibirla de la otra persona, de modo pasivo. El órgano superior, en cambio, imita libremente la influencia recibida de la otra persona en el órgano inferior. Pero, como dice el texto citado más arriba, el órgano superior no puede modificar libremente al órgano inferior, porque en caso contrario la influencia de esta causa externa no estaría puesta como algo real y constituiría una pura producción del sujeto.

La articulación del órgano superior funciona de modo análogo a como lo hace una persona cuando habla. Un sujeto puede hablar si al mismo tiempo escucha lo que él mismo está diciendo. Esto último es posible, a su vez, sólo si el sujeto reproduce internamente lo que está escuchando. Pero, si su actitud fuera totalmente pasiva, sólo hablaría y, si fuera únicamente activa, sólo escucharía. Esta relación entre el órgano superior e inferior es lo que Fichte llama el sentido (Sinn).

El cuerpo articulado tiene un sentido, entonces, si la voluntad produce o imita, por medio de este cuerpo, a una influencia externa ejercida sobre ella. Pero debe imitarla de modo tal, de poder dejar de hacerlo cuando quisiera.

Como se argumenta en el $\S 3$, la otra persona, en tanto que ha influido sobre el yo, debe ser necesariamente un ser racional. A fin de poder afirmar la racionalidad del otro, debe demostrarse que actuó libremente, esto es, que podía actuar de otra manera y que por lo tanto no lo hizo ni por azar ni por necesidad. Debió haber podido elegir una entre varias alternativas disponibles, es decir que él mismo debió disponer de una esfera propia de acción.

\footnotetext{
${ }^{451}$ Cfr. Schrader, (1972), 80; Zöller, (2001), 100-101:

452 “(...) ein doppeltes Organ, die sich folgendermaassen zu einander verhalten: das erstere, in welchem die Person die aufgehobene Bewegung hervorbringt, und das wir das höhere Organ nennen wollen, kann modificirt werden durch den Willen, ohne dass es dadurch das andere, welches wir das niedere Organ nennen wollen, werde.“ (GNR, § 6; SW, III, 64; AA, I, 3, 367).
} 
Antes de proseguir con la demostración, es necesario preguntarse qué tipo de acción es la opuesta a la acción de la exhortación. Luego deberá mostrarse que el sujeto de la exhortación pudo haber realizado esta acción, si así lo hubiera querido. Si una persona no es tratada como un individuo con sentido, y con una esfera de acciones o fines posibles, o sea, con un cuerpo, recibe el trato correspondiente a una materia dura o inalterable. ${ }^{453} \mathrm{Si}$ la persona es tratada como un ser racional, la decisión de ser afectada o no por la otra persona queda en poder de su órgano superior. Cuando la persona reproduce o imita la exhortación recibida en su órgano inferior, puede responder a la misma eligiendo una de entre las acciones posibles.

Esto es, puede atribuirse un cuerpo, pero queda siempre en su voluntad la posibilidad de no hacerlo. Lo opuesto a la interrelación de la exhortación es la posición de un objeto en el mundo, según el $\S 3$. Pero la acción de poner un objeto en el mundo se realiza en la extensión en la forma de la afección del sujeto por una materia puesta por él como dura o inalterable.

La afección del cuerpo por una materia dura o inalterable es lo opuesto a la exhortación, porque la suspensión de esta afección no depende de la voluntad (o sea de su órgano superior). Cuando una materia con determinadas relaciones de fuerza afecta al cuerpo (por ejemplo, el agua que cae sobre el propio cuerpo cuando llueve), la persona no puede dejar de tomar consciencia de ello.

Esto no significa que, cuando su cuerpo es afectado por la materia dura, la persona pierde su libertad de reflexionar sobre ello. La razón de esto es que, desde el punto de vista de su "forma", es una acción producida por la libertad absoluta del yo. La posición de la materia es una acción del yo, porque nada puede aparecer a su consciencia que no sea puesto por él.

Pero, en lo relativo a la "materia" o contenido de la reflexión, inevitablemente debe ejercerse sobre la modificación sufrida por uno de los miembros del cuerpo. El miembro del cuerpo modificado y afectado por la materia sufre una restricción de su actividad. Este impedimento de la actividad del cuerpo es un elemento más de la articulación o configuración de sus miembros en orden a la actividad de la reflexión. Dado que la articulación supone una relación de interdependencia entre sus miembros, cada vez que el sujeto conozca su cuerpo tomará nota de esta afección. De lo cual se desprende la siguiente afirmación:

Tengo que poner esta inhibición del libre movimiento en mi cuerpo necesariamente como posible en relación con la contraposición postulada, y mi cuerpo recibe, una vez más, una nueva determinación. Como condición de tal contraposición, debo poner fuera de mi una materia dura e inalterable, capaz de resistir al libre movimiento de mi

\footnotetext{
${ }^{453}$ GNR, § 6; SW, III, 67-68; AA, I, 3, 369-370.
} 
cuerpo, y así, por esta ulterior determinación de mi cuerpo, también es determinado ulteriormente el mundo sensible. ${ }^{454}$

Como señala Fichte, la introducción de la idea de un cuerpo propio ha completado las conclusiones de los $\S \S 1$ y 2 , y no sólo de la teoría de la relación legal del $\S 4$. Pero Fichte da un paso más y deduce que el cuerpo debe conservar alguna forma de libertad, a pesar de estar afectado por una materia dura e inalterable opuesta a él.

Esto es así porque la materia dura e inalterable es puesta por el yo como perteneciente al mundo sensible, o sea que es el producto de su actividad. El cuerpo es la esfera de las actividades posibles del yo, y la posición de la materia dura e inalterable es parte de esta esfera de acciones posibles. Por lo tanto, el cuerpo debe poder resistir y dominar a la materia dura e inalterable, si es que esta materia debe ser puesta por el yo. Pero, para poder resistir a su influencia, el cuerpo debe también estar compuesto del mismo tipo de materia. ${ }^{455}$

Si el cuerpo del yo está compuesto de materia dura e inalterable, entonces el cuerpo de la otra persona, que lo exhorta a la acción, también lo está. El yo entonces es el objeto de la influencia de la otra persona por medio de leyes causales mecánicas. Dicho de otra manera, la materia dura e inalterable de su cuerpo puede ser afectada por la materia dura e inalterable del cuerpo de la otra persona. Esta influencia puede tener lugar solamente de una manera, toda vez que las leyes causales mecánicas son absolutamente regulares. Pero la exhortación del otro a la acción es una afección del cuerpo del yo, de acuerdo con los fines que se propuso el otro.

La limitación de la propia libertad según fines supone la elección de un fin, entre otros posibles dentro de una esfera de acciones, lo que implica que la acción sea indeterminada e imprevisible. Por eso concluye Fichte que la otra persona ha tratado al destinatario de su acción como un individuo racional (como un cuerpo con sentido) y no como una mera

\footnotetext{
454 "Diese Hemmung der freien Bewegung in meinem Leibe muss ich, zum Behuf der postulirten Entgegensetzung, nothwendig als möglich setzen; und mein Leib ist abermals weiter bestimmt. Als Bedingung derselben muss ich ausser mir setzen eine zähe haltbare Materie, fähig, der freien Bewegung meines Leibes zu widerstehen; und so ist durch die weitere Bestimmung meines Leibes auch die Sinnenwelt weiter bestimmt.“ (GNR, § 6; SW, III, 68; AA, I, 3, 370).

${ }^{455}$ Fichte apunta: "De acuerdo con esto, debo liberarme de la coacción vinculante, por medio del movimiento libre de la parte restante de mi cuerpo, y con ello poder ejercer una causalidad sobre la materia bruta; el cuerpo debe tener fuerza física, para resistir su influjo, si bien mediatamente por medio del arte, es decir por medio de la aplicación de la voluntad a la parte de la articulación que ha quedado todavía libre."

("Ich muss sonach, durch die freie Bewegung des übrigen Theils meines Leibes, den gebundenen des Zwanges entledigen, mithin auch auf die zähe Materie eine Causalität üben können; der Leib muss physische Kraft haben, ihrem Eindrucke, wenn auch nicht unmittelbar durch das Wollen, dennoch mittelbar durch Kunst, d.i. durch Anwendung des Willens auf den noch freien Theil der Articulation, zu widerstehen."; GNR, § 6; SW, III, 68; AA, I, 3, 370).
} 
materia. ${ }^{456}$ Recién luego de este paso se completa la deducción, iniciada en el $\S 4$, de la otra persona como un ser racional. ${ }^{457}$

Ahora bien, si la otra persona ha actuado sobre el cuerpo del destinatario de la exhortación, debe haberlo hecho por medio de alguna materia, toda vez que el cuerpo afectado es material. Pero esta influencia no pudo haber tenido lugar por medio de una materia dura e inalterable, según se dijo más arriba. Por lo tanto, debe haber ocurrido gracias a una materia que afectara a la voluntad, pero de modo tal que la voluntad se limitara a sí misma para no destruir esta influencia, pero conservara de todos modos la facultad de suprimirla si así lo quisiera. Esto es, debe tratarse de una materia más sutil y fina que la materia dura e inalterable. ${ }^{458}$

La materia sutil debe afectar sólo al órgano superior, para así permitir que la voluntad se exprese libremente. De allí se desprende que la materia sutil no puede tener ningún efecto sobre el órgano inferior, porque es un órgano coaccionado y vinculado, por medio del cual el sujeto pone el mundo sensible como independiente de su acción.

La materia sutil es entonces el medio por el que el cuerpo de la otra persona influye sobre el yo y tiene lugar la exhortación. Esto no significa que la materia dura e inalterable no juegue ningún rol en este proceso. Gracias al órgano inferior y su afección por la materia dura e inalterable, el yo puede poner a la otra persona en el mundo sensible. Es decir que la acción es una exteriorización de fuerzas que sólo puede ser conocida por medio del órgano inferior. Por ejemplo, si la exhortación tiene lugar por medio del lenguaje, el lenguaje debe exteriorizarse ante todo por medio de sonidos en el aire o de letras dibujadas en el papel.

Estas son modificaciones de la materia dura e inalterable, que afectan al órgano inferior y por eso pueden ser conocidas por la persona. La persona debe dejar que su órgano inferior ejerza influencia sobre el superior, porque es la única manera de tomar conocimiento de la exhortación de la otra persona. Pero, dado que el órgano superior en realidad imita las

\footnotetext{
456 "Si él me hubiera tomado como una mera materia, y hubiera querido ejercer un influjo sobre mí, entonces hubiera actuado sobre mí del mismo modo en que yo opero sobre todo aquello que considero como materia bruta. Él no ha actuado de esa manera, por esto no ha tenido el concepto de mí como materia bruta, sino como un ser racional, y ha restringido su capacidad de acuerdo con este concepto; y ahora queda la consecuencia por primera vez totalmente justificada y necesaria: la causa de la influencia sobre mí, descripta más arriba, no es otra que un ser racional"

("Hätte er mich für blosse Materie gehalten, und er hätte auf mich einwirken wollen, so würde er so auf mich eingewirkt haben, gleicher Weise wie ich auf alles, was ich für blosse Materie halte, einwirke. Er hat nicht so gewirkt, mithin nicht den Begriff der blossen Materie von mir gehabt, sondern den eines vernünftigen Wesens, und durch diesen sein Vermögen beschränkt; und erst jetzt ist der Schluss vollkommen gerechtfertigt und nothwendig: die Ursache der oben beschriebenen Einwirkung auf mich ist keine andere, als ein vernünftiges Wesen“; GNR, § 6; SW, III, 69; AA, I, 3, 371).

${ }^{457} \mathrm{El}$ cuerpo se transforma entonces en un "(...) punto de encuentro y en un medio del conocimiento recíproco de los seres racionales (...)" ("[...] Treffpunkt und zum Medium der gegenseitigen Erkennung der vernünftigen Wesen (...)“(López-Domínguez, 1999, 276).

${ }^{458}$ GNR, § 6; SW, III, 69-70; AA, I, 3, 371.
} 
modificaciones que recibe del inferior, o sea que las recibe activamente, se reserva siempre para sí la libertad de interrumpir esta afección cuando así lo desee.

Como se dijo más arriba, la relación del órgano superior con el inferior es tal que el superior sufre la afección por parte del inferior y se la apropia, imitándola. El órgano superior reproduce lo percibido en el órgano inferior y, de este modo, accede a la materia sutil a partir de la materia dura e inalterable. Dos ejemplos de Fichte pueden ayudar a aclarar esto. El primero tiene que ver con la apreciación de una obra de arte. Cuando interpretamos una pintura, en primer lugar debemos retener los colores y formas de que está compuesta, es decir reproducir en nuestra cabeza la afección que ha sufrido el ojo. Por eso dice Fichte que

(...) incluso gente inculta, es decir, todavía no suficientemente educada, en la que las disposiciones de la humanidad aún no han llegado a ser capacidades, toca el cuerpo sublime que quiere mirar correctamente o toca la superficie del cuadro, del grabado o del libro que leen. ${ }^{459}$

El segundo ejemplo hace referencia a la relación entre escuchar y hablar. ${ }^{460}$ Una persona no puede hablar mientras escucha lo que otra le dice, porque debe reproducir internamente los sonidos que la otra emite a fin de comprender su significado. La finalidad del oyente es, entonces, la percepción de la materia sutil transmitida por la materia dura de los movimientos de aire o sonidos producidos por el hablante. Cuando alguien pide a otro que repita lo que ha dicho porque no lo ha comprendido, en realidad quiere decir que no ha podido reproducir adecuadamente los sonidos emitidos por él.

Pero también puede ocurrir que la relación entre el órgano superior y el inferior siga la dirección contraria. Es decir, que la persona decida modificar la materia sutil que está bajo su influencia. Para ello, debe operar sobre la materia dura y por lo tanto, actuar por medio de su órgano inferior. Este es el caso, por ejemplo, del escritor que debe modificar un papel dibujando letras sobre él, para poder transmitir un pensamiento o idea estética por medio de la materia sutil del lenguaje. Dice Fichte,

Por ejemplo, asi son formadas en el ojo, como órgano activo, la figura o la letra, y lanzadas sobre el papel antes de que sobre éste la fije la lenta mano del pintor o del escritor, guiada por el ojo y sometida a sus órdenes. En este caso el cuerpo sirve como instrumento. ${ }^{461}$

\footnotetext{
459 “ ‘...) auch ungezogene, d.h. noch nicht genug erzogene Leute, bei denen die Verrichtungen der Menschheit noch nicht zu Fertigkeiten geworden sind, einen erhabenen Körper, den sie recht besehen wollen, oder wohl gar die Fläche eines Gemäldes, eines Kupferstichs, des Buchs, das sie lesen, zugleich betasten.“ (GNR, § 6; SW, III, 71; AA, I; 3, 372).

${ }^{460}$ Cfr. Zöller, (2001), 101.

461 "So wird z.B. im Auge, als thätigem Organ, die Gestalt oder der Buchstabe gebildet, und auf die Fläche hingeworfen, ehe die langsame, durch das Auge geleitete und unter seinem Gebote stehende Hand des Malers oder des Schreibers sie darauf befestigt. - In diesem Falle dient der Leib als Werkzeug." (GNR, § 6; SW, III, 71; AA, I, 3, 373).
} 
Como se dijo más arriba, el cuerpo tiene un sentido en la medida en que sirve a determinados fines. Por eso, en la medida en que opera como un instrumento del órgano superior, tiene un sentido superior. Pero tiene un sentido inferior si pone resistencia al órgano superior y es un mero vehículo del órgano inferior. Esto ocurre, por ejemplo, cuando la mano del poeta no puede, por diversos impedimentos, traducir en letras su pensamiento.

Si volvemos a la relación de influencia recíproca que se da en la exhortación, deberá concluirse que esta interrelación puede tener lugar sólo por medio del sentido superior de cada una de las personas. Esto es, cada persona puede entrar en relación con la otra sólo si tiene en cuenta, en el fin propuesto para su acción, que la otra, en tanto que objeto de esta acción, tiene un sentido superior, y por eso un órgano superior.

En este parágrafo alcanza su determinación completa la argumentación iniciada en el $1^{\circ}$ Teorema ( $(1$ y 2), acerca de la posición del mundo sensible. El mundo sensible es puesto entonces por el yo como existiendo en una relación determinada con su cuerpo, es decir en forma de materia. Pero el cuerpo fue deducido a partir de la acción libre de la persona. Esto es, el cuerpo es puesto por la persona, para poner una esfera de acciones posibles y, dado que lo fundado no puede ir más allá de su fundamento, podemos concluir de esto que el cuerpo no puede existir independientemente del agente o sujeto volente. ${ }^{462}$

A su vez, la condición de posibilidad del agente es la relación de reconocimiento recíproco gobernada por el principio del derecho. Por lo tanto, el cuerpo se deduce a partir del concepto de la comunidad legal. La comunidad legal, como se concluye en el $\S 4$, es establecida por una decisión libre de los individuos, lo que implica que la posición del mundo, a su vez, es un producto de la misma decisión voluntaria. Pero esto no significa que el mundo pueda ser puesto del modo en que ellos quieran, sino que más bien debe ser conocido según las leyes necesarias que rigen la actividad de poner un mundo (causalidad, etc, según el $§ 2$ ).

Fichte argumenta en el $\S 6$ que la persona, a fin de constituirse como tal, debe atribuirse un cuerpo, que se articula en dos órganos, que tienen como objeto sendas formas de materia. ${ }^{463}$ Pero, si admitimos que el carácter de la personalidad implica necesariamente la posición del mundo sensible como materia en relación al cuerpo del yo, y que el impulso externo a la acción le viene al yo de otra persona, debemos aceptar que esta persona pone el

\footnotetext{
462 "El estar dado de mi cuerpo fue concluido a partir de la independencia y la libertad. Pero este existe en la medida en que es puesto. Por eso también, dado que lo fundado no puede ir más allá del fundamento, el cuerpo [existe] sólo para aquello por medio de lo cual es puesto."

("Das Vorhandenseyn eines Leibes wurde geschlossen aus der Selbstständigkeit und Freiheit. Aber diese ist nur, inwiefern sie gesetzt wird: Mithin auch, da das Begründete nicht weiter gehen kann, als der Grund, der Leib nur für den, durch den er gesetzt wird."; GNR, § 6; SW, III, 72; AA, I, 3, 374).

${ }^{463}$ Cfr. el desarrollo de esta conclusión en López-Domínguez, (1999), 285-286.
} 
mismo mundo sensible que el yo y de la misma manera. Esto significa que el yo debe atribuir a la otra persona también un cuerpo articulado en dos órganos, y la capacidad de poner una materia dura y una sutil.

Por consiguiente, tengo que atribuir a la persona externa a mi el hecho de que, en caso de que ella me ponga como persona, admita de mí lo mismo que yo admito de mí $y$ de ella; y al mismo tiempo admita de mí que yo admito lo mismo de ella. ${ }^{464}$

Ambas personas deben compartir entonces ciertos conceptos, a fin de que pueda tener lugar la relación legal: el de sí misma y de la otra como sujetos que articulan su acción por medio de los dos órganos y la posición de los dos tipos de materia. De este modo se profundiza y complejiza la idea del mutuo reconocimiento, propia de los $\S \S 3$ y 4 , donde se trata ante todo de la atribución mutua de la capacidad de restringir la propia libertad en vista de los fines propuestos y de respetar la esfera de acción propia y ajena.

\section{4. La deducción de la "figura" humana en el cuerpo de la otra persona}

Solamente luego de que el otro ha influido sobre el yo exhortándolo a la acción, el yo se constituye como persona y puede actuar. Pero entonces dependería del capricho o de la buena voluntad del otro el exhortar o no al yo a la acción, y por lo tanto el reconocerlo como un ser racional. Esto es, el otro podría ir al encuentro del yo, pero decidir no entrar con él en esta relación intersubjetiva. Si el otro decidiera no entrar en una comunidad legal con el yo, no correría ningún riesgo, ya que seguiría de todos modos existiendo como un ser racional.

El otro no perdería nada y no se ve por qué motivo decidiría entrar en una comunidad legal. Pero la existencia del otro como un ser racional, a su vez, también estaría sometida al arbitrio de un tercero, y así al infinito. De acuerdo con esta objeción, las condiciones de la constitución de una persona podrían explicarse sólo de modo azaroso y contingente, lo que no sería una explicación en absoluto. Puede responderse esta objeción si se encuentra una condición que obligue al otro a ser coherente y a reconocer al yo como un ser racional. Se trata de una condición que debería darse previamente a la acción de la exhortación.

Si el otro ya ha reconocido al yo antes de la exhortación de alguna manera como ser racional, no podrá arbitrariamente dejar de exhortarlo a la acción, sin caer en contradicción consigo mismo. Si reconociera al yo como un ser racional pero decidiera no exhortarlo a la

\footnotetext{
464 "Ich muss demnach der Person ausser mir zuschreiben, dass, falls sie mich als Person setze, sie dasselbe von mir annehme, was ich selbst von mir, und ihr annehme; und zugleich von mir annehme, dass ich dasselbe von ihr annehme.“ (GNR, § 6; SW, III, 73; AA, I, 3, 374).
} 
acción, estaría suponiendo que es racional pero a la vez estaría tratándolo como si no lo fuera. Pero, si el otro aspira a constituirse como una persona, debe respetar ante todo la coherencia lógica en sus acciones. Por lo tanto, se verá lógicamente "coaccionado" a exhortar al yo a la acción. De ese modo, la constitución de la persona no quedaría librada al azar y la contingencia. Se trata del problema de la determinación de la última condición de la existencia de la autoconsciencia. Por eso, su tratamiento exige retomar la argumentación reconstruida en el $\S 1$.

La hipótesis de Fichte consiste en que el otro se ve obligado por la coherencia lógica a exhortar al yo la acción, porque el yo previamente lo ha reconocido como un ser racional. Para demostrar la hipótesis, es necesario concluir que el yo puede actuar sobre la otra persona antes de que lo exhorte a la acción, porque si el yo no actuara no sería posible ninguna forma de reconocimiento. Pero no queda claro cómo es posible que el yo pueda actuar sobre el otro antes de constituirse en sujeto esto es, en un individuo capaz de acción. Fichte concluye que "por tanto, debo actuar sin actuar, actuar sin actividad."

La argumentación de Fichte requiere de una concepción de la persona como una mera facultad que todavía no ha sido actualizada. Pero la facultad de la persona no es otra cosa que la esfera de sus acciones posibles, que existe en la forma de un cuerpo articulado. Por lo tanto, el cuerpo preexiste a la persona, como la posibilidad de que empiece a actuar y se constituya como tal.

Luego, el cuerpo existirá todo el tiempo que exista la persona, porque es idéntico a su capacidad de agencia. Antes de la exhortación, el cuerpo opera sobre la otra persona, pero no en el sentido de que realice alguna acción que afecte al otro, porque el único agente es la persona misma. Esto es, el cuerpo puede expresar la voluntad de la persona, pero no puede llevar a cabo ninguna acción sin una voluntad que lo articule. Más bien debe tratarse de algún tipo de influencia que el cuerpo ejerce por su mera figura (Gestalt), de modo tal que el otro la reconozca como la figura de una persona y, en virtud de la ley de la concordancia consigo mismo, se decida a exhortarla a la acción.

El cuerpo ejerce una influencia sobre la otra persona, a fin de obligarla a que la exhorte por exigencia de coherencia, en tanto que actúa sobre su órgano superior, según lo demostrado arriba. Pero una persona puede influir sobre el órgano superior de la otra en la medida en que modifica la materia sutil, por medio de la cual se da la comunicación. El cuerpo debe ejercer una influencia sobre el órgano superior de la otra persona, antes de que la persona pueda comenzar a actuar a través de él.

\footnotetext{
465 “Ich soll sonach wirken, ohne zu wirken; wirken ohne Thätigkeit” (GNR, § 6; SW, III, 74; AA, I, 3, 375).
} 
Por lo tanto, el órgano superior de la otra persona debe ser modificado en virtud de la mera figura del cuerpo en reposo, existente en el espacio. ${ }^{466}$ La otra persona, en la medida en que es un ser racional, debe concebir a la figura del cuerpo en el espacio como la representación de un ser racional. Es decir, si puede explicarse cómo la otra persona puede conocer que ese cuerpo humano, que está en reposo en el espacio, es el medio de expresión de una voluntad meramente posible, podrá explicarse finalmente cómo es que influye el yo sobre el otro, obligándolo a que lo exhorte a la acción libre.

La conceptualización de un fenómeno culmina cuando se obtiene un todo completo que permita explicar cada una de sus partes, y cuyas partes a su vez pueden dar cuenta de él. Fichte entiende al proceso de elaboración del concepto de un fenómeno, como la recolección de sus elementos hasta que se llega a un punto en el que todos encajan en una totalidad, a la que no le falta nada. Por eso no se puede concebir a tal o cual fenómeno como el cuerpo de un ser racional, si no se conectan los elementos de este fenómeno entre sí hasta llegar a agruparlos en una unidad, que presente los rasgos propios de un ser racional. La argumentación de Fichte es genética, porque recorre un camino que va desde la recolección de los diversos elementos que se presentan en la figura del cuerpo humano en el espacio, hasta la totalidad comprensiva que permite elaborar un concepto del mismo.

El primer paso que debe dar el otro para elaborar un concepto del cuerpo del yo como expresión de una figura humana, surge claramente a la vista de cualquier cuerpo humano. Este se presenta como un todo natural organizado y no divisible en partes, a diferencia de la materia inorgánica. Si se divide un trozo de piedra en partes, el mineral mantendrá su composición en los pedazos resultantes. Pero, si se divide de la misma manera un organismo vivo, se lo destruirá por completo. Entonces, el cuerpo humano no puede ser pensado en analogía con la materia inorgánica, sino más bien con la obra de arte.

Cuando se aprecia una obra de arte, cada parte remite a la otra y, finalmente, a la totalidad, que no puede ser apreciada si se no vuelven a tomar en cuenta cada una de sus partes. Pero la obra de arte está compuesta de partes que están gobernadas por leyes mecánicas, a diferencia del cuerpo humano, cuyas partes son producidas mediante su propia fuerza interna (der innere Bildungstrieb). ${ }^{467}$ Por otro lado, mientras que el fin del producto natural organizado es la producción misma de sus partes, esto es, su propia existencia, la obra

\footnotetext{
${ }^{466}$ Fichte compara por analogía a la materia sutil, modificada por la mera figura en reposo en el espacio, con el aire y la luz. Ambos son inalterables pero visibilizan los fenómenos que en ellos tienen lugar. Su permanencia permite la transmisión de los conceptos de los seres racionales con transparencia (GNR, § 6; SW, III, 76; AA, I, $3,377)$.

${ }_{467}^{4}$ GNR, § 6; SW, III, 78; AA, I, 3, 378.
} 
de arte remite a un autor externo y tiene por finalidad la expresión de determinadas ideas estéticas.

El producto natural, en cambio, se conserva y se produce constantemente a sí mismo. Por ejemplo, cuando la piel es lastimada, se regenera a sí misma. El carácter autorganizado del producto natural tiene su perfecta expresión en los vegetales. El fin último de la planta es la reproducción de su organización, que a su vez es posible gracias a la semilla, con la cual comienza de nuevo el ciclo de la vida del organismo, y así al infinito. La planta es un producto natural organizado, porque su estructura puede ser explicada únicamente en función de la conservación y reproducción de su organización.

Pero el cuerpo humano tiene también un "movimiento libre determinado" (bestimmte freie Bewegung). El hombre y los animales tienen en común este movimiento libre determinado, porque, si bien es libre en cuanto que supone cierta capacidad de acción, es determinado porque está marcado y dirigido por el instinto. Ahora bien, el movimiento libre determinado no está orientado exclusivamente a la reproducción del organismo. Por eso es necesario agregar que se trata de un cuerpo articulado.

Pero el movimiento libre determinado del cuerpo articulado no es suficiente tampoco para construir el concepto de la figura humana. ${ }^{468}$ El movimiento libre determinado conlleva la circunscripción de un “(...) círculo determinado del movimiento arbitrario”,469, esto es, una limitación de los movimientos posibles del sujeto. Pero, como ya se demostró en los $\S \S 1$ al 4 , el ser racional puede determinarse a la acción según una infinidad de fines posibles. Mientras que el animal es un ser acabado y completado en sí mismo, porque su actuar viene determinado por el instinto, el hombre es, en principio, capacidad pura. ${ }^{470} \mathrm{El}$ animal es determinado, pero el hombre es determinable al infinito ${ }^{471}$.

El animal ya está formado, pero el hombre se define por su capacidad para formarse (Bildsamkeit). ${ }^{472}$ Dicho de otra manera, el animal es lo que es y no puede ser otra cosa; el hombre, por el contrario, debe tomar la decisión de actuar como un ser racional. La persona reconocerá la figura del cuerpo humano en el espacio como la representación de un ser racional en la medida en que le atribuya la capacidad de formarse y de constituirse como tal. Para ello deberá aplicar a esta figura humana el concepto de sí misma que necesariamente ya debe poseer por el hecho de ser una persona con capacidad de agencia.

\footnotetext{
${ }^{468}$ Zöller, (2001), 105.

469 “(...) bestimmten Umkreis der willkürlichen Bewegung” (GNR, § 6; SW, III, 79; AA, I, 3, 379).

${ }^{470}$ Schrader, (1972), 81-82.

${ }^{471}$ Cfr. Fischbach, (1999), 59.

472 "La naturaleza ha completado todas sus obras, sólo sacó su mano del hombre, y de este modo lo puso [al hombre] en manos de sí mismo." ("Die Natur hat alle ihre Werke vollendet, nur von dem Menschen zog sie die Hand ab, und übergab ihn gerade dadurch an sich selbst“; GNR, § 6; SW, III, 80; AA, I, 3, 379).
} 
En realidad la persona debe aplicar siempre el concepto que tiene de sí misma a fin de conocer todos los objetos del mundo sensible, dado que esta actividad es constitutiva de la consciencia de sí. Por lo tanto, aplicará también este concepto a la figura humana que encuentra como existiendo en el espacio. Luego, la ley de la concordancia consigo mismo exige que la persona reconozca a esta figura como su semejante y la exhorte a la acción. ${ }^{473}$

Ahora bien, ¿cómo se puede reconocer en concreto a un objeto del mundo sensible como un ser humano? Fichte rechaza el criterio kantiano de la capacidad para la representación de leyes, porque considera que deja indeterminada la cuestión de la identificación del ser racional en el mundo sensible. ${ }^{474}$ El reconocimiento del otro se da de modo inmediato cuando puede constatarse en él una cierta capacidad comunicativa, lo que implica que debe tener algún sentido de la reciprocidad. Si hay una predisposición al diálogo y no una actitud de huida o de ataque, puede concluirse que se está en presencia de un cuerpo humano.

Fichte desarrolla una línea argumentativa adicional para apoyar su demostración con datos biológicos y antropológicos. En primer lugar, Fichte constata que el hombre necesita de la comunicación y de la educación para garantizarse la autoconservación. ${ }^{475} \mathrm{El}$ carácter indeterminado del hombre lo empuja, por así decirlo, a la comunicación con los demás hombres. Dicho de otra manera, el hombre necesita ser educado por otros para transformarse

\footnotetext{
${ }^{473}$ GNR, § 6; SW, III, 80; AA, I, 3, 379.

474 "Kant dice: obra de modo tal que la máxima de tu voluntad pueda ser el principio de una legislación universal. Pero ¿quién debe pertenecer a este reino, que es gobernado por esta legislación, y tener interés en su protección? Yo debo tratar a ciertos seres de modo tal, que pueda querer que ellos a su vez me traten de acuerdo con las mismas máximas. Pero yo actúo todos los días sobre animales y objetos sin cuerpo [que puedan atribuir a sí mismos], sin hacerme esta pregunta en serio. Entonces se me dirá: se entiende que se trata sólo de seres que son capaces de representarse leyes, es decir de seres racionales; y tengo por cierto, en vez de un concepto indeterminado, otro [objeto indeterminado], pero de ninguna manera una respuesta a mi pregunta. Porque ¿cómo sé entonces cuál objeto determinado es un ser racional; si la protección de aquella legislación le corresponde al europeo blanco, o también al negro, o sólo al hombre adulto, o también al niño, o si no debiera corresponderle también al animal doméstico fiel? En la medida en que esta pregunta no es respondida, este principio no tiene, en toda su excelencia, ninguna aplicabilidad ni realidad."

("Kant sagt: handle so, dass die Maxime deines Willens Princip einer allgemeinen Gesetzgebung seyn könne. Aber wer soll denn in das Reich, das durch diese Gesetzgebung regiert wird, mit gehören, und Antheil an dem Schutze derselben haben? Ich soll gewisse Wesen so behandeln, dass ich wollen kann, dass sie umgekehrt mich nach der gleichen Maxime behandeln. Aber ich handele doch alle Tage auf Thiere und leblose Gegenstände, ohne die aufgegebene Frage auch nur im Ernste aufzuwerfen. Nun sagt man mir: es versteht sich, dass nur von Wesen, die der Vorstellung von Gesetzen fähig sind, also von vernünftigen Wesen, die Rede sey; und ich habe zwar statt des einen unbestimmten Begriffes einen anderen, aber keinesweges eine Antwort auf meine Frage. Denn wie weiss ich denn, welches bestimmte Object ein vernünftiges Wesen sey; ob etwa nur dem weissen Europäer, oder auch dem schwarzen Neger, ob nur dem erwachsenen Menschen, oder auch dem Kinde der Schutz jener Gesetzgebung zukomme, und ob er nicht etwa auch dem treuen Hausthiere zukommen möchte? So lange diese Frage nicht beantwortet ist, hat, bei aller seiner Vortrefflichkeit, jenes Princip keine Anwendbarkeit und Realität"; GNR, § 6; SW, III, 80-81; AA, I, 3, 380)

${ }^{475}$ Taver traza un paralelismo en este punto con la idea de Gehlen del carácter contingente y carenciado del hombre (Taver, 2003, 53 - 56). Recuérdese que en el caso de Arnold Gehlen, este carácter de abierto e inacabado del hombre lo lleva a sostener la necesidad de un estado fuerte -el nacionalsocialismo- en donde "anclar" su constitutiva carencia de instintos adecuados al entorno. Y, por cierto, Gehlen apoya su teoría en el propio Fichte.
} 
en humano, en un proceso que comienza con la exhortación a la acción y el reconocimiento implícito en ella. ${ }^{476}$

Cuando el animal nace, ya está completo y determinado por el instinto, porque la naturaleza lo ha equipado ya con todas las herramientas que necesita para sobrevivir. Por ejemplo, el animal recién nacido ya puede moverse hasta su madre y buscar por sí mismo el alimento en su pecho. El hombre, en cambio, necesita que la madre lo busque y le proporcione el alimento que necesita. ${ }^{477}$ Luego hará falta aún una larga educación para poder desempeñarse exitosamente en la vida. Como apunta Fichte, la planta procura la reproducción de su especie por medio de la semilla que arroja en la tierra, pero el género humano puede asegurar su conservación sólo por medio de la educación. La razón misma, que lo define como persona, sólo puede ser conservada si se educa y retiene los descubrimientos de las generaciones pasadas, progresando a partir de ellos. ${ }^{478}$

Fichte también apoya su teoría a partir del estudio de la conformación de los órganos táctiles y prensiles. ${ }^{479} \mathrm{El}$ tacto tiene la función de tomar contacto con la materia para poder manipularla y adaptarla a nuestros fines. El hombre tiene el sentido del tacto distribuido por todo el cuerpo, de modo tal que podría manipular la materia con el órgano que quiera, dado que siempre está en condiciones de tomar contacto con ella. Fichte ve ejemplos claros de esto en aquellos hombres que cosen con los pies o que son ventrilocuos. ${ }^{480}$ Pero el hombre ha puesto su capacidad para manipular la materia en la punta de sus dedos.

El hombre también pudo elegir, a lo largo de su historia como especie, la posición en la que camina o corre. El hombre camina erguido, pero podría hacerlo perfectamente en cuatro patas, como lo demuestran los casos de hombres que se han criado con animales. Los gestos del rostro son imprecisos e indeterminados al momento del nacimiento, pero se desarrollan como producto de la educación y la socialización. Fichte concluye de allí que

Todo esto (...), es lo que fuerza a cualquiera con semblante humano a reconocer y respetar por doquier la figura humana, tanto cuando ella esté meramente sugerida y sea deducida con necesidad por primera vez por él, como cuando se encuentre ya en un cierto grado de perfeccionamiento. La figura humana es necesariamente sagrada para el hombre. ${ }^{481}$

\footnotetext{
${ }^{476}$ Düsing ve en esta idea fichteana semejanzas con el pensamiento de Herbart (Düsing, 1986, 287-288).

${ }^{477}$ Cfr. Philonenko, (1984), $47-48$.

${ }^{478}$ GNR, § 6; SW, III, 82; AA, I, 3, 381.

${ }^{479}$ Cfr. Lauth, (1984), 140.

${ }^{480}$ Cfr. López-Domínguez, (1999), 284.

481 "Dieses alles, (...) ist es, was jeden, der menschliches Angesicht trägt, nöthigt, die menschliche Gestalt überall, sie sey nun bloss angedeutet, und werde erst durch ihn, abermals mit Nothwendigkeit, darauf übergetragen, oder sie stehe schon auf einer gewissen Stufe der Vollendung, anzuerkennen und zu respectiren. Menschengestalt ist dem Menschen nothwendig heilig.“ (GNR, § 7; SW, III, 84-85; AA, I, 3, 383).
} 


\section{5. El cuerpo como condición de la aplicación del derecho}

Como ya se demostró, la figura humana del cuerpo de la persona obliga a la otra, gracias a la ley de la concordancia consigo mismo, a reconocerla como persona y tratarla como tal. Si la persona quiere constituirse en un ser racional, está coaccionada por la coherencia lógica a seguir tratando como un ser semejante a quien en un primer momento ya ha reconocido como tal. Pero nunca podrá reconocer al otro si no respeta su libertad y se sujeta al principio del derecho.

La idea de la comunidad legal, que se erige a partir del principio del derecho, es en realidad un concepto abstracto, mientras no se establezcan sus condiciones de posibilidad en el mundo sensible. Fichte sostiene que el cuerpo es el medio en el que se da la libertad, como el conjunto de acciones posibles para la persona. El derecho se aplica a restringir las esferas de acción de cada persona, es decir, que el cuerpo es el objeto de su regulación. Si cada uno no pudiera atribuirse un cuerpo, entonces no sería posible ninguna comunidad legal ni se podría hacer reinar el derecho entre los hombres. 


\section{Conclusiones del Capítulo 4}

Las teorías de Cohen y Fichte tienen como un común denominador la idea de que la corporalidad de cada ciudadano es una conditio sine qua non del derecho y, por lo tanto, del Estado. En la $E r W$, el derecho no es posible si cada ciudadano no participa en la constitución de esa persona jurídica que es el Estado. Para ello, cada uno debe ser legislarse a sí mismo por medio de sus representantes en el Parlamento.

Pero esto es imposible si cada ciudadano no puede determinarse a la acción, responsabilizarse por sus transgresiones a la ley y, sobre todo, mantenerse en la existencia. Puede decirse que a la base de la teoría de la autonomía hay una exigencia de garantizar a los ciudadanos de todo Estado democrático de derecho, su "derecho a la existencia". La corporalidad es en Cohen la condición fundamental para que el individuo sea un sujeto histórico y tome la parte que le corresponde en la realización de la autoconsciencia.

Fichte también sostiene que el cuerpo es la mediación indispensable para que las autoconsciencias se conviertan en individuos y puedan actuar en el mundo sensible. La corporalidad es el equivalente a la cantidad de libertad de la que dispone cada persona. Esto significa que el cuerpo es el conjunto de las esferas de acción que resulta de la aplicación del principio del derecho. La totalidad de los cuerpos es entonces la comunidad legal misma.

A pesar de que las dos teorías tienen este punto en común, difieren en su idea de la corporalidad. Cohen la entiende como un derecho a garantizar por el Estado, en la forma de una serie de condiciones objetivas para la subsistencia del cuerpo. Fichte, por el contrario, sostiene que el cuerpo exige la autoconsciencia de la persona, porque es el resultado de la atribución a sí misma de una esfera de acciones posibles. Dicho de otro modo, el cuerpo es parte integrante de la autoconsciencia. Esto significa que el cuerpo tiene una estructura reflexiva, porque es parte integrante de la vuelta del yo sobre sí mismo.

Sin embargo, esto no significa que en Fichte el cuerpo se repliegue a la esfera de lo privado, porque esto significaría caer en el solipsismo. Por el contrario, es una condición básica de la regulación de la existencia en común. Esto nos permite sospechar que tiene aún otro elemento en común con la ética de Cohen. Se trata de la idea de un derecho a la existencia, del que me ocuparé en el capítulo siguiente. 
Capítulo 5: El derecho a la existencia 


\section{Capítulo 5: El derecho a la existencia}

Cohen recurrió al concepto de la autoconservación para echar luz sobre el debate que él mismo denominó como la Magenfrage (la cuestión del estómago). Se trataba de la necesidad o no de garantizar la satisfacción de las necesidades básicas de toda la población en orden a la promoción de la ilustración y el progreso.

En este contexto, se objetó al socialismo la reducción del hombre a un estado de animalidad, condenándolo a mantenerse en una existencia bruta. ${ }^{482}$ Cohen, inspirado claramente en las ideas de Feuerbach, respondió a esta objeción señalando que se trataba de un dilema falso, porque la autoconservación es una condición del progreso cultural. ${ }^{483}$ Dicho de otro modo, si el hombre no puede alimentarse, no puede tampoco pensar ni crear. ${ }^{484}$

$\mathrm{Si}$ el hombre vive en la miseria, tampoco tiene la libertad necesaria para autodeterminarse políticamente, porque depende de la dádiva de los poderosos para poder vivir. ${ }^{485}$ Este es uno de los motivos determinantes que llevaron a Cohen a adoptar el ideal cooperativista, que tiene como finalidad que el obrero deje de ser un instrumento para enriquecer al capitalista, y por lo tanto pueda decidir por sí mismo. ${ }^{486}$

La discusión sobre la cuestión de la autoconservación en Fichte es mucho más elaborada que la de Cohen, y tiene sus raíces en su simpatía por la Revolución Francesa y, en particular, por las ideas políticas revolucionarias de Robespierre. La exigencia de Fichte de garantizar a todos los ciudadanos la subsistencia (das Lebenkönnen), es muy similar a los planteos de Robespierre quien, en su discurso del 2 de diciembre de 1792, afirmó que todos los miembros de la sociedad deben tener asegurado el acceso a los frutos de la tierra que son necesarios para su existencia. Este es el sentido de su famosa alocución:

\footnotetext{
${ }^{482} \operatorname{ErW}, 295$

${ }^{483}$ Philonenko, (1989), 74.

${ }^{484} \operatorname{ErW}, 311$.

${ }^{485}$ Cfr. Lübbe, (1963), 244. Es importante señalar que la ausencia de libertad definida como quien vive a merced de los otros se inscribe en una larga tradición filosófico-jurídica que se remonta al derecho romano y la idea del alieni iuris o sujeto de derecho ajeno.

${ }^{486}$ EmkN, 113. Cfr. Ollig, (1979, b), 127.
} 
¿Cuál es el primer fin de la sociedad? Mantener los derechos imprescriptibles del hombre. ¿Cuál es el primero de esos derechos? El de existir. La primera ley social es, pues, la que asegura a todos los miembros de la sociedad los medios para existir, todas las demás se subordinan a éstas: la propiedad no ha sido instituida, ni ha sido garantizada, sino para cimentar aquella ley, es por lo pronto para vivir que se tiene propiedades, y no es verdad que la propiedad pueda jamás estar en oposición con la subsistencia de los hombres. ${ }^{487}$

Este es el sentido del artículo 21 de la Constitución Jacobina de $1793 .^{488}$ Fichte consideraba que todas las instituciones sociales debían cooperar con este fin. Pero ni la nobleza ni la iglesia aportaban nada a la garantía del derecho a la existencia del pueblo. Por eso Fichte proponía dar por anulados los contratos que el Estado tenía con estas instituciones.

Del derecho a la autoconservación de los ciudadanos se deriva la teoría fichteana de las fronteras naturales, que consiste en que el Estado tiene derecho a la cantidad de terreno y recursos naturales que necesita para satisfacer las necesidades de los ciudadanos. Por lo tanto, en caso de necesidad, se puede avanzar sobre el territorio de los demás Estados, ya sea por la fuerza militar o por medios económico-financieros. ${ }^{489}$

Fichte pensaba que este derecho fundamental podía ser garantizado sólo en una economía planificada centralmente, porque no confiaba en la economía de libre mercado. Fichte creía que el libre mercado dejaba a la subsistencia del pueblo librada al azar de que haya gente que quiera ofrecer o buscar tal trabajo o tales mercancías. ${ }^{490}$ El liberalismo podría lograr en el mejor de los casos un mero equilibrio ciego del comercio, liberado de toda reglamentación estatal. ${ }^{491}$

En el capítulo anterior se reconstruyó la argumentación de Cohen en defensa del derecho a la autoconservación, o sea a la subsistencia física. De allí resultó que el concepto de autoconservación juega un rol central en esta teoría, porque es una condición necesaria para el ejercicio de la autonomía por medio de la legislación en el Parlamento.

Como se dijo en el capítulo anterior, se trata del cuarto y último significado de la autonomía, que es la condición de todos los demás. La autonomía es el conjunto de requisitos que deben cumplirse para que los ciudadanos puedan participar en la actividad de la legislación en el Estado y en las diversas instituciones sociales. En primer lugar, la legislación

\footnotetext{
487 “Quel est le premier objet de la société? c'est de maintenir les droits imprescriptibles de l'homme. Quel est le premier de ces droits? celui d'exister. La première loi sociale est donc celle qui garantit à tous les membres de la société les moyens d'exister; toutes les autres sont subordonnées à celle-là; la propriété n'a été instituée ou garantie que pour la cimenter; c'est pour vivre d'abord que l'on a des propriétés. Il n'est pas vrai que la propriété puisse jamais être en opposition avec la subsistance des hommes." Esta cita ha sido tomada del website: http://membres.lycos.fr/discours/discours.htm. Cfr. Buhr, (1991), 43 - 44.

${ }^{488}$ Braun, (1991), 28.

489 Batscha, (1970), 192.

$490 \mathrm{SW}, \mathrm{X}, 554$

$491 \mathrm{SW}, \mathrm{III}, 511$.
} 
puede ser autónoma sólo si es a la vez autolegislación, es decir si los ciudadanos se dan la ley a sí mismos por medio de sus representantes en el Parlamento. Pero la autolegislación presupone a su vez la capacidad de los ciudadanos para iniciar cursos de acción por sí mismos, sin coacción alguna, ni por parte de los otros ciudadanos ni en razón de obstáculos internos. Este es el segundo significado de la autonomía, entendida como autodeterminación.

Ahora bien, no es suficiente con que el ciudadano haya realizado la acción de legislar por sí mismo para hablar de autonomía, porque debe poder identificarse a sí mismo como el autor de esta acción. Por eso Cohen introduce el concepto de la autonomía como autorresponsabilidad, que es un requisito fundamental tanto del cumplimiento de la ley como de la imputación de las transgresiones a la misma. Es decir que el ciudadano podrá someterse a la ley de modo autónomo sólo si considera a este sometimiento como un acto de fidelidad a la promesa de cumplir con esta ley, contraída una vez que la misma fue promulgada. Este es el fundamento también de la aceptación y el cumplimiento de la pena que le corresponde cuando ha cometido un delito, así como el punto de partida para su reintegración paulatina a la vida social.

Pero no tiene sentido decir que el ciudadano se autolegisla por medio de la actividad del Parlamento, se autodetermina a esta acción y se responsabiliza por ella, si no tiene la capacidad de existir como un sujeto corporal y concreto, es decir como éste o aquél individuo. Este es el motivo de la oposición vehemente de Cohen contra la pena de muerte, entendida como la aniquilación de la autoconsciencia del Estado. Pero de ello se deriva aún otra consecuencia de peso, que es la exigencia de que el Estado cuide de que los ciudadanos puedan satisfacer sus necesidades básicas para permanecer en la existencia.

Cohen no establece el mecanismo concreto del que se servirá el Estado para proveer a la subsistencia de todos, pero no sería contradictorio con su teoría la previsión de algún mecanismo para redistribuir bienes y recursos de un modo centralizado. Sin embargo, también podría jugar este rol el sistema de cooperativas que Cohen propone para humanizar el capitalismo y dar al obrero el control sobre el proceso productivo. Estas consecuencias serían compatibles con su teoría, aunque el filosófo de Marburgo no se ocupó de aclararlo de manera definitiva.

Dado que en el capítulo anterior traté en detalle la teoría de Cohen acerca de la autoconservación, no la reconstruiré en este capítulo para evitar repeticiones inútiles. En lo que sigue concentraré mi análisis en la teoría fichteana del derecho de los ciudadanos a la subsistencia por medio de su trabajo. Examinemos con mayor detenimiento su proceder argumentativo. 


\section{El derecho a la existencia}

\section{1. La deducción del derecho de propiedad a partir del concepto de autoconsciencia}

Según lo argumentado en el capítulo 1, el yo se constituye como tal cuando puede acceder a la autoconsciencia, es decir en el momento en que puede atribuirse a sí mismo la acción de conocer un objeto en el mundo sensible, y está en condiciones de saber que es un ser racional. Como se dijo más arriba, esto es posible sólo si otro yo lo exhorta a la acción, es decir, si lo reconoce como un ser racional. Pero esta relación de reconocimiento es imposible si el otro aplica la fuerza o la coacción sobre el yo para que actúe de un modo determinado, porque la exhortación a la libertad requiere que el yo pueda responder a ella como le parezca mejor.

Esta no es la única razón por la que la coacción debe estar excluida de la relación de reconocimiento. El segundo motivo consiste en que no sólo el yo debe ser reconocido por el otro como un ser racional, sino que a su vez el yo debe también reconocer al otro como tal. La razón de esto es que el otro ha reconocido al yo como ser racional sólo problemáticamente, al tomar la decisión de exhortarlo a la acción. Es decir, que aún le queda al otro por confirmar si el yo que ha exhortado a la acción es un ser racional o no. El otro podrá confirmar categóricamente la racionalidad del yo a partir de la respuesta que dé a su exhortación a la acción.

Es decir, si el yo se comporta racionalmente frente a la invitación del otro, entonces el otro podrá confirmarlo plenamente como un igual. Pero el otro podrá saber que el yo se comporta racionalmente sólo si el yo respeta su esfera de libertad y no lo obliga a seguir un determinado curso de acción. Dicho de otro modo, el yo podrá ser reconocido plenamente por el otro como un ser racional en la medida en que él mismo reconozca al otro como tal. Por lo tanto, la relación de reconocimiento que hace posible la autoconsciencia del yo debe ser necesariamente una relación de reconocimiento recíproco.

La condición fundamental de esta relación de reconocimiento mutuo es el principio del derecho, que prescribe a los yoes el respeto de la libertad de acción del otro. El principio del derecho, según el $\S 4$, garantiza a cada persona la misma esfera de acción que aquella de la que gozan todas las demás. Esto significa que cada persona tiene el mismo derecho que las demás a realizar sus fines en el mundo sensible. 
Pero la persona puede llevar a cabo el fin que se haya propuesto, sólo si el mundo sensible está estructurado del mismo modo tanto cuando esta persona lo conoce al elaborar el concepto del fin de la acción, como cuando lleva a cabo el fin propuesto efectivamente en el mundo sensible. ${ }^{492}$ Pero la única perturbación imprevisible del mundo sensible puede provenir sólo de la causalidad libre de otra persona, porque este tipo de causalidad no está sujeta a leyes mecánicas. Por lo tanto, debe neutralizarse esta posible perturbación del mundo sensible por medio de la coacción de la otra persona, esto es, de la determinación de su voluntad según reglas.

El objetivo del derecho civil, que se ocupa de la propiedad, es la delimitación de las esferas de acción de los ciudadanos, y no la mera posesión de objetos en el mundo sensible. ${ }^{493}$ La razón de esto es que el derecho surge de la mutua delimitación de las esferas de acción de las personas, por lo cual la propiedad ya no es el derecho que da el título de propiedad a excluir a otro de la posesión de tal o cual cosa, sino más bien el derecho a excluirlo de la propia esfera de acción. ${ }^{494}$

Este giro copernicano en la concepción de la propiedad implica a su vez un cambio en la concepción de la relación entre la libertad y la posesión de objetos. La libertad no está determinada por la posesión de tal o cual objeto, sino que más bien la posesión de los objetos depende de la esfera de acción que le corresponde al agente, y de la idoneidad de estos objetos como medios para los fines propuestos. ${ }^{495}$

Fichte traslada el debate sobre la propiedad, desde la discusión clásica sobre el derecho de apropiación original de la naturaleza por los individuos, a la dimensión social y comunitaria de la propiedad. ${ }^{496}$ Por eso la investigación de Fichte sobre la propiedad tiene como puntos centrales la distribución del ingreso entre los ciudadanos para garantizar su derecho a la existencia y la división social del trabajo. Se trata de un desplazamiento desde una concepción substancialista de la riqueza hacia una funcionalista. ${ }^{497}$

\section{2. El contrato de propiedad}

\footnotetext{
${ }^{492}$ Cfr. Merle, (1997), 149-150.

${ }^{493}$ GNR, § 18; SW, III, 210; AA, I, 4, 20.

${ }^{494}$ Cfr. Hahn, (2003), 156.

${ }^{495}$ Cfr. Braun, (1991), 18.

${ }^{496}$ Merle, (2000), p. 120; (2001), 159 - 161.

${ }^{497}$ Es decir, que la riqueza no es más la posesión estática de un grupo de individuos privilegiados, sino que está en función de objetivos sociales. Cfr.Philonenko, (1984), 52 - 53. Cfr. Hahn, (2003), 155.
} 
Según lo investigado en el capítulo 3, los individuos deciden formar parte de un Estado sólo para proteger su libertad y su propiedad de los posibles ataques de los demás. Siempre según el capítulo 3, Fichte parte del supuesto del egoísmo universal, del que se desprende la necesidad de que los ciudadanos deleguen todo su poder en un tercero, encargado de dirimir las disputas de derechos. Se trata de los gobernantes, que deben unificar el poder ejecutivo, legislativo y judicial en sus manos, por razones de eficiencia en la aplicación del principio del derecho.

Entonces el pueblo desaparece como comunidad soberana en el acto de la firma del contrato de transferencia de su poder al Estado. Pero el gobierno omnipotente, que resulta de este acto contractual, sigue de algún modo supeditado al control del pueblo por medio de la institución del eforato. Los éforos son los encargados de llamar a la asamblea popular y dictar el interdicto, si llegaran a tener elementos suficientes para demostrar que el gobierno ha atentado contra la Constitución.

De acuerdo con la idea fichteana del contrato de ciudadanía, la propiedad debe ser garantizada en dos sentidos. En primer lugar, cada ciudadano debe conservar sólo su esfera de actividad declarada ante los demás y reconocida por ellos, y dejar el resto para los demás, esto es, abstenerse de pretender su posesión (según el contrato de propiedad). Asimismo, debe cuidarse de que cada ciudadano ceda parte de su propiedad para proveer a la defensa de la propiedad de todos los demás, esto es, en orden a la conservación y el funcionamiento del Estado. El sostenimiento del Estado exige el pago de impuestos, la imposición de diferentes cargas públicas sobre los ciudadanos, etc. (en el espíritu del contrato de protección).

Dado que el derecho de propiedad se ejerce sobre esferas de acción, en realidad está orientado a la garantía de la realización de fines que sean compatibles con los fines de otras personas. ${ }^{498}$ Se trata de la regulación de las metas de acción que se propone cada uno, porque la propiedad de cada uno es en realidad la parte del mundo sensible que nos permite usos posibles de cosas materiales. ${ }^{499}$

Fichte fundamenta el derecho de propiedad fundamental de la ciudadanía, el derecho a la existencia (o a poder vivir, das Lebenkönnen), a partir del análisis de la acción misma. ${ }^{500} \mathrm{La}$

\footnotetext{
${ }^{498}$ Cfr. Rickert, (1922/1923), 161. En este sentido, es posible encontrar una analogía con el concepto kantiano de propiedad privada, que sólo adquiere legitimidad si es compatible con la libertad (y por tanto la propiedad) de todos.

${ }^{499}$ Merle, (2000), 123.

500 Si bien Fichte no utiliza la expresión de "derecho a la existencia", sino más bien de "poder vivir" (das Lebenkönnen) o de "mínimos de existencia" (Existenzminimum), prefiero utilizar esta denominación, porque expresa con claridad la idea que Fichte tiene en mente. Como se puede ver a partir de esta investigación, Fichte defiende la idea de un derecho a la existencia que el Estado debe garantizar por medio de ciertos mecanismos redistributivos, como correlato de la asignación de un puesto de trabajo a cada ciudadano. Si el Estado no
} 
persona, esto es, el ser racional en tanto que ejerce su causalidad en el mundo sensible, se propone, en el concepto del fin, su propia autoconservación, como se argumenta en el $\S 11 .^{501}$ Esto es, cuando una persona elabora el fin de su acción, cualquiera que esta sea, necesariamente incluye en él la condición de poder percibir el estado de cosas que se propone lograr.

Un estado de cosas no es algo que exista independientemente del sujeto cognoscente, sino que es más bien una construcción de la consciencia misma, de la actividad libre del yo sujeta a leyes, según el $\S 2$. Entonces, cuando una persona se propone realizar un fin determinado, espera necesariamente poder conocer ese estado de cosas, porque en caso contrario éste no podría darse. Lo que es decir que cada persona quiere, con el fin de su acción, permanecer existiendo como tal en el futuro. ${ }^{502}$

Pero este argumento se aplica sólo en la eventualidad de que el sujeto quiera constituirse en un ser racional. En el derecho, como se argumenta en relación con el problema del derecho de coacción en el $\S 14$, se debe suponer que cada ciudadano tiene una voluntad mala, esto es, que no determina su voluntad por la ley de la coherencia consigo mismo, sino meramente por el auto-interés, sin consideración para con la propiedad de los demás. Si el sujeto no quiere constituirse en una persona, entonces debe ejercerse un mecanismo de coacción sobre su voluntad, de modo tal que, a fin de satisfacer su propio interés, deba tomar en consideración inevitablemente la libertad y propiedad de los demás.

\section{3. La deducción del derecho a la existencia a partir del concepto del cuerpo humano como un producto natural organizado}

Movido por el supuesto del egoísmo universal, Fichte abandona el argumento a partir de la acción de una persona o ser racional, para pasar a considerar el modo en que actúan todos los sujetos, aún quienes no decidan comportarse de modo racional. En vistas de este objetivo, Fichte reorienta su investigación y se pregunta si este fin no podrá hallarse en la constitución del cuerpo humano mismo, toda vez que siempre y en todo caso la acción en el mundo sensible es posible gracias a la atribución a sí mismo de un cuerpo articulado.

garantiza la subsistencia, entonces el ciudadano tiene derecho a romper con el contrato social, y ya no está obligado a respetar la ley.

${ }^{501}$ Merle, (1997), 165-166.

${ }^{502}$ Cfr. De Pascale, (1988), 605. 
El problema a considerar es, entonces, de qué modo está prevista, en el funcionamiento del cuerpo humano, esta tendencia inevitable de la persona a permanecer existiendo en el futuro. Si se pudiera constatar que el cuerpo tiene una tendencia a la autoconservación, entonces puede decirse que el cuerpo de todo sujeto, sea o no sea una persona, dispone de mecanismos que permiten determinar la voluntad en orden a querer su propia autoconservación.

Fichte fundamenta sus conclusiones en los resultados de su investigación acerca del cuerpo humano articulado, que ha sido examinada en el capítulo 4 de este trabajo. Allí se concluyó que el cuerpo articulado es un producto natural organizado, esto es, una totalidad orgánica. La naturaleza puede ser pensada sólo teleológicamente, como teniendo una finalidad que determina a su vez los fines de cada una de sus partes. Si el cuerpo tiene la función de realizar acciones libres en el mundo sensible, entonces debe tener algún mecanismo inmanente que le permita realizar este fin.

En primer lugar, Fichte argumenta que, dado que la voluntad debe representarse necesariamente, en el concepto del fin de su acción, su propia permanencia en el futuro, sus acciones deben asegurar inevitablemente la persecución de su autoconservación. ${ }^{503}$ La acción debe estar íntimamente unida a la autoconservación.

Pero no debe estar condicionada por un mecanismo tal como un deseo del futuro. Esto no permitiría explicar el modo en que la naturaleza se asegura de que el cuerpo busque su autoconservación, porque podría ocurrir que algunos sujetos no tengan deseo alguno de realizar algo en el futuro, y en este caso, no se podría fundamentar la autoconservación.

El deseo del futuro, en realidad, nos lleva a una aporía, porque para ello debe recurrirse a la estructura de la acción humana. Veamos en qué consiste este círculo argumentativo. Si se fundamenta el deseo del futuro a partir de la acción presente, postulándolo como un elemento constitutivo de la misma, se vuelve al punto de partida, porque la acción presente sólo puede ser explicada en base al deseo del futuro, toda vez que es la consecuencia de la anticipación que ha hecho previamente el agente del estado de cosas que quiere lograr con la acción.

Fichte propone salir de este círculo argumentativo por medio de la constatación de un mecanismo inherente al cuerpo y que permite dar cuenta de su deseo de autoconservación. Se trata del dolor que le produce al cuerpo la falta de nutrición y de hidratación, es decir, el hambre y la sed. Estos mecanismos fisiológicos provocan tal dolor en el cuerpo, que la voluntad se determina siempre y en todo momento a calmarlo.

\footnotetext{
${ }^{503}$ GNR, § 18; SW, III, 211; AA, I, 4, 21.
} 
De este modo, la naturaleza, como totalidad organizada teleológicamente, permite explicar la necesidad del cuerpo de autoconservarse. Este es el móvil (Triebfeder) básico y fundamental de toda actividad del cuerpo $y$, toda vez que el cuerpo es la condición de posibilidad de la actividad libre sobre el mundo sensible, la autoconservación es el último móvil y objetivo de la acción de toda persona. Por esta razón, el Estado debe garantizar la nutrición e hidratación de todos sus ciudadanos, si pretende asegurar su libertad. ${ }^{504}$ Este es el sentido de estas afirmaciones de Fichte:

Por lo tanto, el objetivo último y universal de toda actividad libre es el poder vivir. Todos se proponen esta meta; $y$, en la medida en que es garantizada la libertad en general, este objetivo es garantizado. Sin el logro [de esta meta] la libertad y la continuidad de la persona no serían posibles en absoluto. ${ }^{505}$

De aquí se desprende que el derecho constitutivo y fundamental de la ciudadanía es el derecho a la existencia. ${ }^{506}$ Fichte plantea, por un lado, que la autoconservación (el poder-vivir, la subsistencia) es el fin supremo de toda actividad humana, mientras que, cuando define el derecho original (Urrecht), entiende a la actividad libre como último fin. Pero, ¿cómo podemos ser libres, si nuestro fin supremo es la obediencia al determinismo de la naturaleza (la satisfacción del hambre y la sed)? ¿No es la autoconservación más bien el supuesto de todo fin, antes que el fin supremo mismo? ${ }^{507}$

La relación entre la libertad y la naturaleza debe entenderse aquí más bien en sentido teleológico, ya que en la teoría de Fichte el logro de la autoconservación es el primer paso en la liberación del determinismo de la naturaleza, de la necesidad y la dependencia ${ }^{508}$. El ordenamiento legal apunta meramente a la conservación material de los hombres, y no se ocupa de su perfeccionamiento moral y espiritual (objeto de la teoría moral). ${ }^{509}$

\section{4. El derecho a la existencia y la obligación de trabajar}

\footnotetext{
${ }^{504}$ Verweyen, (1975), 115.

505 "Der höchste und allgemeine Zweck aller freien Thätigkeit ist sonach der, leben zu können. Diesen Zweck hat jeder; und wie daher die Freiheit überhaupt garantirt wird, wird er garantirt. Ohne seine Erreichung würde die Freiheit, und die Fortdauer der Person, gar nicht möglich seyn.“ (GNR, § 18; SW, III, 212; AA, I, 4, 22).

${ }^{506}$ Fichte complementa en otros textos el ideal del mero Lebenkönnen con el más ambicioso de una angenehmes Leben. Fichte toma este ideal del pietismo, esto es, una vida en la cual el hombre no sea tratado como un animal de carga (Lasttier), sino que pueda llevar una vida decente de acuerdo a su función social (ej., un campesino puede darse por satisfecho con una alimentación vegetariana y la posibilidad de ir a trabajar con zapatos de madera y usar en los días festivos zapatos de cuero, mientras que el sabio necesita de una alimentación variada y de un reine Umgebung). Cada uno debe poder trabajar con alegría y poder ver el cielo en condiciones de tranquilidad (Der geschlossene Handelstaat, SW, III, 414 ff.). Cfr. el ejemplo de los Herrenhuter (Excurse zur Staatslehre, SW, VII, 609) (Cfr. Hell, 2003, 137; Merle, 1997, 204).

${ }^{507}$ Merle, (2001), $167-168$.

${ }^{508}$ Merle, (2000), 127-128; (2001), 169.

${ }^{509}$ Merle, (2001), 169.
} 
En el contrato de propiedad, cada ciudadano se compromete a no impedir al otro la realización de los fines que se propone en el mundo sensible. El derecho a la existencia determina entonces claramente el significado del contrato de propiedad, de modo tal que puede resignificarse a partir de la inclusión de la protección del derecho del otro a la existencia. ${ }^{510}$ El cuerpo es la totalidad de la esfera de acciones posibles del otro, por lo tanto su protección implica el respeto por la libertad del otro. Este es el sentido del principio que debe contener toda constitución que aplique el derecho natural, y dice: "cada uno debe poder vivir de su trabajo" (Jederman soll von seiner Arbeit leben können). ${ }^{511}$

Por eso la unidad de distribución de la propiedad es la profesión u oficio que cada ciudadano desee desempeñar. Esta constituye el contenido concreto de la esfera de acción de cada ciudadano y, dado que el último fin de cada acción es satisfacer las necesidades de nutrición del agente, la profesión u oficio del ciudadano debe permitirle vivir de ella. ${ }^{512} \mathrm{La}$ tarea más propia y original del Estado, en virtud del contrato de ciudadanía, es la regulación de las instituciones de modo tal que este que sea posible que cada uno viva de su trabajo, como veremos más adelante. ${ }^{513}$

El ejemplo que pone el mismo Fichte aclara el sentido de este principio: en un pueblo de ciudadanos que anden desnudos no tiene sentido desarrollar el oficio de sastre, porque un sastre no podría vivir allí de su trabajo. ${ }^{514} \mathrm{Si}$ el Estado reconoce la pretensión del ciudadano de realizar tal o cual oficio, esto es, si reconoce su propiedad declarada, entonces debe garantizar las condiciones para su realización. ${ }^{515}$ Volviendo al ejemplo del sastre, si los ciudadanos reconocen su derecho a ejercer este oficio, deben comprometerse a comprarle sus

\footnotetext{
${ }^{510}$ Los padres de Fichte habían sido siervos que luego fueron liberados, pero vivieron siempre en condiciones de extrema pobreza. Fichte, a pesar de haber alcanzado una existencia holgada como académico, nunca olvidó sus orígenes y procuró que los ciudadanos de su Estado justo no sufran las penurias que pasaron sus padres (Wood, 2004, 95).

${ }_{511}$ GNR, § 18; SW, III, 212; AA, I, 4, 22.

${ }^{512}$ Taver constata similitudes entre esta concepción de Fichte, relativa a la autoconservación del hombre por medio del trabajo y no en virtud de un instinto infalible como en los animales, y la teoría de Gehlen (Cfr. Taver, 2003, $56-57)$.

${ }^{513}$ Por eso puede decirse que en Fichte no hay ciudadanos "abstractos", sino siempre "concretos", dado que se definen de acuerdo a su rol y lugar en la división racionalizada del trabajo. De este modo, el ciudadano logra su individualidad y particularidad en la medida en que participa en la lucha de su comunidad contra la naturaleza por medio del trabajo. El status social del inidividuo caracteriza su definición como ciudadano (Batscha, 1981, 276-277).

${ }^{514}$ GNR, § 18; SW, III, 213; AA, I, 4, 23.

${ }^{515}$ Sobre la relación entre el derecho a trabajar y el organicismo implícito en la teoría del contrato de unificación, Cfr. Batscha, (1981), 275. Véase el interesante paso del oficio a la propiedad declarada, esto es, y en continuidad con la tradición kantiana, que el oficio de cada uno se considera como formando parte de la propiedad y, por ende, es un aspecto constitutivo de la libertad exterior o sensible.
} 
trajes. ${ }^{516}$ Estos son el producto de su trabajo, y sólo así podrá vivir de su oficio. ${ }^{517}$ Respetar la propiedad del individuo significa reproducir las condiciones que hacen posible esa propiedad.

El hombre no es un sujeto aislado, sino que está siempre inmerso en relaciones sociales, y su libertad externa está condicionada por la actividad de cada uno de los demás, de acuerdo con el rol que cada uno ocupa en la división del trabajo ("en su puesto propio", an ihrer eigenen Stelle). ${ }^{518}$ Por lo tanto, el Estado tiene un derecho absoluto sobre los recursos o medios de producción, dado que tiene la obligación inexcusable de distribuirlos entre todos los ciudadanos. Pero cada uno puede disfrutar como quiera y sin limitaciones del producto de su trabajo, siempre y cuando este disfrute no implique la cooperación y el trabajo de otros, en cuyo caso deberán tomarse en consideración también los derechos de los demás. ${ }^{519}$

La consecuencia necesaria de este principio es que cada ciudadano tiene derecho a coaccionar a todos los demás, por medio de las instituciones del Estado, para que cumplan con el compromiso, que han adquirido en el contrato de ciudadanía, de garantizarle el ejercicio de un oficio o profesión. ${ }^{520}$ Además, cada ciudadano tiene derecho a obligar al Estado a que ponga las condiciones necesarias para que él pueda vivir de la profesión u oficio, cuyo desempeño el Estado se ha comprometido a garantizar. ${ }^{521}$

Si su derecho a la existencia no está garantizado, el ciudadano no está obligado a reconocer la propiedad de los demás, porque han violado y anulado el contrato de propiedad, constitutivo de la ciudadanía. Todos los demás tienen la obligación de ceder la parte de sus propiedades que el Estado necesite para satisfacer esta demanda. En realidad, estas propiedades pertenecen al ciudadano necesitado por derecho, y por eso deben ser

\footnotetext{
${ }^{516}$ Cfr. Batscha, (1970), $184-187$.

517 En caso de que un ciudadano no pueda vivir de su trabajo, tiene derecho a pedir al Estado apoyo y la designación de un nuevo puesto de trabajo. Esta idea se corresponde con la realidad social de la Alemania de la época de Fichte, en la que un grupo social no podía asegurarse la subsistencia por medio del trabajo (los campesinos) y el otro grupo no quería trabajar (la nobleza) (Batscha, 1970, 178-179; 1981, 278).

518 (SW, VII, 577 - 578) (Cfr. Braun, 1991, 24 - 25).

${ }^{519}$ Merle, (2001), 171.

${ }^{520}$ Cfr. Hammacher, (2004), 200.

${ }^{521}$ El rol del Estado en la organización de la división coloca a la teoría de Fichte, según Rickert, en la tradición del socialismo. "Él exige un Estado que regula también la vida económica y se convierte en un Estado social. La organización política del trabajo es en realidad aquello que puede caracterizarse como la exigencia socialista más universal. Dado que Fichte defiende esta exigencia, pertenece a los socialistas" ("Er verlangt einen Staat, der auch das ökonomische Leben regelt und so zum Sozialstaat wird. Politische Organisation der Arbeit ist geradezu das, was man als die allgemeinste sozialistische Forderung bezeichnen kann. Deswegen, weil Fichte sie vertrat, gehört er zu den Sozialisten“; Rickert, ,1922/1923, 163).
} 
redistribuidas por el Estado. ${ }^{522}$ Cada uno tiene derecho a la posesión de tales o cuales objetos o privilegios, sólo si los demás ciudadanos pueden vivir de su trabajo. ${ }^{523}$

La necesidad de coaccionar a los ciudadanos para proteger la propiedad de cada uno de los demás, no es otra cosa que el contenido del contrato de protección, que constituye la segunda parte del contrato de ciudadanía. El ciudadano es protegido no sólo cuando los demás son coaccionados para que respeten su integridad física o sus propiedades, sino sobre todo cuando se les obliga a que entreguen sus propiedades a quien las necesita para vivir.

Pero el derecho a la existencia tiene también otras consecuencias. Si cada ciudadano debe poder vivir de su trabajo, entonces no sólo debe recibir del Estado las condiciones para trabajar, sino que también debe administrar los bienes y derechos que le han sido otorgados, de modo tal de poder autoconservarse. El Estado tiene, entonces, el derecho de inspeccionar (Aufsicht) el modo en que los ciudadanos se ganan el pan, de modo tal de coaccionar a los ociosos (Müssiggänger) para que se pongan a trabajar. ${ }^{524}$ Dicho de otra manera, si los ciudadanos tienen el derecho a trabajar para vivir, adquieren de este modo la obligación correlativa de hacerlo. ${ }^{525}$

El correctivo que permite evitar los problemas que acarrea la atenuación del "riesgo de vida" (Lebensrisiko) por parte del Estado (paternalismo, asistencialismo, etc.), es la obligación de trabajar (Arbeitspflicht). ${ }^{526}$ Por lo tanto, el contrato de ciudadanía se lleva cabo concretamente cuando el ciudadano declara oficialmente la profesión u oficio en la que quiere trabajar y este derecho le es reconocido por el Estado. ${ }^{527}$ Debe quedar claro y libre de malentendidos el tipo de ocupación pretendido, de modo tal que el Estado pueda arbitrar todos los objetos y derechos de que tiene necesidad el ciudadano para ejercer su profesión u oficio. $^{528}$

\footnotetext{
${ }^{522}$ Fichte comparte con Rousseau el ideal de una sociedad sin ricos ni pobres, en la cual todos los ciudadanos tengan algo pero ninguno demasiado. Piensa en una sociedad de pequeños productores de mercancías (Kleinwarenproduzenten), esto es, de una robusta clase media, que busca asegurar su existencia en una comunidad que todavía no conoce la acumulación de capital (Batscha, 1981, 274).

${ }^{523}$ Lo novedoso de la postura de Fichte es que fundamenta la obligación del Estado de distribuir la riqueza desde una perspectiva que a partir del siglo XIX llamaríamos liberal, esto es, desde el derecho inalienable de los ciudadanos a llevar su vida privada como ellos quieran (feliz o no, virtuosa o no, etc). El objetivo del Estado es, en todo caso, el asegurar que ningún individuo sea tan pobre como para no poder llevar una vida libre e independiente y que nadie tenga tanta riqueza como para poder reducir a los demás a una posición de dependencia o de ausencia de libertad (Cfr. Wood, 2004, 96-99).

${ }^{524}$ GNR, § 18; SW, III, 214; AA, I, 4, 23.

${ }^{525}$ Cfr. Braun, (1991), 32.

${ }^{526}$ Braun, (1991), $31-32$.

${ }^{527}$ Si bien Fichte a veces habla de "Klasse", el "Stand" no debe ser confundido con el concepto moderno de clase, ya que significa el trabajo o el rol que le toca objetivamente al individuo en el proceso de trabajo (Beruf). Es el punto de unión (Bindeglied) entre el individuo y la sociedad (Batscha, 1970, 212).

${ }^{528}$ Esto es, Fichte sostiene la necesidad de una economía planificada burocráticamente (Batscha, 1981, 274). Para poder salvar a la persona de la inseguridad respecto de su propiedad, es necesaria también la Planwirtschaft,
} 
El ciudadano tiene derecho a aquellos objetos que le son indispensables para su tarea, y a nada más. Con palabras de Fichte,

En este sentido, el contrato dice: cada uno promete hacer todo lo que esté a su alcance, para poder vivir de las libertades y los derechos que le han sido concedidos; frente a esto, la comunidad [promete] en nombre de todos los particulares, adjudicarle más [libertades y derechos], en caso de que sin embargo, no pueda vivir [de ellos]. Todos los particulares se comprometen a aportar para este fin (...) y en el contrato de ciudadanía está prevista una institución de asistencia, así como es establecido un poder de protección. Tanto la adhesión a la primera como al segundo, son condiciones para el ingreso en el Estado. El poder del Estado tiene la supervisión suprema de esta parte del contrato, así como sobre todas las partes del mismo, y [tiene] tanto el derecho de coacción como el poder para obligar a cada uno a cumplir con el mismo. ${ }^{529}$

Puede parecer arbitraria la determinación de la ciudadanía en base al oficio o la profesión que desempeña cada uno. Sin embargo, este requisito tiene un fundamento que es coherente con el resto de la teoría. El motivo por el cual Fichte vincula a la adquisición de la ciudadanía con el rol que cada persona juega en la división del trabajo, tiene que ver con las características mismas de la tarea que ocupa a los ciudadanos en cada puesto de trabajo.

Es decir, la parte del mundo sensible sobre la que trabaja cada profesión u oficio tiene tal complejidad que exige un conocimiento minucioso y complejo de la misma. Por lo tanto, para que la división del trabajo sea eficaz, debe impedirse que los ciudadanos puedan rotar de ocupación constantemente. A continuación reconstruiré, en sus rasgos esenciales, la teoría fichteana de la división del trabajo, a fin de aplicar los principios generales explicados más arriba.

\footnotetext{
dado que en caso contrario ella quedaría abandonada al azar (Zufall) de las fuerzas ciegas del libre mercado (Fonnesu, 1997, 96).

529 "Der Vertrag lautet in dieser Rücksicht so: Jeder von allen verspricht, alles ihm mögliche zu thun, um durch die ihm zugestandenen Freiheiten und Gerechtsame leben zu können; dagegen verspricht die Gemeine, im Namen aller Einzelnen, ihm mehr abzutreten, wenn er dennoch nicht sollte leben können. Alle Einzelne machen sich für diesen Behuf zu Beiträgen verbindlich, so wie sie es zum Schutze überhaupt gethan haben, und es wird eine Unterstützungsanstalt sogleich im Bürgervertrage mit getroffen, sowie eine schützende Gewalt errichtet wird. Der Beitritt zu der ersteren ist, wie der Beitritt zu der letzteren, Bedingung des Eintritts in den Staat. Die Staatsgewalt hat die Oberaufsicht über diesen Theil des Vertrages, sowie über alle Theile desselben, und Zwangsrecht sowohl als Gewalt, jeden zur Erfüllung desselben zu nöthigen" (GNR, § 18; SW, III, 215; AA, I, 4, 23-24)
} 


\section{La propiedad de los productores (die Producenten)}

Fichte denomina a la clase social más amplia y básica de todas como los productores, porque son quienes obtienen la materia prima, con la cual los artesanos elaboran los productos que consumen los ciudadanos. Dado que el objetivo supremo del Estado es garantizar la subsistencia de todos los ciudadanos, la base de la pirámide social está constituida por quienes obtienen de la naturaleza los medios necesarios para la nutrición de todos. ${ }^{530} \mathrm{El}$ derecho de propiedad adquiere diferentes formas según las actividades que llevan a cabo los productores. Por eso analizaré por separado cada una de ellas: la agricultura, la ganadería, la caza y, dentro de ella, la pesca (que tiene un status jurídico sui generis, como se verá).

\subsection{La agricultura}

Fichte considera que la actividad de la agricultura es muy importante, dado que el derecho básico de la ciudadanía es poder vivir de su trabajo. Es decir, cada ciudadano debe poder alimentarse e hidratarse, y el cultivo del suelo permite extraer los nutrientes necesarios para asegurar la autoconservación de todos los ciudadanos. Sin embargo, podría planificarse la economía del Estado de modo tal que la nutrición de los ciudadanos sea asegurada por medio de la recolección de frutos silvestres. Pero, por el contrario, Fichte otorga una prioridad absoluta a la agricultura por sobre la recolección. ${ }^{531}$ La recolección presenta dos problemas: en primer lugar, no garantiza necesariamente la cantidad de alimento necesaria para los nuevos ciudadanos, en caso de un crecimiento demográfico intenso, porque la naturaleza, que actúa regularmente, produce siempre la misma cantidad.

En segundo lugar, tampoco asegura la protección de la cantidad actualmente producida de alimentos respecto de los accidentes climáticos, porque depende absolutamente de los

\footnotetext{
${ }^{530}$ Fichte toma de los fisiócratas la idea de que la economía puede basarse sólo en la agricultura, que es la única actividad productiva. Por eso concibe al comercio como el intercambio de mercancías sin que esta actividad implique un cambio alguno en el valor de las mercancías intercambiadas. Esto es, no se ve al mercado como formador de precios y de valor (Hammacher, 2004, 202).

${ }^{531}$ Cfr. "Lo que crece de modo salvaje debe ceder su lugar en todos lados al cultivo, porque por medio de esto último puede asegurarse mejor la subsistencia, que a través de lo primero. Por lo tanto, todas las tierras sin cultivar deben ser repartidas, en la medida en que la necesidad de cada uno así lo exija; y lo que cada uno quiere poseer para llevar a cabo la agricultura, no debe quedar sin cultivar."

"Der wilde Wuchs muss allenthalben der Cultur weichen, weil durch die letztere mehr Unterhalt gewonnen wird, als durch den ersten. Jene unangebauten Ländereien müssen sonach vertheilt werden, sobald das Bedürfniss der Einzelnen es erfordert; und was irgend Jemand zum Acker besitzen will, darf nicht unangebaut liegen." (GNR, § 19; SW, III, 220; AA, I, 4, 28).
} 
caprichos de la naturaleza. La agricultura presenta la ventaja sobre la recolección de que es un arte, porque está orientada a la transformación de la naturaleza conforme a reglas. ${ }^{532}$ Se trata de una actividad que puede planificarse y se adecua mejor a la economía centralizada del GNR.

El ciudadano que desee trabajar como agricultor debe, como todos los demás, declarar su voluntad expresa en la oficina correspondiente. Si el Estado está en condiciones de garantizarle un puesto, reconocerá y certificará oficialmente su derecho a cultivar el campo. Pero el reconocimiento de este derecho conlleva, necesariamente, la garantía de todos los objetos y derechos indispensables para tal fin. Ante todo, el agricultor deberá recibir, entonces, la propiedad del suelo que trabaja. La adjudicación de la propiedad del suelo al agricultor presenta en primer lugar un problema, porque el suelo es el apoyo de todas las personas en el mundo sensible.

Es, pues, un objeto de propiedad común y no parece razonable excluir de su uso a un grupo para garantizárselo a otro. Por otro lado, si el uso de la tierra es común, entonces no puede aceptarse su propiedad exclusiva, porque nunca podría ser determinada en vistas de una actividad particular. Por lo tanto, para poder dar razón de la propiedad del suelo por parte del agricultor, es necesario determinar su necesidad en función de la actividad que le ocupa. Fichte fundamenta la propiedad del suelo por parte del agricultor del mismo modo en que ha pensado el derecho de propiedad en general. El campesino debe cultivar la tierra siguiendo las leyes de la naturaleza, por lo cual el suelo no debe ser alterado arbitrariamente por otras personas. En caso contrario, el agricultor no podría siquiera proponerse el fin de cultivar la tierra y no podrá vivir de su trabajo.

Por lo tanto, el suelo le pertenece al agricultor, pero sólo en función de su actividad. ${ }^{533}$ Fichte utiliza la terminología aristotélica para aclarar la distinción que acaba de trazar: nadie puede poseer el suelo como substancia, esto es, poseerlo sin más y de modo absoluto. Más bien sólo se lo puede poseer en base de algún accidente del suelo, es decir, de su idoneidad para la agricultura. ${ }^{534}$

De acuerdo con esto, el mismo suelo queda sujeto a la propiedad de otras personas, si éstas lo necesitan para trabajar y su tarea no obstaculiza a la del campesino. Este sería el caso,

\footnotetext{
${ }^{532}$ Fichte entiende al tala de bosques no como una actividad del tipo de la recolección de frutos silvestres, sino más bien como un tipo de arte análogo al de la agricultura, y reclama la propiedad del suelo sobre el que crecen los árboles para el leñador (GNR, § 19; SW, III, 220; AA, I, 4, 28).

${ }_{533}^{53}$ GNR, § 19; SW, III, 217-218; AA, I, 4, 26.

534 Téngase en cuenta que esta misma distinción entre substancia -el suelo- y accidentes -los productos del trabajo del suelo- es la que utiliza Kant para oponerse a la teoría lockeana de la propiedad privada producto del trabajo agregado ( $M d S$, AA, VI, 265). Además, es evidente que Fichte conoce la vieja distinción entre dominium -posesión absoluta- y posesión ligada al uso del suelo sin que eso implique la posibilidad de abuso, alienación, y exclusividad.
} 
por ejemplo, del minero que utiliza el subsuelo del campo, siempre y cuando no arruine el suelo o vuelva peligroso el andar sobre él. Lo mismo para quien quisiera aprovechar el campo, luego de la cosecha y antes de que se vuelva a sembrar, con la finalidad, por ejemplo, de criar ganado.

El Estado debe velar por la protección de la propiedad del campesino. Para esto es necesario poner mojones (Grenzsteine) en los límites del campo, y castigar a su vez severamente a quien los destruya o traslade a otro lugar. Si el campesino no puede vivir de su trabajo, deberá adjudicársele parcelas cada vez mayores, a fin de asegurarle la cantidad de tierra que le permita ganarse el sustento. En contrapartida, el campesino tiene la obligación de trabajar para vivir, cuyo cumplimiento deberá ser sometido a la inspección del Estado. ${ }^{535}$ Es decir, que a fin de poder ser propietario del suelo, el campesino debe cumplir con su parte, según lo establecido en el contrato de protección.

Está obligado, de este modo, a pagar sus impuestos con una parte del producto de su trabajo. Una vez que el campesino cumpla con sus obligaciones tributarias, está en condiciones de exigir del Estado la protección de su propiedad respecto del ataque de terceros. Inclusive Fichte prevé que el Estado proteja la propiedad del suelo del campesino en aquellas partes que no están destinadas al cultivo, pero cuyo uso por parte de otras personas podría llegar a perturbar el desempeño adecuado del agricultor. ${ }^{536}$

\subsection{La minería}

Fichte comprende bajo la denominación de minería no sólo la búsqueda de metales, sino también los yacimientos de arena, arcilla, etc. La minería supone un tipo de propiedad del suelo diferente a la que corresponde a la agricultura. En el caso de la minería no se extrae de la tierra un recurso renovable y que puede producirse de modo artificial, sino que más bien se trata de una cantidad limitada de recursos que son descubiertos de modo azaroso. Esto es, no pueden ser obtenidos de acuerdo a una regla, como en la agricultura.

No puede saberse cuándo uno encontrará tal o cual metal ni qué cantidad. Por esta razón, esta actividad no puede ser confiada a ningún ciudadano particular, dado que no podrá ganar su sustento de este modo. De esta tarea puede hacerse cargo sólo un sujeto colectivo que pueda invertir en el largo plazo y hacer frente a las pérdidas que ocasione el fracaso en la

\footnotetext{
${ }^{535}$ GNR, § 19; SW, III, 218; AA, I, 4, 26-27.

${ }^{536}$ GNR, § 19; SW, III, 219; AA, I, 4, 27.
} 
búsqueda del metal. ${ }^{537}$ De este modo, este sujeto colectivo podrá tener la paciencia necesaria para esperar hasta poder obtener las ganancias pretendidas.

Pero sólo el Estado puede hacerse cargo de esta tarea, porque escapa a las posibilidades de cualquier ciudadano, que vive únicamente del producto de su trabajo. ${ }^{538}$ No debe olvidarse que en el Estado fichteano no hay lugar para la especulación financiera y la acumulación de capital, por lo cual ningún ciudadano puede ser tan rico como para dedicarse a la minería. El mecanismo que permite evitar el enriquecimiento excesivo de algunos ciudadanos está previsto justamente en el contrato de protección, según el cual los productos que cada ciudadano no necesite para vivir serán transferidos al Estado por medio de un sistema de impuestos para proteger la propiedad de los demás.

Por lo tanto, la explotación de la minería pertenece a la órbita estatal. ${ }^{539}$ De esto se desprende que el minero no es propietario del suelo del mismo modo en que lo es el agricultor, porque no vive del producto de su trabajo. Es un trabajador asalariado, que recibe su pago independientemente de los resultados obtenidos. ${ }^{540}$

El Estado debe garantizar la obtención de los minerales necesarios para la vida de los ciudadanos, por ejemplo, el carbón para la calefacción o la cocina, los metales necesarios para elaborar diversos utensilios, para los medios de transporte, etc. También es indispensable la minería en orden a la fabricación de armas para proveer a la defensa común. La riqueza que se obtiene por medio de la minería es transferida directamente a las arcas públicas, lo que las convierte en regalías naturales (natürliche Regale). Gracias a estos ingresos, el Estado puede bajar los impuestos a los ciudadanos y permitir que su conjunto de oportunidad se amplíe.

\section{3. La ganadería y la caza}

Los animales que el hombre necesita para su alimento, o cuyo cuero, etc., es utilizado para elaborar productos, deben ser necesariamente criados como animales domésticos. La razón de esto es que, para asegurarse que los animales crezcan y estén en condiciones de servir de alimento, deben ser criados de acuerdo con las leyes de su cuerpo natural organizado. Pero no puede dejarse en manos de la naturaleza la provisión del alimento y el

\footnotetext{
${ }^{537}$ Cfr. Batscha, (1970), $182-183$.

${ }^{538}$ GNR, § 19; SW, III, 222; AA, I, 4, 29.

${ }^{539}$ Fichte contempla también la posibilidad de que el Estado ceda la explotación de minas a particulares, pero en el caso de que no esté en condiciones de hacerlo o no tenga sentido realizar esta inversión (GNR, $\S 19 ; \mathrm{SW}$, III, 222; AA, I, 4, 29).

${ }^{540}$ Cfr. Batscha, (1981), 280 - 281.
} 
agua que necesitan, porque la naturaleza no tiene necesariamente por objetivo su alimentación y crecimiento. Por lo tanto, debe asegurarse su nutrición mediante el trabajo sistemático y paulatino de la crianza. Pero este trabajo, al igual que sucede con la agricultura, exije que el criador tenga la propiedad exclusiva del animal.

La fundamentación del derecho de propiedad del animal se retrotrae a la fundamentación del derecho de propiedad en general. El ganadero necesita impedir a los demás que intervengan arbitrariamente sobre el animal, porque la actividad de la crianza tiene la misma estructura que toda acción. Es decir, la actividad de la crianza supone que el criador se propone los fines que va a llevar a cabo en cada una de sus actividades.

Pero en el concepto del fin debe estar contenido el concepto del estado de cosas que se quiere lograr. Por lo tanto, los cambios que se produzcan en el animal desde que el criador se propone el fin de la acción hasta que la lleva a cabo deben ser previsibles. Por esta razón, debe impedirse toda intervención arbitraria de los demás sobre el animal. Dicho de otra manera, el criador tiene una propiedad absoluta sobre el animal.

El derecho doméstico (Hausrecht) tiene por objeto precisamente la determinación de la propiedad de los animales domésticos (zahmes Vieh). El derecho doméstico exige en primer lugar que el Estado declare públicamente cuáles especies pueden ser domesticadas por los ciudadanos y cuáles no. Esta es una condición necesaria para el derecho doméstico, porque de este modo los ciudadanos pueden determinar cuándo los demás toman arbitrariamente o no un animal que se encuentre fuera del lugar al que pertenece.

La propiedad del ganado no puede ser determinada por mojones, como la propiedad del suelo, porque el ganado se mueve por sí mismo y puede trasladarse de un lado al otro. Por eso, no basta con señalar el lugar y el terreno donde cada animal debería encontrarse, sino que deben tomarse estas medidas adicionales. Luego de la declaración pública del carácter doméstico de ciertas especies, y la marcación de cada animal que a ellas pertenezca, pueden resolverse las transgresiones a la propiedad. Si una persona mata a un corzo que ha sido domesticado, pero no es considerado como un animal doméstico por el Estado, dice Fichte, no es culpable de haber invadido la propiedad ajena. Pero, si la misma persona hubiera disparado contra un caballo, necesariamente habría atentado contra el derecho doméstico, porque el caballo es una especie que es domesticada en todos lados, por lo que necesariamente debe pertenecer a alguien, ya sea a un ciudadano particular o al Estado. ${ }^{541}$

Dado que el Estado puede satisfacer las necesidades de sus ciudadanos sólo si actúa de acuerdo con un plan, y la caza de animales silvestres es azarosa, entonces, no debe ser parte

\footnotetext{
${ }^{541}$ GNR, § 19; SW, III, 224; AA, I, 4, 31.
} 
de la economía planificada por el Estado. Los animales salvajes son, en realidad, normalmente enemigos de la agricultura y la ganadería, porque son altamente perjudiciales para ambas actividades (como es el caso de los lobos, etc.). Por eso el objetivo del Estado debe ser perseguir y aniquilar a los animales salvajes. De ahí que, a pesar de que la caza no debería ser regulada por el Estado por su carácter azaroso, Fichte la incluye en su teoría de la división del trabajo.

El cazador recibe como pago en propiedad las presas que obtiene, pero no es dueño del terreno sobre el cual caza, porque la superficie del suelo debe ser reservada exclusivamente para la agricultura, según lo argumentado más arriba. En el caso de que el cazador provoque algún daño en el suelo cultivado, deberá indemnizar al agricultor por ello. El juez en este tipo de conflictos debe ser el Estado, porque es la instancia inapelable en la aplicación del derecho. ${ }^{542}$

Esta es la razón por la cual el Estado debe delegar la actividad de la caza en ciudadanos particulares y no puede él mismo llevarla a cabo, a diferencia de lo que se dijo más arriba sobre la minería. Dicho de otra manera, las cuantiosas ganancias que pueden obtenerse con la caza hacen pensar que el juez podría ser corrompido fácilmente por los cazadores. El Estado podría preferir estas ganancias al bien común, y con ello se convertiría en una voluntad particular más, lo que no puede ocurrir sin echar a perder la comunidad legal.

La regulación de la pesca es un tema interesante, porque su tratamiento es diferente al de la caza, si bien son actividades similares. Podría pensarse que la pesca es un tipo de caza y que, por lo tanto, debe estar sometida a la misma regulación que hemos estado analizando. Pero, en realidad, se trata de una actividad mixta, a medio camino entre la cría de animales y la caza. Por eso resulta compleja su implementación. No presenta los mismos problemas que la caza, porque los peces no ponen en peligro la agricultura ni la ganadería, en tanto que viven en un medio acuático.

Pero la pesca no es una actividad que pueda planificarse, porque consiste en la captura azarosa de los peces. Por lo tanto, puede otorgarse al pescador la superficie del río en propiedad, pero sólo en los aspectos que tienen que ver con su actividad. La propiedad, como argumenta Fichte en el $\S 18$, no consiste en la apropiación de la substancia de los objetos en cuestión, esto es, no puede ser pensada como su posesión exclusiva sin más. Más bien la propiedad de un objeto significa el derecho a determinarlo en orden a la realización de nuestros fines.

\footnotetext{
${ }^{542}$ GNR, § 19; SW, III, 228-231; AA, I, 4, 34-36.
} 
Por lo tanto, el pescador conserva la propiedad del río sólo en cuanto que sea necesario para sus fines, y debe permitir a los otros ciudadanos que desarrollen en el río sus tareas específicas. Dicho de otra manera, el pescador recibe el río en propiedad, pero de un modo tal que debe trabajar en armonía con los demás ciudadanos que también lo hayan recibido en propiedad, como es el caso de quienes tengan la tarea de navegar por el río, o de cultivar en sus orillas, etc. ${ }^{543}$ Pero, a semejanza del derecho de caza, el pescador tendrá como pago solamente las presas que consiga, y el excedente que no necesite para vivir deberá ser transferido al Estado en calidad de impuestos.

\section{La propiedad de los artesanos (Künstler)}

Los artesanos son necesarios para la vida común porque ellos son quienes manufacturan y elaboran la materia prima obtenida por los productores de la naturaleza. Los productores adaptan su facultad al funcionamiento de la naturaleza organizada en el producto que trabajan, a fin de lograr el resultado esperado. Mientras que los productores tienen el fundamento de su actividad en el funcionamiento de la naturaleza misma, los artesanos tienen el fundamento de su actividad en ellos mismos. Es decir, los artesanos transforman la materia prima según el concepto del fin que se proponen realizar con ella. ${ }^{544}$

Por eso la tarea de los artesanos requiere de una formación especial y un control diferente al que corresponde a la actividad de los productores. Fichte propone que la responsabilidad no recaiga solamente en cada artesano individual, dada la sistematicidad, formación y experiencia que requiere esta tarea, sino que más bien esté a cargo de una corporación (Zunft). ${ }^{545}$ La propiedad de los artesanos es garantizada por el Estado de otra manera que en el caso de los productores. El Estado contrata con cada ciudadano de acuerdo con la siguiente cláusula: el artesano tiene el derecho a poder vivir de su trabajo y a todo lo necesario para realizarlo, siempre y cuando entregue al Estado la cantidad y calidad de productos que los demás ciudadanos necesiten.

Cada artesano debe recibir su trabajo como propiedad exclusiva, de modo tal que no se viole el contrato de propiedad. Es decir, si el artesano no tuviera el derecho de excluir a los demás ciudadanos de la realización de su actividad, entonces el contrato de propiedad sería unilateral y, por lo tanto, nulo. En ese caso, el artesano habría renunciado a realizar las

\footnotetext{
${ }^{543}$ GNR, § 19; SW, III, 228-229; AA, I, 4, 34.

${ }^{544}$ GNR, § 19; SW, III, 232; AA, I, 4, 37.

${ }^{545}$ GNR, § 19; SW, III, 233; AA, I, 4, 38.
} 
actividades de los demás, o en otras palabras, a enajenar su propiedad, pero los demás no lo habrían hecho. El Estado debe controlar, entonces, que nadie más que los integrantes del gremio estén facultados para realizar esta tarea.

El mecanismo para garantizar este resultado es evidente: el Estado se compromete, como resultado del contrato de propiedad con cada ciudadano, a comprarle los productos de su trabajo sólo a los trabajadores de su gremio. En consecuencia, los demás ciudadanos desistirán de llevar a cabo una actividad por la que no reciben recompensa alguna. Por eso Fichte rechaza la liberalización de las corporaciones y la libre competencia de los artesanos en el mercado, sin la mediación del Estado. ${ }^{546}$

La corporación debe trabajar, entonces, bajo la supervisión del Estado, en tanto que controla la idoneidad, formación y calidad del trabajo de sus miembros. También es un buen instrumento de ayuda para la planificación estatal de la división del trabajo, porque podría encargarse de calcular cuántos artesanos podrían vivir de su oficio. En razón de los cálculos del Estado respecto a cuántos artesanos son socialmente necesarios en tal o cual rama, la corporación podría regular el ingreso de nuevos aspirantes a ejercer el oficio.

\section{La propiedad de los comerciantes (Kaufmannsstand)}

\subsection{La necesidad de la clase de los comerciantes para el funcionamiento del Estado}

Los artesanos necesitan de los productores para poder vivir, pero los productores también reclaman con derecho los productos de los artesanos (zapatos, abrigo, vivienda, muebles, herramientas para cultivar la tierra, etc.). Ambos deben recibir del otro los productos que necesitan para vivir durante su tiempo de trabajo, según el derecho a la existencia. Por lo tanto, el intercambio entre ellos debe ser regulado, toda vez que forma parte de la actividad del Estado, y debe tomar por lo tanto la forma de la ley. El Estado debe desarrollar el sistema legal de modo tal de determinar las condiciones de validez de los contratos entre los productores y los artesanos.

Pero sus contratos no pueden llevarse a cabo libre y espontáneamente, porque su función no es enriquecer a estos ciudadanos tanto como ellos quieran o sea posible, sino más bien asegurar que cada uno reciba los productos necesarios para vivir durante el proceso de

\footnotetext{
${ }^{546} G N R$, § 19; SW, III, 233; AA, I, 4, 38.
} 
trabajo. ${ }^{547}$ Dada la complejidad de esta tarea, y la imparcialidad que supone, Fichte propone la institución de un tercer grupo social: los comerciantes.

Los comerciantes deben asegurar un precio máximo a cada producto, de modo tal que todos puedan acceder a los bienes que necesitan. Pero los productores tendrán una capacidad mayor de negociación frente a los artesanos, porque sus productos son más urgentes y necesarios para la autoconservación. Para contrarrestar esta asimetría, el Estado puede asegurar el acceso de los artesanos a estos productos por medio de la disposición de establecimientos propios (Magazinen), donde los productores los pongan en venta gracias a la intermediación de los comerciantes. Queda por saber qué rol juegan los comerciantes en el comercio exterior del Estado.

En realidad, Fichte niega la necesidad de incluir al comercio exterior en el seno de la economía planificada del Estado, porque, por un lado, vuelve dependiente al Estado respecto de los otros Estados y, por el otro, es una actividad de difícil planificación. ${ }^{548}$ El comercio exterior no depende de las decisiones soberanas del Estado, sino de las de los demás gobiernos. ${ }^{549}$ Pero éstos no son predecibles, porque no están sujetos a la ley de este Estado, que tiene que proteger y sustentar a sus propios ciudadanos.

Además, los ciudadanos del otro Estado no pertenecen a esta comunidad legal y por lo tanto no les corresponde el contrato de ciudadanía y no quedan vinculados a cumplirlo, por lo cual no puede contarse con su cooperación. Por lo tanto, dada la impredecibilidad de esta actividad y, por lo tanto, de su incapacidad para someterse a una regla, no es conveniente incluirla en la división del trabajo centralmente organizada.

\section{2. Teoría del dinero}

La teoría del dinero es parte integrante de la teoría fichteana de la división del trabajo, porque es el medio que compete por excelencia a la clase de los comerciantes. Ellos son los responsables de hacer circular la moneda, porque son los encargados de devolver a los ciudadanos el sobrante de sus impuestos en forma de dinero. Por eso es pertinente exponer la teoría del dinero en esta sección sobre la propiedad de los comerciantes. En primer lugar, es necesario retomar los contratos de ciudadanía. Según el contrato de propiedad, cada

\footnotetext{
${ }^{547}$ De allí la incompatibilidad de la teoría de Fichte con el liberalismo de mercado (Cfr. Rickert, 1922/1923, 175 -177 ).

${ }^{548}$ GNR, § 19; SW, III, 234; AA, I, 4, 39.

${ }^{549}$ Cfr. Merle, (1997), 235.
} 
ciudadano conserva un espacio de libertad inalienable y se abstiene de interferir en el de los demás pero, en virtud del contrato de protección, se compromete a ceder parte de su libertad para proteger a la libertad de los otros.

Entonces pareciera que la libertad protegida por el contrato de propiedad es inalienable, pero a la vez puede ser alienada para proteger a los demás ciudadanos. Podría decirse que la libertad inalienable del sujeto es el espacio de acción que queda luego de la cesión de su libertad en el contrato de protección. Pero nunca puede resultar del contrato de protección una cantidad insignificante de libertad, porque entonces el contrato mismo no tendría sentido, toda vez que no habría una cantidad razonable de libertad que proteger.

Es importante, a fin de comprender la argumentación que sigue, tener presente que la libertad significa en este contexto la distribución de la propiedad. Fichte intenta resolver, por medio de la teoría del dinero, esta tensión entre la libertad que necesita el Estado, a fin de poder proteger a los ciudadanos, y la libertad de los ciudadanos, que debe ser protegida.

Dado que los ciudadanos necesitan de una cantidad determinada de propiedad para poder realizar sus fines individuales, según el derecho originario, el Estado no podrá garantizarles tal o cual bien particular, como sucede en el caso de la protección del derecho a la existencia. El derecho a la existencia, como se dijo más arriba, es una parte insustituible del derecho originario, porque garantiza la posibilidad misma de que el sujeto pueda actuar en el mundo sensible por medio de su cuerpo articulado.

El derecho a la existencia puede ser garantizado sólo si se distribuye entre los ciudadanos lo necesario para su alimentación, vivienda, abrigo, y se garantiza su acceso a la salud. Es decir, las condiciones del derecho a la existencia son las mismas para todos los ciudadanos, porque se trata de las mismas necesidades básicas, si bien deben ser satisfechas de acuerdo con la ocupación que desempeñe cada ciudadano. Por esta razón, el Estado puede planificar centralmente la aplicación del derecho a la existencia. Pero la cantidad indeterminada de fines que el sujeto se propone a título individual no puede ser planificada del mismo modo, porque requiere de una cantidad y variedad infinita de objetos, en calidad de medios.

Fichte defiende una instancia que media entre los bienes que se poseen y la satisfacción de fines indeterminados, que no es otra que el dinero. El dinero debe garantizar esta propiedad de carácter indeterminado, porque representa la cantidad de propiedad que el ciudadano ha producido. Pero debe posibilitarle al ciudadano al mismo tiempo la adquisición de una diversidad de bienes, atendiendo a los múltiples fines de sus acciones. Por esta razón el dinero tiene un carácter simbólico, esto es, representa una cantidad determinada de propiedad. 
El dinero debe estar constituido de modo tal que lo material en él sea insignificante en orden a la satisfacción de fines específicos. En caso contrario, perdería su carácter simbólico. Para aclarar esto con un ejemplo del mismo Fichte, no es conveniente que el dinero esté acuñado con plata, dado que este metal mismo puede ser trabajado en orden a la producción de bienes determinados (utensilios, etc.), que tienen un valor en sí mismos. ${ }^{550} \mathrm{Si}$ el dinero tuviera un valor en sí mismo, entonces ya no cumpliría su función de representar el valor de otra cosa. Por eso Fichte propone fabricar el dinero con cuero o papel. ${ }^{551}$

Ahora bien, no sólo es importante la constitución del dinero sino también el modo de su circulación. El ciudadano entrega todo el producto de su trabajo al Estado, puesto que éste es el encargado de distruibuir la propiedad entre los ciudadanos, y en última instancia de velar por el cumplimiento del derecho a la propiedad. El Estado calcula, en base a la cantidad de productos que ha recibido, el valor total de los bienes de que se dispone. En base a este cálculo, fija el valor del dinero. Independientemente de cuánta moneda se emita o circule, el valor del dinero permanecerá siempre vinculado a la suma total de bienes producidos. ${ }^{552}$

Si la cantidad de dinero circulante es mayor que la suma total de bienes, su valor decrecerá, y en caso contrario se incrementará. El Estado, luego de haber recibido todos los productos de manos de los ciudadanos, debe redistruibuirlos, en primer lugar, en razón de las necesidades vitales de los contribuyentes. Una vez garantizado el derecho a la existencia, el Estado debe calcular cuántos de estos productos necesita para proveer a su funcionamiento, en el espíritu del contrato de protección.

El sobrante es devuelto a los ciudadanos en proporción a la cantidad que han producido. ${ }^{53}$ Dado que los ciudadanos ya tienen garantizado su derecho a la existencia, necesitan del resto del producto de su trabajo para realizar sus fines particulares. Por lo tanto, debe devolverse al ciudadano lo que le corresponde en forma de dinero, para que haga de esta propiedad el uso que quiera. El ciudadano que posee dinero, entonces, ya ha honrado previamente sus obligaciones impositivas.

La disposición de dinero es el mejor certificado del cumplimento de los contratos de ciudadanía. Fichte rechaza la implementación de un impuesto al dinero, porque el dinero es, por definición, el sobrante que queda luego de que se han pagado todos los impuestos. Fichte

\footnotetext{
${ }^{550}$ GNR, § 19; SW, III, 239; AA, I, 4, 43.

${ }^{551}$ Para el comercio exterior, Fichte prefiere que el dinero sea fabricado con plata y oro, porque son metales que conservan un valor similar entre los Estados, y evitaría los problemas que acarrea la conversión de la moneda de cada país en la del otro. Esta es una razón adicional para que el Estado monopolice la explotación de la minería (GNR, § 19; SW, III, 239; AA, I, 4, 43).

${ }^{552}$ Sólo el Estado puede acuñar dinero, porque sólo él está en condiciones de garantizar su valor (GNR, § 19; SW, III, 239; AA, I, 4, 43).

${ }^{553}$ Cfr. Batscha, (1970), $188-189$.
} 
entiende que su teoría minimiza los riesgos de sobreemisión de moneda, porque el valor del dinero es estable, toda vez que es calculado en base a la cantidad de mercancías disponible.

\section{El derecho a la propiedad privada (absolutes Eigenthum)}

\section{1. La propiedad del dinero}

Fichte establece la necesidad de que cada ciudadano disponga de una vivienda inviolable a partir de un problema práctico que ha surgido en la teoría del dinero. Como consecuencia de lo argumentado hasta aquí, el Estado debe garantizar al ciudadano su propiedad, entregada en forma de dinero luego de que haya pagado sus impuestos. Se trata de una propiedad absoluta o inviolable, objeto de protección del Estado según el contrato de ciudadanía. Pero esta conclusión deja abierto un problema práctico. No queda claro cómo puede el Estado garantizar esta propiedad, porque no se puede establecer un signo unívoco que la indique.

La propiedad del suelo, como se dijo más arriba, es indicada por el signo unívoco de los mojones. De este modo pueden resolverse con facilidad y de modo expeditivo los litigios relativos a la propiedad del suelo cultivable. Pero en el caso del dinero, el Estado no puede disponer de ningún signo que indique que estos billetes pertenecen a tal ciudadano y no a otro. Dicho de otra manera, la naturaleza misma del dinero es tal que circula de modo anónimo de una mano a otra, y no presenta marca de propiedad particular alguna. ${ }^{554}$

Pero la propiedad del dinero presenta otro problema, dado que aún si el Estado pudiera determinar quién es el propietario de tal o cual billete, no estaría legitimado para adquirir este conocimiento, porque se trata de una propiedad absoluta. Lo que cada ciudadano hace con su dinero pertenece a su esfera privada, que debe ser protegida por la ley.

\footnotetext{
${ }^{554}$ Como dice Fichte:

"Debe quedar registrado en los libros del palacio de justicia de mi localidad que el campo, que está ubicado en tales tierras y está marcado por tales mojones, me pertenece y no es de nadie más; y si llegara a surgir alguna disputa en relación a ello, estos libros las resolverán sin más. Pero ¿cómo puede determinarse que este tálero particular me pertenece a mí y a nadie más? Todos los táleros tienen la misma apariencia, y deben cambiar de propietarios sin mayores formalidades, en la medida en que son unos táleros determinados."

"Dass der zwischen diesen und jenen Grundstücken liegende, durch solche Grenzsteine bezeichnete Acker mein gehöre und keinem anderen Menschen, soll in den Gerichtsbüchern meines Orts niedergeschrieben stehen; und wenn darüber ein Streit entstünde, werden dieselben ohne weiteres entscheiden. Aber dass dieses bestimmte Thalerstück mein gehöre, und keinem Anderen, wie lässt sich denn dies bezeichnen? Alle Thalerstücke sehen einander gleich, und sollen es, weil sie bestimmt sind, ihre Eigenthümer ohne weitere Formalität zu wechseln“ (GNR, § 19; SW, III, 240-241; AA, I, 4, 44)
} 
Esto la sustrae claramente al control del Estado, porque, si fuera controlada, el sujeto no podría someter el dinero al uso absolutamente espontáneo y libre de su voluntad, ya que debería someterse enteramente a las reglas del Estado. Dicho de otra manera: el Estado no tiene derecho de inspección sobre el uso que hacen los ciudadanos de su dinero. ${ }^{555}$

Fichte resuelve este problema con dos estrategias argumentativas. Pero ambas tienen algo en común: se trata de encontrar un elemento que la persona pueda controlar de modo inmediato y que esté vinculado directamente al dinero. Pero este elemento determinado y determinable por la persona debería dejar el uso del dinero librado a su exclusiva privacidad. De este modo, cada ciudadano podría indicar ostensiblemente ante los demás, si quisieran apoderarse de su dinero, que es de su propiedad y, sin embargo, conservar el derecho de utilizarlo como quiera.

La primera estrategia consiste en indicar un elemento particular con el que la persona está inmediatamente vinculada. No hay otro elemento vinculado más inmediatamente con la persona que su cuerpo, según lo argumentado en los $\S \S 5$ al 7. Esto es, si la persona lleva en los vestidos que están sobre su cuerpo una cierta cantidad de dinero, y no media denuncia de robo contra ella, entonces esto será siempre un signo incontestable de su propiedad, en el caso de que otra persona pretendiera reclamarlo como propio. ${ }^{556}$

La segunda estrategia demuestra la necesidad de que el ciudadano disponga de una vivienda privada. Esto se desprende a partir del uso que se espera que el ciudadano haga de su dinero. Cada ciudadano no utiliza su dinero sólo para satisfacer sus necesidades presentes, sino que es de esperar que también guarde una parte para utilizar en vista de sus necesidades futuras. La razón de esto es que se prevé que el ciudadano utilice su dinero en el período que va desde el pago de los impuestos al plazo siguiente de pago. Se supone que cada ciudadano tendrá necesidades que satisfacer a lo largo de todo este período y no sólo al comienzo.

Pero no puede esperarse que el ciudadano lleve todo el tiempo la suma completa de dinero en sus vestidos sobre su cuerpo, porque no sólo sería algo poco práctico, sino sobre todo inseguro respecto de los ataques de los demás. ${ }^{557}$ Puede disponerse, sin embargo, de una solución análoga a la que ya hemos visto. Pero el dinero no puede vincularse ya más de modo inmediato con la persona, sino por medio de otra cosa. Se trata de la vivienda, figura que en Fichte significa no sólo la propiedad de una casa o el alquiler de una habitación, sino también todo aquél espacio en el cual el ciudadano puede poner a seguro su dinero.

\footnotetext{
${ }^{555}$ GNR, § 19; SW, III, 241; AA, I, 4, 44.

${ }^{556}$ GNR, § 19; SW, III, 242; AA, I, 4, 44-45.

557 Como señala Fichte, los vagabundos (Lazzaronis) llevan todo el dinero en sus vestidos, pero esto es justamente un signo de su desprotección ( GNR, § 19; SW, III, 242; AA, I, 4, 45).
} 
Ejemplos de esto son el baúl de la sirvienta (die Lade der Dienstmagd), el cofre que uno entrega al correo (der Koffer, der auf die Post gegeben wird), etc. La cerradura de la propia vivienda marca el límite de nuestra privacidad, y todo el que irrumpa allí violentamente y sin nuestro consentimiento debe ser castigado por el Estado. ${ }^{558}$ Este es el motivo de las afirmaciones de Fichte:

El control del Estado llega hasta la cerradura, y a partir de allí comienza el mío. La cerradura es la frontera que separa el poder estatal del poder privado. ${ }^{559}$

De este modo, el derecho a una vivienda se integra indisolublemente al conjunto de los derechos de ciudadanía.

\section{2. El problema del manejo privado del dinero}

El ciudadano puede utilizar su propiedad absoluta, que recibe del Estado en la forma de dinero, de la manera en que quiera, según lo concluido en las secciones anteriores. Pero las transacciones que el ciudadano lleva a cabo en su esfera privada tienen consecuencias para su propiedad, por lo que pareciera ser que el Estado tiene el derecho y la obligación de controlarlas y regularlas. De este modo, el Estado garantizaría al ciudadano una esfera de propiedad inviolable, y se reservaría a la vez el derecho de intervenir en esta esfera, lo que es contradictorio.

Fichte desarrolla diversas estrategias para que el Estado evite o prevenga que los ciudadanos sean perjudicados a consecuencia de sus transacciones privadas, que contemplan desde los casos de estafas hasta la donación y el testamento. No se puede permitir que el Estado pueda de alguna manera violar la propiedad absoluta de los ciudadanos, porque de este modo se violaría el contrato de propiedad. ${ }^{560}$ Por lo tanto, todas las transacciones que los ciudadanos quieran realizar en el ámbito informal de sus relaciones privadas quedan libradas a su leal saber y entender y no son asunto del Estado.

El Estado no podría evitar las estafas, porque no cuenta, entre sus atribuciones, la de obligar en lo concerniente a la buena fe o la confianza entre los ciudadanos. La propiedad de

\footnotetext{
${ }^{558}$ Rickert, (1922/1923), 179.

559 "Die Aufsicht des Staates geht bis zum Schlosse, und von da geht die meinige an. Das Schloss ist die Grenzscheidung der Staatsgewalt und der Privatgewalt.“ (GNR, § 19; SW, III, 242; AA, I, 4, 45).

${ }^{560}$ Este elemento impide hablar en Fichte de un socialismo colectivista, a pesar de la defensa de una economía planificada centralmente (Renaut, 1986, 437 - 438).
} 
los ciudadanos sería necesariamente insegura, porque ellos tienen derecho a prestar dinero de buena fe a otros sin el control del Estado, esto es, sin recurrir a pagarés o letras de cambio.

El Estado mismo es fruto de la desconfianza entre los hombres, por lo que no puede él mismo obligarlos a que confíen mutuamente unos en otros. Pero esto tendría además consecuencias indeseables desde el punto de vista legal, ya que, si el Estado coaccionara a los ciudadanos para que confíen mutuamente en los otros, al mismo tiempo los obligaría a poner en riesgo su propiedad, mientras que su obligación primordial es resguardarla y custodiarla. Por otro lado, la buena fe y la confianza mutua caen en el ámbito de la moralidad, es decir, fuera de la jurisdicción del derecho y, por lo tanto, del Estado.

El estafador que ha abusado de la confianza y la buena fe de los otros ciudadanos, sin embargo, les ha producido un daño considerable y queda a consecuencia de ello deshonrado. ${ }^{561}$ Dicho de otra manera, los demás ciudadanos ya no confiarán en la fidelidad del estafador a su palabra dada. Pero puede ocurrir que otros ciudadanos que no conocen la estafa sean engañados en el futuro, por lo cual el Estado puede hacerlo público y deshonrar al estafador ante todos. Esta es una alternativa razonable, porque no implica ningún control ni regulación de las transacciones privadas.

El ciudadano deshonrado ha recibido suficiente castigo con la pérdida de la confianza de los demás, por las consecuencias que esto acarrea para sus relaciones sociales. El honor es un bien muy estimado por los hombres por la relevancia que tiene para desarrollar sus vínculos entre sí. Por eso el ciudadano que ha sido deshonrado sin causa alguna, esto es, ha sido injuriado o difamado tiene el derecho, en sí meramente negativo, de exigir al Estado que le restituya su honor y se retracte en público.

La donación y el testamento son casos de adquisición de la propiedad que presentan una cierta complejidad, porque en ellos no se trata de la mera adquisición original de la propiedad por parte del Estado ni del comercio usual entre los ciudadanos. En el caso de la adquisición original de la propiedad, el Estado acrecienta su patrimonio en virtud de la cesión de la propiedad de los ciudadanos, de acuerdo con el contrato de protección. En cambio, las relaciones comerciales implican la cesión de cada ciudadano de su propiedad a otro a cambio de otra de valor similar, pero esto no implica un incremento de la propiedad total, sino sólo hace referencia a su circulación.

\footnotetext{
${ }^{561}$ Fichte apunta que el robo a un amigo o familiar en su domicilio suele ser considerado por la opinión pública como mucho más grave que el asalto en la calle, porque supone el abuso de la confianza y la buena fe de la víctima. Lo mismo constata respecto de la ofensa a un invitado por parte de su anfitrión y viceversa $(G N R, \S 19$; SW, III, 243; AA, I, 4, 46).
} 
Ni la adquisición original ni el comercio presentan problemas teóricos especiales, porque quedan incluidos bajo la órbita del contralor del Estado. Fichte pone dos ejemplos que ilustran claramente cómo debe controlar el Estado las transacciones comerciales entre los ciudadanos. ${ }^{562}$ En primer lugar, el Estado debe cuidar de que la mercadería adquirida por medio del comercio sirva a la profesión o el oficio que desempeña el ciudadano que la ha comprado.

En caso contrario, el ciudadano abandonaría su propiedad para conseguir otra, de cuyo uso no se beneficiaría el Estado. Es decir, del uso de esta propiedad no se seguiría el fortalecimiento del Estado, por lo cual se desperdiciaría un recurso necesario para la protección de la propiedad de todos. En segundo lugar, el Estado tiene la obligación de controlar que ningún ciudadano enajene toda su propiedad en sus transacciones comerciales, sino que siempre conserve un resto para procurar su subsistencia. La razón de esto es que, de acuerdo con el contrato de ciudadanía, el Estado es responsable de la autoconservación de todos.

Por lo tanto, el Estado puede intervenir en las transacciones comerciales que tienen lugar en el ámbito público. Pero en la donación y el testamento ocure algo muy diferente, porque por medio de estos procesos, un ciudadano transfiere su propiedad a otro, total o parcialmente, sin recibir nada a cambio. Ambas transacciones pertenecen al derecho doméstico, lo que dificulta su regulación estatal. Es decir, en los dos casos el ciudadano intercambia con los demás su propiedad absoluta, de la que dispone con total independencia.

Estas transacciones deben ser controladas por el Estado, porque toda adquisición de propiedad es legal en tanto que es reconocida estatalmente, pero a la vez estas transacciones tienen lugar en el ámbito privado, que en principio al menos escapa al control del Estado. Esta es la tensión que Fichte busca resolver con su teoría de la donación y el testamento. En el caso de la donación, sin embargo, el Estado tiene claramente la potestad de intervenir, aunque se trate del derecho doméstico.

La razón de esto es que la donación puede poner en peligro la autoconservación misma del ciudadano, por lo cual se le aplica el requisito antes mencionado para las transacciones comerciales. Dicho de otra manera: la donación de una propiedad puede traer como consecuencia tanto que el donante enajene un recurso que necesita para su trabajo, como que entregue aquello que necesita para vivir. Por eso la donación debe ser declarada ante el Estado, para que pueda efectuarse la fiscalización correspondiente. Si el ciudadano que cede

\footnotetext{
${ }^{562}$ GNR, § 19; SW, III, 256; AA, I, 4, 56.
} 
parte de su propiedad conserva lo necesario para ejercer su profesión o para seguir viviendo, entonces puede tener lugar la donación y ser reconocida por el Estado.

El testamento, por otro lado, no exige ni permite controles como los propuestos para la donación, porque no se trata de la transferencia de un bien por parte de un ciudadano que permanece existiendo, sino que más bien tendrá lugar sólo luego de su muerte. Por lo tanto, aquí no se presenta el problema de si el ciudadano está enajenando con este acto algo necesario para realizar su oficio o para su autoconservación. Pero, como resultado del testamento, un ciudadano o un grupo de ellos incrementa su propiedad, lo cual de por sí reclama el control del Estado, porque toda propiedad puede ser reconocida sólo por su intermedio.

Podría sostenerse simplemente que, una vez muerto el propietario, sus bienes pasarían automáticamente a ser propiedad del Estado, en virtud del contrato de protección. El contrato de protección entraría en tensión, de este modo, con el contrato de propiedad, según el cual cada individuo tiene derecho a disponer libremente de su propiedad absoluta.

Sin embargo, no se da en realidad esta tensión en la figura del testamento, porque el ciudadano no asegura aquí ni su propiedad, toda vez que ya no existirá más luego de completada la transferencia, ni la propiedad del Estado, porque este último tiene derecho a exigir su contribución al ciudadano mientras permanezca existiendo.

Por otro lado, puede invocarse un motivo suficiente para exigir la regulación del testamento. La herencia es un bien para los ciudadanos, ya que tiene consecuencias importantes para su vida. Baste para ello pensar en los efectos que tiene para el propietario la convicción de sus herederos de que recibirán sus bienes luego de su muerte. Esta convicción puede motivar a los herederos a cuidar mejor del ciudadano en vida, a expresarle su afecto, etc. $^{563}$

Los ciudadanos tienen derecho a pedir al Estado que legisle en todos los aspectos de su vida en los que consideren necesaria una regulación especial. Por ello es necesario que el Estado garantice que los bienes dejados en herencia serán recibidos por los herederos, según la voluntad del difunto. En consecuencia, el Estado debe comprometerse a reconocer la propiedad heredada. ${ }^{564}$

Los herederos se ocuparán con seguridad de que se sigan todos los procedimientos establecidos por la ley, porque está en juego su adquisición de la herencia. Sin embargo, no es sencilla la regulación del derecho sucesorio, porque el Estado, en caso de que la herencia no corresponda a quienes la reclaman, será el beneficiario directo de esta propiedad. Por lo tanto,

\footnotetext{
${ }^{563}$ GNR, § 19; SW, III, 257-258; AA, I, 4, 57.

${ }^{564}$ Batscha, (1970), $167-168$.
} 
si el Estado mismo fuera responsable del proceso de la sucesión, sería juez y parte en el mismo asunto, lo cual es contradictorio.

En el proceso sucesorio se presentan dos partes: los herederos, por un lado, y el Estado, por el otro. De este modo, debe preverse por ley la actuación de un funcionario que no esté bajo control del Estado, sino de la única comunidad que resta, es decir del pueblo. Entonces el magistrado que instruya el proceso de la sucesión debe poder ser controlado y denunciado por cualquier ciudadano. El pueblo se constituye como representante en la persona de los testigos (Zeugen), quienes tienen la función de controlar que la herencia cumpla con todas las condiciones previstas por la ley.

\section{3. La protección de la seguridad y la inviolabilidad personales en el derecho doméstico}

Es notable que en el contrato de ciudadanía no esté presente explícitamente la cláusula de la protección de la integridad de la persona. Pero en realidad ocurre con este derecho lo mismo que con el derecho a la existencia: no constituye ningún derecho particular o determinado que deba ser protegido, sino que más bien es un derecho básico. Esto es, es un derecho que fundamenta todos los demás y permite su ejercicio. Dicho de otra manera, en la medida en que el contrato de ciudadanía tiene por objeto asegurar la propiedad de los ciudadanos, se protege implícitamente el derecho de la persona a la autoconservación y la integridad de su cuerpo. Por esto afirma Fichte:

El ataque al cuerpo es una violación de todos los derechos del ciudadano de un solo golpe; por lo tanto, es naturalmente un crimen contra el Estado, porque el goce de todos sus derechos está condicionado por la libertad de su cuerpo. ${ }^{565}$

Cualquier ataque a la integridad personal, que tenga lugar en el espacio público, es protegido inmediatamente por el Estado, por lo que el ciudadano está protegido por la ley mientras está fuera de su casa, según el contenido del contrato de ciudadanía. Cuando el ciudadano entra en su casa, se vuelve problemática la protección de su integridad personal, porque se trata del ámbito doméstico. En este ámbito, el ciudadano hace uso de su propiedad absoluta y queda sustraído al control del Estado. Si consideramos el caso de que un agresor irrumpa violentamente en la casa de otra persona, no hay dudas respecto a las obligaciones del Estado para con el propietario y el agresor.

\footnotetext{
565 "Angriff auf den Körper, ist Verletzung aller Rechte des Bürgers auf einmal; sonach allerdings ein Verbrechen im Staate, weil der Gebrauch aller seiner Rechte durch die Freiheit seines Körpers bedingt ist.“ (GNR, § 19; SW, III, 246; AA, I, 4, 48).
} 
Ante todo, porque la casa de la víctima está inserta en el ámbito público, en tanto que es su propiedad declarada y reconocida por el Estado. Si alguien irrumpe violentamente en la casa, el Estado tiene el derecho y el deber de instruir un procedimiento legal de oficio. Este delito no queda sujeto a la negociación amigable o la reconciliación de los ciudadanos, porque en realidad está en juego la seguridad y la protección de todos los demás ciudadanos, aunque no hayan sido víctimas de esta agresión. Es decir, si el afectado tuviera la facultad de perdonar al agresor y de cerrar de este modo la causa, el delincuente quedaría libre y la propiedad de todos estaría en peligro.

Por otro lado, puede ocurrir que el ciudadano sea agredido, en su persona o en su propiedad, por otro, a quien ha permitido ingresar a su casa. Le ha abierto la puerta, dándole el permiso de ingresar a su casa, lo que Fichte denomina das Herein. Le ha brindado su confianza, toda vez que, si hubiera sospechado que lo iba a atacar, no le hubiera permitido entrar. Ahora bien, el Estado no podría intervenir en su defensa porque el ataque ha ocurrido dentro del ámbito doméstico, donde rige una privacidad absoluta. Es decir, que el Estado no puede ni debe saber lo que ocurre dentro de esas paredes.

Sin embargo, el Estado es responsable y garante de la seguridad de la propiedad de todos los ciudadanos. Por lo tanto, debe haber un mecanismo por medio del cual todo ciudadano pueda ponerse bajo su protección, aún estando en la intimidad de su hogar. Se trata en realidad de un recurso muy sencillo: la denuncia (Klage) ante el Estado de una agresión sufrida en la propia persona o bienes.

Si el ciudadano no denuncia ante el Estado la injusticia de que ha sido víctima, este no puede intervenir de oficio, como ocurre en el espacio público. Con palabras de Fichte: "donde no hay un acusador, no hay ningún juez" (wo kein Kläger ist, ist kein Richter). ${ }^{566}$. Por lo tanto, el Estado no puede intervenir inmediatamente en su defensa, sino sólo mediatamente. Una vez que el ciudadano, por medio de su denuncia, ha renunciado a su derecho absoluto a la intimidad, su propiedad queda bajo la garantía del Estado.

La denuncia es el recurso legal, entonces, que garantiza la protección del ciudadano por el Estado en su ámbito doméstico. Pero puede ocurrir que el ciudadano sea asesinado en su casa y que, entonces, no esté en condiciones de denunciar el ilícito. Naturalmente, la familia de la víctima podría hacer ella misma la denuncia. Pero, si se deja librada la denuncia de un asesinato sólo a la familia de la víctima, no se ve cómo podría hacerse justicia si uno de sus parientes hubiera sido el agresor. Entonces pareciera que no puede preverse un

\footnotetext{
${ }^{566}$ GNR, § 19; SW, III, 247; AA, I, 4, 49.
} 
mecanismo que garantice la vigencia de la ley para los asesinatos ocurridos en el ámbito privado.

Sin embargo, si este problema permaneciera irresuelto, estaría en peligro la teoría entera, porque los ladrones optarían directamente por matar a la víctima para evitar ser castigados. ${ }^{567}$ Dicho de otra manera, si la autoconservación no puede ser garantizada en el ámbito doméstico, quedan anulados los contratos de propiedad y protección y, con ellos, el contrato de ciudadanía mismo. Fichte propone, para este tipo de crímenes, la figura de una voluntad de todos que reemplace, por decirlo así, a la voluntad de la víctima asesinada y efectúe la denuncia de su agresión. Se trata de una voluntad que representaría a la voluntad de la víctima y haría lo que ella misma hubiera hecho en vida, esto es efectuaría la denuncia del crimen.

No se trata de la voluntad universal del Estado, sino de la voluntad particular del grupo de todos los demás ciudadanos. Es una voluntad particular, porque no incluye a todos los ciudadanos, sino más bien a todos los demás, menos al criminal. Por otro lado, el Estado debe quedar excluído de la voluntad de todos, porque tiene la función de juzgar y garantizar la imparcialidad en la sentencia, lo que implica que no puede ser juez y parte. Debe instituirse entonces la figura de un representante de la voluntad de la mayoría para este tipo de delitos, que efectúe la denuncia en nombre de todos los ciudadanos que representan a la víctima. Se trata de un acusador público (öffentlicher Ankläger), quien puede iniciar las acciones legales en cualquier momento, ya sea por motu propio o a instancias de otros ciudadanos.

Todos tienen el derecho de solicitarle que haga la denuncia o de controlar su desempeño y de acusarlo, en caso de ser necesario. ${ }^{568}$ El acusador tiene derecho a pedir la colaboración de todos los ciudadanos que crea conveniente. Nadie puede sustraerse a esta carga pública, sin que le corresponda el delito de incumplimiento del contrato de protección y, con él, del contrato de ciudadanía. El proceso de investigación es, de todos modos, siempre necesario, ya que el Estado debe recabar la información acerca de la causa de la muerte de cada ciudadano. La muerte de cada ciudadano es un acto público, tanto como su nacimiento.

Este registro es indispensable para la actividad gubernamental. De este modo, queda solucionado el problema de si no es más conveniente para el ladrón asesinar a la víctima, ya que de este modo tendría la impunidad asegurada. La conclusión que se desprende del razonamiento elaborado hasta aquí es más bien la contraria. Es decir, es más conveniente al ladrón dejar a la víctima con vida, porque de este modo quizás no efectúe la denuncia del robo

\footnotetext{
${ }^{567}$ GNR, § 19; SW, III, 248; AA, I, 4, 50.

${ }^{568}$ GNR, § 19; SW, III, 248; AA, I, 4, 50.
} 
y puedan arreglar amistosamente la cuestión. En caso contrario, la víctima levantará la denuncia en la persona del acusador público y no podrá evitar el castigo consecuente.

Otro problema fundamental del derecho doméstico es la cuestión de la legítima autodefensa del ciudadano en caso de un ataque en la esfera doméstica. El derecho de autodefensa se inscribe en la problemática general del derecho de necesidad (Nothrecht). Fichte ilustra el concepto del derecho de necesidad por medio del ejemplo clásico de los dos náufragos, cuya salvación depende de una sola tabla de madera, que puede sostener sólo a uno de los dos. ${ }^{569}$ El derecho de necesidad, según el argumento de Fichte, no es un derecho en absoluto, porque no cumple con las condiciones básicas de toda relación legal. ${ }^{570}$ Una comunidad legal es un modo en el que pueden coexistir (Beisammenbestehen) seres libres.

Si no pueden coexistir de ningún modo, como es el caso del ejemplo de los náufragos, donde uno puede vivir sólo si el otro muere, entonces, el concepto de relación legal carece de sentido. De allí se desprende que un grupo de personas que no dispongan de una cantidad moderada de bienes que puedan distribuir entre ellos, no pueden convivir y, por lo tanto, no pueden constituirse en una comunidad legal. En el $G N R$ se vuelve superficial la discusión sobre el derecho de necesidad, esto es, el derecho a la autoconservación en situaciones límites, donde la propia supervivencia se ve amenazada (por ejemplo, el derecho a robar alimentos en caso de que el ciudadano se encuentre en peligro de desnutrición y no tenga trabajo ni ingresos, etc.).

Esto es así porque el Estado garantiza ya desde el contrato de ciudadanía (Bürgergesellschaftsvertrag) una cantidad determinada de propiedad a todos los ciudadanos. Si este no fuera el caso, no se reconocería el derecho de propiedad de los individuos y el contrato quedaría anulado. El Nothrecht, la necesidad física, no es un derecho, ya que no pertenece al sistema legal, y debe más bien ser superado para restablecer el estado de derecho y la comunidad política. ${ }^{571}$

Estas consideraciones previas son necesarias para enfocar el problema del derecho de autodefensa en Fichte, entendido como un derecho diferente del derecho de necesidad. Dicho de otra manera, Fichte trata el derecho de autodefensa como un derecho inscrito en el marco de una comunidad legal que protege la vida y propiedad de los ciudadanos. De ahí la importancia que adquieren en esta teoría conceptos como el de la denuncia y el del pedido de socorro.

\footnotetext{
${ }^{569}$ GNR, § 19; SW, III, 252; AA, I, 4, 53.

${ }^{570}$ Cfr. Hösle, (1989), 15 - 16.

${ }^{571}$ Merle, $(1997$, b), $58-59$.
} 
Entrando en el problema del derecho de autodefensa, debe definirse el contexto en el que surge este problema. No se trata de la defensa propia en el caso de ser agredido en el espacio público, porque en este ámbito el responsable de la defensa de la vida y las propiedades del ciudadano es el Estado mismo. Pero si la persona es agredida en la esfera privada, ya sea en su cuerpo o en su propiedad, tiene derecho a defenderse por todos los medios, ya que su derecho originario reclama la conservación de su cuerpo, su libertad y su propiedad. Pero el guardián natural de los ciudadanos es el Estado, según el contrato de ciudadanía.

Por lo tanto, sólo el Estado puede defender a la persona en caso de un ataque. Pero pareciera que la persona no tiene derecho a la autodefensa en caso de ataque en el ámbito doméstico, sino que más bien debe elevar una denuncia. Si la víctima no está en condiciones o no tiene tiempo de elevar una denuncia, en virtud de un peligro presente e inevitable, entonces no habría ninguna solución legal a esta cuestión. Fichte sostiene que la ley debe prever el recurso al pedido de auxilio (das Schreien um Hülfe, Hülferuf, Aufruf zur Hülfe). ${ }^{572}$ El pedido de auxilio reemplaza entonces a la denuncia pública.

Cuando el ciudadano pide auxilio de un modo evidente, está diciendo que cede al Estado su derecho a la privacidad o propiedad absoluta. De este modo, pone a disposición del Estado inmediatamente su propiedad, que antes estaba mediatamente en su poder, sólo en caso en que éste presentara una denuncia pública. Pero ahora el ciudadano está diciendo, con su grito de socorro, algo más: que el Estado no puede acudir inmediatamente en su ayuda. Por lo tanto, todo ciudadano que oiga el llamado de auxilio no sólo está facultado para acudir y poner orden, sino que además está obligado absolutamente en tanto que ciudadano, en virtud del contrato de protección.

La víctima de la agresión tiene derecho a matar a la otra persona en defensa propia sólo si nadie acude a su pedido de auxilio, porque en ese caso el Estado no puede protegerla del ataque y ella tiene el derecho originario a resistirse a ello. Pero la defensa propia es legítima sólo cuando se han agotado todas estas instancias, a fin de que el Estado cumpla con su función de guardián natural. Si todos los ciudadanos tuvieran derecho a matar a sus agresores en defensa propia sin mediar pedido de socorro alguno, entonces, la propiedad de todos se tornaría muy insegura, porque sería muy difícil probar ante un juzgado que uno estaba siendo atacado y que no tenía otra alternativa.

Pero el pedido de socorro, en caso de que fuera oído por los demás y ninguno hubiera podido acurrir en ayuda de la víctima, proporciona por sí mismo una prueba irrefutable de que

\footnotetext{
${ }^{572}$ GNR, § 19; SW, III, 251-252; AA, I, 4, 52-53.
} 
el sujeto no podía defenderse de otra manera. Si los ciudadanos acuden en su defensa, deben extremar sus esfuerzos para detener al criminal y, de este modo, dar fin a la agresión. Luego, el Estado deberá instruir las investigaciones correspondientes y determinar el castigo que recaerá sobre el agresor. 


\section{Conclusiones del Capitulo 5}

De lo argumentado hasta aquí puede concluirse que tanto Cohen como Fichte fundamentan la actividad del Estado en el respeto del derecho derecho a la existencia de sus ciudadanos, o sea a la satisfacción de sus necesidades básicas. Como se dijo en el capítulo 3, ambas teorías coinciden en que la corporalidad de los ciudadanos es la condición de posibilidad del sistema legal, si bien se fundan en razones diferentes.

Cohen considera que el Estado es una comunidad legal, estructurada como una persona jurídica. Como se dijo en el capítulo 1, el Estado consiste en la expresión continua de la voluntad pura, es decir la voluntad común expresa en la Constitución, que consiste en una serie de reglas que deben seguirse para promulgar y aplicar la ley. El Estado y el derecho tienen entonces una forma contractual, es decir que resultan del acuerdo permanente de los ciudadanos entre sí.

Pero además de tener esta forma, el Estado tiene un contenido. Se trata de una forma de subjetividad, que se realiza en su personalidad jurídica, que Cohen denomina como autoconsciencia. Es una subjetividad ficticia y puramente legal, sin fundamentos en ninguna comunidad prepolítica, tales como alguna comunidad de sangre, lengua o tradiciones. La persona jurídica aparece como opuesta a los intereses individuales de los ciudadanos, porque es producto del acuerdo de todos. Por lo tanto, representa los intereses universales de la comunidad política, y trasciende las voluntades individuales y empíricas de cada uno de sus miembros.

Es decir, que luego de concluido el debate en el Parlamento y una vez promulgada la ley, todos los ciudadanos aceptan someterse a ella y cumplirla, o aceptar las penas que les sobrevendrán si no lo hacen. Este requisito es lo que Cohen denomina como la "autorresponsabilidad", elemento fundamental de la autonomía.

La autoconsciencia no es entonces una realidad espiritual suprasensible que de algún modo misterioso se desarrolle dentro de nuestra consciencia individual, sino que es un producto cultural, es decir que es el resultado de la acción del hombre en la historia. La autoconsciencia es la acción misma del Estado, y es realizada efectivamente gracias a la actividad de la legislación. Pero estas afirmaciones son muy abstractas y no dejan en claro cómo es posible que la autoconsciencia se realice progresiva y continuamente en la historia, si 
no se garantiza la existencia corporal de cada ciudadano, porque son sus acciones quienes mantienen viva a la voluntad pura del Estado.

De allí la necesidad de introducir el requisito de la autoconservación en la teoría de Cohen. Sólo si el Estado garantiza a los ciudadanos la autoconservación en la existencia corporal, puede garantizar a su vez su autoconservación como comunidad legal. Este es uno de los motivos fundamentales del rechazo enérgico a la pena de muerte en la $\mathrm{ErW}$. Si el criminal presumiblemente ha aceptado la ley que él mismo ha promulgado, argumenta Cohen, entonces el cumplimiento de la pena por su transgresión es parte fundamental de aquel consentimiento previo. Pero luego el criminal necesariamente debe recorrer el proceso de resocialización necesario para retomar la actividad de la realización de la autoconsciencia, que es una parte insustituible de la ciudadanía. Por eso la pena de muerte significa no sólo la aniquilación del individuo particular, sino que también atenta contra la comunidad espiritual del Estado.

Si bien Cohen no tiene una teoría acerca de los mecanismos por medio de los cuales el Estado debe garantizar la subsistencia de todos y cada uno de los ciudadanos, esta es una exigencia irrenunciable de todo Estado justo, como se sigue de lo que se ha argumentado hasta aquí. Pero no sólo es coherente con esta teoría la idea de una planificación de la distribución de ingresos y recursos, centralizada en el Estado, sino que también es plausible la mediación de estos recursos por medio de un sistema de cooperativas organizado estatalmente, aún cuando Cohen no haya elaborado una teoría completa en este sentido.

Como se dijo en el capítulo 2 de este trabajo, el objeto que tienen las cooperativas en la teoría de Cohen es devolver al ciudadano el señorío de sí mismo, que le ha quitado sistemáticamente el modo de producción capitalista. La industrialización ha llevado al obrero a un estado tal, que se ha convertido en un mero medio para incrementar la riqueza del capitalista, cuando no del Estado mismo. El remedio para esta situación inmoral es otorgar al ciudadano la participación en la dirección del proceso de producción, como un co-legislador de la empresa, junto con sus compañeros.

Sólo de este modo el obrero será tratado como un fin en sí mismo -en el sentido kantiano que Cohen le otorga a esta consigna- y no ya como un instrumento para los fines de otros. Pero el obrero no recuperará el dominio sobre sus acciones si sigue dependiendo del capricho de los capitalistas para poder satisfacer sus necesidades básicas. Por eso la participación en la cooperativa constituirá un cambio significativo en las relaciones de producción capitalistas sólo si a la vez se garantiza la subsistencia de quienes participan en ella. 
Al igual que en la $E r W$, Fichte fundamenta el derecho de los ciudadanos a la existencia en el carácter indispensable de su corporalidad para la realización del derecho. En este punto se conecta lo dicho en esta sección con la investigación desarrollada en el capítulo 4 de este trabajo. Allí se concluyó que el cuerpo articulado es el conjunto de acciones posibles de que dispone cada individuo. Dado que el derecho regula las esferas de acción de cada uno de los ciudadanos, para que todos tengan disponible el mismo conjunto de oportunidades, el derecho tiene su lugar de aplicación en el cuerpo mismo de cada ciudadano.

El cuerpo es además la mediación que hace posible la relación de exhortación y de reconocimiento recíproco entre los yoes. Es decir, que la tarea que desempeñan los órganos inferior y superior del yo es la condición de posibilidad de que el otro lo confirme como un ser racional. Por lo tanto, la protección del cuerpo es el requisito fundamental para que tenga lugar la relación intersubjetiva que el derecho debe garantizar.

De este modo queda suficientemente fundamentada la necesidad de un derecho a la existencia para hacer posible la teoría del GNR. Por lo tanto, el ciudadano del Estado fichteano puede dar por anulado el contrato de ciudadanía, si su derecho a existir no ha sido garantizado. Pero el derecho a existir tiene como correlato la obligación de trabajar. Es decir, que si el ciudadano no trabaja, el Estado considerará que ha incumplido con su contrato de ciudadanía y dará lugar a las sanciones que correspondan.

El Estado es la mediación indispensable para la vigencia de este derecho, porque el mercado es demasiado azaroso y arbitrario para hacerlo. Por eso Fichte desarrolla, digámoslo así, un diseño institucional que haría posible el desarrollo de un conjunto de oportunidades iguales para todos. $\mathrm{Y}$ en este punto la teoría fichteana es mucho más explícita que la coheniana.

Como se dijo más arriba, Fichte fundamenta toda la división del trabajo en el cultivo del suelo. La razón de esto es que el Estado no debe nunca perder de vista que su función es ante todo garantizar el derecho a la existencia de todos sus ciudadanos. Esto implica necesariamente la satisfacción de las necesidades de nutrición, que sólo pueden ser calmadas con los alimentos que brinda el suelo.

Pero estos productos naturales necesitan ser elaborados y manufacturados, para subvenir a las necesidades primarias de cada uno. Este es el rol de los artesanos, quienes requieren aún de una mayor cualificación. Los comerciantes son quienes hacen posible el intercambio entre las materias primas de los productores y los productos elaborados de los artesanos, indispensable para que la economía funcione. 
Fichte retomó entonces la herencia de la Revolución Francesa, y en especial de Robespierre, y elaboró una teoría del derecho donde el hombre concreto e individual tiene un lugar central. Cohen se hizo eco de esta idea para fundamentar su socialismo ético y explicar el modo en que la autoconsciencia se hace realidad en la historia humana. Tanto Cohen como Fichte se enfrentaron con el problema de la desigualdad e injusticia que produce el mercado cuando es dejado de la mano del Estado. Se trata de propuestas interesantes, válidas para un lugar y momento históricos determinados pero con consecuencias legítimas más allá del contexto en el que nacieron, que permiten evaluar el alcance -y las limitaciones- de autores reputados como "idealistas", aunque en teoría moral y política no olvidaron que una teoría normativa debe ser construida teniendo en cuenta también las condiciones sociales de la existencia que hacen posible la autonomía, en el caso de Cohen, o la acción libre en el caso de Fichte. 
Conclusiones finales 


\section{Conclusiones finales}

En la Introducción a este trabajo me propuse poner a prueba la tesis de Gadamer acerca de la influencia ejercida por la filosofía de Fichte sobre el neokantismo, a partir de la comparación de la propuesta ético-política de la $E r W$ con la del GNR. A la hora de las conclusiones, considero que esta tesis tiene sentido. Pero esto no significa que ambos pensadores coincidan en todos los puntos relevantes de sus teorías. De lo argumentado hasta aquí puede concluirse que, junto a las semejanzas profundas que pueden constatarse en Cohen y Fichte, conviven también diferencias en no pocos asuntos de peso.

Esto puede verse claramente luego de un breve repaso por las hipótesis iniciales de este trabajo y los resultados a los que arribé en cada uno de sus capítulos. En primer lugar, mi conjetura era que Cohen y Fichte sostienen conceptos diferentes de autoconsciencia. De lo argumentado en el Capítulo 1 puede concluirse que, mientras que Cohen entiende a la autoconsciencia como la subjetividad que se construye por medio de la legislación en el Estado, Fichte la refiere a la capacidad del yo para atribuirse una acción. Pero esta diferencia fundamental entre la $E r W$ y el $G N R$ nos remite a un elemento en común, que consiste en la deducción de la autoconsciencia a partir de la alteridad.

En ambos casos la subjetividad no puede ser pensada de modo monológico, sino que siempre está inserta en un entramado de relaciones sociales. En la teoría de Cohen, la autoconsciencia es la expresión de la voluntad común de los ciudadanos, que resulta de la unificación de sus voluntades particulares en la ley producto de la deliberación en el Parlamento. Por lo tanto, la autoconsciencia resulta de una cierta correlación entre el individuo y la universalidad de todos los demás. Dicho de otro modo, si la ley fuera el resultado de la voluntad absoluta de un monarca, entonces no podría realizarse la autoconsciencia en la historia.

Fichte considera que el yo puede ser consciente de sí mismo sólo si otro lo exhorta a la acción libre. Se trata de una relación de reconocimiento que despierta al yo al uso de sus capacidades cognitivas y prácticas. Para que la autoconsciencia sea posible no sólo es necesario que el yo sea reconocido por el otro como un ser racional y libre, sino también que el yo reconozca al otro como tal. Dicho de otro modo, si el yo no puede asegurarse de que el otro que lo exhorta a la acción es un ser racional, entonces no puede saberse reconocido por 
él, porque el reconocimiento puede tener lugar sólo entre iguales. De este modo, también en Fichte la alteridad es constitutiva de la autoconsciencia.

En la introducción general trabajé bajo el supuesto de que existe una íntima conexión entre esta interrelación de la alteridad y la autoconsciencia, y el concepto mismo de relación legal que ambas teorías sostienen. Como argumenté en el Capítulo 2, de esta estructura de la autoconsciencia se deriva para la $E r W$ y el $G N R$ una concepción dialógica de la relación legal. Cohen construye el concepto de la relación legal en base al modelo de la persona jurídica de la cooperativa, que tiene una forma contractual. Es decir, que la existencia misma de la cooperativa depende de la legislación de los cooperadores, que hacen posible la unificación de sus voluntades particulares en la voluntad común que resulta del debate y el acuerdo posterior de todos.

Fichte estructura la relación legal en torno al principio del derecho, que exige de sus miembros la mutua delimitación de espacios iguales de libertad. Es decir, que cada sujeto debe disponer de la misma esfera de acción que los demás, porque esta es la condición de posibilidad de la relación de reconocimiento mutuo que los constituye como sujetos. De esta relación legal estructurada dialógicamente resulta una comunidad legal, que tiene como eje la ley de la coherencia consigo mismo. De acuerdo con ella, cada sujeto debe cuidar de que sus acciones no se contradigan entre sí. Por eso una vez que ha limitado su libertad según el principio del derecho, ya no puede dejar de hacerlo en el futuro sin perder su racionalidad.

Siempre de acuerdo con lo investigado en el Capítulo 2, a pesar de que tanto Cohen como Fichte coincidan respecto del carácter dialógico de toda relación legal, difieren en cuanto al status de comunidad que resulta de ella. Cohen sostiene que la relación legal constituye una voluntad común que unifica las voluntades empíricas de los ciudadanos en una universalidad superior. Por el contrario, Fichte piensa en una comunidad legal que no logra superar la individualidad de sus miembros, si bien estos deben atenerse en sus acciones a la ley de la coherencia lógica, que vincula sus arbitrios particulares. Es decir, que en la comunidad legal del GNR las voluntades individuales no son trascendidas y permanecen siendo tales, si bien sujetas al principio del derecho.

Según mis hipótesis iniciales, esta diferencia en torno al concepto de relación legal tiene consecuencias determinantes para cada una de las teorías del Estado. Según los resultados del trabajo desarrollado en el Capitulo 3, Cohen defiende una democracia deliberativa, en la cual el Estado es una persona jurídica que puede existir sólo con la participación de los ciudadanos en su regulación. Fichte, en cambio, introduce la figura del Estado como condición sine qua non de la garantía de la propiedad de los individuos. En el 
Estado fichteano ya no es necesario que los ciudadanos participen en la actividad legislativa, porque los gobernantes están en condiciones de dictar las regulaciones necesarias para garantizar la paz y el derecho. Por eso los ciudadanos delegan todo el poder en sus manos y se reservan el control de los actos de gobierno por medio de la institución del eforato.

También me propuse demostrar, a comienzos de este trabajo, que a pesar de las diferencias evidentes en los dos conceptos del Estado, puede encontrarse un momento de coincidencia profunda entre ellos. Se trata del rol fundamental que tiene la corporalidad del individuo para la constitución del Estado. Como puede concluirse del Capítulo 4, Cohen considera que la autoconservación del ciudadano en la existencia es la condición fundamental del ejercicio de la autonomía, es decir de la actividad de la legislación. Por lo tanto, el Estado debe garantizar la integridad psico-física de sus miembros, tanto en sentido positivo, por medio de la satisfacción de sus necesidades vitales, cuanto en sentido negativo, protegiéndolo del robo o el asesinato. De allí la oposición vehemente de Cohen contra la pena de muerte.

Fichte también considera que el cuerpo es fundamental para la constitución del Estado, porque es una condición necesaria de la aplicación del principio del derecho. La razón de esto es que el principio del derecho se ejerce sobre la libertad de los sujetos, o sea sobre sus esferas de acción, que son idénticas a su cuerpo articulado. Por eso Fichte, al igual que Cohen, exige del Estado que garantice a los ciudadanos el derecho a la existencia, entendido sobre todo como el derecho a la nutrición y la hidratación, según las conclusiones del Capítulo 5. Pero Fichte no confía en la capacidad del mercado para garantizar este derecho supremo, porque el mercado es azaroso y arbitrario. Entonces el Estado debe hacerse cargo de esta tarea, planificando la economía de modo centralizado.

La relación entre la ciudadanía y el derecho a una existencia material garantizada, no sólo es un asunto que tiene una innegable actualidad en el debate académico, sino que también es una deuda pendiente de nuestras sociedades latinoamericanas, marcadas por la desigualdad y la exclusión. Esta es una de las razones por las cuales, según creo, el pensamiento de ambos autores -poco conocidos y poco estudiados en el mundo académico hispano- sigue teniendo vigencia e interés desde el punto de vista de la filosofía práctica en general. Pretendo haberlo dejado claro a lo largo de estas páginas, y también espero haber mostrado la complejidad y riqueza de las argumentaciones filosóficas de ambos pensadores. 
Bibliografía Consultada 


\section{Bibliografía Consultada}

\section{Abreviaturas utilizadas:}

AA: Johann Gottlieb Fichte: Gesamtausgabe der Bayerischen Akademie der Wissenschaften. Hrsg. v. Reinhard Lauth u. Hans Jacob. Stuttgart-Bad Cannstatt 1962ff. (se cita con indicación del volumen y de la paginación).

BBU: Fichte, J. G., Beitrag zur Berichtigung der Urtheile des Publicums über die französische Revolution

EmkN: Cohen, H., Einleitung mit kritischem Nachtrag

ErW: Cohen, H., Ethik des reinen Willens

GNR: Fichte, J.G., Grundlage des Naturrechts nach der Prinzipien der Wissenschaftslehre

LrE: Cohen, H, Logik der reinen Erkenntnis

MdS: Kant, I., Die Metaphysik der Sitten. Cito por la edición de la Academia de Berlín, a cargo de Paul Natorp (AA, VI, 203-493).

SW: Johann Gottlieb Fichte: Sämmtliche Werke. Hrsg. v. Immanuel Hermann Fichte. Leipzig 1845f. (se cita con indicación del volumen y de la paginación).

ZDF: Fichte, J. G., Zurückforferung der Denkfreiheit

\section{Hermann Cohen}

\section{1. Bibliografía Primaria}

(1907), Ethik des reinen Willens, en: (2002), Herman Cohen. Werke, herausgegeben vom Hermann-Cohen-Archiv am Philosophischen Seminar der Universität Zürich unter der Leitung von Helmut Holzhey, Band 7, System der Philosophie. 1. Teil. Ethik des reinen Willens, Georg Olms Verlag, Hildesheim-Zürich-New York. Einleitung von Peter A. Schmid. Nachdruck der 2. revidierten Auflage, (Berlin, Bruno Cassirer, 1907).

(1914), Logik der reinen Erkenntnis, en: (2005), Herman Cohen. Werke, herausgegeben vom Hermann-Cohen-Archiv am Philosophischen Seminar der Universität Zürich unter der Leitung von Helmut Holzhey, Band 6, System der Philosophie. 1. Teil. Logik der reinen Erkenntnis, Georg Olms Verlag, Hildesheim-Zürich-New York. Einleitung von Helmut Holzhey. Nachdruck der 2. verbesserten Auflage (Berlin, Bruno Cassirer, 1914). 
(1914), Einleitung mit kritischem Nachtrag, Leipzig, Verlag von Friedrich Brandstetter.

(1978), Religion der Vernunft aus den Quellen des Judentums. Nach dem Manuskript des Verfassers neu durchgearbeitet und mit einem Nachwort versehen von Bruno Strau $\beta$, Wiesbaden, Fourier Verlag.

\section{2. Bibliografía secundaria}

Adelmann, D., (1968), Einheit des Bewusstseins als Grundproblem der Philosophie Hermann Cohens, Heidelberg, Dissertation.

Adelmann, D., (1997), "H. Steinthal und Hermann Cohen“, in: Moses, S., Wiedebach, H., (1997), Hermann Cohens Philosophy of Religion. International Conference in Jerusalem 1996, Hildesheim-Zürich-New York, Georg Olms Verlag, pp.1-33.

Adler, M., (1904), "Kant und der Sozialismus", en: (1925), Kant und der Marxismus. Gesammelte Aufsätze zur Erkenntniskritik und Theorie des Sozialen, Berlin, pp. 83-132. Cito por su reimpresión en: Sandkühler, H.J., De la Vega, R., (Hrsg.), (1970), Texte zum Neukantianischen Sozialismus, Frankfurt am Main, Suhrkamp Verlag.

Albertini, F., (2003), Das Verständnis des Seins bei Hermann Cohen, Würzburg, Königshausen \& Neumann.

Alexy, R., Meyer, L. Paulson, S., Sprenger, G., (Hrsg.), (2002), Neukantianismus und Rechtsphilosophie. Mit einer Einleitung von Stanley Paulson, Baden-Baden, Nomos Verlagsgesellschaft.

Brandt, R.., Orlik, F., (Hrsg.), (1993), Philosophisches Denken - Politisches Wirken. Hermann Cohens Kolloquium Marburg 1992, Hildesheim-Zürich-New York, Georg Olms Verlag.

Camarotta, G.P., (2002), L'idealismo messianico di Hermann Cohen, Napoli, Edizioni Scientifique Italiane.

Cassirer, E., (1912), "Hermann Cohen und die Erneuerung der Kantischen Philosophie", Kant-Studien XVII (1912), pp.252-273.

Cassirer, E., (1918), "Hermann Cohen. Worte gesprochen an seinem Grabe am 7. April 1918“, Neue Jüdische Monatshefte II Jg. (1918), Heft 15/16 (Sonderheft Hermann Cohen), S. 347-352. in: Holzhey, H., (Hrsg.), (1994), Auslegungen. Band 4. Hermann Cohen, Frankfurt am Main-Berlin-Bern-New York-Paris-Wien, Peter Lang, pp.67-74.

De Schmidt, Winrich, (1976), Psychologie und Transzendentalphilosophie, Bonn, Bouvier Verlag Herbert Grundmann.

Deuber-Mankowsky, A., (2000), Der frühe Benjamin und Hermann Cohen. Jüdische Werte, Kritische Philosophie, vergängliche Erfahrung, Berlin, Vorwerk 8. 
Dreyer, M., (1985), Die Idee Gottes im Werk Hermann Cohens, Königstein/Ts., Verlag Anton Hain Meisenheim GmbH.

Ebbinghaus, J., (1956), "Hermann Cohen als Philosoph und Publizist", Archiv für Philosophie 6 (1956), S. 109-122. In: Holzhey, H., (Hrsg.), (1994), Auslegungen. Band 4. Hermann Cohen, Frankfurt am Main-Berlin-Bern-New York-Paris-Wien, Peter Lang, pp.189-204.

Ferraro, A., E., (2000), La ética del positivismo jurídico, Bs. As., EUDEBA, Departamento de Publicaciones de la Facultad de Derecho de la Universidad de Buenos Aires.

Figal, G., (1982), "Recht und Moral bei Kant, Cohen und Benjamin", Zeitschrift für philosophische Forschung 36 (1982), pp.361-377. In: Ollig, H.L., (Hrsg.), (1987), Materialen zur Neukantianismus Diskussion, Darmstadt, Wissenschaftliche Buchgesellschaft, pp.163183.

Fiorato, P., (1993), Geschichtliche Ewigkeit. Ursprung und Zeitlichkeit in der Philosophie Hermann Cohens, Würzburg, Königshausen \& Neumann.

Fiorato, P., (1994), “ 'Die Gegenwart muß indessen zur Zukunft werden'. Über die ,logischen' Grundlagen des Cohenschen Messianismus", in: Orth, E.W., Holzhey, H., (Hrsg.), (1994), Neukantianismus. Perspektiven und Probleme, Würzburg, Königshausen \& Neumann, pp.366-378.

Fiorato, P., (1997), "Die Erfahrung, das Unbedingte und die Religion: Walter Benjamin als Leser von Kants Theorie der Erfahrung", in: Moses, S., Wiedebach, H., (1997), Hermann Cohens Philosophy of Religion. International Conference in Jerusalem 1996, HildesheimZürich-New York, Georg Olms Verlag, pp.71-84.

Gadamer, H. G., (1975, a), "Kant und die hermeneutische Wendung”, en: (1987), Gesammelte Werke, Band 3, Neuere Philosophie. I: Hegel.Husserl. Heidegger, Tübingen, J.C.B. Mohr (Paul Siebeck).

Gadamer, H. G., (1975, b), "Subjektivität und Intersubjektivität, Subjekt und Person", en: (1995), Hans Georg Gadamer: Gesammelte Werke, Bd. 10: Hermeneutik im Rückblick, Tübingen, J.C.B. Mohr (Paul Siebeck).

Gadamer, H. G., (1981), "Die Geschichte der Philosophie”, en: (1987), Gesammelte Werke, Band 3, Neuere Philosophie. I: Hegel.Husserl. Heidegger, Tübingen, J.C.B. Mohr (Paul Siebeck).

Gadamer, H. G., (1987), Gesammelte Werke, Bd.3, Neuere Philosophie - 1. Hegel, Husserl, Heidegger, Tübingen, Mohr Siebeck.

Gadamer, H. G. (1995), Gesammelte Werke, Bd.10, Hermeneutik im Rückblick, Tübingen, Mohr Siebeck.

Geismann, G., (1993), "Der Berliner Antisemitimusstreit und die Abdankung der rechtlichpraktischen Vernunft", en: Kant-Studien, 83. Jahrg., pp. 369-380. 
Gibbs, R., (2000), "Hermann Cohen's Messianism: The History of the Future“, in: Holzhey, H., Motzkin, G., Wiedebach, H., (Hrsg.), (2000), ,,Religion der Vernunft aus den Quellen des Judentums". Tradition und Ursprungsdenken in Hermann Cohens Spätwerk, HildesheimZürich-New York, Georg Olms Verlag, pp.331-349.

Gibbs, R., (eds.), (2006), Hermann Cohen's Ethics, Leiden-Boston, Brill.

Giesecke, P., (1990), Kant und der Sozialismus. Studien zum Marburger Neukantianismus, Philosophisches Kritizismus und Kritischen Rationalismus, München, Dissertation.

Gigliotti, G., (1994), "Ethik und das Faktum der Rechtswissenschaft bei Hermann Cohen", in: Holzhey, H., (Hrsg.), Ethischer Sozialismus, Frankfurt, Suhrkamp, pp.166-184.

Gordon, J., (1927), Der Ichbegriff bei Hegel, bei Cohen und in der Südwestdeutschen Schule hinsichtlich der Kategorienlehre untersucht, Berlin, Akademie Verlag.

Görland, A., (1912), "Hermann Cohens systematische Arbeit im Dienste des kritischen Idealismus“, Kant-Studien, XVII (1912), pp.222-251.

Guariglia, O., (1987), "El lugar de L. Nelson en la filosofía contemporánea", Revista Latinoamericana de Filosofía 13 (1987), pp. 161-193.

Guariglia, O., (1992), "Kantismo", en: Enciclopedia Iberoamericana de Filosofía, Vol. II: Concepciones de la ética, Madrid, Trotta, pp. 53-72.

Günther, H., (1971), System und Fortschritt im Denken Hermann Cohens, Köln, Dissertation.

Günther, H., (1972), Philosophie des Fortschritts. Hermann Cohens Rechtfertigung der bürgerlichen Gesellschaft, München, Wilhelm Goldmann Verlag.

Hake, A.K., (2003), Vernunftreligion und historische Glaubenslehre Immanuel Kant und Hermann Cohen, Würzburg, Königshausen \& Neumann.

Hartmann, N., (1912), Frankfurter Zeitung, 4.Juli 1912 (56 Jahrg. Nr. 183), in: Holzhey, H., (Hrsg.), (1994/2), Auslegungen. Band 4. Hermann Cohen, Frankfurt am Main-Berlin-BernNew York-Paris-Wien, Peter Lang, pp.27-37.

Heidegger, M., (1919), Phänomenologie und transzendentale Wertphilosophie. Vorlesung Sommersemester 1919, en: (1987), Gesamtausgabe Bd. 55/56, Frankfurt a. M., Vittorio Klostermann, pp. 119-203.

Heinz, M., (1997), "Die Fichte-Rezeption in der südwestdeutschen Schule des Neukantianismus“, en: Fichte-Studien, Bd. 13, 1997, pp. 109-129.

Hermann, W., (1916), "Der Begriff der Religion nach Hermann Cohen“, Die Christliche Welt, 30. Jg., Nr. 44, Marburg. In: Holzhey, H., (Hrsg.), (1994/2), Auslegungen. Band 4. Hermann Cohen, Frankfurt am Main-Berlin-Bern-New York-Paris-Wien, Peter Lang, pp.61-66.

Holzhey, H., (1992), "Neukantianische Ethik", in: Pieper, A., (Hrsg.), (1992), Geschichte der neueren Ethik. Band 2: Gegenwart, Tübingen, Francke Verlag Tübingen und Basel, pp.29-54. 
Holzhey, H., (1993), "Hermann Cohen: der Philosoph in Auseinandersetzung mit dem politischen und gesellschaftlichen Probleme seiner Zeit", in: Brandt, R.., Orlik, F., (Hrsg.), (1993), Philosophisches Denken - Politisches Wirken. Hermann Cohens Kolloquium Marburg 1992, Hildesheim-Zürich-New York, Georg Olms Verlag, pp.15-36.

Holzhey, H., (Hrsg.), (1994, a), Ethischer Sozialismus, Frankfurt.

Holzhey, H., (Hrsg.), (1994, b), Auslegungen. Band 4. Hermann Cohen, Frankfurt am MainBerlin-Bern-New York-Paris-Wien, Peter Lang.

Holzhey, H., (1994, c), "Die praktische Philosophie des Marburger Neukantianismus. Versuch einer moralischen Bilanz“, in: Orth, E.W., Holzhey, H., (Hrsg.), (1994), Neukantianismus. Perspektiven und Probleme, Würzburg, Königshausen \& Neumann, pp.136-155.

Holzhey, H., (1994, d), "Einleitung“, in: Holzhey, H., (Hrsg.), (1994/2), Auslegungen. Band 4. Hermann Cohen, Frankfurt am Main-Berlin-Bern-New York-Paris-Wien, Peter Lang, pp.925.

Holzhey, H., (2006), "Ethik als Lehre vom Menschen. Eine Einführung in Hermann Cohens Ethik des reinen Willens", en: Gibbs, R., (eds.), (2006), Hermann Cohen's Ethics, LeidenBoston, Brill, pp. 17-36.

Holzhey, H., Motzkin, G., Wiedebach, H., (Hrsg.), (2000), "Religion der Vernunft aus den Quellen des Judentums“. Tradition und Ursprungsdenken in Hermann Cohens Spätwerk, Hildesheim-Zürich-New York, Georg Olms Verlag.

Kant, I., (1997), La metafísica de las costumbres, trad. esp. de Adela Cortina Orts y Jesús Conill Sancho, Madrid, Altaya.

Kautsky, K., (1906), Ethik und materialistische Geschichtsauffassung. Ein Versuch, Stuttgart. Cito por su reimpresión en: Sandkühler, H.J., De la Vega, R., (Hrsg.), (1970), Texte zum Neukantianischen Sozialismus, Frankfurt am Main, Suhrkamp Verlag.

Klatzkin, J, (1919), Hermann Cohen, Berlin, Jüdischer Verlag.

Kersting, W., (2002), "Neukantianische Rechtsbegründung. Rechtsbegriff und richtiges Recht bei Cohen, Stammler und Kelsen“, in: Alexy, R., Meyer, L. Paulson, S., Sprenger, G., (Hrsg.), (2002), Neukantianismus und Rechtsphilosophie. Mit einer Einleitung von Stanley Paulson, Baden-Baden, Nomos Verlagsgesellschaft.

Kinkel, W., (1924, a), Hermann Cohen. Sein Leben und sein Werk, Stuttgart, Verlag von Strecker und Schröder.

Kinkel, W., (1924, b), Hermann Cohen. Eine Einführung in sein Werk, Stuttgart, Verlag von Strecker und Schröder.

Klatzkin, J., (1919), Hermann Cohen, Berlin, Jüdischer Verlag.

Klein, J., (1976), Die Grundlegung der Ethik in der Philosophie Hermann Cohens und Paul Natorps - eine Kritik des Neukantianismus, Göttingen, Vandenhoeck \& Ruprecht. 
Kneller, J., Axinn, S., (eds.), (1998), Autonomy and Community. Readings in Contemporary Kantian Social Philosophy, New York, State University of New York Press.

Köhnke, K.Ch., (1986), Entstehung und Aufstieg des Neukantianismus. Die deutsche Unversitätsphilosophie zwischen Idealismus und Positivismus, Frankfurt am Main, Suhrkamp.

Lehmann, G., (1963), "Kant im Spätidealismus und die Anfänge der Neukantischen Bewegung“, Zeitschrift für philosophische Forschung 17 (1963), pp. 438-456. In: Ollig, H.L., (Hrsg.), (1987), Materialen zur Neukantianismus Diskussion, Darmstadt, Wissenschaftliche Buchgesellschaft, pp. 44-65.

Lembeck, K.-H., (1994), Platon in Marburg. Platonrezeption und Philosophiegeschichtsphilosophie bei Cohen und Natorp, Würzburg, Königshausen \& Neumann.

Levy. H., (1927), Die Hegel Renaissance in der deutschen Philosophie. Mit besonderer Berücksichtigung des Neukantianismus, Pan-Verlag Rolf Heise.

Lindheimer, F.P., (1900), Beiträge zur Geschichte und Kritik der Neukantianischen Philosophie, Berna, Dissertation.

Lisser, K., (1922), Der Begriff des Rechts bei Kant. Mit einem Anhang über Cohen und Görland, Berlin, Verlag von Reuter \& Reichard.

Lübbe, H., (1958), "Die politische Theorie des Neukantianismus und des Marxismus", in: Holzhey, H., (Hrsg.), (1994), Auslegungen. Band 4. Hermann Cohen, Frankfurt am MainBerlin-Bern-New York-Paris-Wien, Peter Lang, pp. 229-246.

Lübbe, H., (1963), "Neukantianische Sozialismus", in: Politische Philosophie in Deustchland. Studien zu ihrer Geschichte, Basel, Schwabe Verlag, SS.85-125. In: Ollig, H.L., (Hrsg.), (1987), Materialen zur Neukantianismus Diskussion, Darmstadt, Wissenschaftliche Buchgesellschaft, pp.219-263.

Mehring, F., (1899/1900), "Kant und der Sozialismus“, en: Die neue Zeit 18 (1899/1900), pp. 33-37. Cito por su reimpresión en: Sandkühler, H.J., De la Vega, R., (Hrsg.), (1970), Texte zum Neukantianischen Sozialismus, Frankfurt am Main, Suhrkamp Verlag.

Merz-Benz, (1994), 'Die begriffliche Konstitution der Sozialwelt. Ferdinand Tönnies' Weg zu einer ,Methode, die mit der Schöpfung der Dinge selbst übereinstimmt" “, in: Orth, E.W., Holzhey, H., (Hrsg.), (1994), Neukantianismus. Perspektiven und Probleme, Würzburg, Königshausen \& Neumann, pp. 250-268.

Merz-Benz, P., Renz, U., (hrsg.), (2004), Ethik oder Ästhetik? Zur Aktualität der neukantianischen Kulturphilosophie, Würzburg, Königshausen \& Neumann.

Meyer, T., (1993), "Eine unzeitgemäße Intervention, die an der Zeit war. Hermann Cohens neukantianischer Sozialismus und die sozialdemokratische Ideologie im Kaiserreich“, in: Brandt, R.., Orlik, F., (Hrsg.), (1993), Philosophisches Denken - Politisches Wirken. Hermann Cohens Kolloquium Marburg 1992, Hildesheim-Zürich-New York, Georg Olms Verlag, pp. 257-269. 
Moses, S., Wiedebach, H., (1997), Hermann Cohens Philosophy of Religion. International Conference in Jerusalem 1996, Hildesheim-Zürich-New York, Georg Olms Verlag.

Müller, C., (1994), Die Rechtsphilosophie des Marburguer Neukantianismus. Naturrecht und Rechtpositivismus in der Auseinandersetzung zwischen Hermann Cohen, Rudolf Stammler und Paul Natorp, Tübingen, J.C.B. Mohr (Paul Siebeck).

Munk, R., (1997), "The Self and the Other in Cohen's Ethics and Works on Religion", in: Moses, S., Wiedebach, H., (1997), Hermann Cohens Philosophy of Religion. International Conference in Jerusalem 1996, Hildesheim-Zürich-New York, Georg Olms Verlag, pp. 161181.

Munk, R., (2000), "Who is the Other? Alterity in Cohen's ,Religion der Vernunft\# ,, in: Holzhey, H., Motzkin, G., Wiedebach, H., (Hrsg.), (2000), „, Religion der Vernunft aus den Quellen des Judentums “. Tradition und Ursprungsdenken in Hermann Cohens Spätwerk, Hildesheim-Zürich-New York, Georg Olms Verlag, pp.275-286.

Natorp, P. (u.a.), (1912), Philosophische Abhandlungen. Hermann Cohen zum 70 sten Geburstag (4. Juli 1912), dargebracht, Berlin, Bruno Cassirer.

Natorp, P., (1912), "Kant und die Marburger Schule“, Kant-Studien, XVII (1912), pp. 193221.

Natorp, P., (1913), "Recht und Sittlichkeit. Ein Beitrag zur kategorialen Begründung der praktischen Philosophie. Mit besonderem Bezug auf Hermann Cohens, Ethik des reinen Willens' und Rudolf Stammlers, Theorie der Rechtswissenschaft' „, Kant-Studien, XVIII (1913), pp. 1-79.

Natorp, P., (1918), "Hermann Cohens philophische Leistung unter dem Gesichtspunkte des Systems", Berlin, Philophische Vorträge der Kant-Gesellschaft, Nr. 21. In: Holzhey, H., (Hrsg.), (1994), Auslegungen. Band 4. Hermann Cohen, Frankfurt am Main-Berlin-Bern-New York-Paris-Wien, Peter Lang, pp. 75-103.

Ollig, H. L., (1979, a), Religion und Freiheitsglaube, Forum Academicum in der Verlagsgruppe Athenäum, Hain, Scriptor, Hanstein.

Ollig, H.-L., (1979, b), Der Neukantianismus, Stuttgart, Metzler.

Ollig, H.L., (Hrsg.), (1987), Materialen zur Neukantianismus Diskussion, Darmstadt, Wissenschaftliche Buchgesellschaft.

Orth, E.W., Holzhey, H., (Hrsg.), (1994), Neukantianismus. Perspektiven und Probleme, Würzburg, Königshausen \& Neumann.

Palmer, G., (2006), "Judaism as a ,method' with Hermann Cohen and Franz Rosenzweig", en: Gibbs, R., (eds.), (2006), Hermann Cohen's Ethics, Leiden-Boston, Brill, pp. 37-63.

Pascher, M., (1992), Hermann Cohens Ethik als Gegenentwurf zur Rechtsphilosophie Hegels, Innsbruck, Verlag des Instituts für Sprachwissenschaft der Universität Innsbruck. 
Pascher, M., (1993), "Cohens Ethik im Spannungsfeld zwischen Kant und Hegel" in: Brandt, R.., Orlik, F., (Hrsg.), (1993), Philosophisches Denken - Politisches Wirken. Hermann Cohens Kolloquium Marburg 1992, Hildesheim-Zürich-New York, Georg Olms Verlag, pp. 95-109.

Pascher, M., (1997), Einführung in den Neukantianismus. Kontext - Grundpositionen Praktische Philosophie, München, Wilhelm Fink Verlag.

Philonenko, A., (1989), L'Ecole de Marbourg, Paris, Libraire Philosophique Vrin.

Poma, A., (2006), "The existence of the ideal in Hermann Cohen's Ehics", en: Gibbs, R., (eds.), (2006), Hermann Cohen's Ethics, Leiden-Boston, Brill, pp. 65-84.

Rawls, J. (1980), "Kantian Constructivism in Moral Theory", The Journal of Philosophy, 77 (1980), 515-572. Cito por la traducción española de Miguel Angel Rodilla, en: (1986), Justicia como equidad y otros ensayos. Madrid, Tecnos, pp. 137-186.

Sandkühler, H.J., De la Vega, R., (Hrsg.), (1970), Texte zum Neukantianischen Sozialismus, Frankfurt am Main, Suhrkamp Verlag.

Schmidt, C., (1900), "Sozialismus und Ethik", en: Socialistische Monatshefte, 4 (1900), pp. 522-531. Cito por su reimpresión en: Sandkühler, H.J., De la Vega, R., (Hrsg.), (1970), Texte zum Neukantianischen Sozialismus, Frankfurt am Main, Suhrkamp Verlag.

Schmid, P., (1993), Ethik als Hermeneutik. Systematische Untersuchungen zu Hermann Cohens Rechts und Tugendlehre, Würzburg, Könighausen \& Neumann.

Schmid, P., (2000), "Die Tugendlehre in der ,Religion der Vernunft" „, in: Holzhey, H., Motzkin, G., Wiedebach, H., (Hrsg.), (2000), "Religion der Vernunft aus den Quellen des Judentums". Tradition und Ursprungsdenken in Hermann Cohens Spätwerk, HildesheimZürich-New York, Georg Olms Verlag, pp. 287-302.

Schmill, U., (2003), "Diálogo en Marburgo entre Hermann Cohen y Kelsen“, en: Doxa 26 (2003), pp. 583-608.

Schmill, U., (2004), “Algunas influencias de Hermann Cohen en Hans Kelsen”, en: Isonomia, $\mathrm{N}^{\circ} 21$, octubre de 2004, pp. 117-155.

Schulte, Ch., (1997), "Theodizee bei Kant und Cohen“, in: Moses, S., Wiedebach, H., (1997), Hermann Cohens Philosophy of Religion. International Conference in Jerusalem 1996, Hildesheim-Zürich-New York, Georg Olms Verlag, pp. 205-229.

Schwarzschild, S., (1956), "The Democratic Socialism of Hermann Cohen", in: Holzhey, H., (Hrsg.), (1994), Auslegungen. Band 4. Hermann Cohen, Frankfurt am Main-Berlin-Bern-New York-Paris-Wien, Peter Lang, pp.205-227.

Sieg, U., (1994), Aufstieg und Niedergang des Marburger Neukantianismus. Die Geschichte einer philosophischen Schulgemeinschaft, Würzburg, Könighausen \& Neumann.

Solowiejczyk, J., (1930), Das reine Denken und die Seinskonstituierung bei Hermann Cohen, Berlin, Dissertation. 
Staudinger, F., (1901), "Sozialismus und Ethik", en: Socialistische Monatshefte, 8 (1901), pp. 433-438. Cito por su reimpresión en: Sandkühler, H.J., De la Vega, R., (Hrsg.), (1970), Texte zum Neukantianischen Sozialismus, Frankfurt am Main, Suhrkamp Verlag.

Staudinger, F., (1904), "Kant und der Sozialismus. Ein Gedenkwort zu Kants Todestage", en: Socialistische Monatshefte, 8 (1904), pp. 103-114. Cito por su reimpresión en: Sandkühler, H.J., De la Vega, R., (Hrsg.), (1970), Texte zum Neukantianischen Sozialismus, Frankfurt am Main, Suhrkamp Verlag.

Stolzenberg, J., (1995), Ursprung und System. Probleme der Begründung systematischer Philosophie im Werk Hermann Cohens, Paul Natorps und beim frühen Martin Heidegger, Göttingen, Vandenhoeck \& Ruprecht.

Stolzenberg, J., (2002), "Fichte im Neukantianismus. Probleme der Fichte-Rezeption bei Wilhelm Windelband, Heinrich Rickert, Hermann Cohen und Paul Natorp“, in: Alexy, R., Meyer, L. Paulson, S., Sprenger, G., (Hrsg.), (2002), Neukantianismus und Rechtsphilosophie. Mit einer Einleitung von Stanley Paulson, Baden-Baden, Nomos Verlagsgesellschaft, pp. 421434.

Tucker, B., (1984), Ereignis. Wege durch die politische Philosophie des Marburger Neukantianismus, Frankfurt am Main - Bern - New York, Peter Lang.

Van der Linden, H., (1988), Kantian Ethics and Socialism, Indianapolis/Cambridge, Hackett Publishing Company.

Van der Linden, H., (1994), "Cohens sozialistische Rekonstruktion der Ethik Kants", in: Holzhey, H., (Hrsg.), Ethischer Sozialismus, Frankfurt, Suhrkamp, pp. 146-165.

Van der Linden, H., (1998), "A Kantian Defense of Enterprise Democracy", in: Kneller, J., Axinn, S., (eds.), (1998), Autonomy and Community. Readings in Contemporary Kantian Social Philosophy, New York, State University of New York Press, pp. 213-237.

Vorländer, K., (1911), Kant und Marx. Ein Beitrag zur Philosophie des Sozialismus, editado originalmente en Tübingen, J. C. B. Mohr (Siebeck). Cito por su reimpresión en: Sandkühler, H.J., De la Vega, R., (Hrsg.), (1970), Texte zum Neukantianischen Sozialismus, Frankfurt am Main, Suhrkamp Verlag.

Wiedebach, H., (1997, a), Die Bedeutung der Nationalität für Hermann Cohen, HildesheimZürich-New York, Georg Olms Verlag.

Wiedebach, H., (1997, b), "Hermann Cohens Theorie des Mitleids", in: Moses, S., Wiedebach, H., (1997), Hermann Cohens Philosophy of Religion. International Conference in Jerusalem 1996, Hildesheim-Zürich-New York, Georg Olms Verlag, pp. 231-244.

Wiedebach, H., (2006), "Physiology of the pure will: concepts of moral energy in Hermann Cohen's Ethics", en: Gibbs, R., (eds.), (2006), Hermann Cohen's Ethics, Leiden-Boston, Brill, pp. 85-103.

Wiehl, R., (1997), "Das Prinzip Treue in Hermann Cohens Ethik und Religionsphilosophie“, in: Moses, S., Wiedebach, H., (1997), Hermann Cohens Philosophy of Religion. International 
Conference in Jerusalem 1996, Hildesheim-Zürich-New York, Georg Olms Verlag, pp. 245261.

Willey, Th., (1978), Back to Kant. The Revival of Kantianism in German Social and Historical Thought, 1860-1914, Detroit, Wayne State University Press.

Winter, E., (1980), Ethik und Rechtswissenschaft. Eine historisch-systematische Untersuchung zur Ethik-Konzeption des Marburger Neukantismus im Werke Hermann Cohens, Berlin, Duncker \& Humblot.

Zank, M., (2006), "The ethics in Hermann Cohen's philosophical system", en: Gibbs, R., (eds.), (2006), Hermann Cohen's Ethics, Leiden-Boston, Brill, pp. 1-15. 


\section{Johann G. Fichte}

\section{1. Bibliografía Primaria}

Grundlage des Naturrechts nach Principien der Wissenschaftslehre Zurückforferung der Denkfreiheit

Beitrag zur Berichtigung der Urtheile des Publicums über die französische Revolution.

Estas obras se citan de acuerdo a las siguientes ediciones:

Johann Gottlieb Fichte: Sämmtliche Werke. Hrsg. v. Immanuel Hermann Fichte. Leipzig $1845 \mathrm{f}$.

Johann Gottlieb Fichte: Gesamtausgabe der Bayerischen Akademie der Wissenschaften. Hrsg. v. Reinhard Lauth u. Hans Jacob. Stuttgart-Bad Cannstatt $1962 \mathrm{ff}$.

\section{2. Bibliografía secundaria}

Archard, D., (2001), "Familiy Law (First Annex)", en: Merle, J. Ch., (Hrsg.), Johann Gottlieb Fichte. Grundlage des Naturrechts, Klassiker Auslegen, Band 24, Akademie Verlag, Berlin, pp. 187-196.

Aristóteles, (1993), Politica, Traducción española de Carlos García Gual y Aurelio Pérez Jiménez, Barcelona, Altaya.

Bartuschat, W., (1992), "Zur Deduktion des Rechts aus der Vernunft bei Kant und Fichte", en: Kahlo, M., Wolff, E., Zaczyk, R., (hrsg.), Fichtes Lehre vom Rechtsverhältnis. Die Deduktion der $\S \S$ 1-4 der Grundlage des Naturrechts und ihre Stellung in der Rechtsphilosophie, Vittorio Klostermann, Frankfurt am Main, pp.173-192.

Batscha, Z., (1970), Gesellschaft und Staat in der politischen Philosophie Fichtes, Frankfurt am Main, Europäische Verlagsanstalt.

Batscha, Z., (1981), Studien zur politischen Theorie des deutschen Frühliberalismus, Frankfurt am Main, Suhrkamp Verlag.

Becker, H. J. (2003), "Fichte und das Judentum - das Judentum und Fichte", en: FichteStudien, Band 22, (2003), pp. 19 - 36.

Bertomeu, M.J., (2005), "Las raíces republicanas del mundo moderno: en torno a Kant"; en: Bertomeu, M. J., Domenech, A, de Francisco, A., (2005), Republicanismo y Democracia, Bs. As, Miño y Dávila, 2005, pp 123-140.

Brandom, R., (2004), "Selbstbewusstsein und Selbst-Konstitution. Die Struktur von Wünschen und Anerkennung“, en: Halbig, Ch., Quante, M., Siep, L., (Hrsg.), Hegels Erbe, Frankfurt, Suhrkamp, pp. 46-77. 
Braun, J., (1991), Freiheit, Gleichheit, Eigentum. Grundfragen des Rechts im Lichte der Philosophie J.G. Fichtes, Tübingen, J.C.B. Mohr (Paul Siebeck).

Bubner, R., (2001), "Von der Aufforderung zur Anerkennung"; en: Stolzenberg, J., (hrsg.), (2001), Subjekt und Metaphysik : Konrad Cramer zu Ehren aus Anlaß seines 65. Geburtstages, pp. $61-71$.

Buhr, M., (1965), Revolution und Philosophie. Die ursprüngliche Philosophie Johann Gottlieb Fichtes und die Französische Revolution, Berlin, VEB, Deutscher Verlag der Wissenschaften.

Buhr, M., (1991), "Die Philosophie Johann Gottlieb Fichtes und die Französische Revolution“, en: Buhr, Manfred, Losurdo, Domenico, (hsrg.), (1991), Fichte - die Französische Revolution und das Ideal vom ewigen Frieden. Mit Unterstützung des Istituto Italiano per gli Studi Filosofici, Napoli, Berlin, Akademie Verlag, pp. 9-73.

Cattin, E., (2001), "L' enseignement de 1'idéalisme“, en: Kairos, N 17, 2001, pp.11-29.

Cesa, C., (1992), "Zur Interpretation von Fichtes Theorie der Intersubjektivität", en: Kahlo, M., Wolff, E., Zaczyk, R., (hrsg.), Fichtes Lehre vom Rechtsverhältnis. Die Deduktion der $\$ \S$ 1-4 der Grundlage des Naturrechts und ihre Stellung in der Rechtsphilosophie, Vittorio Klostermann, Frankfurt am Main, pp. 53-69.

Constant, B., (1919), Reise durch die deutsche Kultur, hg. Von Schwarz, Potsdam.

Crone, K., (2005), Fichtes Theorie konkreter Subjektivität. Untersuchungen zur ,,Wissenschaftslehre nova methodo “, Göttingen, Vandenhoeck \& Ruprecht.

De Pascale, C., (1988), "Droit à la Vie, Nature et Travail chez J.G. Fichte", en: Archives de Philosophie, 51, pp. 597-612.

De Pascale, C., (2001), "Das Völkerrecht (Zweiter Anhang) )“; en: Merle, J. Ch., (Hrsg.), Johann Gottlieb Fichte. Grundlage des Naturrechts, Klassiker Auslegen, Band 24, Akademie Verlag, Berlin, pp. 197-210.

Düsing, E., (1986), Intersubjektivität und Selbstbewusstsein. Behavioristische, phänomenologische und idealistische Begründungstheorien bei Mead, Schütz, Fichte und Hegel, Köln, Verlag für Philosophie Jürgen Dinter.

Düsing, E., (1991), "Das Problem der Individualität in Fichtes früher Ethik und Rechtslehre", en: Fichte-Studien, Band 3, (1991), pp. 29 - 50.

Düsing, E., (1995), "Autonomie-soziale Heteronomie - Theonomie“, en: Fichte-Studien, Band 8, (1995), pp.59 - 85.

Düsing, E., (1997), “Individuelle und soziale Bildung der Ich-Identität. Fichtes Konzeption im Horizont moderner Alternativen“, en: Fichte-Studien, Band 11, (1997), pp. 113 - 132.

Fischbach, F., (1999), Fichte et Hegel. La reconnaissance, Paris, Presses Universitaires de France. 
Fischbach, F., (2000), "Reconnaissance et philosophie pratique chez Fichte", en: Bienenstock, M., Crampe-Casnabet, M., (2000), Dans quelle mesure la philosophie est pratique. Fichte, Hegel. Avec la collaboration de Jean-Francois Goubet, Fontenay/Saint-Cloud, Ens Éditions, pp. 131-146.

Fischbach, F., (2001), "La reconnaissance: de 1'honneur à 1'estime“", en: Kairos, № 17, 2001, pp.215-230.

Fonnesu, L., (1997), "Die Aufhebung des Staates bei Fichte“, “ en: Fichte-Studien, Band 11, (1997), pp. 85 - 97.

Fuchs, E., (2004), "Fichte und die Berliner Aufklärung. Einige charakteristische Linien", en: De Pascale, C., Fuchs, E., Ivaldo, M., Zöller, G., (hrsg.), (2004), Fichte und die Aufklärung, Hildesheim-Zürich-New York, Georg Olms Verlag, pp. 53-68.

Gadamer, H. G., (1998), "Hegels Dialektik des Selbstbewusstseins", en: Fulda, H. F., Henrich, D., (Hrsg.), Materialien zu Hegels „Phänomenologie des Geistes“, Frankfurt, Suhrkamp, pp. 217-242.

Geismann, G., (1991), “Fichtes ,Aufhebung' des Rechtsstaates“, en: Fichte-Studien, Band 3, (1991), pp. 86 - 117.

Giassi, L., (2000), "De la déduction fichtéenne à la phénoménologie hegelienne", en: Bienenstock, M., Crampe-Casnabet, M., (2000), Dans quelle mesure la philosophie est pratique. Fichte, Hegel. Avec la collaboration de Jean-Francois Goubet, Fontenay/SaintCloud, Ens Éditions, pp. 147-167.

Gueroult, M., (1974), Études sur Fichte, Hildesheim - New York, Georg Olms Verlag.

Hahn, K., (2003), "Die Relevanz der Eigentumstheorie Fichtes im Zeitalter der Globalisierung unter Berücksichtigung Proudhons und Hegels“" en: Fichte-Studien, Band 24, (2003), pp. 155 $-163$.

Hammacher, K., (2000), "Fichte und die Philosophie der Maurerei“, in: Fichte-Studien, Band $18,(2000)$, pp. $65-82$.

Hammacher, K., (2004), "Gemeinnutzen und Vertragstheorie in Fichtes Rechtsphilosophie", en: De Pascale, C., Fuchs, E., Ivaldo, M., Zöller, G., (hrsg.), (2004), Fichte und die Aufklärung, Hildesheim-Zürich-New York, Georg Olms Verlag, pp. 183-212.

Heinz, M., Kuster, F., (1998), "Vollkommene Vereinigung'. Fichtes Eherecht in der Perspektive feministischer Philosophie“, en: Deutsche Zeitschrift für Philosophie, 46. Jahrgang, (1998), Heft 5, pp. 823 - 839.

Hegel , G.W.F., (1988), Phänomenologie des Geistes, Hamburg, Felix Meiner Verlag,

Held, K., Hennigfeld, J., (hrsg.), (1993), Kategorien der Existenz. Festschrift für Wolfgang Janke, Würzburg, Könighausen \& Neumann.

Hell, J., (2003), "Stellung und Spuren einer Sozialethik in Fichtes Philosophie", en: FichteStudien, Band 24, (2003), pp. 135 - 141. 
Hirsch, H., (2003), "Fichtes Planwirtschaftsmodell als Dokument der Geistesgeschichte und als bleibender Denkanstoß“, en: Fichte-Studien, Band 24, (2003), pp. 165 - 177.

Honneth, A., (2001), "Die transzendentale Notwendigkeit von Intersubjektivität (Zweiter Lehrsatz, § 3)“, en: Merle, J. Ch., (Hrsg.), Johann Gottlieb Fichte. Grundlage des Naturrechts, Klassiker Auslegen, Band 24, Akademie Verlag, Berlin, pp. 63-80.

Hösle, V., (1992), "Intersubjektivität und Willensfreiheit in Fichtes ,Sittenlehre'“, en: Kahlo, M., Wolff, E., Zaczyk, R., (hrsg.), Fichtes Lehre vom Rechtsverhältnis. Die Deduktion der $\$ \S$ 1-4 der Grundlage des Naturrechts und ihre Stellung in der Rechtsphilosophie, Vittorio Klostermann, Frankfurt am Main, pp. 29-52.

Hösle, V., (1989), "Was darf und was soll der Staat bestrafen? Überlegungen im Anschluss an Fichtes und Hegels Straftheorien“, en: Hösle, V., (hrsg.), (1989), Die Rechtsphilosophie des deutschen Idealismus. In Verbindung mit dem Instituto Italiano per gli Studi Filosofici, Hamburg, Felix Meiner Verlag, pp.1-55.

Horstmann, R.-P., (2001), "Theorie des Urrechts (§§ 8-12)“, en: Merle, J.-Ch., (Hrsg.), Johann Gottlieb Fichte. Grundlage des Naturrechts, Klassiker Auslegen, Band 24, Akademie Verlag, Berlin, pp. 113-123.

Ivaldo, M., (2003), "Fichte und Leibniz zur Intersubjektivität", en: Fichte-Studien, Band 22, (2003), pp. $59-72$.

Kaufmann, M., (2001), “Zwangsrecht (§§ 13-16)“, en: Merle, J.-Ch., (Hrsg.), Johann Gottlieb Fichte. Grundlage des Naturrechts, Klassiker Auslegen, Band 24, Akademie Verlag, Berlin, pp. $125-137$.

Kelly, G. A., (1998), "Bemerkungen zu Hegels Herrschaft und Knechtschaft", en: Fulda, H. F., Henrich, D., (Hrsg.), Materialien zu Hegels „Phänomenologie des Geistes“, Frankfurt, Suhrkamp, pp. 189-216.

Köhler, M., (1992), "Zur Begründung des Rechtszwangs im Anschluss an Kant und Fichte“, in: Kahlo, M., Wolff, E., Zaczyk, R., (hrsg.), Fichtes Lehre vom Rechtsverhältnis. Die Deduktion der $\S \S$ 1-4 der Grundlage des Naturrechts und ihre Stellung in der Rechtsphilosophie, Vittorio Klostermann, Frankfurt am Main, pp. 93-125.

Kojève, A., (1975), Hegel. Eine Vergegenwärtigung seines Denkens. Kommentar zur Phänomenologie des Geistes, Frankfurt, Suhrkamp.

Kojève, A., (1998), "Zusammenfassender Kommentar zu den ersten sechs Kapiteln der Phänomenologie des Geistes“, en: Fulda, H. F., Henrich, D., (Hrsg.), Materialien zu Hegels „Phänomenologie des Geistes“, Frankfurt, Suhrkamp, pp. 133-188.

Lasson, A., (1863), Johann Gottlieb Fichte im Verhältnis zu Kirche und Staat, Neudruck der Ausgabe Berlin 1863, (1968), Darmstadt, Scientia Verlag Aalen.

Lauth, R., (1984), Die transzendentale Naturlehre Fichtes nach den Prinzipien der Wissenschaftslehre, Hamburg, Felix Meiner Verlag. 
Lazzari, A., (2001), “'Eine Fessel, die nicht schmerzt und nicht sehr hindert': Strafrecht (§ 20)“; en: Merle, J.-Ch., (Hrsg.), Johann Gottlieb Fichte. Grundlage des Naturrechts, Klassiker Auslegen, Band 24, Akademie Verlag, Berlin, pp. 173-186.

Lendvai, F. L., (2003), "Stellung und Spuren einer Sozialethik in Fichtes Philosophie", en: Fichte-Studien, Band 24 (2003), pp. 127 - 133.

Lindau, H., (1900), Johann Gottlieb Fichte und der neuere Sozialismus, Berlin W, F. Fontane \& Co. Nachdruck en: Lindau, H., Weber, M., (1987), Schriften zu J.G. Fichtes Sozialphilosophie. Mit Personenregistern von Hans Michael Baumgartner, Hildesheim Zürich - New York.

López-Domínguez, V., (1999), "Die Idee des Leibes im Jenaer System“, en: Fichte-Studien, Band 16, (1999), pp.273 - 293.

Losurdo, D., (1991), "Fichte, die Französische Revolution und das Ideal vom ewigen Frieden“", en: Buhr, M., Losurdo, D., (hsrg.), (1991), Fichte - die Französische Revolution und das Ideal vom ewigen Frieden. Mit Unterstützung des Istituto Italiano per gli Studi Filosofici, Napoli, Berlin, Akademie Verlag, pp. 74-136.

Maesschalk, M., (1996), Droit et creation sociale chez Fichte. Une philosophie moderne de l'action politique, Louvain-Paris, Éditions de L'Institut Supérieur de Philosophie Louvain-LaNeuve, Éditions Peeters.

Marquardt, J., (1991), "Der geschlossene Handelstaat", en: Deutsche Zeitschrift für Philosophie, 3/1991, pp. 294-303.

Marx, W., (1986), Das Selbstbewusstsein in Hegels Phänomenologie des Geistes, Frankfurt am Main, Vittorio Klostermann.

Mather, R., (2003), "On the Concepts of Recognition“, en: Fichte-Studien, Band 23, (2003), pp. $85-103$.

Maus, I., (2001), "Die Verfassung und ihre Garantie: das Ephorat (§ 16, 17 und 21)", en: Merle, J. Ch., (Hrsg.), Johann Gottlieb Fichte. Grundlage des Naturrechts, Klassiker Auslegen, Band 24, Akademie Verlag, Berlin, pp. 139-158.

Merle, J.-Ch., (1991), "Indolenza e politica in Fichte.La libertá, il male, la azione”, en: Rivista internazionale di filosofia del diritto, 1, pp. 22-43.

Merle, J.-Ch., (1997, a), Justice et progrès, Paris, Presses Universitaires de France.

Merle, J.-Ch., (1997, b), "Notrecht und Eigentumstheorie im Naturrecht, bei Kant und bei Fichte", in: Fichte-Studien, Band 11, (1997), pp. 41 - 61.

Merle, J.-Ch., (2000), "Le droit de proprieté chez Fichte", en: Bienenstock, M., CrampeCasnabet, M., (2000), Dans quelle mesure la philosophie est pratique. Fichte, Hegel. Avec la collaboration de Jean-Francois Goubet, Fontenay/Saint-Cloud, Ens Éditions, pp. 159-172. 
Merle, J.-Ch., (2001), "Eigentumsrecht (§§ 18-19)“; en: Merle, J.-Ch., (Hrsg.), Johann Gottlieb Fichte. Grundlage des Naturrechts, Klassiker Auslegen, Band 24, Akademie Verlag, Berlin, pp. 159 - 172.

Merle, J.-Ch., (2003), "Fichtes Begründung des Strafrechts“, en: Fichte-Studien, Band 24, (2003), pp. $73-83$.

Morrison, D., (1996), "Women, Family and State in Fichte's Philosophy of Freedom", en: (1996), Breazale, Daniel, Rockmore, Tom, (eds.), (1996), New Perspectives on Fichte, New Jersey, Humanities Press International, pp. 179-191.

Neuhoser, F., (2001), "The Efficacy of the Rational Being (First Proposition: $\S 1$ 1)", en: Merle, J. Ch., (Hrsg.), Johann Gottlieb Fichte. Grundlage des Naturrechts, Klassiker Auslegen, Band 24, Akademie Verlag, Berlin, pp. 39-49.

Nowak - Juchacz, E., (2003), "Das Anerkennungsprinzip bei Kant, Fichte und Hegel", en: Fichte-Studien, Band 23, (2003), pp. 75 - 84.

Oncina Coves, F., (1997), "Wahlverwandtschaften zwischen Fichtes, Maimons und Erhardts Rechtslehren“, en: Fichte-Studien, Band 11, (1997), pp. 63 - 84.

Oncina Coves, F., (1999), "Das Tempo in Fichtes Jenaer Rechtsphilosophie: der Zeitrhytmus des Rechtsgesetzes“, en: Fichte-Studien, Band 16, (1999), pp. 213 - 235.

Oncina Coves, F., (2004), "Fichtes Kritik des aufklärerischen Republikanismus", en: De Pascale, C., Fuchs, E., Ivaldo, M., Zöller, G., (hrsg.), (2004), Fichte und die Aufklärung, Hildesheim-Zürich-New York, Georg Olms Verlag, pp. 213-226.

Perrinjaquet, A., "Individuum und Gemeinschaft in der WL zwischen 1796 und 1800", en: Fichte-Studien, Band 3, (1991), pp. 7 - 28.

Piché, C., (2001), "Die Bestimmung der Sinnenwelt durch das vernünftige Wesen (Folgesatz: $\S 2)^{\prime}$; en: Merle, J.-Ch., (Hrsg.), Johann Gottlieb Fichte. Grundlage des Naturrechts, Klassiker Auslegen, Band 24, Akademie Verlag, Berlin, pp. 51-62.

Philonenko, A., (1984), L'Oeuvre de Fichte, Paris, Libraire Philosophique Vrin.

Philonenko, A., (1997), Métaphysique et politique chez Kant et Fichte, Paris, Libraire Philosophique Vrin.

Philonenko, A., (1999), La liberté humaine dans la philosophie de Fichte, Paris, Libraire Philosophique Vrin.

Pöggeler, O., (1998), "Selbstbewusstsein als Leitfaden der Phänomenologie des Geistes“, in: Köhler, D., Pöggeler, O., (Hrsg.), G.W.F. Hegel. Phänomenologie des Geistes, Reihe Klassiker Auslegen, Band 16, Berlin, Akademie Verlag, pp. 129-141.

Radrizzani, I., (1993), Vers la fondation de l'intersubjectivité chez Fichte. Des Principes a la Nova Methodo, Paris, Libraire Philosophique J. Vrin. 
Rametta, G., (2004), "Politik der Vernunft und Vernunftstaat bei Fichte (1793-1808)“, en: De Pascale, C., Fuchs, E., Ivaldo, M., Zöller, G., (hrsg.), (2004), Fichte und die Aufklärung, Hildesheim-Zürich-New York, Georg Olms Verlag, pp. 227-241.

Renaut, A., (1986), Le Système de Droit. Philosophie et droit dans la pensée de Fichte, Paris, Presses Universitaires de France.

Renaut, A., (2001), "Deduktion des Rechts (Dritter Lehrsatz: § 4), en: : Merle, J. Ch., (Hrsg.), Johann Gottlieb Fichte. Grundlage des Naturrechts, Klassiker Auslegen, Band 24, Akademie Verlag, Berlin, pp. 81-95.

Rickert, H., (1922/1923) "Die philosophischen Grundlagen von Fichtes Sozialismus", Logos. Zeitschrift für systematische Philosophie, Heft 11, pp. 149-180.

Schleiermacher, F.D.E., (1980), Kritische Gesamtausgabe, Im Auftrag der BerlinBrandenburgischen Akademie der Wissenschaften und der Akademie der Wissenschaften zu Göttingen hrsg. Von Hermann Fischer u.a. Berlin, 1980 ff., Abt. I, Band 2.

Schrader, W., (1972), Empirisches und absolutes Ich. Zur Geschichte des Begriffs Leben in der Philosophie J.G. Fichtes, Stuttgart - Bad Cannstatt, Friedrich Frommann Verlag Günther Holzboog KG.

Schüssler, I., (1997), "Die Deduktion des Begriffs des Rechts aus Prinzipien der Wissenschaftslehre (J.G. Fichte: Grundlage des Naturrechts, §§ 1-4)“, en: Fichte-Studien, Band 11, (1997), pp. 23 - 40.

Senigaglia, C., (2003), "Die Bestimmung des Bürgers beim späten Fichte", en: FichteStudien, Band 24, (2003), pp. 113 - 126.

Siemek, M. J., (2003), "Fichtes und Hegels Konzept der Intersubjektivität", en: FichteStudien, Band 23, (2003), pp. 57-74.

Siep, L., (1979), Anerkennung als Prinzip der praktischen Philosophie. Untersuchungen zu Hegels Jeaner Philosophie des Geistes, München, Verlag Karl Alber Freiburg.

Siep, L., (1992, a), Praktische Philosophie im Deutschen Idealismus, Frankfurt am Main, Suhrkamp.

Siep, L., (1992, b), "Naturrecht und Wissenschaftslehre“, en: Kahlo, M., Wolff, E., Zaczyk, R., (hrsg.), Fichtes Lehre vom Rechtsverhältnis. Die Deduktion der §§ 1-4 der Grundlage des Naturrechts und ihre Stellung in der Rechtsphilosophie, Vittorio Klostermann, Frankfurt am Main, pp. 71-91.

Siep, L., (1993), "Leiblichkeit bei Fichte"; en: Held, K., Hennigfeld, J., (hrsg.), (1993), Kategorien der Existenz. Festschrift für Wolfgang Janke, Würzburg, Könighausen \& Neumann, pp. 107-120.

Siep, L., (1998), "Die Bewegung des Anerkennens in der Phänomenologie des Geistes“, en: Köhler, D., Pöggeler, O., (Hrsg.), G.W.F. Hegel. Phänomenologie des Geistes, Reihe Klassiker Auslegen, Band 16, Berlin, Akademie Verlag, pp. 107-127. 
Stadler, Ch., (2003), "Der Transzendentalphilosophische Rechtsbegriff und seine systematische Begründungsleistung“, en: Fichte-Studien, Band 24, (2003), pp. 19 - 48.

Stadler, Ch., (2000), Freiheit in Gemeinschaft. Zum traszendentalphilosophischen Rechtsbegriff Johann Gottlieb Fichtes, Cuxhaven - Dartford, Traude Junghans Verlag.

Stolzenberg, J., (1995), "Fichtes Begriff des praktischen Selbstbewusstseins", en: Hogrebe, W., (1995), Fichtes Wissenschaftslehre. 1794. Philosophische Resonanzen, Frankfurt am Main, Suhrkamp, pp. 71-95.

Takada, M., (2000), "Vergleich der Fichteschen Anerkennungslehre mit der Hegelschen", en: Fichte-Studien, Band 18, (2000), pp. 85 - 99.

Taver, K. V., (2003), "Fichte und Arnold Gehlen. Fichtes Philosophie des Rechts von 1796 und 1812 im Fokus von Arnold Gehlens philosophischer Anthropologie“, en: Fichte-Studien, Band 24, (2003), pp. 49 - 71.

Taylor, Ch., (1998), Hegel, Übersetzt von Gerhard Fehn, Frankfurt, Suhrkamp.

Traub, H., (2003), “J. G. Fichte, der König der Juden spekulativer Vernunft. Überlegungen zum spekulativen Anti-Judaismus“, en: Fichte-Studien, Band 21, (2003), pp. 131 - 150.

Verweyen, H. J., (1975), Recht und Sittlichkeit in J. G. Fichtes Gesellschaftslehre, München, Verlag Karl Alber Freiburg.

Vincenti, L., (1997), Pratique et réalité dans les philosophies de Kant et de Fichte, Paris, Éditions Kimé.

Von Manz, H. G., (1994), "Selbstgewissheit und Fremdgewissheit", en: Fichte-Studien, Band 6, (1994), pp. 195 - 213.

Weber, M., (1900), Fichte's Sozialismus und sein Verhältnis zur Marx'schen Doktrin, Tübingen Freiburg i.B. und Leipzig, Verlag von J.C.B. Mohr (Paul Siebeck). Reimpreso en: Lindau, H., Weber, M., (1987), Schriften zu J.G. Fichtes Sozialphilosophie. Mit Personenregistern von Hans Michael Baumgartner, Hildesheim - Zürich - New York.

Wildt, A., (1982), Autonomie und Anerkennung. Hegels Moralitätskritik im Lichte seiner Fichte-Rezeption, Stuttgart, Klett-Cotta.

Wildt, A., (1992), "Recht und Selbstachtung, im Anschluß an die Anerkennungslehren von Fichte und Hegel“", en: Kahlo, M., Wolff, E., Zaczyk, R., Fichtes Lehre vom Rechtsverhältnis. Die Deduktion der $\$ \S 1-4$ der Grundlage des Naturrechts und ihre Stellung in der Rechtsphilosophie, Vittorio Klostermann, Frankfurt am Main, pp. 127-171.

Williams, R., (1994) "The Question of the Other in Fichte's Thought", en: Breazale, Daniel, Rockmore, Tom, (eds.), (1994), Fichte. Historical Contexts/Contemporary Controversies, New Jersey, Humanities Press International, pp. 142-157.

Wood, A., (1990), Hegel's Ethical Thought, Cambridge, New York, Port Chester, Melbourne, Sidney, Cambridge University Press. 
Wood, A., (2004), "Kant and Fichte on Right, Welfare and Economic Redistribution", en: Internationales Jahrbuch des Deutschen Idealismus - International Yearbook of German Idealism, Band 2, (2004), pp. 77 - 101.

Zaczyk, R, (1981), Das Strafrecht in der Rechtslehre J. G. Fichtes, Berlin, Duncker \& Humblot.

Zaczyk, R, (1992), "Die Struktur des Rechtsverhältnisses (§§ 1-4-) im Naturrecht Fichtes“, en: Kahlo, M., Wolff, E., Zaczyk, R., (hrsg.), Fichtes Lehre vom Rechtsverhältnis. Die Deduktion der $\S \S 1-4$ der Grundlage des Naturrechts und ihre Stellung in der Rechtsphilosophie, Vittorio Klostermann, Frankfurt am Main, pp. 9-27.

Zöller, G., (1998), "Die Individualität des Ich in Fichtes Zweiter Jenaer Wissenschaftslehre (1796-99)“", en: Revue Internationale de Philosophie, Volume 52, $\mathrm{N}^{\circ}$ 206, 4/1998, pp. 641663.

Zöller, G., (2001), "Leib, Materie und gemeinsames Wollen als Anwendungsbedingungen des Rechts (Zweites Hauptstück: $\S \S ~ 5-7) “$, en: : Merle, J. Ch., (Hrsg.), Johann Gottlieb Fichte. Grundlage des Naturrechts, Klassiker Auslegen, Band 24, Akademie Verlag, Berlin, pp. 97111.

Zöller, Günter, (2004), "Kant, Fichte und die Aufklärung“, en: De Pascale, C., Fuchs, E., Ivaldo, M., Zöller, G., (hrsg.), (2004), Fichte und die Aufklärung, Hildesheim-Zürich-New York, Georg Olms Verlag, pp. 35-52. 